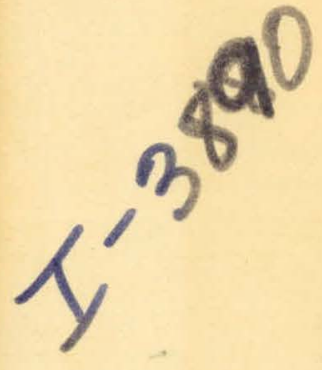

DO NOT MICROFILM COVER

May 1982

\title{
A User's Guide to SERICPAC: A Computer Program for Calculating Electric-Utility Avoided Costs Rates
}

\section{A Subcontract Report}

Robert Wirtshafter

Michael Abrash

Michael Koved

Stephen Feldman

University of Pennsylvania

Energy Center

Philadelphia, PA

Prepared Under Subcontract No. XS-0-9275-1
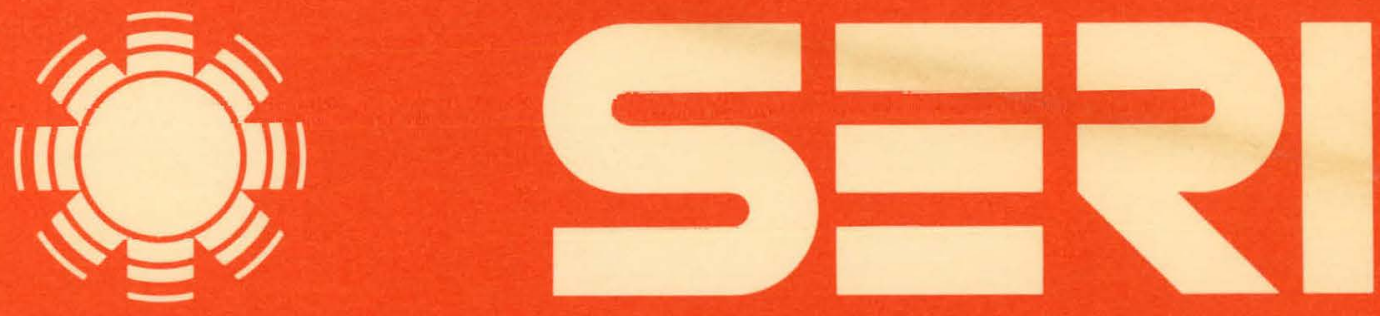

Solar Energy Research Institute

A Division of Midwest Research Institute

1617 Cole Boulevard

Golden, Colorado 80401

Operated for the

U.S. Department of Energy under Contract No. EG-77-C-01-4042 


\section{DISCLAIMER}

This report was prepared as an account of work sponsored by an agency of the United States Government. Neither the United States Government nor any agency Thereof, nor any of their employees, makes any warranty, express or implied, or assumes any legal liability or responsibility for the accuracy, completeness, or usefulness of any information, apparatus, product, or process disclosed, or represents that its use would not infringe privately owned rights. Reference herein to any specific commercial product, process, or service by trade name, trademark, manufacturer, or otherwise does not necessarily constitute or imply its endorsement, recommendation, or favoring by the United States Government or any agency thereof. The views and opinions of authors expressed herein do not necessarily state or reflect those of the United States Government or any agency thereof. 


\section{DISCLAIMER}

Portions of this document may be illegible in electronic image products. Images are produced from the best available original document. 


\author{
Printed in the United States of America \\ Available from: \\ National Technical Information Service \\ U.S. Department of Commerce \\ 5285 Port Royal Road \\ Springfield, VA 22161 \\ Price. \\ Microfiche $\$ 3.00$ \\ Printed Copy $\$ 7.25$
}

\title{
NOTICE
}

This report was prepared as an account of work sponsored by the United States Government. Neither the United States nor the United States Department of Energy, nor any of their employees, nor any of their contractors, subcontractors, or their employees, makes any warranty, express or implied, or assumes any legal liability or responsibility for the accuracy, completeness or usefulness of any information, apparatus, product or process disclosed, or represents that its use would not infringe privately owned rights. 
SERI/TR--09275-1

DE82. 016997

A User's Guide to SERICPAC:

A Computer Program for

Calculating Electric Utility

Avoided Cost Rates

A Subcontract Report

Robert Wirtshafter

Michael Abrash

Michael Koved

Stephen Feldman

University of Pennsylvania

Energy Center

Philadelphia, PA

May 1982

Prepared Under Subcontract No. XS-0-9275-1

SERI Technical Monitor: Theresa Flaim

Solar Energy Research Institute

A Division of Midwest Research Institute

1617 Cole Boulevard

Golden, Colorado 80401

Prepared for the

U.S. Department of Energy

Contract No. EG-77-C-01-4042 


\section{THIS PAGE \\ WAS INTENTIONALLY \\ LEFT BLANK}




\section{FOREWORD}

SERICOST and SERICPAC are companion computer models for use in estimating technology-specific avoided cost rates for electric utility purchases from distributed power producers. SERICOST is a modified version of MARGINALCOST, the marginal cost estimation model developed by Charles Cicchetti, William Gillen, and Paul Smolensky. SERICOST calculates the electric utility's avoided cost by time period, independent of the type of technology used by the qualifying facility.

SERICPAC contains models that (1) simulate the performance of wind turbines, low-head hydro facilities, and several biomass systems, (2) accumulate production estimates by utility time period, and (3) take the output from SERICOST and combine it with the time-correlated production estimates to calculate weighted average annual rates. Thus, the models are designed to estimate rates for facilities when time-of-production metering is not feasible.

Many computer models are available for estimating avoided costs. For example, most generating utilities have production cost and capacity expansion models that they use regularly for planning purposes. These planning models could be used directly to estimate avoided cost rates. However, except for very large facilities, it would be prohibitively expensive to use these planning models to estimate separate avoided cost rates for each qualifying facility. The combined use of SERICOST and SERICPAC provides a method for taking the output from the more complex planning tools, and developing avoided cost rates for different types of technologies without having to rerun the planning models for every facility or technology type.

In addition, SERICOST and SERICPAC are designed for maximum flexibility, ease of use, and public accessibility. The models are flexible in that they can be used together or separately if the user wants to substitute a different technology performance or avoided cost model. In addition, the user can execute a single model within SERICPAC without having to run other models.

Although it is advisable to create some data files in advance, both SERICOST and SERICPAC are interactive and easy to operate. They also contain background information on avoided costs and the different technologies' performance characteristics. Finally, unlike many other models, both SERICOST and SERICPAC are fully documented and publicly available. 
Volume I is the User's Guide to SERICPAC and also contains a full listing of the computer programs. Volume II is the User's Guide to SERICOST and contains a full listing of the computer program. These models are available through the National Energy Software Center, Argonne. National Laboratory, 9700 South Cass Avenue, Argonne, IL · 60439.

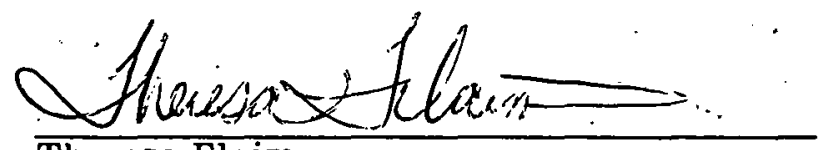

Theresa Flaim

Project Monitor

Approved for

SOLAR ENERGY RESEARCH INSTITUTE

Jack Stone, Manager
Photovoltaics and Wind Program Office

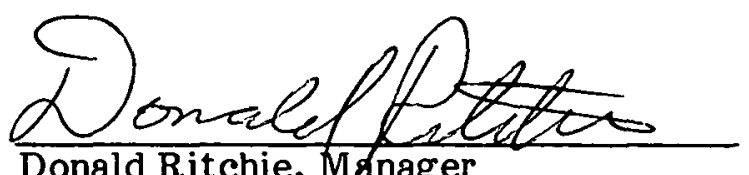

Donald Ritchie, Manager

Solar Electric Conversion Research Division 


\section{SUMMARY}

\section{Objectives}

To develop computer models that can be used to estimate technology-specific avoided cost rates for electric utility purchases from qualifying distributed power producers, as required by Section 210 of the Public Utility Regulatory Policies Act of 1978.

\section{Discussion}

This report is Volume I of a two-volume report, and is the User's Guide to SERICPAC, the companion model to SERICOST. Used in combination, the two models calculate average annual avoided cost rates for wind turbines, low-head hydro facilities, and several biomass systems.

Volume II is the User's Guide to SERICOST. SERICOST is a modified version of MARGINALCOST, the marginal cost estimation model developed by Charles Cicchetti, William Gillen, and Paul Smolensky. SERICOST calculates the electric utility's avoided cost by time period, independent of the type of technology used by the qualifying facility.

\section{Conclusions}

The primary advantage of SERICOST and SERICPAC over other available models is that they can be used to estimate technology-specific avoided cost rates without having to rerun more complex utility planning models for every qualifying facility or technology type. If the qualifying facility is large enough to justify time-of-production (TOP) metering, then SERICOST alone can calculate appropriate rates. If TOP metering is infeasible, then the use of both models is recommended for calculating average annual rates. 


\section{THIS PAGE}

\section{WAS INTENTIONALLY}

\section{LEFT BLANK}


1.0 InTRODUCTION $\ldots \ldots \ldots \ldots \ldots \ldots \ldots \ldots \ldots \ldots \ldots \ldots \ldots \ldots \ldots \ldots \ldots \ldots \ldots \ldots \ldots$

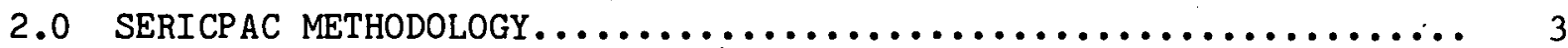

2.1 TECHNOLOGY SIMULATIONS (SIMULATE) $\ldots \ldots \ldots \ldots \ldots \ldots \ldots \ldots \ldots$

2.1.1 Hydro-Electric Production (HYDRO).............. 4

2.1.2 Wind Energy Conversion Systems (WIND)............ 5

2.1.3 Conventional Fuel Input (CONFUI) ................. 6

2.1.4 Rated Power (CONTOO).......................... 7

2.1.5 Direct Combustion of Biomass (COMBUS)............. 10

2.1.6 Methane Production and Generation (BIOGAS)......... 11

2.1.7 Municipal Waste Electric Generation (MUNI)......... 17

2.1.8 Producers' Gas Production and Generation (GASSIF).... 20

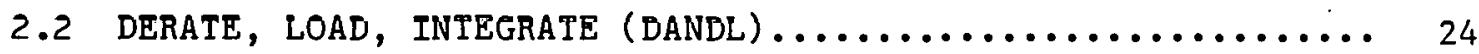

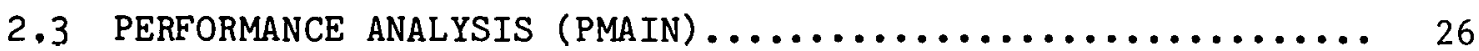

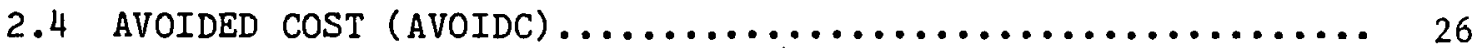

3.0 SERICPAC USER'S GUIDE........................... 29

3.1 INTRODUCTION............................... 29

3.1 .1 Symbols Used in Guide..................... 29

3.2 TECHNOLOGY SIMULATION (SIMULATE) $\ldots \ldots \ldots \ldots \ldots \ldots \ldots \ldots \ldots \ldots \ldots \ldots \ldots$

3.2 .1 Interactive Options......................... 32

3.2 .1 .1 List................................. 33

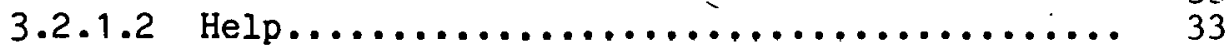

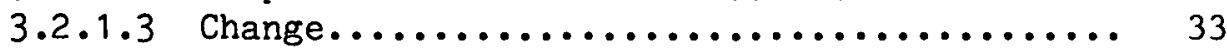

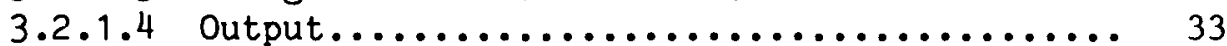

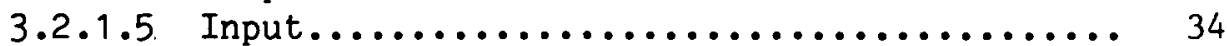

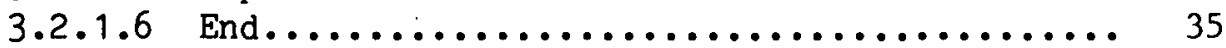

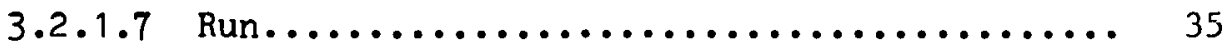

3.2.2 Technology Options........................... 35

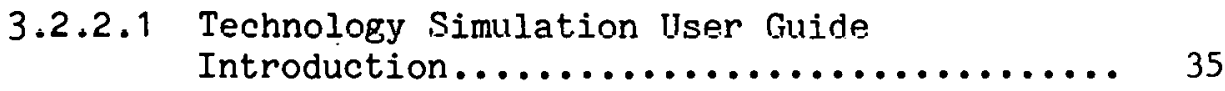

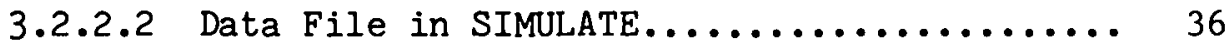

3.2.2.3 Hydro-Electric Production (HYDRO)......... 36

3.2.2.4 Wind Energy Conversion Systems

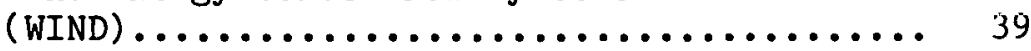

3.2.2.5 Conventional Fuel Input (CONFUI)......... 44 
TABLE OF CONTENTS (continued)

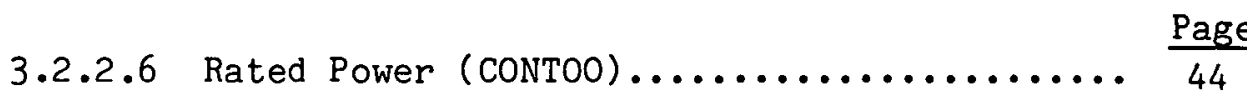

3.2.2.7 Direct Combustion of Biomass (COMBUS)...... 45

3.2.2.8 Methane Production and Generation (BIOGAS).. 48

3.2.2.9 Municipal Waste Electric Generation (MUNI).. 51

3.2.2.10 Producers' Gas Production and

Generation (GASSIF).................. 51

3.2.3 Exit Simulate Main Program.................. 52

3.2.3.1 Output Descriptions................. 53

3.3 DANDL : DERATE, INTEGRATE, AND LOAD .............. 53

3.3 .1 Introduction......................... 53

3.3.2 The Mode System: Discussion................... 54

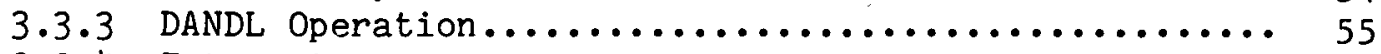

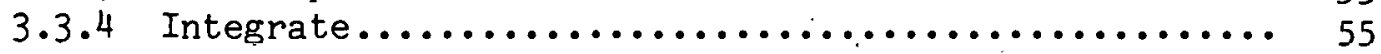

3.3.4.1 Interactive User Load............... 55

3.3 .4 .2 Disk Read Prompts.................. 56

3.3 .5 Derate................................ 5.7

3.3 .5 .1 Flat Basis........................ 57

3.3 .5 .2 Hourly Basis...................... 57 .

3.3 .5 .3 Monthly Basis....................... 58

$3.3 .6^{\circ}$ Entering l'echnology Simulation............... 58

3.3 .7 Output.............................. 60

3.4 PMAIN : PERFORMANCE ANALYSIS................... 61

3.4 .1 Introduction........................... 61

3.4 .2 Main Branchpoint.......................... 61

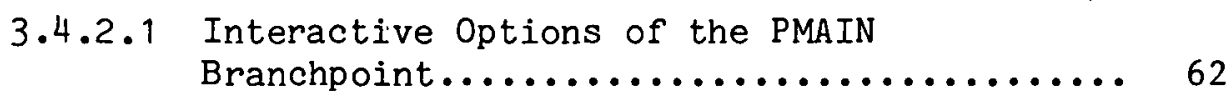

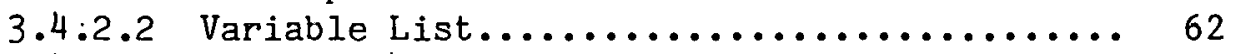

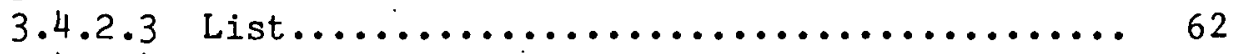

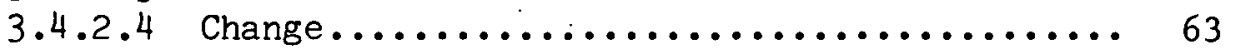

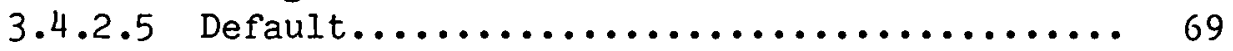

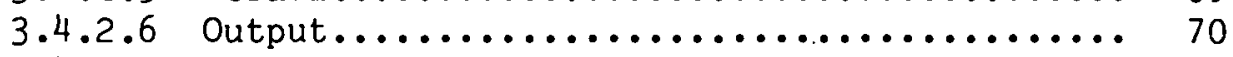

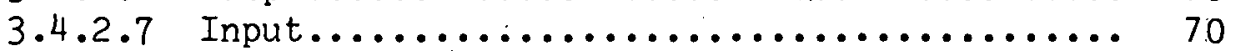

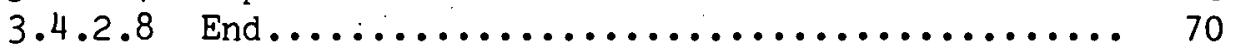

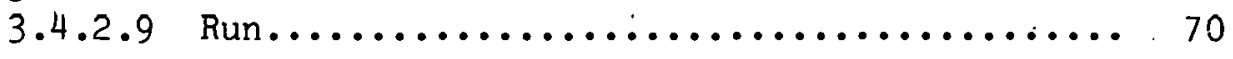

3.4 .3 Output................................... 71 


\section{TABLE OF CONTENTS (continued)}

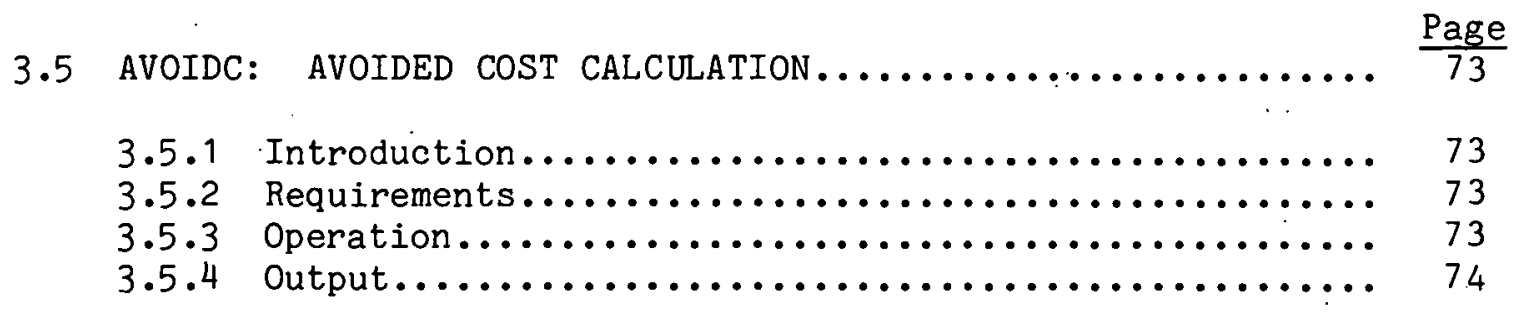

4.0 BIBLIOGRAPHY....................................... 75

APPENDIX A. Notes on Disk File Access..................... 79

APPENDIX B. Source Code SERICPAC....................... 81 
2-1. Properties of the Equipment for Three

$\underline{\text { Page }}$

Cogeneration Systems ...........................

2-2. Typical Higher Heating Values of Some Wood

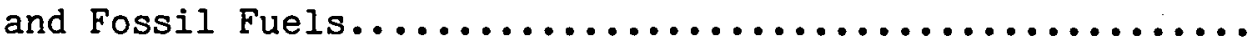

2-3. Effect of Pretreatment on Residue Digestion.

\section{LIST OF FIGURES}

1-1. Overview of SERICPAC Methodology (located in

the Summary) $\ldots \ldots \ldots \ldots \ldots \ldots \ldots \ldots \ldots \ldots \ldots \ldots \ldots \ldots \ldots$

2-1. Diesel Cogeneration..........................

2-2. Flow Diagram Illustrating Processes involved in the Anaerobic Digestion of Municipal Solid Waste..........

2-3. Flow Sheet of Anaerobic Digestion Process for

Solid Waste Utilization......................... 19

2-4. General Diagram of Updraft Gasifier................. 21

2-5. General Diagram of Downgrade Gasifier............... 22

3-1. Flow Chart of SIMULate Main Program................. 31 


\section{SECTION 1.0}

\section{INTRODUCTION}

SERICPAC is a computer program intended for use in calculating the avoided costs rates for decentralized electric production. SERICPAC is a companion program to SERICOST, a program developed by Madison Consulting Group, Inc. to calculate the avoided costs of electric utilities. SERICPAC utilizes the results of SERICOST to determine the appropriate rates selling of electricity to electric utilities from qualifying facilities (QF's) as stipulated under Section 210 of the Public Utility Regulatory Policies Act (PURPA) of 1978 .

The two computer programs are designed to work in tandum. The user first uses SERICOST to determine the avoided cost of a particular utility. Next, SERICPAC couples that cost structure with the performance characteristics of the particular qualifying facility. Together, these programs allow the user to determine the revenues that may be expected from sales by QF's to utilities, and rates for the electricity that is sold.

SERICPAC is designed to calculate the technology. specific average avoided cost rates. The model was developed originally to handle facilities smaller than $100 \mathrm{~kW}$ where the size did not warrant inclusion in a separate utility generation expansion analysis. The model is capable of determining appropriate rates for any size generation units. However, it may be appropriate for the utility to treat the larger facility in a manner similar to the way that the utility plans and cost accounts it own. facilities. Figure 1.1 shows the overall logic of SERICPAC. 

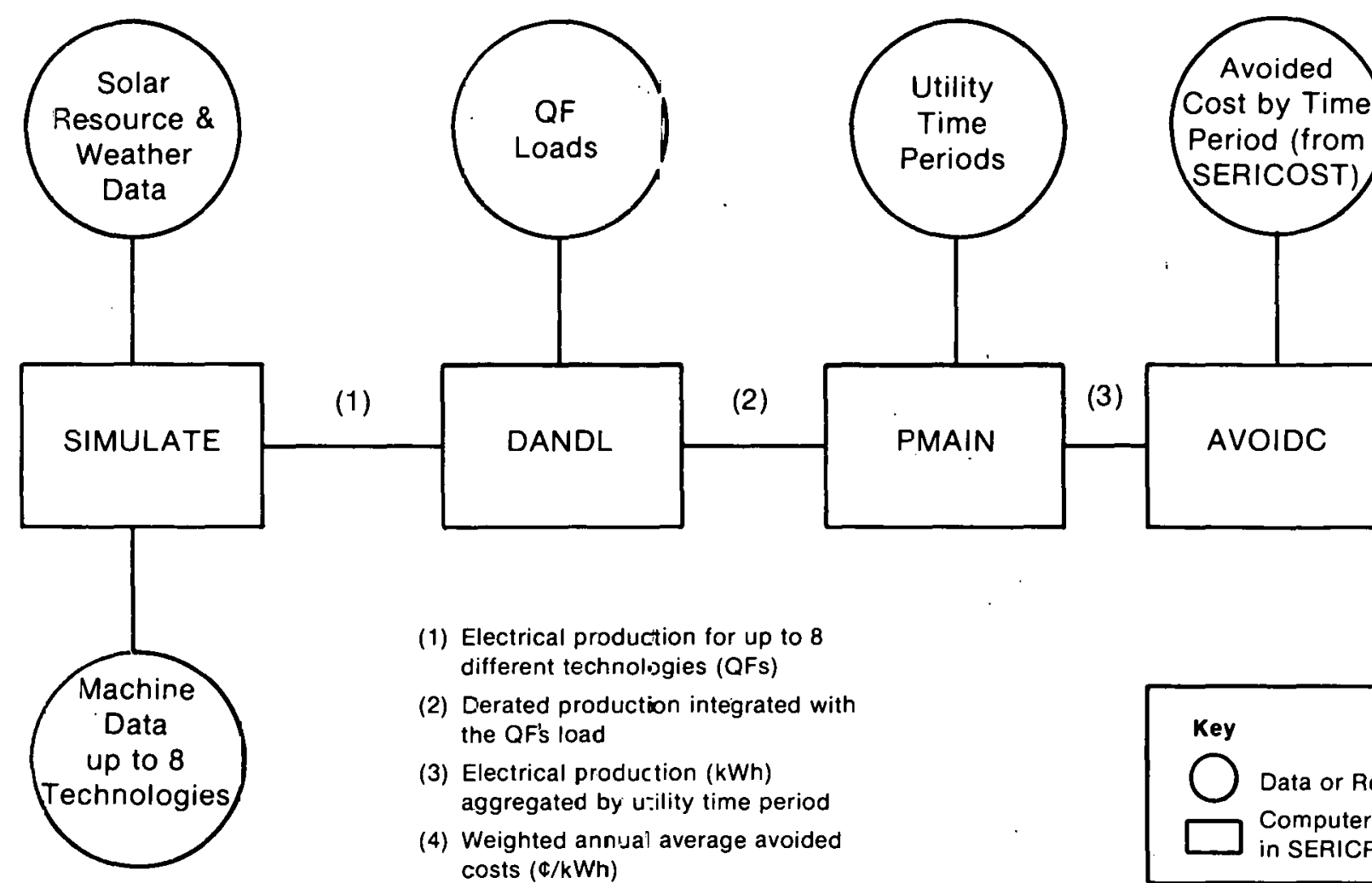

Electrical production for up to 8 different technologgies (QFs)

aggregated by u-ility time period

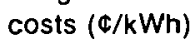

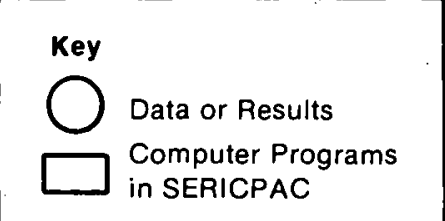

Figure 1-1. Overview of SERICPAC Methodology 
SECTION 2.0

SERICPAC METHODOLOGY

This chapter introduces the user to the major programs of SERICPAC. In this chapter each of the programs is introduced and specific information regarding the use of the program is discussed. Detailed input requirements and operation characteristics are provided in Section 3.0, "The User's Guide to SERICPAC."

The theory involved in the SERICPAC methodology is based on previous work of the authors (see for example S. Feldman and R. Wirtshafter, On the

Economics of Solar Energy: The Public Utility Interface). The electric production of QF's must be evaluated with respect to their impact on the utility loads and finances. Rates are determined that reflect the avoided cost to the utility from the existence of those QF's.

SERICPAC consists of four separable programs. The first program SIMULATE contains the simulation models of the QF's. DANDL (derate, load and integrate) converts the simulations into a more realistic measure of performance by including planned and forced outages. DANDL also allows the user the option of inputting an electric load. This option calculates the net sale of electricity to the utility as well as the total gross production of electricity. PMAIN then converts the electricity for sell back into utility periods, that are defined in SERICOST to represent differences in cost of service. The final program AVOIDC calculates technology specific avoided cost rates.

\subsection{TECHNOLOGY SIMULATIONS (SIMULATE)}

This program simulates the electrical production of the different technologies. The subroutines have been developed at the University of Pennsylvania Energy Center, SERI and independently (see Bibliography, and Appendices). There is also a provision for utilizing a users own simulation and entirely bypassing this routine. The different technologies that are contained in SIMULATE are:

\footnotetext{
HYDRO - a run-of-the-river hydroelectric generation model

WIND - a wind electric generation model

CONFUI - a conventional fuels electricity generating model

CONTOO - a constant production, based upon rated power model

COMBUS - electricity production through direct combustion of biomass fuels

BIOGAS - a methane production and electric generation model

MUNI = a municipal waste eleciric generation model

GASSIF - a producer gas production and generation model
} 


\subsubsection{Hydro-Electric Production (HYDRO)}

The hydro model simulates a run-of-the-river, low-head hydro-electric system. One classification of types of hydro power is based upon the head size. The head size is the distance between the turbine and the surface of the water. For low-head applications the size of the head is generally no more than 20 meters. Run-of-the-river facilities do not include dams or ponding. To accomplish ponding using the above model, a transformation of stream-flow data is necessary.

The basic inputs to the simulation are characteristics regarding the river and its flow, and the turbine and its capacity. For most potential hydroelectric sites it is likely that some survey has been previously performed. The potential hydro-electric sites are most often supplied by data from the U. S. Geological Survey (USGS), the public utility, or from estimates of the Army Corps of Engineer's (U. S. Army Corps, 1979). The Corps' study is primarily a siting methodology which evaluates the electric power potential in a cost/benefit framework. Included in their analysis is a listing of potential sites by river or stream per state as well as an estimated head size, drainage area, and potential turbine capacity.

The U. S. Geological Survey has stream-flow gauging stations along the streams and rivers cited in the Corps' study. The stream-flow data, measured in cubic feet per second (CFS), is generally available by an hourby-hour measurement, often times on computer tapes. Not all of the USGS regions have the stream-flow data in this form. The alternative is to input average daily flow data which is most readily accessible ( 365 records). This method is an alternative to entering. 8760 hourly records.

Hydro-electric turbines can only operate within a small range of stream flow levels. If the flow is too low, generally 40-50\% of turbine design capacity, there is insufficient power to rotate the turbine. If stream flow is too high water will cover the turbine, and prevent its operation. The simulation allows the user to input values for a minimum and maximum range for which the turbine will operate.

The model can simultaneously evaluate many hydro-electric sites built along a river. However, the model assumes that each turbine does not impact the downstream flow and therefore the model may slightly overestimate performance of successsive downsteam turbines.

In general the formula to calculate power production is (see Eq. 2-1):

$$
\text { PKW }=\text { CFS }^{*} \text { PLEFF*HHDLOS* GRHEAD } / 11.8
$$

where:

PKW = electric power produced

CFS = steam flow in cubic feet per second

PLEFF = plant efficiency--the actual performance of the turbine divided by its rated capacity (defaulted at 0.88 ) 

HHDLOS = height head loss as efficiency--the actual flow through head divided by the theoretical potential (defaulted at 0.95 )
GRHEAD = gross head size--the distance between the surface of the water and the turbine

Output of the simulation is electric consumption in $\mathrm{kW}$ per hour. The model also determines average stream flow, average plant capacity and average spillage factor. Plant capacity is determined by dividing the simulated performance of the turbine by the rated performance of the turbine.

Spillage factor is the percentage of water power not utilized by the turbine unit, either because of insufficient or excessive stream flow. For run-ofthe-river plant capacities are normally around $70 \%$, but will vary considerably depending on the stream flow, plant capacity size and minimum and maximum operation inputs.

\subsubsection{Wind Energy Conversion Systems (WIND)}

Wind energy conversion svstems (WECS) were originally designed for agricultural applications. Commercial sized machines range from .1 to $15 \mathrm{~kW}$. Large wind machines have been built with capacity size of 1-3 mW. Wind machines are classified as being either horizontal or vertical axis types. Components of the WECS include: a turbine assembly (includes blade, generator, etc.), a tower support, a battery pack, and, if necessary, an auxiliary engine.

The (WECS) simulation in the SERICPAC model is based upon recent research performed by Justus and Mikhail (1978), and a detailed WECS model developed at SERI by Percival and Harper (1981). Input parameters may cover a wide range of potential configurations and manufacturers' performance ratings. The model is designed to accept hourly or tri-hourly wind speeds and temperatures. Wind speed and direction as well as temperature are available from SOLMET and Typical Metereological Year (TMY) tapes avallable from National Oceanic and Atmospheric Administration (NOAA), Asheville, N. C. (NOAA, 1978). Additional sources for input data can be supplied by local public utilities (see, for example, Paul Gipe, "Șources of Wind Data," Solar Age, May 1981).

Wind speed is normally an average hourly (or tri-hourly) value and does not account for instantaneous variation. Because wind energy is proportional to the cube of the wind speed, accuracy in predicting wind velocity is necessary. An average estimation of wind velocities from "measurement readings" will normally undervalue the wind power. Consequently, a probability distribution chosen for use is the Weibull density function. The critical parameters, $K$ and $C$, are dependent upon the distribution of wind velocities and average velocity.

The cut-in velocity is the speed at which the windmill begins producing power. The cut-out velocity is the speed at which the windmill ceases to produce power for safety reasons. The rated power is the speed at which the windmill begins to produce at maximum (rated) power. The maximum power coefficient is the highest ratio of available wind power to shaft power attainable by the machine. The design velocity at the maximum power coefficient is the velocity at which the maximum power coefficient occurs. 
Rotor diameter is the diameter of the circle described by the tip of the rotor. The anemometer recording height is the height of the recording station above the ground. Elevation above sea level is the height of the windmill site above sea level. Hub height is (for a horizontal windmill) hub height above ground. Clearance height is (for a vertical windmill) the height of the bottom of the rotor above the ground. Constant or variable RPM and horizontal or vertical axis must be specified. The height of the installation (for a vertical windmill) must be specified. The time interval at which data occurs is required.

The wind model operates on a probabalistic basis. The mean and standard deviation of observed wind speeds over a month period are used as parameters to generate a Weibull probability distribution of wind speeds. The range of speeds of operation of the windmill is then partitioned into several intervals. For each of these intervals the probability of a windspeed in that interval can be determined from the Weibull distribution, and power in that interval can be approximated as a function of the mean speed in the interval and the windmill's configuration (rotor area, efficiency). Below the cut-in and above the cut-out velocity there is no power production. Between the rated velocity and the cut-out velocity, power is equal to rated power. Total power production is then simply the sum of the products of interval probability times interval power. For a detailed description including equations, see Justus and Mikhail (1978).

\subsubsection{Conventional Fuel Input (CONFUI)}

Cogeneration is the simultaneous production of electrical or mechanical energy and useful thermal energy. The thermal energy is in the form of hot liquids or gases. The types of cogeneration systems available today are: dual purpose power plants, waste-heat utilization systems, certain types of district heating systems, and total energy systems.

The difference between a conventional energy system, and cogeneration system is that the conventional energy system produces either thermal or electrical energy, whereas the cogeneration system produces both. Recent interest in more efficient use of energy resouces has been spurred by the 1973-74 oil embargo. Historically, there existed a wlde use of cogeneration systems. The contribution of cogeneration applications, however, has declined over the past sixty years. In 1920, industrial fossil fuel electric power generation contributed $22 \%$ of total U.S. electricity production. In 1940 , the percentage declined to $18 \%$, by 1960 only $9 \%$ and in 1976 there was a $4 \%$ contribution (Williams, 1978, p. 315). The development of centralized electric plants is the primary cause of the movement away from industrial cogeneration.

The potential for industrial cogeneration in the 1985 planning horizon, has been studied by several sources: Dow Chemical Company (1975) for the National Science Foundation, Thermo Electron Corporation (1976) for the former Federal Energy Administration (FEA), Resource Planning Associates (RPA) (1977) for the former Energy Research and Development Administration (ERDA) and Synergic Resources Corporation (Limaye et al., 1980) for the Electric Power Research Institute. Estimates for 1985 cogeneration potential are also summarized in Williams (1978, pp. 331-333). 
The choice of cogeneration system depends upon its application. Total energy systems are designed to provide electricity, heating, cooling, and waste-water treatment facilities to entire communities. Waste-heat utilization systems and dual purpose power plants are applied in the industrial and utility market sectors. District heating systems are forms of cogeneration where thermal energy discharged from an industrial or utility process is utilized by the residental sector as a form of home heating.

The cogeneration technologies available today in the industrial and utility sectors are: back pressure steam turbines (Rankine cycle) systems, gas turbines (Bryton cycle) systems, and diesel engines. Table 2.1 describes the equipment properties of the three systems. There are two methods for power generation available for each technology: topping and bottoming cycles. A topping cycle is a system which uses the fuel first to generate electricity, then uses the waste heat for industrial processes. A bottoming cycle uses. the fuel input first to produce heat and/or steam for industrial processes, then utilizes the waste heat and pressure for electricity production (New England Energy Commission, 1978 , p. 121).

SERICPAC incorporates a simulation of topping diesel engine cogeneration system. A schematic of a typical diesel cogeneration systiem is seen in Figure 2.1.

There are two options for a simulation of the cogeneration system. One option is to simply assume operation of the system at its rated level. Fuel needs and heat produced may be determined ex post facto in this case. The rated level is the power input to the generator. The generator operates continuously for the entire year. Alternatively, the fuel inputs and the heat content may be used with the system efficiency to determine outputs to the generator. In essence, these approaches differ in the order of calculation.

The model assumes that the system operates at its rated level at all times of operation, and that a constant input of fuel with uniform heat value jis always utilized. To adjust the output to account for outages, the user should use the DANDL program, Section 2.2 and 3.3 .

The inputs to the model include: rated output of the engine, efficiency of the engine, heat content of the fuel, rate of fuel input, and generator efficiency.

The output is in $\mathrm{kWh}$ 's and is calculated by multiplying the fuel heating value by the input rate and by efficiency losses. The result is the $\mathrm{kW}$ production of the system. Heat produced and fuel used are optional outputs.

\subsubsection{Rated Power (CONTOO)}

This model is a simple program which allows the user to specify only the rated capacity of the generic technology. CONTOO is considered an analytical toul rather than a simulation, because no technology specific input data is required. For instance, the user may be interested in determining the avoided cost rate of a diesel generator. Rather than using the conventional 
Table 2-1. Properties of the Equipment for Three Cogeneration Systems

\begin{tabular}{|c|c|c|c|c|c|}
\hline $\begin{array}{l}\text { Cogeneration } \\
\text { System }\end{array}$ & $\begin{array}{l}\text { Preferred } \\
\text { Size } \\
(\mathrm{MW})\end{array}$ & Fuel & $\begin{array}{c}\text { Electrical } \\
\text { Efficiency }^{a} \\
\%\end{array}$ & Advantages & Disadvantages \\
\hline Steam turbine & $1-1200$ & $\begin{array}{l}\text { Any fuel: } \\
\text { oil, natural } \\
\text { gas, coal } \\
\text { wastes }\end{array}$ & $10-30$ & $\begin{array}{l}\text { Can use inexpensive } \\
\text { fuel; useful for high } \\
\text { heat needs relative to } \\
\text { electricity needs. } \\
\text { Useful in district } \\
\text { heating. }\end{array}$ & $\begin{array}{l}\text { Not useful at } \\
\text { small sites; } \\
\text { low electrical } \\
\text { efficiency. }\end{array}$ \\
\hline Gas turbine & $1-100$ & $\begin{array}{l}\text { \#2 oil; } \\
\text { \#6 oil; } \\
\text { natural gas }\end{array}$ & $20-30$ & $\begin{array}{l}\text { Gives good electrical } \\
\text { efficiency and high- } \\
\text { pressure steam. }\end{array}$ & \\
\hline Diesel & $0.5-25$ & $\begin{array}{l}\text { \#2 oil; } \\
\text { \#6 oil; } \\
\text { natural gas }\end{array}$ & $25-40$ & $\begin{array}{l}\text { Most practical system } \\
\text { for small sites. }\end{array}$ & $\begin{array}{l}\text { Potential air } \\
\text { problems caused } \\
\text { by relatively } \\
\text { large amounts } \\
\text { of nitrogen } \\
\text { oxide } \\
\text { emissions. }\end{array}$ \\
\hline
\end{tabular}

SOURCE: Commonwealth of Massachusetts, 1978, p. 122

${ }^{a}$ Electrical efficiency is the fraction of fuel energy input (in Btu) that is transformed into electricity.

${ }^{b}$ Requires additional treatment to remove impurities. 


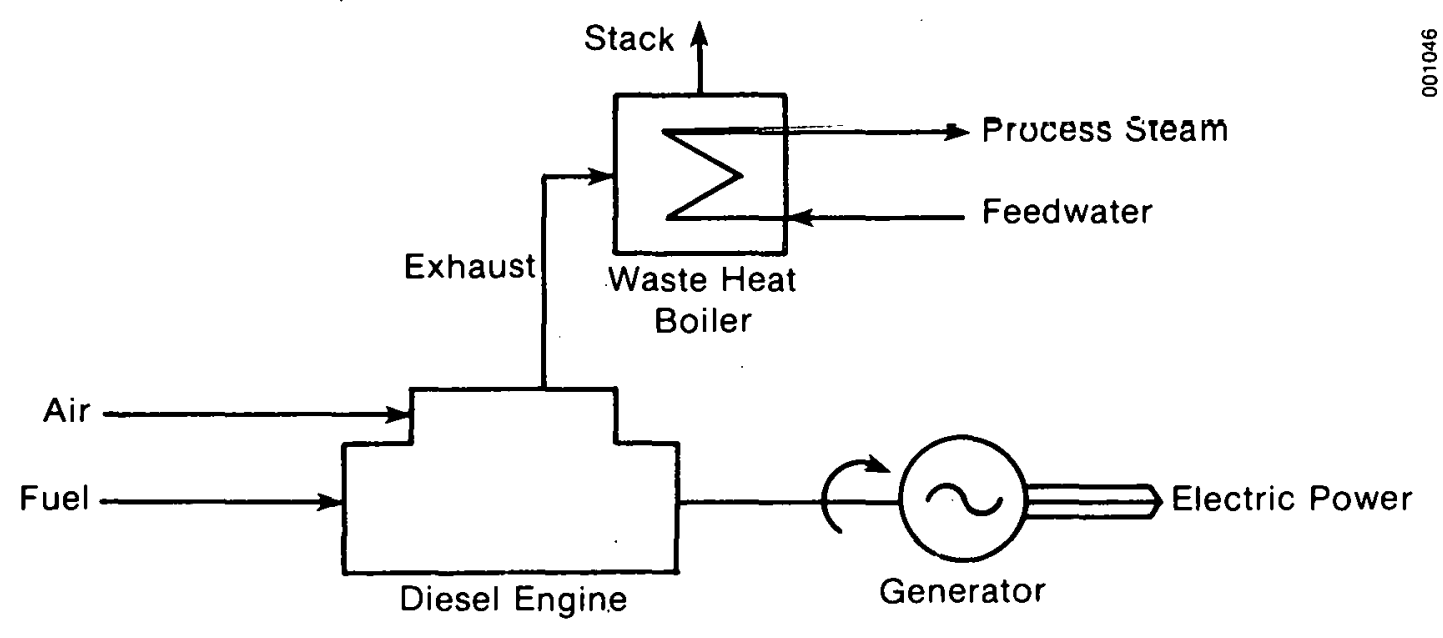

Figure 2-1. Diesel Cogeneration

SOURCE: Commonwealth of Masschusetts, 1978. p. 129 
Fuel (CONFUI) model where the user is required to specify fuel input rates and fuel heating values, the user needs only to know the rated capacity, in $\mathrm{kW}$, of the generator to use CONTOO. Scheduled and/or forced outages effect production patterns. These variations can be accounted for by a derating method. See DANDL, Section 2.2 and 3.3 .

\subsubsection{Direct Combustion of Biomass (COMBUS)}

Biomass fuels can be converted into useful energy through direct combustion. A simulation model has been developed to predict electricity production from a constant biomass source, an "energy plantation" and/or direct combustion utilizing wood residues.

Biomass has in the past been burned primarily to produce steam for electric power generation and/or process heat. Steam generation is a well known technology. Recently research and development has focussed upon increasing efficiency, decreasing operating costs, minimizing pollution and adopting different fuel inputs (ADL, November 1979, p. VII-12).

Types of biomass firing systems available include: 1) fluidized bed combustion, 2) charcoal/oil slurry firing, 3) stoker firing, and 4) suspension firing. Fluidized bed and slurry firing technologies are relatively new and still under development. The stoker and suspension firing technologies are presently well developed and utilized for commercial and residential application.

The types of biomass fuels available are agricultural, industrial, forest products, commercial and residential wastes. An energy plantation could utilize fast growing biomass as fuel to a small generation facility. It is also possible that seasonal availability of some biomass types can affect dependability of electrical production.

There are five options available in using this simulation. Option 1 allows the user to input a constant biomass fuel source. Option 2 and 3 calculates the electric generation from a biomass plantation. Option 2 pelletizes the biomass and option 3 does not pelletize the biomass. Options 4 and 5 calculate the electric generation of wood residues. Option 4 pelletized the residue and option 5 does not. It is possible to select one or more options together.

For constant fuel input, the user needs only to know the amount of biomass fuel per hour. The "energy plantation" concept is based upon a plannod, managed forest with a specified harvesting schedule. The harvesting schedule is designed such that wood is available on a continuous basis. Wood residues are a by-product of lumber manufacturing processes. Based upon physical form, "chippable residues," bark, and shavings are classified as residues.

Because wood fuel has a low energy density, pelletizing may be desirable because it increases the specific gravity. Pelletizing reduces shipping problems and produces a fuel which is clean, stable, readily marketable (SERT, February 1980, p. 51). Fuel inputs from either the "energy plantation" or from wood residues can be in pelletized or non-pelletized. 
form. In each of the five options, a uniform average annual heating value of wood is assumed for the biomass inputs.

Regardless of the form of biomass or its source, several factors are included in the simulation section. The heating value of the wood is essentially the thermal-energy released during combustion. There are three ways of defining the heating value: 1) gross heating value, 2) higher heating value, and 3) net heating value.

The gross heating value (GHV) incorporates a factor for removing the moisture content from the wood. The equation is ( see Eq. 2-2):

$$
\mathrm{GHV}=\mathrm{HHV} \text { (1-moisture content) }
$$

The moisture content (MC) is the percent moisture based upon the wet weight of wood. The higher heating value (HHV), which is the input value required for the simulation, generally ranges from 7900 to $10000 \mathrm{Btu} / \mathrm{lb}$. It is the total thermal energy available from oven dried wood. A list of typical libiglier luedling values can be seen in Table 2.2 .

The net heating value accounts for the negative heating effect of water. This is the real energy available for processing. The net consumption of energy is decreased by $1200 \mathrm{Btu} / \mathrm{lb}$. for every pound of water. The moisture must be superheated to $400 \cdot \mathrm{F}$ and zero pounds of pressure per square inch in order to be released. Vaporizing and superheating occur in the furnace. The formula for net heating value is (see Eq. 2-3):

$$
\mathrm{NHV}=\mathrm{HHV}(1-\mathrm{MC} / 100)-\mathrm{MC} / 100 \times 1200
$$

In all five options the biomass is used to fire an electric generator. The output of the simulation is the average rate of electric power production expressed in $\mathrm{kW}$. The simulation section assumes that the generator runs continuously throughout each day of the year. Outages whether planned or forced are handled in the DANDL Section of SERICPAC, Section 2.2 and 3.3.

\subsubsection{Methane Production and Generation (BIOGAS)}

A second technology which converts biomass into usable energy is anaerobic digestion.

The principles of methane production from decomposing organic matter have been applied for centuries. Initial development applications and experience have been in the less developed countries, primarily in Asia. Recent interest in biogas technology has been prompted by the rapidly rising cost of conventional fuels (National Academy of Sciences, 1977, Part I, Chapter 1).

There are several direct benefits of using organic wastes for anaerobic digestion rather than as fuel for direct combustion or as fertilizer. They include: 1) energy production which can be more efficiently stored, 2) a stabilized residue (sludge) which retains its original value as a fertilizer and 3) conventional fuel savings which result from producing an equivalent 
Table 2-2. Typical Higher Heating Values

of Some Wood and Fossil Fuels ${ }^{8}$

\begin{tabular}{lc}
\hline \multicolumn{1}{c}{ Fuel Type } & $\begin{array}{c}\text { Higher Heating Values (HHV) } \\
(\mathrm{Btu} / \mathrm{lb})\end{array}$ \\
\hline Southern pine bark & 8,900 \\
Hardwood whole tree chips & 8,600 \\
Wood pellets & 8,600 \\
Bituminous coal & 14,000 \\
\#2 Heating Oil & 19,400 \\
\#6 Heating Oil & 18,300 \\
La. natural gas & 21,800 \\
\hline
\end{tabular}

SOURCE: Levi and O'Grady, 1980, p.33.

${ }^{a}$ An average HHV for wood of $8,500 \mathrm{Btu} / \mathrm{lb}$ is used in this text. 
amount of nitrogen fertilizer from synthetic processes. Indirect benefits include reduced health hazards due to partial sterilization of pathogens during the bioconversion process.

All biomass materials are composed of three principal components: cellulose, lignen, and hemicellulose. Anaerobic bacteria reduce complex raw materials to simple organic compounds. Acids are produced at the end of the reduction stage. Methonogenic bacteria use these acids and produce methane and carbon dioxide (National Academy of Sciences, 1977, Part I, Chapter 2). The basic procedure for methane production includes the following steps: collection and transportation of biomass materials, processing biomass, digestion and product outputs (National Academy of Sciences, 1977, p. 61).

Methane has a heating value of 500 to $700 \mathrm{Btu} / \mathrm{ft}^{3}$. The gaseous outputs of the process is 70-50\% methane and 30-50\% carbon dioxide. Methane can be easily burned for cooking, lighting, heating, and refrigeration or as a fuel for an internal combustion engine. Applications for automobiles, however, are rather limited.

Seasonal variation in input fuels influence production rates unless biomass storage is available. In this analysis methane output is considered relatively constant due to crop residue storage (National Academy of Sciences, 1977 , p. 61-71).

The biogas simulation predicts methane generation in terms of million cubic feet and equivalent $\mathrm{kWh}$. We have adopted a computer model from Dynatech R/D (Ashare et al., 1979). It has eight components, each simulating the interaction of physical and biological elements of methane generation. The principles of anaerobic digestion which were discussed earlier are relied upon in the simulation. The eight components include:

1. Feed Composition--calculates biochemical characteristics of the feed (input);

2. Storage--determines number of required units for safe storage;

3. Shredding--finds amount of work necessary to shred biomass;

4. Holding-Mixing--finds energy requirement for this process;

5. Pretreatment--prepares biomass for digestion. Also calculates energy requirements;

6. Digestion--option for batch, continuous stir, and plug flow digestion process. Gas production and heat requirements are calculated;

7. Dewatering--water removal; and

8. Gas Purification--removal of impurities to improve quality. The energy requirements from each section are summed, and subtracted from gross production to determine net available energy. 
One of the major strengths of this model is its fle ibility with regard to input data. Agricultural residues, animal manure, and human refuse can be accepted for use by this model. The biomass input quantity can be easily entered through the interactive input section of the SIMULATE program. The configuration of the methane generation system will vary as the size of the farm varies. The system capabilities are additionally a function of the type of input.

Biological and chemical parameters will change as physical inputs vary. For example, digester retention time will fall as feedstock size decreases for crop residues (Ashare et al., 1979, p. 150). Additionally, the percentage of biodegradability of volatile solids changes with type of crop residue.

Another strength of biogas simulation model is the ability to consider virtually infinite system configurations. The biogas systems available for simulation include batch, continuous stir, and plug flow methods. Each of these systems are able to be simulated using the same input list.

Both the continuous stirred tank reactor (CSTR) and the plug flow reactor promote continuous digestion. The major difference between the CSTR and plug flow systems is particle residence time in the reactor. Each particle in the plug flow has the same residence time, whereas the CSTR digester has a wide distribution of residence times. The application of both of these techniques to utilize crop residues has been primarily on a small scale basis (Ashare et al., 1979, p. 65-66).

Batch digester designs have been applied to methane production from crop residues and biomass with high solids content, such as food processing wastes and other agricultural residues. Methane production from sanitary landfills are an application of batch designs. There are four stages of gas production in a landtill. The final process y1elds 50-70\% metharle. Varluus pretreatment options increase production rates. "Controlled landfill" methods have recently attracted considerable attention to the relative economic success of gas extraction from existing sites. Dynatech's study indicates "controlled landfill" batch reactors are more economically attractive to the small scale farm user than conventional CS'lR because batch reactors require less labor input and less capital costs (Ashare et al., 1979, pp. 145-149).

The same flexibility is available for dairy farms and poultry farm gasification. The output of the system is then used immediately to power an internal combustion engine, which then runs an electric generator. The mathematics of digester reaction are based upon the so-called first order kinetics of chemical reaction engineering theory. The essence of the entire model is founded upon the following reaction rates (see Eq. 2-4, 2-5, and $2-6)$ :

$$
G=A * C B O * K \div(1-k t)
$$




$$
\begin{gathered}
\text { Plug Flow } \\
G=A * \mathrm{CBO} * \mathrm{~K} \exp (-\mathrm{Kt}) \\
\text { Batch } \\
\mathrm{G}=\mathrm{A} * \mathrm{CBO} *(1-\exp -\mathrm{Kt})
\end{gathered}
$$

G - volume of gas produced per reactor volume per day (VVD)

$\mathrm{CBO}$ - inlet concentration of biodegradable volatile solids

$\mathrm{K}$ - first order reaction rate constant

$t$ - hydraulic retention time (reactor volume/inlet volumetric flow rate)

A - volume of gas produced per mass converted

There are a variety of system processes available to the user. The options simulated are storage, shredding (physical pretreatment), holding and/or mixing, chemical/thermal pretreatment, heat exchange, dewatering, and gas purif'ication. 'The input lists default values and work requirements are listed in the users' guide. A brief description of the components follows.

The size of the site specific storage unit(s) can be included in the input section of the simulation program. Additionally the density in the storage can be interactively entered. Because crop residues are a seasonal product, storage is necessary; especially for the CSTR digesters.

In regions where large amounts of wastes are available for methane production, the digester may receive the wastes directly. If such a design is implemented, equilibrating/mixing chambers can be installed to heat the waste before entering the digester and as a result maintain better control of the composition of feedstock. In such situations, where digester inputs are not directly utilized, storage facilities are necessary (National Academy of Sciences, 1977, p. 42).

Pretreatment is a method by which the biomass material is processed so that it will break down more rapidly during anaerobic digestion and yield higher methane output. There are several methods available: chemical, physical, and temperature. Generally, an economic analysis is performed to determine whether the economic benefits of additional gas production outweigh the costs of pretreatment.

The forms of pretreatment offered in the simulation are in the forms of physical and chemical pretreatment. The chemical pretreatment utilized in the analysis is a pretreatment conversion of $50 \%$ with an addition of sodium hydroxide with a 4-hour retention time at $115^{\circ} \mathrm{C}$ and $5 \%$ loss of input biodegradable volatile solids (Ashare et al., 1979, pp. 153-55). See Table 2.3 for the effect of pretreatment of residue digestion.

The model also allows three additional options. A heat exchanger can be included to recover sensible heat from the digester effluent stream (Ashare et al., 1979, p. 96). Dewatering can be included in order to utidize digester effluents in a more concentrated form, and to provide recycled water (Ashare \& Wilson, 1979, p. 131). Finally, gas purification can be 
Table 2-3. Effect of Pretreatment on Residue Digestion ${ }^{2}$

\begin{tabular}{llll}
\hline & Corn Stover & Rice Straw & Wheat Straw \\
\hline Small scale & & & \\
Annual gas production (MM Btu) & $2.68 \times 10^{3}$ & $\begin{array}{l}3.2 \times 10^{3} \\
12.36\end{array}$ & $\begin{array}{l}2.4 \times 10^{3} \\
12.76\end{array}$ \\
$\quad$ Unit gas cost (\$/MM Btu) & 12.81 & & \\
Intermedite scale & & & \\
$\quad$ Annual gas production (MM Btu) & $4.56 \times 10^{5}$ & $5.47 \times 10^{5}$ & $4.10 \times 10^{5}$ \\
$\quad$ Unit gas cost (\$/MM Btu) & 5.29 & 5.18 & 5.15 \\
Large scale & & & \\
$\quad$ Annual gas production (MM Btu) & $4.56 \times 10^{6}$ & $5.47 \times 10^{6}$ & $4.10 \times 10^{6}$ \\
$\quad$ Unit gas cost (\$/MM Btu) & 4.33 & 4.38 & 4.15 \\
\hline
\end{tabular}

SOURCE: Ashare et al., 1979, p. 154.

a Pretreatment conditions:

$\mathrm{NaOH}$ requirements $=5 \%$ of feed solids

conversion $=50 \%$ of nonbiodegradable solids

temperature $=115^{\circ} \mathrm{C}$

retention time $=4$ hours 
utilized in large-scale applications for the cleaning and compression of the gas before pipeline delivery.

As mentioned above, the user has the option available to vary the system configuration. System capabilities include small, medium and large systems. The output of the model is an average rate of electric power production for the smoothly operating system.

\subsubsection{Municipal Waste Electric Generation (MUNI)}

A subset of the anaerobic digestion model is a simulation of methane production from municipal solid wastes (MSW) and subsequent transformation to electricity. Municipal solid wastes can produce methane from either anaerobic digestion processes, or through extraction from landfills. The model that has been developed for the SERICPAC methodology is specifically designed to predict methane production from the anaerobic digestion of MSW.

For methane production from MSW, there are four necessary components to the process: pretreatment, digestion, product recovery, and residue treatment. Figure 2.2 illustrates a flow diagram of the process. Pretreatment separates inorganic matter and materials, as well as enhancing the biodegradability of the substrate, the material prepared for digestion. The digestion process produces methane $\left(\mathrm{CH}_{4}\right)$ and carbon dioxide $\left(\mathrm{CO}_{2}\right)$. The product recovery stage separates the $\mathrm{CO}_{2}$ from the $\mathrm{CH}_{4}$ providing "pipeline quality" methane for commercial distribution or electricity generation. Residue treatment removes undigested materials including water (dewatering). The residue can be disposed of either through a landfill, an incinerator, or can be used as a soil conditioner. The conceptual design widely accepted for methane production from MSW was prepared by Kisert et al. (1975) (see also Scaramelli, 1979, p. 251). Figure 2.3 illustrates this design. It is discussed in greater detail below.

The inputs to the system first pass through size reduction equipment. This stage efficiently separates organic materials from inorganic matter found in the MSW, and causes the feed to become more soluable for digestion. There are both wet and dry separation systems for removing grit, glass, and metals in order to increase the feedstock concentration of digestible matter. The dry separation process is flexible in terms of selecting a water content of the feed to the digesters. The wet separation handles low solid concentrations in aqueous slurries, requiring a dewatering stage.

Nutrients from the sewage sludge are added to the organic feedstock, together with control chemicals. Ferrous salts and lime are also added for $\mathrm{pH}$ and hydrogen sulfide control. Raw water or recycled filtrate can be added to the substrate in order to facilitate pumpimg the slurry.

Primary research on anaerobic digestion from MSW has been completed at the Illinois University at Urbana by Quindry et al. (1976), and Brown et al. (1976). The digestion conversion occurs in two stages: Solids are first digested by enzymatic action, and then soluable products are fermented in a series of reactions producing $\mathrm{CH}_{4}$ and $\mathrm{CO}_{2}$. The resultant product is composed of two streams. One stream is the gaseous output, the other, a slurry stream containing undigested organic matter. 


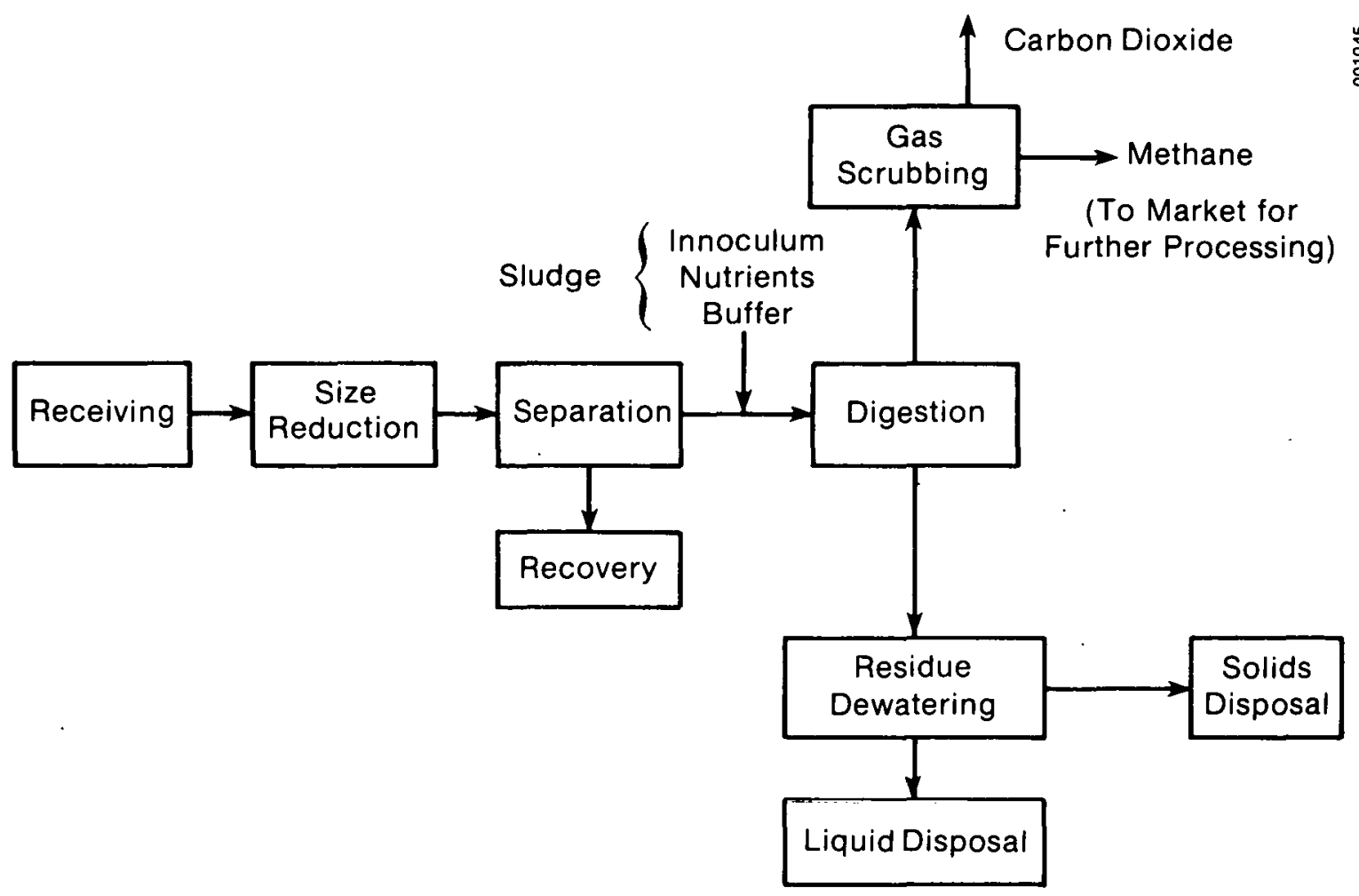

Figure 2-2. Processes in the Anaerobic Digestion of Municipal Solid Waste 


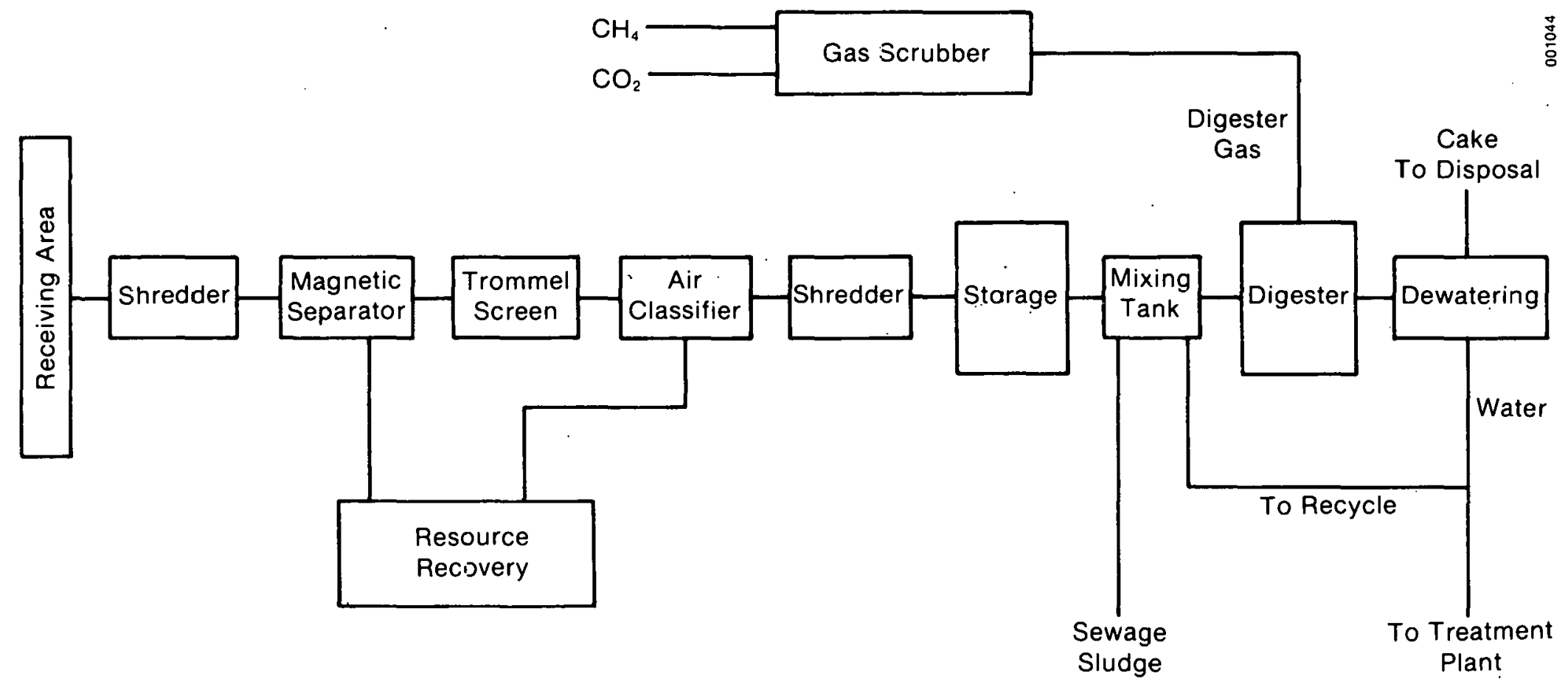

Figure 2-3. Anaerobic Digestion Process for Solid Waste Utilization

SOURCE: Kispert et al., 1975 
The gaseous output of the digestion process contains both $\mathrm{CO}_{2}$ and $\mathrm{CH}_{4}$. Acid gases are also represented, and require removal in order to prepare "pipeline quality" methane. A chemical (monoethanolamine) is utilized as an absorbant, removing $\mathrm{CO}_{2}$ and hydrogen sulfide. The chemical is recirculated and regenerated. Additionally, the methane is dried using a dehydration process. If the gas is used off-site, it is normally pressurized.

For effluent handling and disposal, the water and nondigestible matter must be removed at a rate equal to the rate of feed input. Therefore during a steady state operation of waste digestion, the system must be bled continuously. Normally, the substrate is well stirred to maintain homogeneous slurry composition. The slurry is then removed by separating the solids from the liquids. The liquid can either be recycled or returned to the sewage treatment plant. The solids can be incinerated, sent to a landfill, or utilized as a soil conditioner (Scaramelli, 1979, pp. 251-55).

The computer simulation of the generalized design has been adapted from Kispert et al. (1974). Their model was prepared with the objective of sizing equipment at the lowest cost. Performance inputs are aligned wi.th the laws of conservation of mass, the first and second laws of thermodynamics and the rate equations which define the size of the equipment in terms of the driving forces and resistances (Kispert et al., 1974, pp. $16-17$ ).

His model has been simplified for computational ease. The underlying assumption for methane production is a ratio of 1000 tons per day of MSW yielding $140.9 \times 10^{6}$ Btu per day. A human population of 571,400 is necessary to support a flow rate of 1000 tons per day. It is assumed that a per capita refuse generation rate is 3.5 lb/capita/day (Quindry et al., 1976 , p. 5). It is also assumed that the input rate is constant and that there is a uniform Btu content of fuel input. The efficiency of the generator can be interactively entered as an input. The output is constant electricity production measured in $\mathrm{kW}$ per hour.

\subsubsection{Producers Gas Production and Generation (GASSIF)}

Air gasification to obtain producer's gas is one of several technologies designed for utilizing biomass fuels as an energy source. Of the four gasification processes, air gasification is one of the least complicated forms of gasification. Carbon monoxide is a low Btu gas, having a Btu content of 100-150 Btu/Standard Cubic Foot (SCF). There are two types of air gasifiers, updraft (counter-flow) and downdraft (co-flow). The distinction is based upon where the injection of both air, heat and the biomass enters the system.

In the updraft systems, air is drawn up through a fixed bed of biomass on a grate located at the bottom of a shaft furnace. Combustion and char gasification occur on the grates supporting the biomass. High temperatures are encountered and the resultant gases rise. Carbon dioxide $\left(\mathrm{CO}_{2}\right)$ and water $\left(\mathrm{H}_{2} \mathrm{O}\right)$ are reduced to carbon monoxide $(\mathrm{CO})$ and hydrogen $\left(\mathrm{H}_{2}\right)$. As these gases rise to the lower temperature zones (200-500 $\mathrm{C}$ ) they meet the biomass descending from the top of the shaft and pyrolyze. The gases continue to rise and contact more wet incoming biomass, which subsequently dries due to 
the high temperatures. The gas exits at a lower temperature, saturated with pyrolysis oils and tars.

If the gas temperature cools below a specified temperature, chemicals, tars and oils will condense in the pyrolysis zone. A "close-couple" mode is utilized to prevent this condensation. This method more efficiently produces the gas and leaves no residues.

In the downdraft gasifier, air is injected through tuyeres (a pipe or nozzle) between the char zone and the zone of pyrol sis. Heat from the char zone pyrolyzes the biomass above. Oil vapors also pass through the bed of hot charcoals where they are "cracked" to simplified gases and chars. Figures 2.4 and 2.5 illustrate both the up and downdraft reactors.

If the temperature is too high, endothermic reactions occur thereby cooling the gases. When the temperatures are too low, exothermic reactions occur keeping the gases hot (SERI, July 1979, p. 19, and SERI, April 1980, p. 15).

Our gasification simulation model is based upon research completed at the University of California, Davis, and by SERI (SERI, July 1979; SERI, April 1980; and Levy and $0^{\prime}$ Grady, 1980). GASSIF is a computer model based upon important relationships discussed in these works. The model is straightforward. There are two options available to the user. The program can model a "pure biomass" system or a "dual" system. The distinction between the two systems is that the "dual" system uses a gaseous mixture of fuels in the combustion process.

The principle inputs to the simulation are the system configuration, the residue loading rate, the moisture content of the biomass, the higher heating value of biomass, estimated operation time per day, and several mechanical efficiencies. A more complete list is available in Section 3.

The assumptions utilized in the simulation include uniform biomass heat content. The net heating value muliplied by the residue loading rate (corrected for tons to pounds and years to days) yields available energy before gasification process.

Producers' gas has a low Btu value (100-150 Btu/scf) and is primarily carbon monoxide. The gas is used immediately to power an internal combustion engine, which runs a generator.

The efficiency for all processes, is constant throughout the model. The power output of the engine is then adjusted by the generator efficiency to determine net $\mathrm{kWh}$ produced.

The sole output of this model is the average rate of electricity power production for the smoothly operating system. 


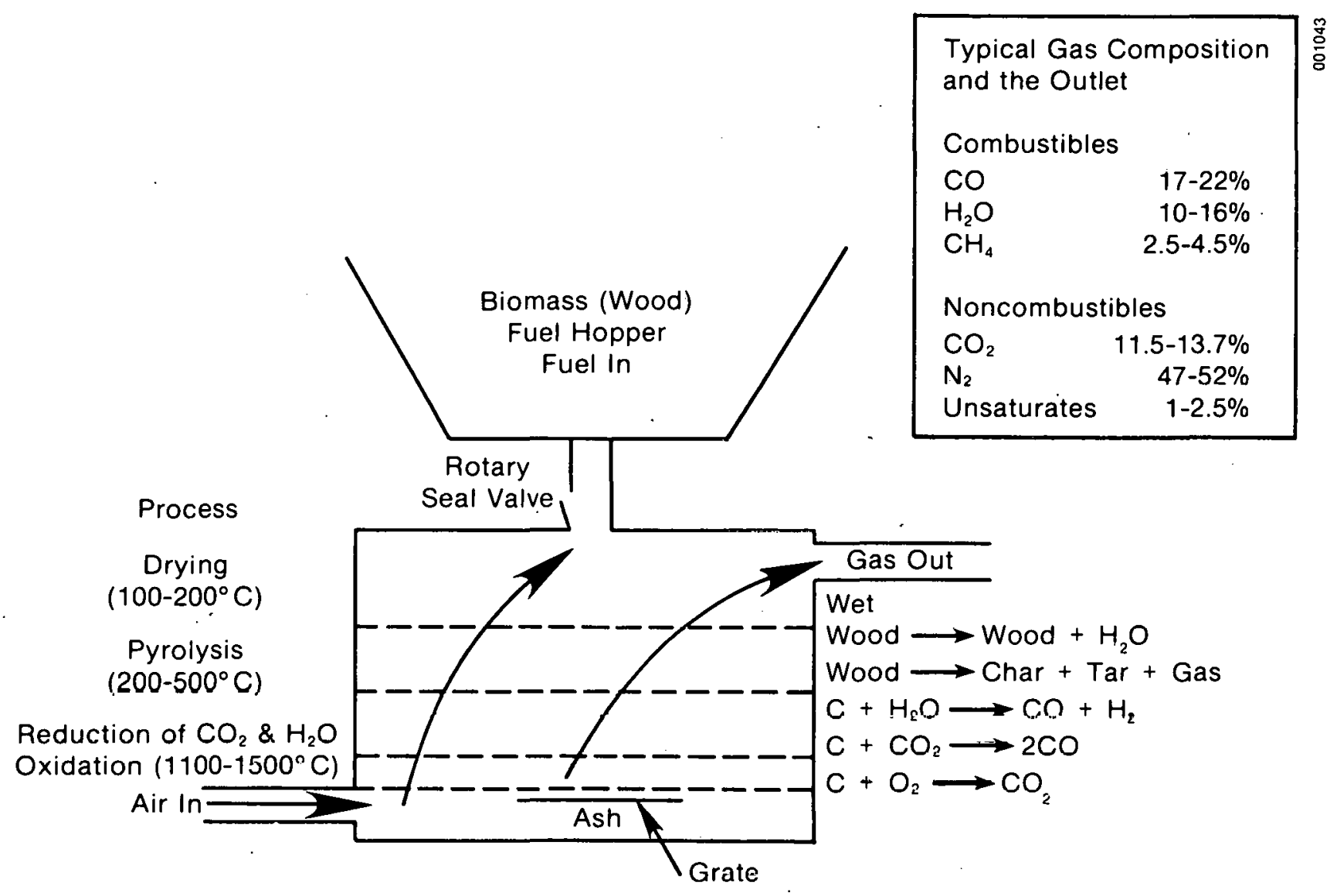

Figure 2-4. Updraft Gasifier

SOURCE: Levy \& O'Grady, Feb. 1980, pp. $91 \& 92$ 


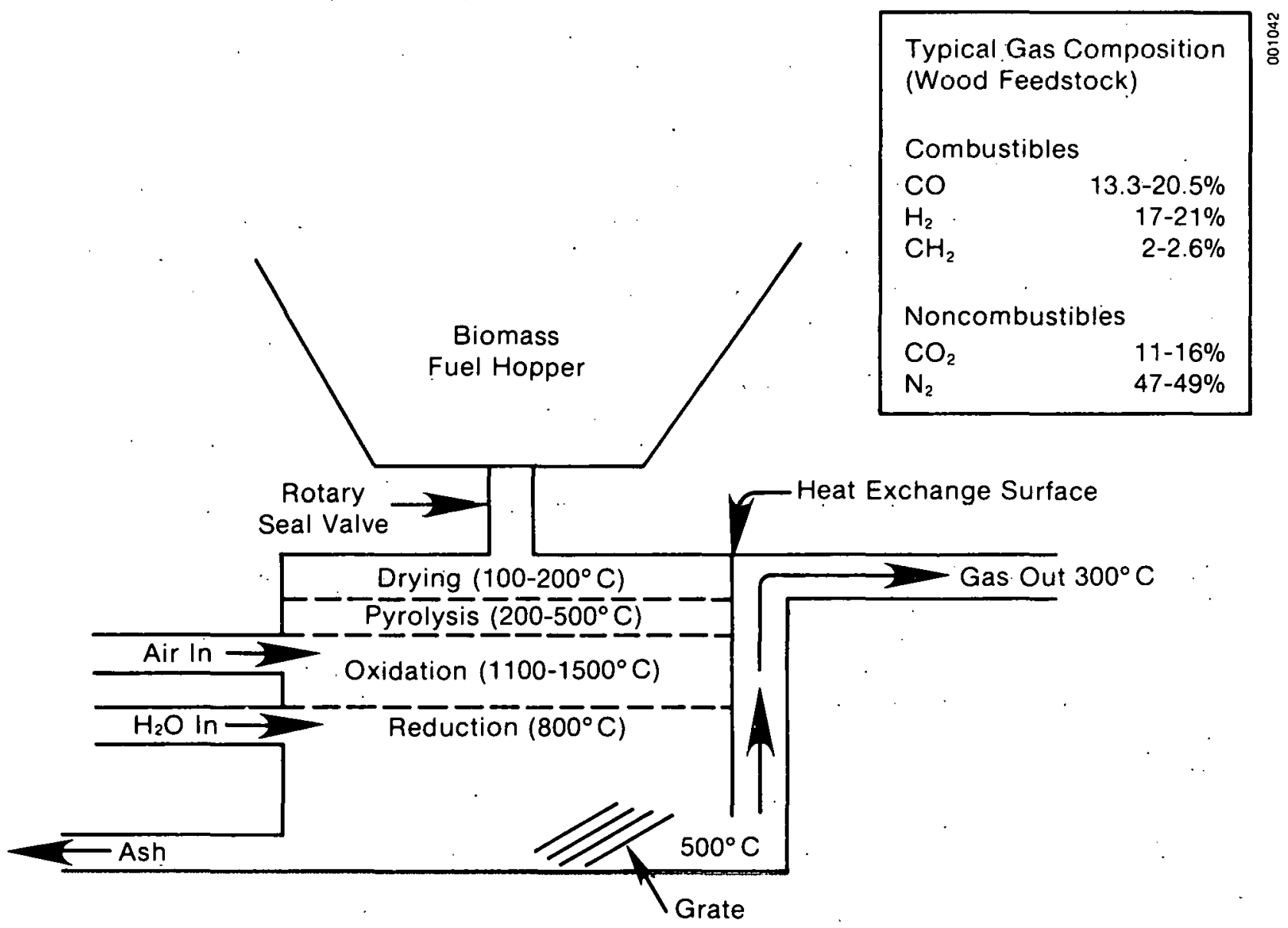

Figure 2-5. General Diagram of Downgrade Gasifier

SOURCE: Levy and O'Grady, Feb. 1980, pp. 91 \& 92 


\subsection{DERATE, LOAD, INTEGRATE (DANDL)}

According to PURPA, the buyback rates set by the utilities should distinguish among technologies based on the cost that is avoided as a result of the existence of the $\mathrm{QF}^{\prime} \mathrm{s}$ produced power. The rates may vary depending upon the time of day, week and month because utility costs of production vary over these time periods. Two components of utility costs, energy and capacity must be distinguished as to the relationship between $Q F$ production and avoided cost rates. The utility avoids energy costs by not having to produce the electricity that is provided by the QF. The avoided energy costs are determined by subtracting the $Q F^{\prime}$ 's sell-back from the total utility load and calculating the energy savings. The utility also may save money if the $\mathrm{QF}$ production and sale coincides with its peak demand. For this to occur, it is necessary that the production is not only available, but that the production is sufficiently reliable to allow the utility to forego other opportunities to meet demand.

Determination of capacity savings is a more complex issue. It centers on determining not only the potential reduction in capacity requirements, but the benefits to the utility of foregoing construction of that capacity. For purposes of this discussion, we will divide these two components into availability and reliability issues, respectively.

Availability concerns the prediction of the performance of the $Q F$ and the production of electricity sold back to the utility. It is the average amount of production that the utility should expect and incorporate into its dispatching plans. Availability must account for variation in production based on variations in input fuel availability, and also variations in the amount of electricity used internally by the $\mathrm{QF}$, and, therefore, not available for sell back. In order for the production to be compatible with the utilities dispatch, it must also account for outages caused by breakdown or routine maintenance. DANDL is written to specifically provide a diversified utility production that is comparable to its own facilities. DANDL derates the maximum outputs to adjust them from individual performance without outages to a diversified production (an amount of production that would be the average performance of a large number of similar systems).

Avoided Capacity Cost and Reliability is best handled through the Capacity Adjustment Factor discussed in Section 2 of SERICOST the companion to this text. The avoided capacity cost should indicate the benefits of reductions in capacity requirements. If the utility cannot be certain that the $Q F$ will exist then an adjustment to the avoided capacity cost is warranted. These considerations are independent of availability which measures how the $Q F$ performs. The DANDL program specifies an average annual diversified production which accounts for variations in weather and operation. The avoided cost benefits in $\$ / \mathrm{kW}$ and the measure of reliability are taken into account in the SERICOST program.

To summarize more clearly how DANDL works, the following description is provided. The output from the SIMULATE program is the maximum performance of facility assuming that the facility is available all year long. While the 
simulations do account for variation in the availability of the input resource such as wind, solar insolation and water, the models do not account for breakdown or maintenance. In addition, not all of the produced power will be sold to the utility; some will be utilized by the QF itself. The utility that is forced to buy power from the QF must plan for the receipt of this power in the future and build and operate its own facilities to match the availability of QF's sell back electricity.

This program, DANDL, converts the maximum output into a diversified sellback production for the utility. Using criteria similar to that used by utilities in analyzing the availability of their own systems, DANDL derates the maximum output and subtracts the user's own load. The product of this program is an average decentralized production for which utilities can anticipate and plan accordingly. It also represents the sell-back production on which the impact on the utility and the subsequent rates can be determined.

DANDL allows the user to derate the maximum output in several manners. These methods are similar to those employed by the utilities in production planning and capacity expansion. The user can specify periods when the unit will be under maintenance, the user can specify a derating factor that reduces production by a fraction equivalent to an unscheduled forced outage probability, or the user can utilize both options together. It is important to note that virtually no data is available for forced outage rates of small power producers. One solution is to use the forced outage rate of the utility's own equipment, until actual data is collected from the QF systems. Derating can be implemented on a yearly, monthly or daily basis. The user's guide Section 3.2 will provide further information regarding its use.

The second part of DANDL integrates the QF's power requirements with its power production. The calculated electric energy from the simulation model can be subtracted from the QF's known load, which is input by the user for each hour or on an average daily/monthly basis. The QF's power demand can be entered interactively or may be read in from file.

There are two options available to integrate the QF's power produced with the QF's power requlrements. They are simultaneous buy/sell and net power. PURPA and the FERC rulings specify that simultaneous buy/sell options are to be permitted. Simultaneous buy/sell is when a QF purchases its entire power requirements from the utility and sells all its production to the utility separately, receiving a rate of the avoided costs. Net power, the amount of production that is not used internally, is the second of the two options available in the load integration section.

As mentioned earlier the integrate section of DANDL standardizes the output from 3IMULATE ma1n program. Performance Analysis (PMAIN) program converts the DANDL output into production by utility period, and is the subject of the next part of this text. 


\subsection{PERFORMANCE ANALYSIS (PMAIN)}

The performance analysis section of the methodology is rather straightforward. Utility cost (especially at the margin) are influenced by the mix, as well as the number of qualifying facilities. Conventional utility planning models estimate capacity requirements based upon load forecasts. The technology simulation module predicted hour-by-hour performance. This output was derated to reflect an average diversified production and then integrated with the QF's own demand requirements. This is essentially the output of the DANDL program. The inputs to PMAIN are: the derated performance which is aggregated into one 24 hour period monthly and the utility period definitions.: Through the interactive input section, the user can selectively change the input variables. The user's guide outlines the procedure in Section 3.3 .

PMAIN takes the output from DANDL and divides the output into aggregate production by utility periods. The periods represent the major divisions in utility cost of production. These utility periods were identified in SERICOST and must be identically specified in PMAIN.

\subsection{AVOIDED COST (AVOIDC).}

The final section to the SERICPAC methodology is the calculation of avoided cost rates. As discussed earlier, rates to $\mathrm{QF}^{\prime} \mathrm{s}$ are supposed to be based upon those costs the public utility avoids as a result of purchasing electric energy from the QF. The purpose of SERICPAC is to methodically calculate the buy-back rate to the $Q F$, based upon avoided costs.

There are two conceptual elements to the calculation; the cost structure of the utility, and the performance of decentralized power source. SERICPAC combines the output of the performance analysis with the avoided costs derived in SERICOST.

Avoided costs represent the opportunity costs of resources available to produce electric power. SERICOST determines the cost of the electricity the utility avoids as a result of purchasing electricity during different periods. The results from SERICOST are to be entered in this section of the methodology

The avoided cost data per time period is combined with the performance of the QF. The performance analysis, calculated in PMAIN, is in the form of aggregated hour performance by utility time period. It is based upon the results from the SIMULATE and DANDL sections of the methodology. The performance analysis can be considered in terms of electricity sold and produced by the. $\mathrm{QF}$.

The output of AVOIDC is the weighted average avoided cost rate for that technology. If time of use rates are desired, then the rates from SERICOST. are the appropriate rates. 
The formula to calculate the weighted average avoided cost is as follows (see Eq. 2-7):

$$
A C R=\sum_{i=1}^{n}\left[\left(k W h_{i}\right)\left(A C_{i}\right)\right] \div \sum_{i=1}^{n} k W h_{i}
$$

where:
ACR = weighted avoided cost rate.
$\mathrm{kWh} \quad=$ the kilowatt hours sold back to the utility in period $i$.
$\mathrm{AC} \quad=$ the utility avoided cost in period $i$ from SERICOST.
$\mathrm{n} \quad=$ the number of utility periods psecified in SERICOST.
$i \quad=$ avoided cost period. 
THIS PAGE

\section{WAS INTENTIONALLY LEFT BLANK}


SECTION 3.0

SERICPAC USER GUIDE*

\subsection{INTRODUCTION}

The SERICPAC methodology is designed to calculate the avoided cost rates for various decentralized technologies. SERICPAC is designed to be compatible with SERICOST a program to calculate the avoided costs of a utility. The program is flexible enough to accommodate other utility costing models or technology simulation programs.

SERICPAC is composed of four main sections. The sections include:

Section Number Title

3.2

3.3

3.4

3.5
SIMULATE :

DANDL :

PMAIN:

AVOIDC:

\section{Description}

This program contains eight different simulations of decentralized technologies.

'I'his section allows the user to account for the availability of qualifying facility production. Simultaneous buy/sell or net energy options are available to the user.

This program takes the net or gross production and breaks it up into utility time periods.

The avoided cost rates are calculated and displayed.

\subsubsection{Symbols Used in Guide}

- An underlined word, phrase, sentence(s) indicates a computerresponse. It should be carefully distinguished from section headings, which are also underlined but preceded by chapter numbers.

- "input"--to be provided by user is between quotes.

- (cr)--a carriage return is required or actuated. When (cr) is preceded by an input quote (described above), the user should enter the input then depress carriage return.

- $\varnothing$-mignifies a blank space.

- *Headings/Subheading s*--headings and subheadings used for clarification purposes will be bracketed by asterisks.

*The user should consult Appendix A in order to operationalize the SERICPAC computer model. 


\subsection{TECHNOLOGY SIMULATION (SIMULATE)}

There are two very important sections in the SIMULATE main program:

*Technology Simulation*--There are eight technology models which simulate their performance, individually, given the inputs to the model and/or configuration chosen. Section 3.2.2.

*Interactive Input Option*--The user is able to inspect, change, save input files, and read previously saved input files. The user is also able to execute the simulation. Section 3.2 .1 .

It is suggested that the user review technology descriptions (found in Section 2) and input requirements to the technology simulations (found in Section 3.2.2) before attempting to execute the SIMULATE main program. A flow diagram of how SIMULATE operates is presented in Figure.3.1.

To activate the technology simulation main program, the user should type "SIMULATE" (cr).

The following appears at the terminal: Do you want printout to terminal? ( $\mathrm{Y} / \mathrm{N})$
(If NO, Printout to file)

"Y"(cr) - The output of the simulation module will appear at the terminal. It will be stored in the file SYSSIMUL.DAT. The prompt proceeds to the Main Branchpoint.

"N"(cr) - The technology simulation output is stored in SYSSIMUL.PRN and unavailable for viewing at the terminal. The prompt proceeds to the Main Branchpoint.

\section{SIMULATION TO EXECUTE-}

\$PH:W:C:G:M:R:B:P:?:E:

This is the main branchpoint for the SIMULATE main program. If the user is unfamiliar with the branchpoint, a question mark "?"(cr) should be entered. The prompt returns.

This is the simulation sectionEnergy systems may be modeled by the appropriate module. Available modules and commands include:

H(ydro) - Hydropower simulation.

W(ind) - Wind production simulation.

G(assif) - Producers gas simulation.

C(onfui) - Level performance, for example for either direct combustion, based on fuel rate and heat content.

$\mathrm{R}$ (ated) - Level performance for any constant output process, based in rated level. This is a useful tool for analysis of a technology with a constant rated output.

$B$ (iogas) - Biogas power production simulation. 

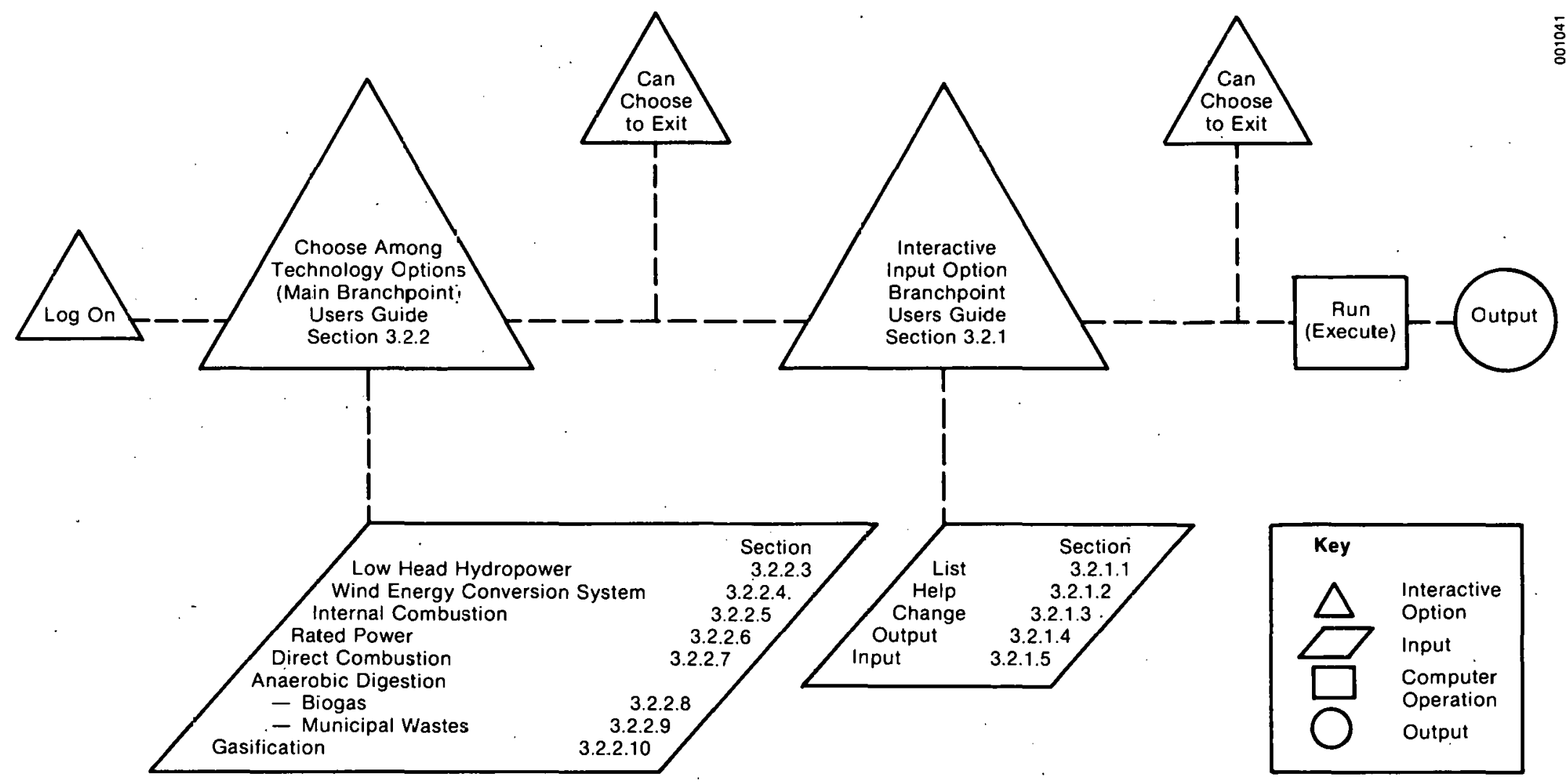

$\omega$

Figure 3-1. Flowchart of the SIMULATE Main Program 


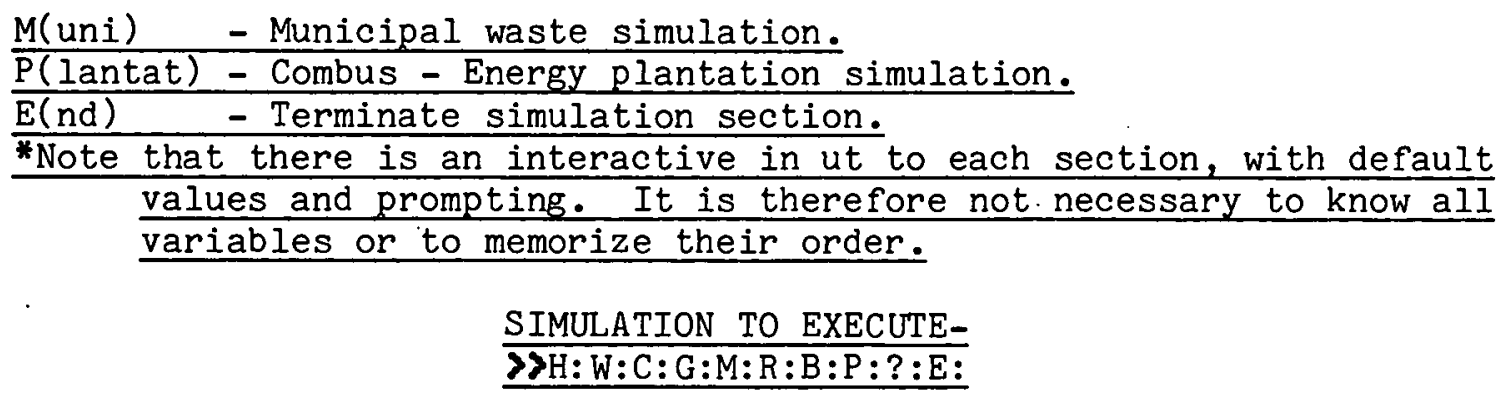

The user should select a technology to simulate and enter the appropriate letter, followed by ( $\mathrm{cr}$ ).

If a response other than the one allowed is entered, the following is returned to the terminal:

ENTER ONE OF THE FOLLOWING: "H" "W" "C" "G" "M" "R" "B" "P" "?" "E" \$ H:W:C:G:M:R:B:P:?:E:

\subsubsection{Interactive Options}

Once the user has selected and entered a technology to simulate, the following branchpoint appears:

Interactive Input Option:

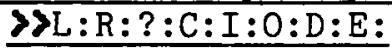

If the user is unfamiliar with this branchpoint, "?" (cr) should be entered.

The following should appear on terminal: This is the interactive input

section. Available commands include:

\begin{tabular}{ll} 
L(ist) & Lists technology input variables. If you respond to the \\
\hline & $\begin{array}{l}\text { following prompt with a positive number, that line will be } \\
\text { listed. If the number is less than zero, all lines will be }\end{array}$ \\
listed. Entry of a zero causes you to be prompted for a \\
range to list. \\
C(hange) & Changes in variables. You will be prompted for the number \\
of the variable to change and the new value. \\
R(un) & Returns to simulation module to execute with variables as \\
specified in this section. \\
S(nput) & Sets data from a previously "output" file. \\
o(utput) & Saves current data to file, suitable for later "input." \\
D(efault) & Resets to defaults. This is done automatically on the \\
\hline first run for each simulation module. \\
Aborts this section without proceeding with run.
\end{tabular}


After executing ( $\mathrm{cr}$ ) the program returns to the interactive option branchpoint, Section 3.2.1.

\subsubsection{List}

If the user wishes to list all of the input variables, "L"(cr) is entered and the following is returned to the terminal:

$$
\text { Number To List ( } 0 \text { for range, }<0 \text { for all): }
$$

Number to list implies the variable's position in the technology simulation input list. It is possible to have some or all of the variables listed at the terminal. For instance, the fifth through tenth variables can be displayed. In such a case "0" is entered. The prompt returns:

\section{First Line Number: (cr)}

The first variable line number "5" should be entered (cr). Prompt returns:

\section{Last Line Number: (cr)}

The last variable number "10" (cr) is to be entered.

Error message: *Invalid values for list range* indicates that either the user entered no responses or only one response, or that the first and last desired line were out of numerical order. If the user is unfamiliar with the input list, a negative number should be entered.

The user is returned to the interactive option branchpoint, Section 3.2.1.

\section{$3.2 .1 .2 \quad \mathrm{Help}$}

The directory assistance option is engaged by entering "?" (cr). The list of available interactive commands was previously listed in Section 3.2.1.

\subsubsection{Change}

The change option enables the user to change specific input variables. Upon entering " $\mathrm{C}$ " ( $\mathrm{cr}$ ), Number To Change appears at the terminal. The variable numbers are available either through the list of options or within the user guide description presented in the next section, 3.2.2.

After the user enters the appropriate number (cr), the prompt returns:

\section{New Value:}

If no value is entered for either or both request( $s)$, the user is returned to the interactive input branchpoint, Section 3.2.1.

\section{2 .1 .4 Output}

It is possible to change the default values and save them for future use by writing them to a user specified file. Enter "o" (cr) prompt returns: 


\section{Name of output file (11 chars--no period):}

Enter file name (cr).

$$
\text { Disk of Data File (A/B): }
$$

Enter appropriate disk "A" or "B" ( see Appendix A).

$$
\text { File header ( } 20 \text { chars } \max ) \text { : }
$$

The user should enter a file name of eleven characters immediately after the returned : with no periods and $(\mathrm{cr})$. A descriptive heading to the file, of no more than twenty characters is a good idea. Spaces between words are not included as characters.

It is important to note that writing a file to an existing file will wipe out the existing file.

The user returns to Section 3.2.1, the interactive branchpoint whether titles have been entered or not.

\subsubsection{Input}

Previously saved files can be read into this section as inputs to the technology simulations, by entering "I" (cr). The prompt response:

Enter Information on Input File Enter Disk of Data File (A/B):

The user should enter either "A" or "B."

\section{Filename ( 11 Chars, no period: Blank to Escape):}

The user should enter the proper filename.

\section{File header (20 chars $\max )$ :}

The name of the input file must be 11 characters, with no periods and entered after the :- The file heading can be only 20 characters total. Spaces between words are not included as characters. A check is performed to determine whether the specified file is in the computer memory. If the test fails the following message appears:

\section{*File not Found*}

If the file is found, then another check is executed to evaluate whether the specified input file requested is for the technology initially chosen. The message:

\section{*File for wrong system type*}

appears if the condition occurs. 
In the event of problems of data transfer, the message:

*Premature end-of-file on channel number--*

The user is returned to Section 3.2.1, the interactive input branchpoint when either the input was successfully completed or no entries were attempted.

3.2 .1 .6 End

"Q" (cr) allows the user to leave or quit the interactive input section without executing the model, returning to the main branchpoint.

3.2 .1 .7 Run

This option enables the user to execute the simulation with the input data changed or left as defaults.

The next section outlines the input data, options (if applicable) and output available per technology after "R" ( $c r$ ) has been entered. It is very important to read this next section before attempting to execute any of the technology simulations.

\section{2. $\quad$ Technology Options}

It is highly recommended that the user review this section before attempting to execute any of the technology simulations. This section outlines the input data, simulation options (if applicable), and output available per technology, after the "R" (cr) has been entered while at the interactive branchpoint.

\subsubsection{Technology Simulation User Guide Introduction}

The general form of the next section $(3 \cdot 2.2 .2--3 \cdot 2.2 .8)$ is as follows:

Irleruduction: Brief description of technology.

Requirements: Data requirements to the technology simulations are listed with the respective portions of sections 3.2.2.1 through 3.2.2.8. Access to vary, save, or create input files is available within section 3.2.1.1 through 3.2 .1 .7 .

Default

Assumptions: These are the input variables to the simulation. Section 3.2.1 outlines the procedure to vary, save, recall, and/or default these input variables.

Additional

Assumptions: Some programs have options which are elaborated upon within this section.

Operation: Instructions for operation. 


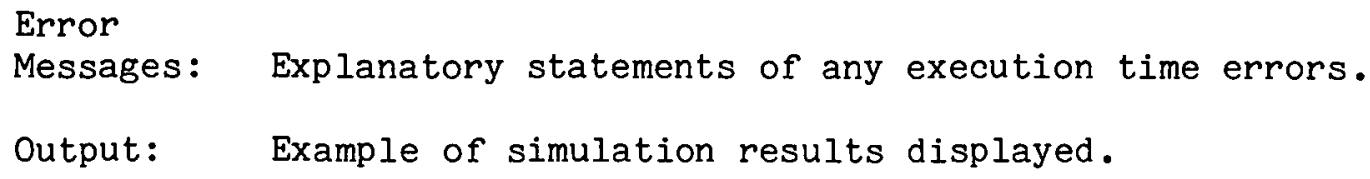

\subsubsection{Data File In SIMULATE}

In order to more accurately perform the technology simulations, weather data are required for some of the technology models. The following technologies require data files:

\section{$\underline{\text { Technology }}$}

Hydro-Electric Production

Wind Energy Conversion Systems
Data

1. River flow measured in cubic feet per second (CFS) for hourly, daily, or monthly gauge readings.

1. Windspeed (meters/sec.) hourly or tri-hourly readings per day.

Format

Variable read format option, defaults to G13.6.

First Line is a descriptive header, one entry per subsequent line. The entry format is G13.7.

Same as above.

2. Temperature (centigrade)

Electric Production (Hydro)

3. .2.3. Hydro-Electric Production (HYDRO)

Based upon Army Corp of Engineer model. See Section 2.1.1 for a further description.

Requirements :

\section{*Data Files*}

River flow measured in cubic feet per second (cfs) for either hourly, daily, or monthly gauge readings.

The file should be titled with 11 characters, containing no periods. The first line should be a header, and one input per line thereafter. There is a variable read format option, which defaults to G13:6.

Default Assumptions:

\begin{tabular}{|c|c|c|}
\hline \multirow{2}{*}{\multicolumn{2}{|c|}{$\begin{array}{c}\text { Variable } \\
\text { Numbers }\end{array}$}} & Default \\
\hline & & Values \\
\hline 1.1 & $\bar{P}$ lant efficiency $(\%)$. & .88000 \\
\hline 2 . & Height head efficiency $(q) \ldots \ldots \ldots \ldots \ldots$ & .95000 \\
\hline 3. & Minimum operational level ( $\%$ of capacity)... & .400000 \\
\hline 4 . & 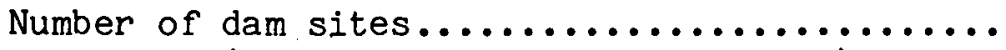 & 1.000000 \\
\hline 5 . & Data flag (1-hourly, 2-d & 1.000 \\
\hline
\end{tabular}


Additional Assumptions:

*Frequency of flow measurements (hourly, daily, monthly)

*For each site:

Gross head size--measured in feet

Plant capacity--measured in $\mathrm{kW}$

*Sample Inputs*

Upon selecting "R" (cr) the computer responds:

*End data set section*

Disk of data file (A/B)

The user should respond with the appropriate letter (cr). The prompt returns:

Filename ( 11 chars, no period: blank to escape)

A file name of the data file containing flow data is to be entered; eleven characters and no periods.

Is the first record of the file a label header? ("Yes" should be the default condition)

$\underline{(\mathrm{N}, \mathrm{Y})}$

"N" (cr) - no header exists

"Y" (cr) - default condition; one line description exists. It is returned to the screen.

Header: (SAMPLE HEADER NAME)

The prompt returns:

Do you wish to use the default data format:

(G13.6)

(N,Y):

This is the variable format option:

"Y" (cr) - defaults format to (G13.6)

"N" (cr) - the following question follows:

Enter new format (including parens: blank to escape):

User should enter appropriate FORTRAN data field descriptor (cr). An example is "(2X,F15.2)." No entry ( $\mathrm{cr}$ ) causes the user to return to Main Branchpoint, Section 3.2 .

The prompt returns with the additional assumption section. 
Name of Site:

The user is asked to provide the name (20 characters or less) of the first site (if more than one site is selected) (cr).

Plant Capacity-kW-(G):

The appropriate plant capacity (in $\mathrm{kW}$ ) is entered with a decimal point (cr).

Gross Head Size-Ft:

The appropriate gross head size (in $\mathrm{ft.}$ ) is entered with a decimal point (cr).

The preceding series of three questions (Name of Site, Plant Capacity, and Gross Head Size) is iterated as many times as specified by input variable 非. Variable 非 4 defaults to 1 ..

Sample Out and Error Messages:

After the final gross head is entered:

Running...

A running message is displayed. Check messages are displayed:

\begin{tabular}{c|c} 
Hour 1000 \\
\hline Hour 2000 \\
\hline
\end{tabular}

This indicates the number of hours the simulation has performed. If input data is daily rather than hourly, then day--is displayed.

If the prompt returns:

This program has no provision for century by century data. We are returning you to the main program--clean up your act.

Then the user should compare value 1 5 from the input list with stream flow data entered from file. It is important to determine whether the elements of the input file match the specifications indicated by variable $\# 5$.

Other error messages are self-explanatory.

The output form of the simulation for three sites is as follows: 


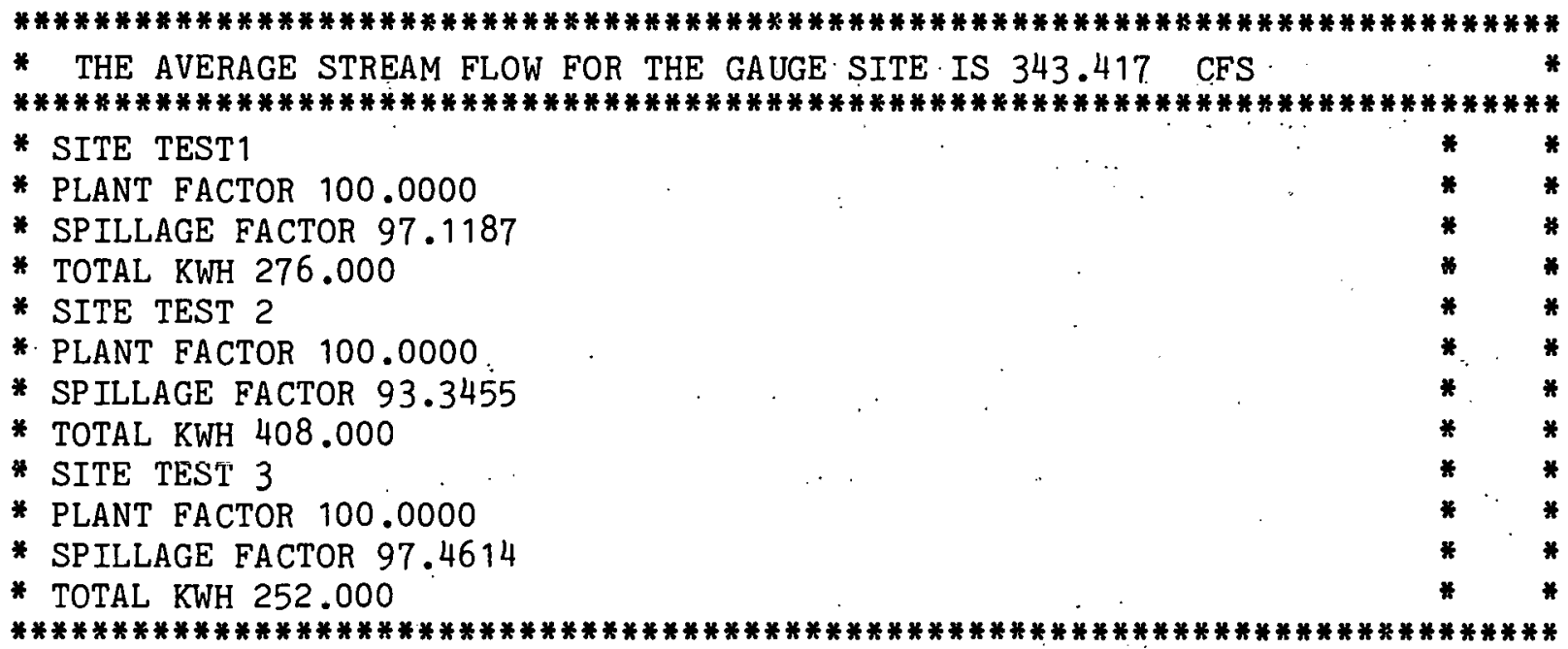

\subsubsection{Wind Energy Conversion Systems (WIND)}

Introduction: WECS model designed to accept hourly or tri-hourly wind speed data. Further description Section 2.1.3.

Requirements: *Data Files*

Two data files are required:

\section{File}

Wind speed $(\mathrm{m} / \mathrm{sec})$

Temperature

(centigrade)

\section{Format}

First line header, one entry per subsequent line. Same as above.

The program is designed to accept this input data for hourly or tri-hourly wind and temperature readings.

The title of the respective file is to be 11 characters (with no periods). The header can be 20 characters maximum. Spaces are not included as characters.

Default Assumptions:

Variable Numbers

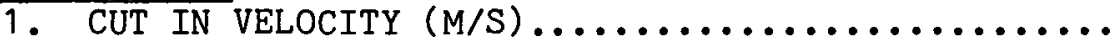

2. CUT OUT VELOCITY $(\mathrm{M} / \mathrm{S}) \ldots \ldots \ldots \ldots \ldots \ldots \ldots \ldots \ldots \ldots \ldots$

3. RATED VELOCITY $(M / S) \ldots \ldots \ldots \ldots \ldots \ldots \ldots \ldots \ldots \ldots$

4. DESIGN VELOCITY AT MAX. POWER COEFF (M/S) ........

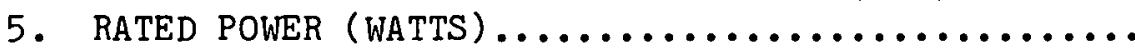

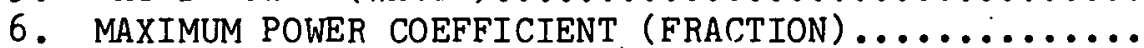

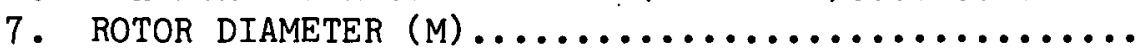

8. ANEMOMETER RECORDING HEIGHT $(M) \ldots \ldots \ldots \ldots \ldots \ldots$

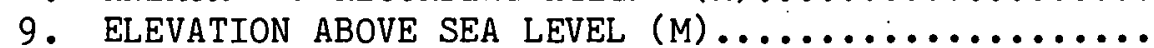

10. HUB HEIGHT IF HORIZONTAL AXIS $(M) \ldots \ldots \ldots \ldots \ldots \ldots$

11. CLEARANCE HEIGHT IF VERTICAL AXIS (M) ...........
Default Values

4.50000

18.0000

11.6000

7.40000

65000.0

.410000

19.5000

6.10000

177.000

22.9000

0.00000 
12. CONSTANT $(=0)$ OR VARIABLE $(=1)$ RPM............ 0.00000

13. HORIZONTAL $(=0)$ OR VERTICAL $(=1)$ AXIS............ 0.00000

14. HEIGHT OF WECS IF VERTICAL AXIS (M) ............ 0.00000

15. TIME INCREMENT OF WIND SPEED DATA (HOURS) ....... 3.00000

Operation:

There are two sets of interactive questions; the first is directed towards wind speed, the second towards temperature.

Upon entering "R" ( $c r$ ) at the interactive option branchpoint, Section 3.2.1, the prompt returns:

\section{Enter data for wind file (meters/sec)- Disk of data file (A/B):}

The user should enter the appropriate response "A" or "B" (cr):

Filename ( 11 chars, no period: blank to escape):

An eleven character file name for the wind speed data is to be entered (cr). No entry (cr) returns the user to the SIMULATE Branchpoint, Section 3.2.

Is the first record of the file a label header?

("Yes" should be the default condition)

$(\mathrm{N}, \mathrm{Y})$ :

"N" (cr) - prompt returns to the next section

"Y" (cr) - a copy of the header is displayed.

Headèr: (Sämple Header)

Do you wish to use the default data format?

(G13.6)

$(\mathrm{N}, \mathrm{Y}):$

"Y" (er) - prompt returns to the next question

"N" (cr) - the user views:

Enter new format (including parens: blank to escape):

The appropriate field descriptor is to be entered, reflecting the formatting of the data file. No entry (cr) allows the user to return to SIMULATE branchpoint, Section 3.2. The prompt returns:

Is the data in meters/second?

$(\mathrm{N}, \mathrm{Y})$ :

"Y" (cr) - the user is returned to the next question

"N" (cr) - prompt returns:

Data may be adjusted by the formula:

Final data. = (Rawdata+addfactor)*multfactor 
The raw data is the input file. The input file eventually is to be in units of meters/sec.

\section{Enter factor to add to raw data:}

Enter appropriate factor (cr) including a decimal point. If no factor is to be added to the raw data, then "0." should be entered (cr).

\section{Enter factor to multiply data by after addition:}

Enter appropriate factor (cr) including decimal point. If the raw data is not to be multiplied by a factor, then "1." (cr) is to be entered.

$$
\begin{aligned}
& \text { Data can be either hourly or in the form of hour/month mean \& } \\
& \text { standard deviation. } \\
& \text { Is the data hourly? ("No" indicates mean \& SD) } \\
& \text { "Y" (cr) - hourly (or daily) inputs are specified } \\
& \text { "N" (cr) - a file containing previously calculated means and } \\
& \text { standard deviation had been entered. }
\end{aligned}
$$

The second input file to be retrieved is temperature data.

$$
\frac{\text { Enter data for temperature file (deg C) }}{\text { Disk of data file (A/B): }}
$$

Enter appropriate disk "A" or "B" (cr).

$$
\text { Filename ( } 11 \text { chars, no period: blank to escape): }
$$

Enter temperature file name, eleven characters and no period (cr).

Is the first record of the file a label header? ("Yes" should be the default condition)

$$
(\mathrm{N}, \mathrm{Y}):
$$

"N" (cr) - prompt returns with next question

"Y" (cr) - user views the temperature file header

$$
\text { Header: (Sample Header) }
$$

Do you wish to use the default data format? (G13.6)

"Y" (cr) - prompt returns with the next question "N" (cr) - prompt returns:

Enter new format (including parens: blank to escape):

User should enter appropriate field descriptor for the temperature data file (cr). No entry (cr) returns the user to the SIMULATE Branchpoint, Section 3.2 . 
Is the data in centigrade?

$(\mathrm{N}, \mathrm{Y})$ :

"N" (cr) - temperature data is converted from fahrenheit into centigrade.

"Y" ( $c r$ ) - temperature data is in centigrade and will be directly utilized.

Error Messages:

All error messages will be self-explanatory.

*Sample Output*

(See following page) 
Output from the simulation appears as follows:

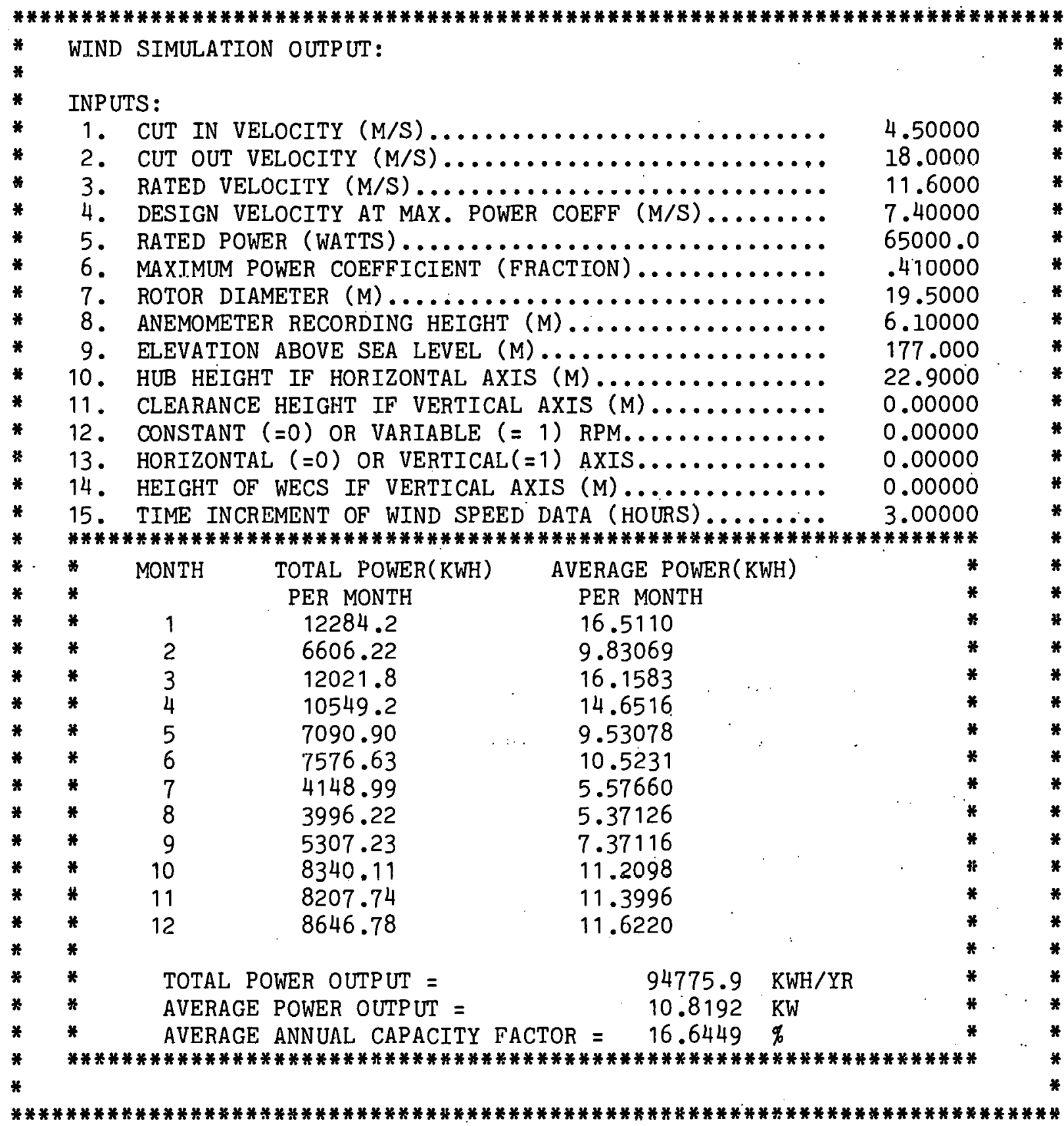

The user is returned to the SIMULATE Branchpoint, Section 3.2. 


\subsubsection{Conventional Fuel Input (CONFUI)}

Introduction: Conventional fossil fuel engine. Description in Section 2.1.3. Requirements: The user, does not have to provide data files.

Default Assumptions:

Variable Numbers Default Values

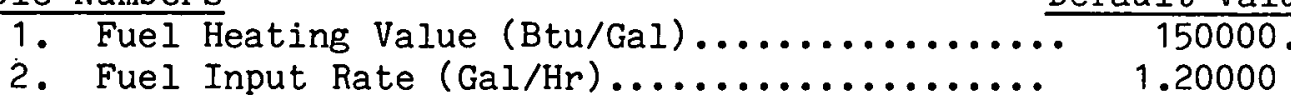

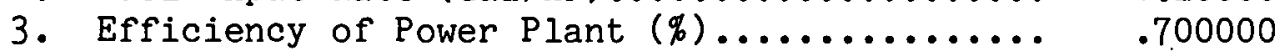

Additional Assumptions: None.

Operation: From Interactive Input Branchpoint, Section 3.2.1, enter "R" (cr). Error Messages: Self-explanatory.

\section{*Sample Output*}

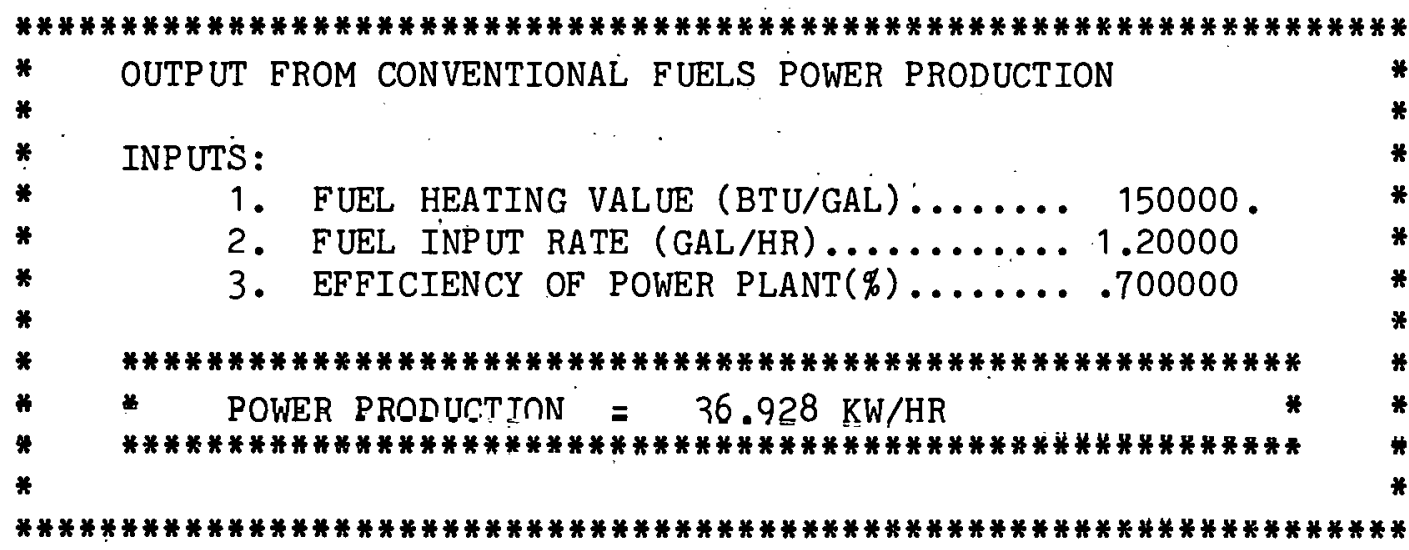

\subsubsection{Rated Power (CONTOO)}

Introduction: Analytical tool to describe technology with constant production. Further description section 2.1.4.

Requirements: Nó additional data files required.

Default Assumptions:

1. Rated Level of Constant Production (kW)..... 100.0000

Additional Assumptions: None.

Operation: From Interactive Input Branchpoint, section 3.2.1, enter "R" (cr). Error Messages: Self-explanatory. 
*Sample Output*

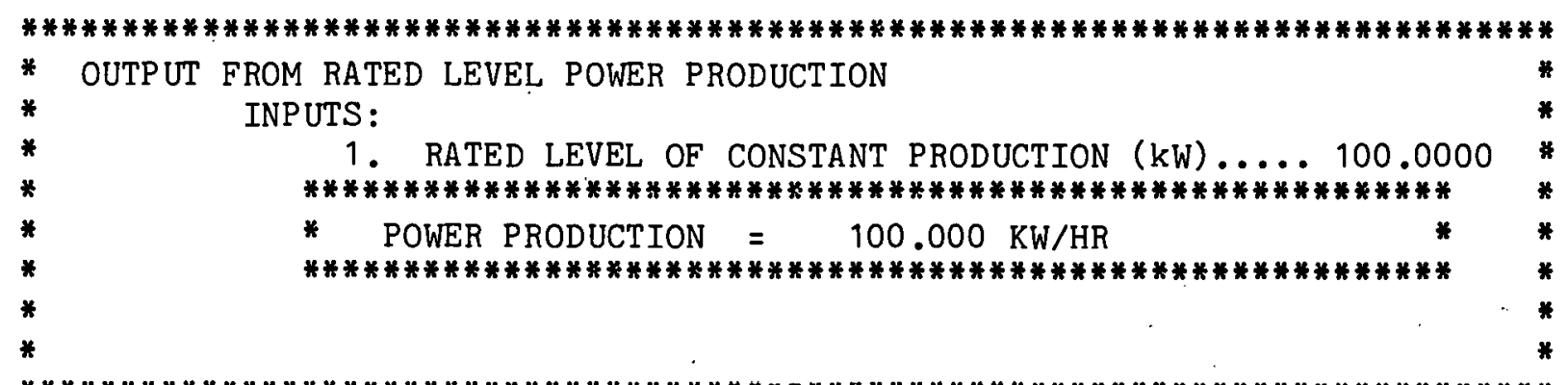

\subsubsection{Direct Combustion of Biomass (COMBUS)}

Introduction: Direct combustion of biomass fuels. A wood plantation, or a constant source of fuels is assumed. See section 2.1.5 for further description.

Requirements: No additional data files are requested.

Default Assumptions:

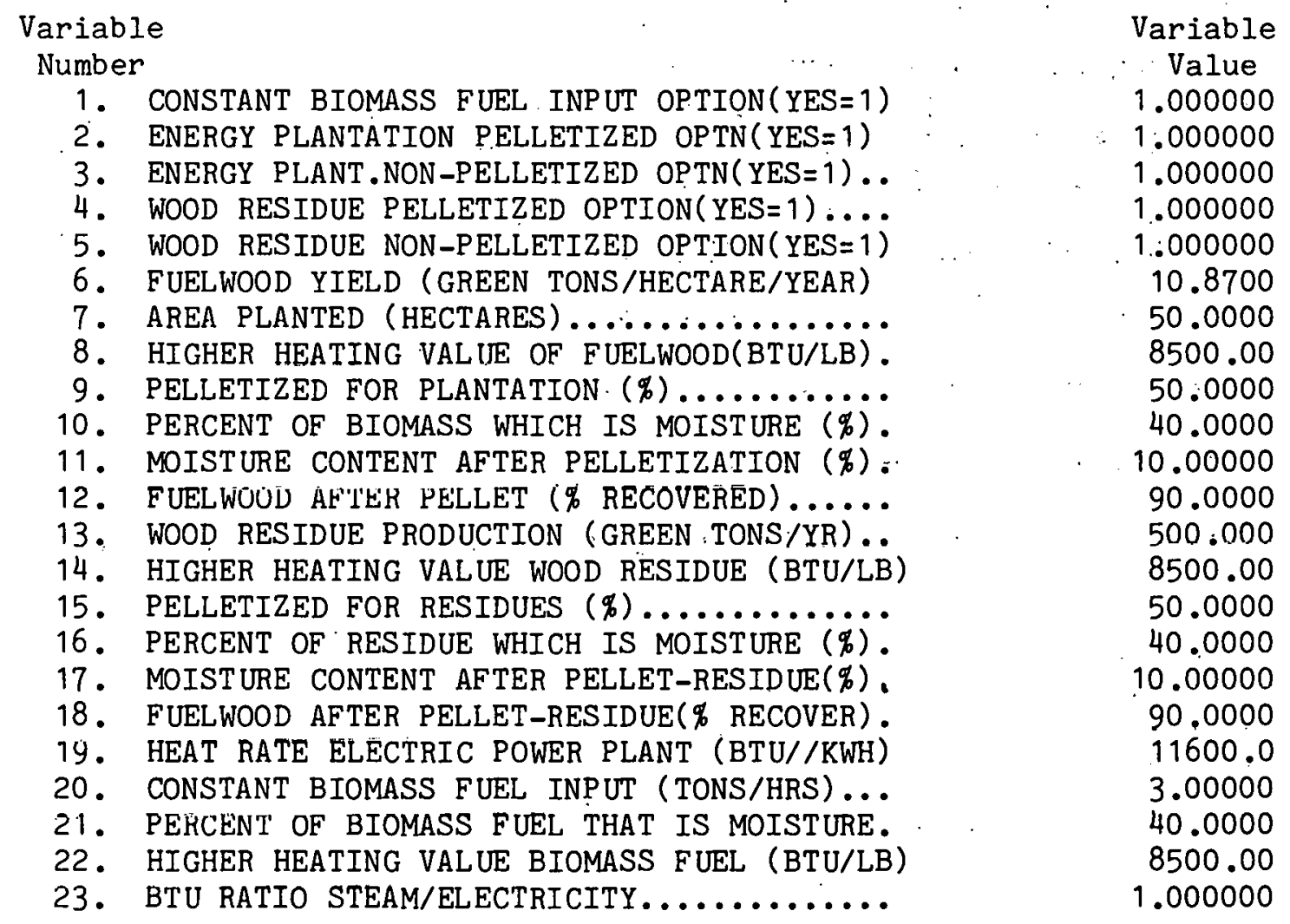

Additional Assumptions: None.

Operation: From Interactive Input Branchpoint, Section 3.2 .1 enter "R" (cr). Error Messages: 3elf explanatory. 
*Sample output*

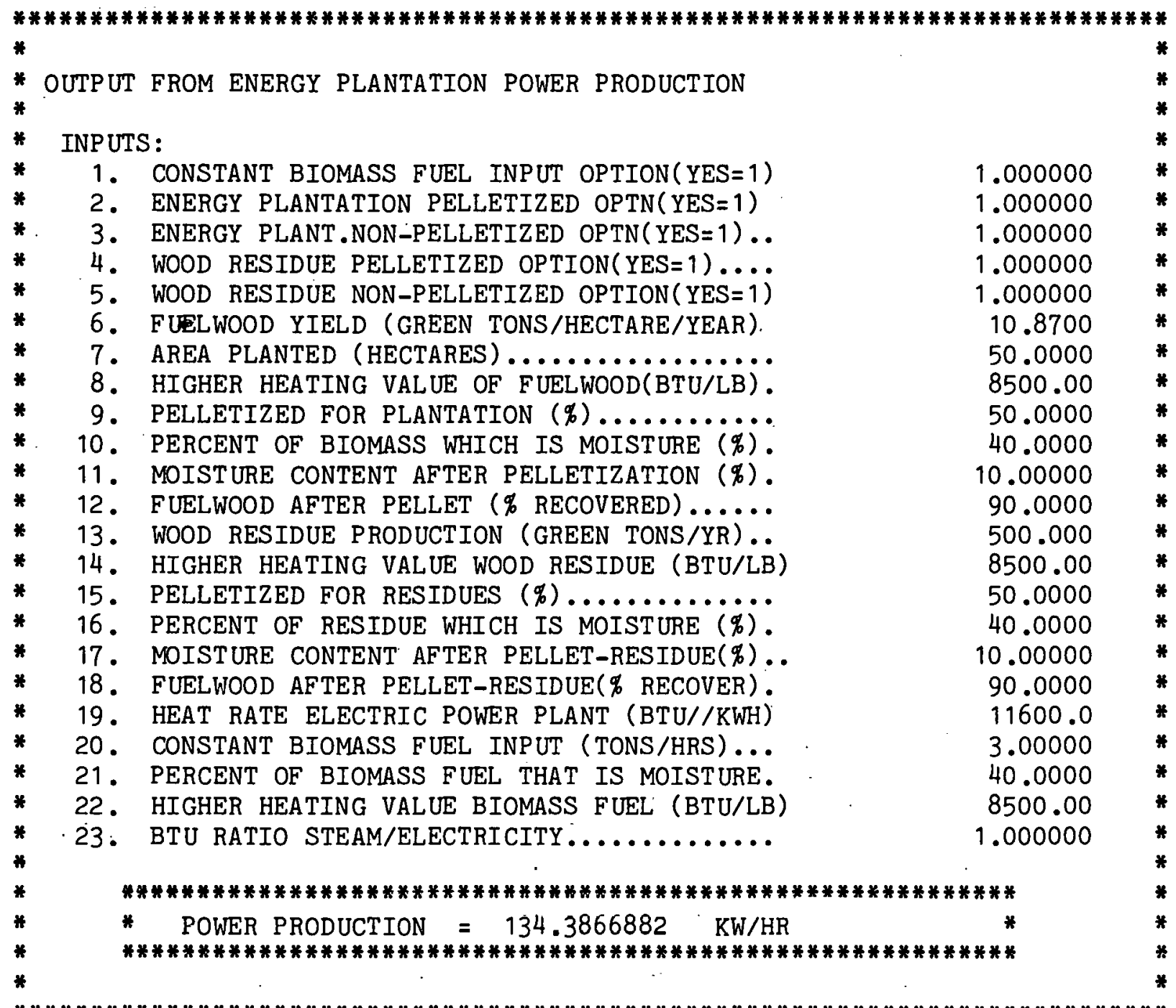

Additional Assumptions: The following options are available for direct combustion technologies:

1. Constant biomass fuel input--the following variables require appropriate values.

Variable

$\frac{\text { Number }}{8}$

10

18

19

Higher Heating Value of Fuelwood (Btu/lb)
$\%$ of Biomass which is Moisture
Heat Rate Electric Power Plant (Btu/kWh)
Tons of Biomass Per Hour

2. Energy Plantation--Pelletized Biomass. The following variables require appropriate values: 


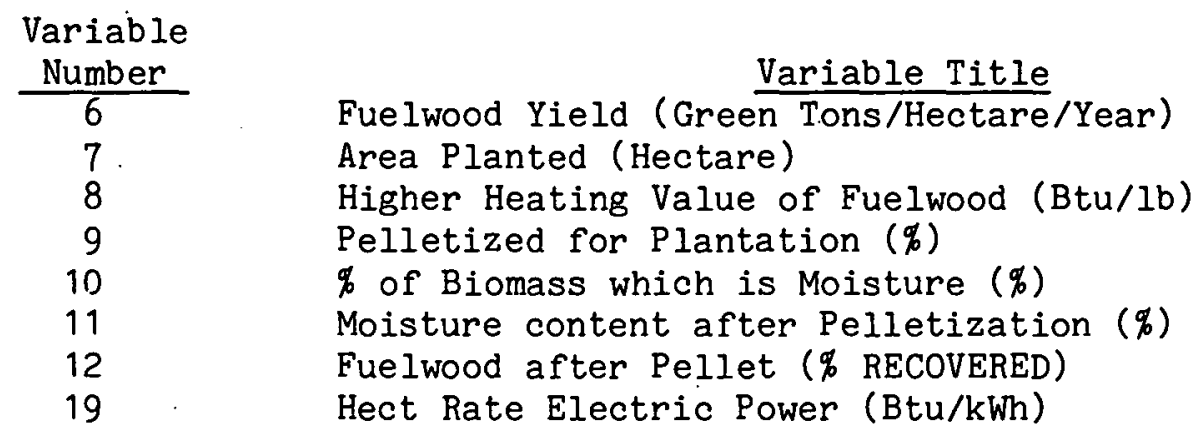

3. Energy Plantation--Non-pelletized Biomass.

The following variables require appropriate values:

Variable

Number $\quad$ Variable Title

6 Fuelwood Yield (Green Tons/Hectare/Year)

7 Area Planted (Hectare)

8 Higher Heating Value of Fuelwood (Btu/lb)

10 \% of Biomass which is Moisture

19 Heat Rate Electric Power (Btu/kWh)

4. Biomass Residues--Pelletized.

The following variables require appropriate values:

Variable

Number

13

Variable Title

14 Higher Heating Value Biomass Residue (Btu/lb)

15 Pelletized for Residues ( $\%$ )

16 \% Residues which is Moisture

17 Moisture Content after Pellet.--Residue (q)

18 Biomass after Pellet.--Residue (\% Recover)

19 Heat Rate Electric Power Plant (Btu/kWh)

5. Biomass Residues--Non-pelletized.

The following variables require appropriate values:

Variable

\begin{tabular}{cl} 
Number & Biomass Residue Production (Green Tons/Yr) \\
\hline 13 & Higher Heating Value Residues (Btu/lb) \\
14 & \% Residues which is Moisture \\
16 & Heat Rate Electric Power Plant (Btu/kWh)
\end{tabular}

NOTE: The user can use any combination (including all five) of the options available, by choosing a value of "1" in variables 1--5. 


\subsubsection{Methane Production and Generation (BIOGAS)}

Introduction: Methane production through anaerobic digestion of biomass materials. See section 2.1.6 for further explanation.

Requirements: No additional data files required.

Default Assumptions: See Additional Assumptions to clarify input of variable numbers 44-51.

Variable Numbers

Default Values

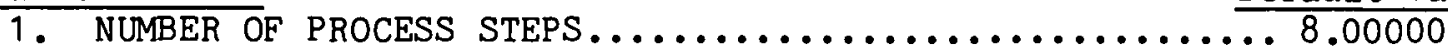

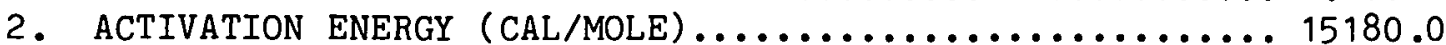

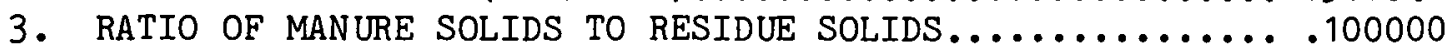

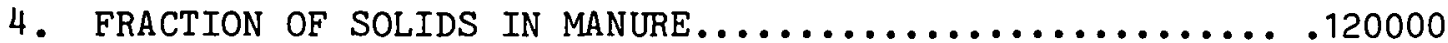

5. FRACTION OF VOL. SOLIDS IN MANURE................. .800000

6. FRACTION OF BIODEG. VOL. SOL. IN MANURE............. .600000

7. HEAT CAP. DIGESTER (SLURRY)(BTU/LB.DEG-F) ............ . . . .

8. HEAT TRANS. COEF. HEAT XCHNG(BTU/HR-FT2-) ............ 80.0000

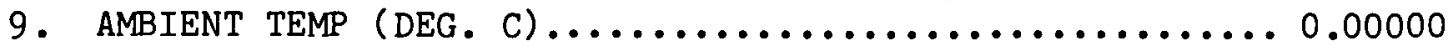

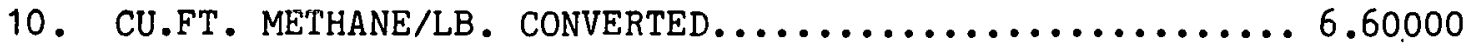

11. FRAC. SOLIDS IN DEWATERED SOL. STREAM.............. 300000

12. MAXIMUM CAPACITY SHREDDER (TONS/HR) .............. 25.0000

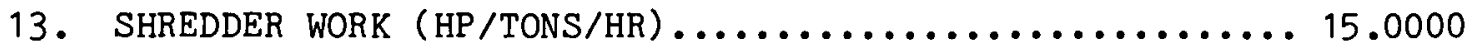

14. STORAGE MAX. CAPACITY(CU.FT.) .................. 300000.

15. HEAT XCHNG MAX. CAPACITY(CU.FT.)................ 0000.00

16. HOLDING/MIXING MAX. CAPACITY(CU.FT.)............. 300000 .

17. PRETREATMENT MAX. CAPACITY(CU.FT.)............... 5469.00

18. DEWATERING MAX. CAPACITY (TON/HR) ................ 0.00000

19. DEWATERING WORK (HP/TON /HR) .................. 0.00000

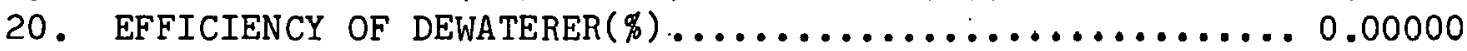

21. GAS PURIFICATION WORK (HP/MM SCFD) ............... 300.000

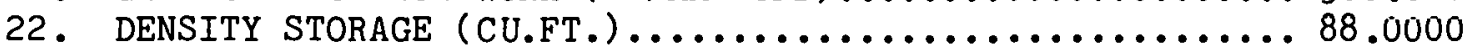

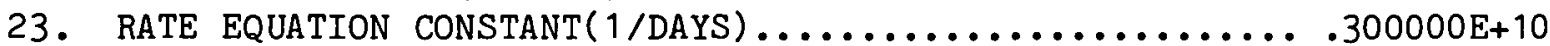

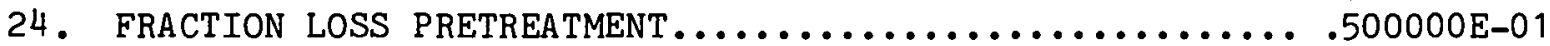

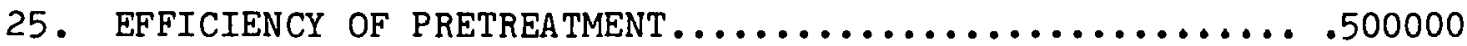

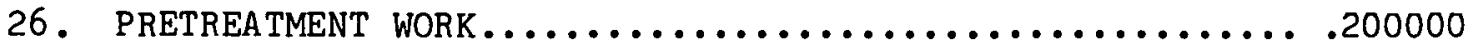

27. RETENTION TIME PRETREATMENT................... 4.00000

28. RETENTION TIME STORAGE(DAYS) .................. 360.000

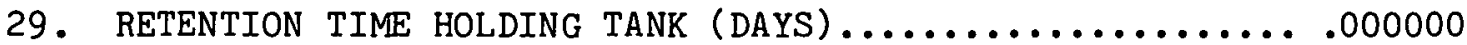

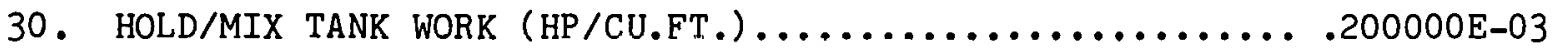

31. DENSITY HOLD/MIX TANK(LB./CU.FT.)................. 64.0000

32. DENSITY PRETREATMENT (LB./CU.FT.)................ 64.0000

33. AMOUNT OF CHEM. REQ. PER SOLID FEED(\%) ............ .500000

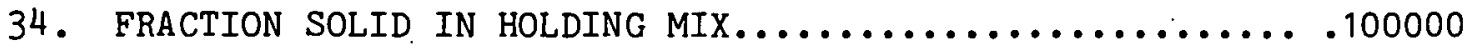

35. FRACTION SOLIDS PRETREATMENT ................... 100000

36. FRACTION SOLIDS IN DIGES. FEED.................. 100000

37. RETENTION TIME DIGESTER (DAYS) ................. 0.00000

38. DIGESTER WORK MAX CAPACITY (CU.FT.)................ 00000.0

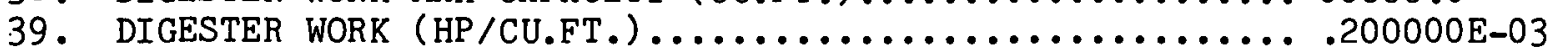

40. DIGESTER DENSITY (LB./CU.FT.).................. 64.0000

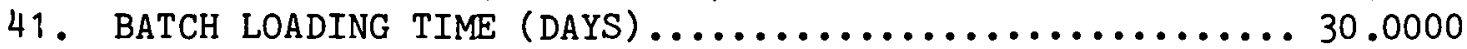

42. DIGESTER TEMP. $($ DEG-C) ........................ 60.0000 


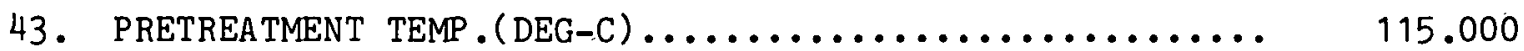

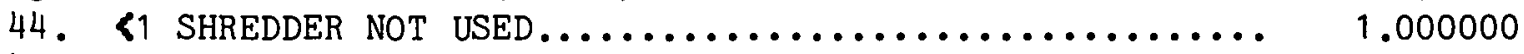

45. SO NO HOLDING; =OHOLDING, NO MIX; >0 HOLD/M........... 1.000000

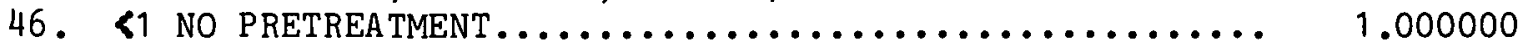

47. \1 NO STORAGE..................................... 1.000000

48 . \&1 NO HEAT EXCHANGER............................. 1.000000

49. \0 CSTR; =0 PLUG FLOW; >0 BATCH.................... -1.000000

50. \$1 NO DEWATERER................................... 0.0000

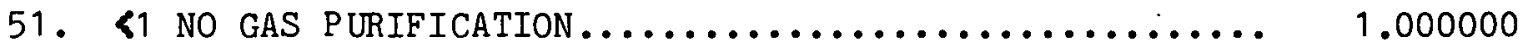

52. FEEDSTOCK RATE (TONS SOL./DAY) .................... 200.000

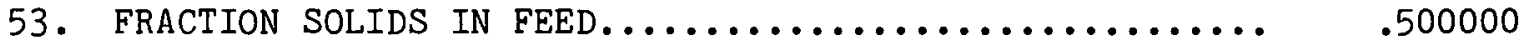

54. FRACTION VOL. SOLIDS IN FEED....................... .950000

55. FRACTION BIODEGR, VOL. SOLIDS IN FEED................ .360000

Additional Assumptions:

\begin{tabular}{|c|c|c|c|c|c|c|}
\hline Variable & & Variable & & NORM & CVE B & CASE \\
\hline Number & Description & Name & Option & SM. & MED. & LARGE \\
\hline 44 & SHREDDER & INSHR & $\begin{array}{ll}\text { EQ. OR LT. } & \text { ZERO } \\
\text { NOT } & \text { USED }\end{array}$ & $\mathrm{Y}$ & $\mathrm{Y}$ & $\mathrm{Y}$ \\
\hline 45 & $\begin{array}{l}\text { HOLDING/ } \\
\text { MIXING }\end{array}$ & INHLD & $\begin{array}{l}\text { LT.ZERO; NOT USED } \\
\text { EQ.ZERO; HOLDING, } \\
\text { NO MIXING }\end{array}$ & $\begin{array}{l}\mathrm{Y} \\
\mathrm{Y}\end{array}$ & $\begin{array}{l}\mathrm{Y} \\
\mathrm{Y}\end{array}$ & $\begin{array}{l}\mathrm{Y} \\
\mathrm{Y}\end{array}$ \\
\hline 46 & PRETREATMENT & INPRT & $\begin{array}{l}\text { EQ. OR LT. ZERO; } \\
\text { NO USED }\end{array}$ & $\mathrm{N}$ & $\mathrm{N}$ & $\mathrm{N}$ \\
\hline 47 & STORAGE & INSTR & Same as Above & $Y$ & $\mathrm{Y}$ & $\mathrm{Y}$ \\
\hline 48 & $\begin{array}{l}\text { HEAT } \\
\text { EXCHANGER }\end{array}$ & INHEX & Same as Above & $\mathrm{Y}$ & $\mathrm{Y}$ & $\mathrm{Y}$ \\
\hline 49 & $\begin{array}{l}\text { DIGESTER } \\
\text { TYPE }\end{array}$ & INDIG & 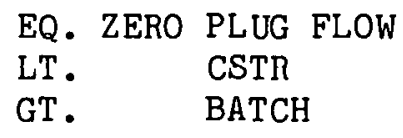 & c & C & c \\
\hline 50 & DEWATERING & INDWT & $\begin{array}{l}\text { EQ. OR LT. ZERO; } \\
\text { NOT USED }\end{array}$ & $\mathrm{N}$ & $\mathrm{N}$ & $\mathrm{N}$ \\
\hline 51 & $\begin{array}{l}\text { GAS } \\
\text { PURIFICATION }\end{array}$ & INPGU & $\begin{array}{l}\text { EQ. OR LT. ZERO; } \\
\text { NOT USED }\end{array}$ & $\mathrm{N}$ & $\mathrm{N}$ & $\mathrm{N}$ \\
\hline
\end{tabular}

Error Messages: Self-Explanatory.

Sample Output and Operation:

Upon entering "R" ( $c r)$ in the interactive input section, the user views:

Finter system header-one line-

An appropriate descriptive statement should be entered $(c r)$. An example of a header is: 
"Test of biogas system simulation"

The output is in the form of:

****************************************************************************

* TEST OF BIOGAS SYSTEM SIMULATION

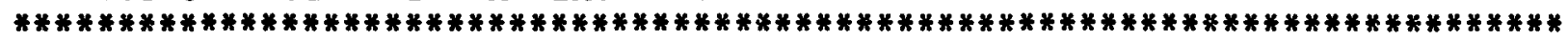

SYSTEM PERFORMANCE

FEED COMPOSITION

TOTAL SOLIDS

SOLIDS FRACTION IN FEED

VOLATILE SOLIDS FRACTION IN SOLIDS

BIODEGR. VOL. SOL. FRACT. IN SOL.

200.000 TONS/D

.500000

.950000

.360000

STORAGE

NUMBER OF UNITS

CAPACITY PER UNIT

$$
\begin{gathered}
6.0000 \\
2727270^{\circ} \text { CU.FT. }
\end{gathered}
$$

SHREDDING

NUMBER OF UNITS

CAPACITY PER UNIT

POWER REQUIREMENT

$$
\begin{gathered}
1.00000 \\
.1667 \mathrm{E}+02 \mathrm{TONS} / \mathrm{HR} \\
.2500 \mathrm{E}+03 \mathrm{HP}
\end{gathered}
$$

HOLDING-MIXING

NUMBER OF UNITS

CAPACITY PER UNIT

1.00000

POWER REQUIREMENT

$.6250 \mathrm{E}+05 \mathrm{CU} . \mathrm{FT}$. $.1250 \mathrm{E}+02 \mathrm{HP}$

PRETREA TMENT

RATIO OF CHEMICAL TO FEED

CONVERSION EFFICIENCY

NUMBER OF UNITS

CAPACITY PER UNIT

CHEMICAL REQUIREMENT

POWER REQUIREMENT

$$
\begin{gathered}
.50000 \mathrm{E}-01 \\
.500000 \\
2.0000 \\
.5469 \mathrm{E}+04 \mathrm{CU} . \mathrm{FT} . \\
.1000 \mathrm{E}+02 \mathrm{TONS} / \mathrm{HR} \\
.2187 \mathrm{E}+04 \mathrm{HP}
\end{gathered}
$$

DIGESTION

CSTR

NUMBER OF UNITS

CAPACITY PER UNIT

DIGESTER TEMPERATURE

RETENTION TIME

CONVERSION EFFICIENCY

POWER REQUIREMENT

$$
\begin{gathered}
8.0000 \\
.9023 \mathrm{E}+05 \mathrm{CU} . \mathrm{FT} . \\
60.00 \mathrm{C} \\
10.00000 \mathrm{DAYS} \\
.767378 \\
.1444 \mathrm{E}+03 \mathrm{HP} \\
1.90639 \mathrm{VVD} \\
.1376 \mathrm{E}+04 \mathrm{MM} \mathrm{BTU} / \mathrm{D}
\end{gathered}
$$

GAS PRODUCTION

HEAT EXCHANGER

NUMBER OF UNITS

HEAT EXCHANGER AREA

3.00000

$.6893 \mathrm{E}+04 \mathrm{SQ} . \mathrm{FT}$. 
DEWATERING-NONE USED

GAS PURIFICATION

CAPACITY PER UNIT

TOTAL WORK REQUIREMENTS $3282.46 \quad$ HP

$\begin{array}{llll}\text { TOTAL ELECTRICITY PRODUCED } & =3361.12 & \mathrm{KW} / \mathrm{HR} \\ \text { TOTAL ENERGY USED } & =2448.72 & \mathrm{KW} / \mathrm{HR} \\ \text { NET ENERGY PRODUCED } & =912.406 & \mathrm{KW} / \mathrm{HR}\end{array}$

3.2.2.9 Municipal Waste Electric Generation (MUNI)

Introduction: Methane production via anaerobic digestion of municipal wastes. Further description can be found in section 2.1.7.

Requirements: No additional data files are required.

Default Assumptions:

1. WASTE USED (TONS PER DAY) .................... 1000.000

2. EFFICIENCY OF GENERATOR..................... .200000

Additional Assumptions: None.

Operation: From Interactive Branchpoint option, section .2, enter "R" (cr).

Error Messages: Self-explanatory •

Sample Output:

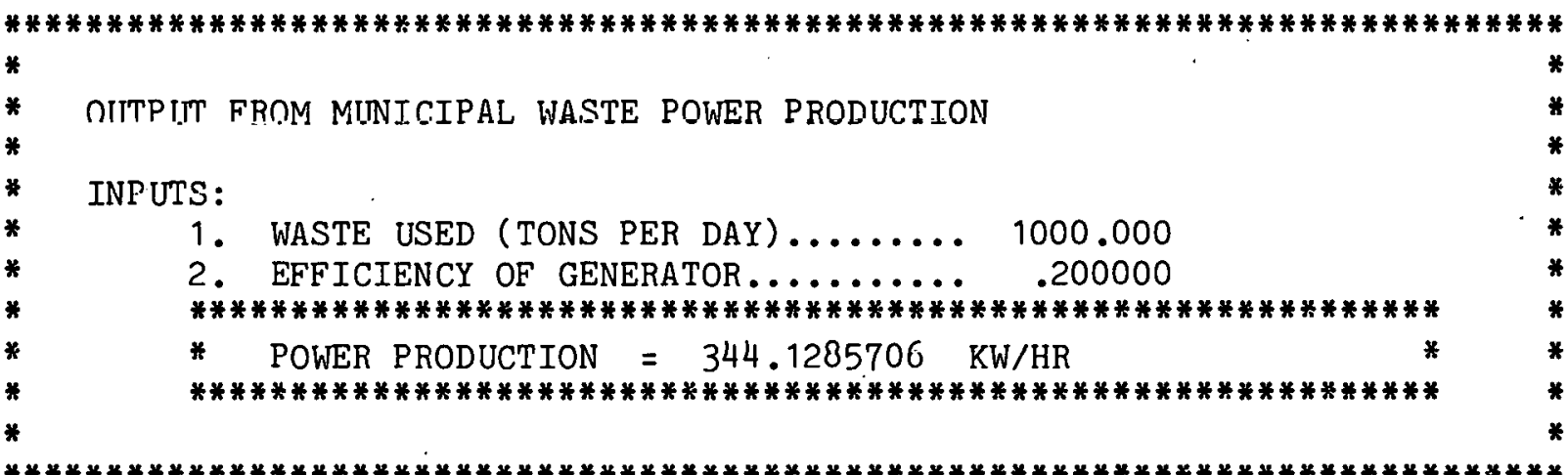

3.2.2.10 Producers' Gas Production and Generation (GASSIF)

Introduction: Producers' gas simulation model. Further description section 2.1.8.

Requirements: No additional data files required. 
Default Assumptions:

1. RESIDUAL LOADING RATE (TONS/DAY) ............. 4.10959

2. HOURS OF OPERATION PER DAY.................. 24.0000

3. HIGHER HEATING VALUE OF BIOMASS (BTU/LB) ......... 8500.00

4. MOIST URE CONTENT OF BIOMASS (\%) ............... . 400000

5. CONVENTIONAL FUEL NET HEAT VALUE(BTU/LB)......... $0 .{ }^{0000}$

6. CONVENTIONAL FUEL RATE (LITERS/HOURS) ............. .00000

7. DENSITY OF CONVENTIONAL FUEL (LBS/LITER) .......... 0.00000

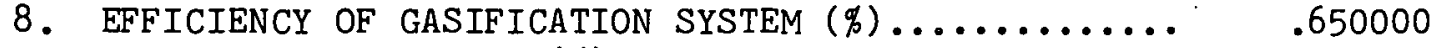

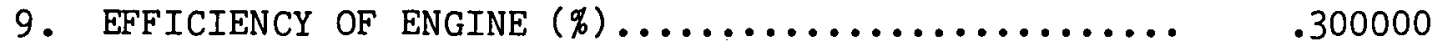

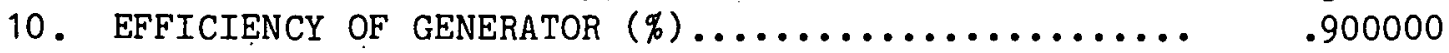

Additional Assumptions:

If a pure system is to be utilized variable number 6 is to be changed to zero. When a dual system is utilized, the conventional fuel rate is to be adjusted accordingly. See section 3.2.1.3 in order to complete these changes.

Operation: From Interactive option Branchpoint, Section 3.2.1 enter "R" (cr).

Error Messages: Self-explanatory.

Sample Output:

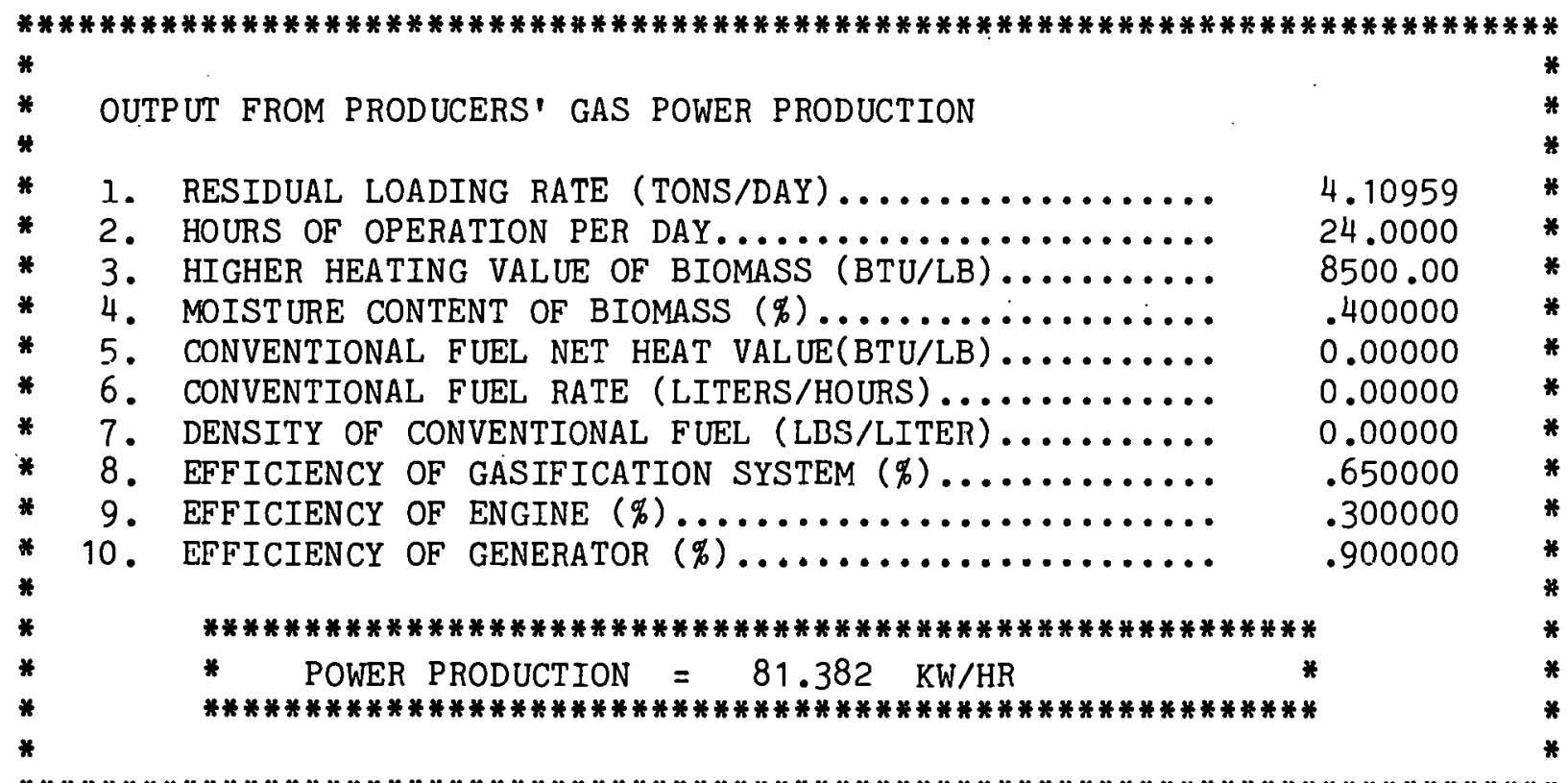

$* * * * * * * * * * * * * * * * * * * * * * * * * * * * * * * * * * * * * * * * * * * * * * * * * * * * * * * * * * * * * * * * * * * * * * * * * * * * *$

\subsubsection{Exit Simulate Main Program}

Upon completing the selected technology simulation, the user is returned to the Main Banchpoint. The user cannot perform a second technology simulation at this point without destroying the results of the existing simulation. 
Entering "E" " $\mathrm{cr}$ ) causes the user to exit the SIMULATE program. The prompt returns:

\section{Simulation section ended stop}

and the user is returned to the main system.

\subsubsection{Output Descriptions}

Printouts, available for inspection, of the completed simulations are stored in SYSSIMUL.PRN. SYSSIMUL.DAT. is the data file which also stores the results of the simulation, but is only available to transfer to the DANDL main program.

\subsection{DANDL: DERATE, INTEGRATE, AND LOAD}

\subsubsection{Introduction}

The DANDL, derate, integrate, and load main program is responsible for simulating availability of technology performance as well as integrating the QF's load with the derated technology performance.

\section{*Requirements for DANDL Operation:*}

\section{Mode System}

Whether the technology performance will be supplied by the user or default to the performance file of the simulation section

Determine which data files have headers as a first line

The DANDL main program has three primary functions:

1. It enables the user to enter the Qualifying Facility's (QF) power requirements (referred to as load) either interactively or via a data file (see section 3.3.4).

2. DANDL integrates the $\mathrm{QF}$ load with its power production by hourly periods.

3. The program enables the user to account for $Q F$ forced and scheduled outages.

The first option in the DANDL program is to integrate the QF production with the $\mathrm{QF}$ power demands (load) by hourly periods. When this integration occurs, the seil back to the utility is termed net energy. The simultaneous buy-sell option occurs when the QF sells its produced electricity to the utility without deducting its load. The Load Integration procedure begins in section 3.3.3. If the net energy option is chosen, then the user should be prepared to enter the $\mathrm{QF}$ load patterns and be familiar with the mode system which is discussed in section 3.3.2. Section 3.3.4.1 allows the user to interactively enter the $Q F$ load. This interactive option enables the 
input of the $Q F$ load as a constant hourly load or by varying load by time of day (TOD) periods only. Section 3.3.4.2 enables the user to enter other QF load patterns by establishing a data file.

The derate option, section 3.3 .5 allows the user to account for scheduled and forced outages of small power producers. Section 2.2 conceptually describes the derating process. In section 3.3.5, the user is able to derate QF production on a flat, monthly, and/or hourly basis. An example, the derating process could be applied to a diesel generator. If its rated capacity is $100 \mathrm{~kW}$ but average production is only $80 \mathrm{~kW}$, then the user would utilize the flat derate option (section 3.3.5.1), entering "80" or ".8." If, for example during the months of July and August, the generator is serviced and can only supply $10 \mathrm{~kW}$ of demand, then the user should enter "10" or ".1" for July and August and "100" or "१" for the remaining months (see section 3.3.5.2). The hourly derate option, section 3.3 .5 .3 allows the user to derate production for each hourly period (24 hours).

The DANDL program allows the user to enter technology performance from a simulation other than those contained in SERICPAC. To enter these technology simulations, see section 3.3.6. The general output format is found within section 3.3 .7 .

\subsubsection{The Mode System: Discussion}

* This section 3.3.2 is only important if user wishes to input a user load or the results of a simulation not contained in SIMULATE*

Both the operating characteristics and the inputs to each simulated technology differ. As a result, output patterns of production will vary. The mode system is a method of differentiating types of QF production. There are four modes. The mode system distinguishes those simulations which have constant production such as a diesel generator, from those technologies which vary by TOD and/or month. The mode system is a computational tool used by the program to insure consistancy and accuracy. It also alerts those users who wish to insert the results of their own technology simulations to the existing formats available to complete the package. Knowledge of the mode system is necessary in order to respond to sections 3.3 .4 and 3.3.6 portions of the DANDL integrate programs. A description of each mode is listed below.

Mode 1 - Constant hourly production of power producers such as diesel engines, and direct combustion typify mode 1 production. "1" is to be entered for mode 1 options.

Mode 2 - Technology performance aggregated in mode 2 varies by time of day (TOD), but there is no monthly variation. Power production is aggregated as an average output $(\mathrm{kW})$ per hour, per month.

Mode 3 - Hour-by-hour aggregation in mode 3 is similar to mode 2, except that there is variation in monthly output. 
Mode 10 - Reflects hour-by-hour production with no aggregation by month. The technologies which receive input data on an hourly basis, such as WECS, and Hydro-electric typically utilize inputs in mode 10 .

\subsubsection{DANDL Operation}

After typing "DANDL" (cr). The prompt returns:

Derating and load integration section

This section derates performance on a flat basis, an hourly basis, and/or a monthly hasis. It also integrates loads with this performance to determine net energy bought, sold, and produced. Do you wish to have a user load integrated? ("Yes" should be used for net sellback determination) $(\mathrm{N} / \mathrm{Y}):$

The user must determine whether the $Q F^{\prime}$ 's load is to be integrated with his/her production. For the simultaneous buy/sell option, the appropriate response is "N." For the net power option, the user should select "Y."

If the response is:

Yes - see section 3.3 .4

No - see section 3.3 .5

Error Message:

If a stray response is entered the following is returned:

Please enter $\mathrm{N}$ or $\mathrm{Y}$ for $\mathrm{NO}$ or YES $\underline{(N / Y):}$

\section{3 .4 Integrate}

A posit1ve response to section 3.3 .3 returns the prompt with:

Do you wish to enter the load from the terminal?

("NO" will result in disk read prompts)

$(\mathrm{N} / \mathrm{Y}):$

Yes - See section 3.3.4.1

No - See section 3.3.4.2

\subsubsection{Interactive User Load}

"Y" provides the user. with the opportunity to interactively enter the QF's load (in decimal fraction, or as whole number with decimal points) for either mode 1 or mode 2 technology performance. Note: The QF production is transferred through an internal file. 
Mode 1 - constant one number production (in $\mathrm{kW}$ )

Mode 2 - varies by TOD but not by month

Loads with mode 3 or 4 specification should be stored on file. The prompt returns:

$$
\text { Mode for load data ( } 1 \text { or } 2 \text { only)? }
$$

Enter appropriate mode number then $(\mathrm{cr})$.

$$
\begin{aligned}
& \text { "1" - constant hourly production } \\
& \text { "2" - varies by (TOD), but not by month }
\end{aligned}
$$

"1". - Prompt returns.

Enter User Load for hour 1 (kWh):

The response should be one whole number with a decimal point, in $\mathrm{kWh}$ per hour. Section 3.3, derating procedure are the following sequence of questions:

"2" - Prompt returns.

Enter user load for hour 1:
Enter user load for hour 2:
Enter user load for hour 3:
Enter user load for hour 24:

All responses appropriately placed with decimal points follow : with (cr). From either a mode 1 or mode 2 response the program proceeds to the derate option, section 3.3 .5 .

3.3.4.2 Disk Read Prompts

Enter load data file informationdisk of data file (A/B):

The user should enter either "A" or "B."

$$
\text { File name ( } 11 \text { Chars, No period): }
$$

The user should type an appropriate filename. An example filename would be "file1111.dat."

Is the first record of the file a label header? (Yes should be the default condition) (N,Y):

A header is assumed to be the first line of the data file. If no, the program will read the first entry as data. 
Do you wish use the default data format?

(G13.6)

$(\mathrm{N}, \mathrm{Y}):$

If the user responds no, then all user entered formats require proper $G$ or $F$ FORTRAN field descriptors and parenthesis. If the user enters "Y," then the program continues to section 3.3 .5 .

\subsubsection{Derate}

This section accounts for forced and schedule outages. The conceptual description is within Section 2.2 .

3.3.5.1 Flat Basis

Derate on a flat basis?

$(\mathrm{N}, \mathrm{Y})$ :

"N" (cr) - a negative response will return the prompt with the next question.

"Y" (cr) - an affirmative response asks:

Derate factor $(0.0 \mathrm{~F} 1.0)$ :

The response can be, for exmaple 75.0 or .75 . Remember, the derate section is estimating the available production. Example, production will be $75 \%$ of rated capacity.

The prompt will return:

3.3.5.2 Hourly Basis

Derate on an hourly basis?

$(\mathrm{N}, \mathrm{Y})$ :

"N" (cr) prompt will return with the next section

"Y" (or) asks the following:

Enter factor for each hour $(0.0$ F 1.0)

Hour 1:

Hour 2:

Hour 3:

Hour 4:

Hour 5:

Hour 6:

Hour 7:

Hour 8:

Hour $24:$ 
There is (cr) after each colon. The number entered is the percentage of the hour during which production is available. The number can be entered as whole number with a decimal point or as a decimal fraction. This choice of entry style does not have to be consistant.

$$
\text { example: } 75.0 \text { or } .75
$$

The prompt returns the next question.

\subsubsection{Monthly Basis}

$$
\begin{aligned}
& \text { Derate on a monthly basis? } \\
& \text { (N,Y): }
\end{aligned}
$$

"N" (cr) A negative response begins the computational section. Interactive options continue in section 3.3 .6 .

"Y" ( $\mathrm{cr}$ ) The following inputs are required:

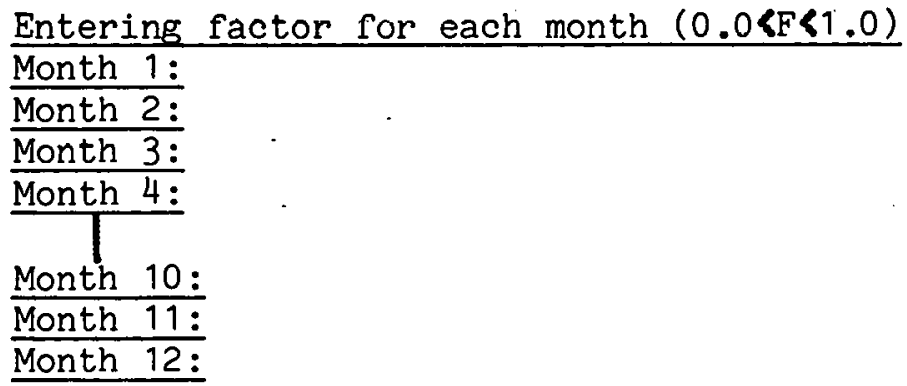

After each : the percentage of available production, per month is entered as a whole number with a decimal point or as a decimal fraction.

$$
\text { Example: } 75 \text {. or } .75
$$

\subsubsection{Entering Technology Simulation}

Are you using the default performance file from the simulation section? $(\mathrm{N}, \mathrm{Y}):$

"Y" (cr) - executes the derate, integrate, and load analysis. An example of the output with the default factors appear in section 3.3.7.

"N" (cr) - Requires the following information:

*File name (11 characters, no periods) of the technology performance.

*Mode number for input files.

If the user enters "N" (cr), the prompt returns: 
Is the performance data in kilowatt hours?

$\underline{(N, Y):}$

"Y" (cr) - user will skip the next question

"N" (cr) - the prompt returns;

Enter conversion factor:

The conversion factor is available to translate energy units, i.e., B.T.U., S.C.F., etc. of the alternate technology performance file to kilowatt hours $(\mathrm{kWh})$. The decimal point is very important to include in any of the conversion factors. The prompt returns:

\section{Enter performance data file information- disk of data file (A/B):}

The user should enter either "A" or "B." The prompt returns:

Filename ( 11 chars, no period):

The alternative performance input file name should be entered. The user should be prepared to answer the following question:

Is the first record of the file a label header?

("Yes" should be the default condition)

$(\mathrm{N}, \mathrm{Y}):$

"Y" (cr) - HEADER: XXXXX The header of the file is returned. The prompt returns.

"N" (cr) - skips to the next question.

Do you wish to use the default data format:

$(\mathrm{G} 13.6)$

$(\mathrm{N}, \mathrm{Y}):$

"Y" (cr) - skips the next question

"N" (cr) - prompt returns

Enter new format (including parens):

The user should enter the appropriate FORTRAN field descriptors, including parentheses. The prompt returns:

Does the file have a mode as its first record?

(N,Y):

As discussed in section 3.3.2, the mode system represents the hourly aggregation of inputs and/or output.

"Y" (cr) - the program begins execution

"N" (cr) - prompt returns. 
The user should be prepared to respond to:

Enter mode the data file is in $(1-3$ or 10$)$ :

The user should enter either "1," or "2," or "3," or "10." If there are uncertainties, then the user should reread section 3.3 .2 and/or check the specified technology performance input file for proper mode number.

When all of the above entries are successfully completed, the program begins execution. The following should appear at the terminal:

\section{Running....}

If there are errors the appropriate message will appear at this point. Error messages are self explanatory.

Otherwise the prompt returns:

$$
\begin{aligned}
& \text { Output to terminal? ("No" will send it to file) } \\
& (\mathrm{N}, \mathrm{Y}): \\
& \text { "N" (cr) - Printout in file "DERALOAD.PRN" } \\
& \text { Derating and load integration section concluded. } \\
& \text { "Y" (cr) - Printout proceeds. }
\end{aligned}
$$

\section{3 .7 Output}

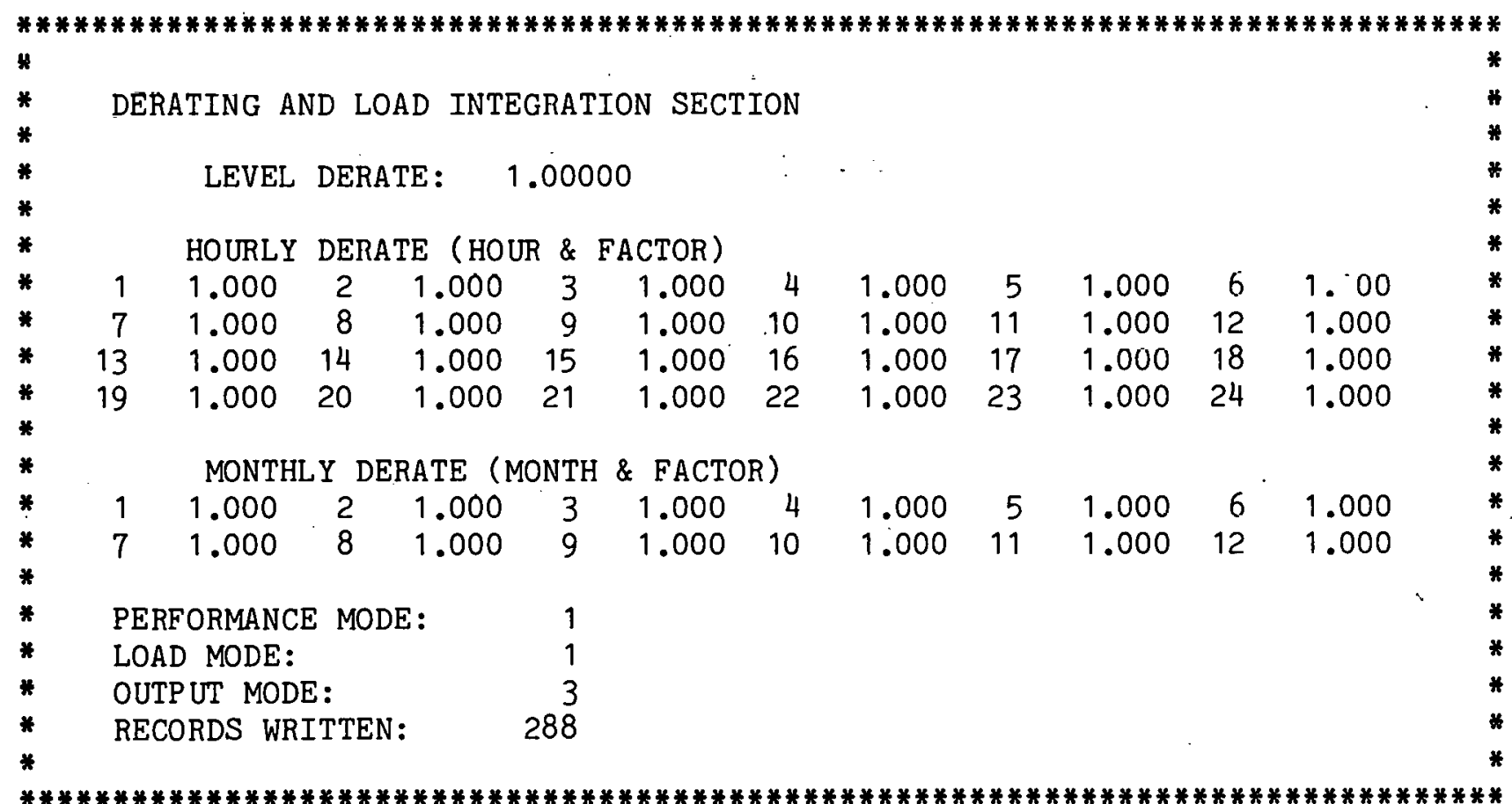

Derating and load integration section concluded

\section{Stop}




\subsection{PMAIN: PERFORMANCE ANALYSIS}

\subsubsection{Introduction}

The performance analysis is designed to aggregate the output from the DANDL main program, into utility time periods, i.e., peak, intermediate, off-peak.

In order to successfully execute this program the following information is necessary:

$$
\begin{aligned}
& \text { Requirements: Utility time periods (Read SERICOST, Section } 3.2 .5 \\
& \begin{aligned}
\text { and } 3.2 .16 \text { ) } \\
\text { - hours during which time period occurs } \\
\text { - number of holidays per month } \\
\text { - months during which time period occurs } \\
\text { Input file from DANDL }
\end{aligned}
\end{aligned}
$$

\subsubsection{Main Branchpoint}

The performance analysis requires the output from DANDL as well as utility time periods. This section is designed to provide interactive ability for the user to enter the utility specific time periods.

There are five input sections to this main program. DANDL output is contained in DERALOAD.DAT. The user need not be concerned with transferring this file to PMAIN. The five input sections include:

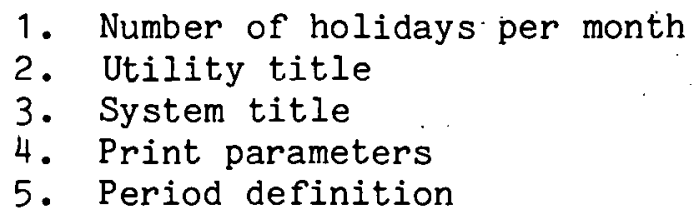

Tn order to begin the perfurmance analysis, the user should enter "PMAIN" $(c r)$. The prompt returns:

Main Branchpoint गPD:L:C:R:?:E:V:I:O:

If a stray response is entered the following appears:

Enter one of the following: "D" "L" "C" "R" "?" "E" "V" "I" "O" PP:L:R:?:E:V:I:0:

If the user is unfamiliar with the branchpoint, he/she should type a question mark "?" ( $\mathrm{cr}$ ). A directory assistance message is presented:

This is the performance analys is section-Data may be defaulted, read from file, or specified by the user. 
Available commands are:

$D$ (efault) - Set data to default values,

L(ist) - List existing value or values,

C(hange) - Change existing value,

R(un) - Get raw data \& execute performance analysis,

E(nd) - Terminate this section without performing a new performance analysis or getting more raw data,

$\mathrm{V}$ (ars) - List \#'s of variables for list or change purposes,

I(nput) - Read a previously written data setup from file,

o(utput) - Write the current data setup to file.

3.4.2.1 Interactive Options of the PMAIN Branchpoint

3.4.2.2 Variable List

In order to view the input section titles the user should enter "V" (cr).

Variables:

$\frac{1-\# \text { holidays/month }}{2-\text { utility title }}$
$\frac{3-\text { system title }}{3-\text { print parameters }}$
$\frac{4-\text { period definition }}{5}$

3.4.2.3 List

"L" (cr) enables the user to list the variables in all five input sections of PMAIN. Upon entering "L" the user should see:

Section \# to list (0 for all):

If the user is uncertain of sections or input variables available, zero is the recommended response. "0" (cr) returns: (The user does not have to enter actual dates.)

SECTION \# 1

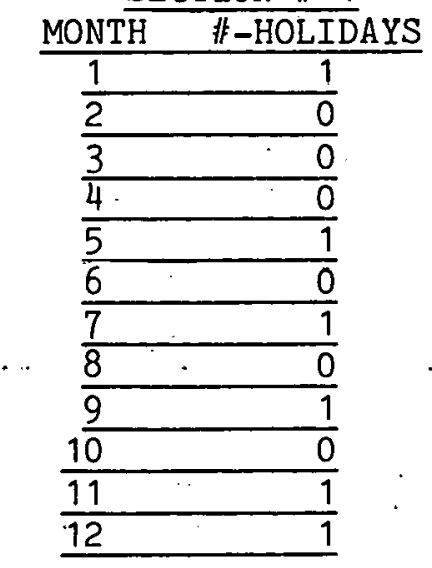


SECTION \# 2

UTILITY DESCRIPTION:

ENTER UTILITY HERE

SECTION 非 3

SYSTEM DESCRIPTION:

ENTER TECHNOLOGY HERE.

SECTION 非

PERFORMANCE ANALYSIS PRINT - YES

PRINTOUT TO TERMINAL (IF NO THEN TO FILE) - NO

SECTION 非 5

PERIOD DEFINITION SECTION

\# OF PERIODS $=2$

\section{PERIOD DEFINITION}

PERIOD 1 PEAK

PERIOD 2 OFFPEAK

PERIOD 2 OFFPEAK

PERIOD 2 OFFPEAK

\begin{tabular}{rr}
$\frac{\text { MONTHS }}{1-12}$ & HOURS \\
\hline $1-12$ & $1-22$ \\
$1-12$ & $23-24$ \\
$1-12$ & $1-24$
\end{tabular}

\begin{tabular}{c} 
WEEKDAYS \\
\hline YES \\
YES \\
YES \\
NO
\end{tabular}

\begin{tabular}{ccc} 
WEEKENDS & & HOLIDAYS \\
\cline { 1 - 1 } & & NO \\
NO & & NO \\
NO & & NO \\
YES & & YES
\end{tabular}

Entering one of the five section numbers will list the specified portion of the input list.

NOTES: Only one number can be entered. The message: STOP will occur when a number greater than 5 is entered. The user will exit from the program and return to the main system, not the PMAIN Branchpoint.

\subsubsection{Change}

The option enables the user to change the default values in all input sections (Sections 1-5).

Requirements: User should be familiar with both the input section numbers and the input variables.

Upon entering the letter "C" (cr), the user views:

\section{Section \# to change:}

The appropriate section number should be entered. No decimal points. For a list of the section numbers, the user should refer to section 3.4.2.2.

NOTE: A number greater than 5 or multiple entries will cause the user to exit the program and return to the main system, not the PMAIN Branchpoint.

If the user is unfamiliar with the section titles and corresponding variables, "O" (cr) or (cr) will display al.J input sestion and variablcz. 
*Section 1 Holidays/Month*

If the user wishes to change Section 1, a "1" (cr) should be entered.

The prompt returns:

\section{For month \#, Enter \# of holidays Month 1:}

After : the user should enter the appropriate number of holidays in January. The number entered is the number of days in the month considered holidays by the utility. After each (cr) the next month will appear at the terminal until month 12, December. The main branchpoint (Section 3.4.2) is returned after the (cr) of month 12 .

\section{*Section 2 Utility Title*}

Entering 2 (cr) to section 非 to change: The prompt returns:

$$
\text { Utility title ( } 80 \text { chars max): }
$$

The user should enter the title of the appropriate facility or utility being evaluated. It is used as heading and does not influence the computations. (cr) returns user to the PMAIN Branchpoint, section 3.4.2.

\section{*Section 3 System Description*}

Upon entering "3" (cr), the following prompt returns:

$$
\text { System title ( } 80 \text { chars max, } 5 \text { lines required): }
$$

Five lines (any or all of which may be blank) must be entered. These lines describe the qualifying facility.

\section{*Section 4 Print Option*}

If "4" were entered in section \# to change, the prompt returns:

Would you like the performance analysis printed to either the terminal or file? $(\mathrm{N}, \mathrm{Y}):$

"N" (cr) - no records of the performance analysis are stored in printout files. Output is however stored in the data file PERFTOTS. DAT. The user is returned to the PMAIN Branchpoint, Section 3.4.2.

"Y" (cr) - the following question is returned:

Print output to terminal? (Answer no for print to file): $(\mathrm{N}, \mathrm{Y}):$ 


$$
\begin{gathered}
\text { "N" (cr) - printouts available in default file PERFANAL.PRN. } \\
\text { "Y" (cr) - the output from the performance analysis is } \\
\text { available at the terminal. }
\end{gathered}
$$

Yes or No the prompt returns to the PMAIN Branchpoint, section 3.4.2.

\section{* Section 5 Period Definition*}

The DANDL program passes the aggregated hourly QF performance to PMAIN. The period definition section is the heart of PMAIN. Within this section, the user is required to identify time of day (TOD) periods which are consistant with those of the electric utility. These utility periods must also agree with the information required in SERICOST Input Format sections 4 through 9 , and Sections 3.2 .5 and 3.2 .16 of SERICOST.

In order to perform period definition, the following must be known: the number of periods, their titles, the months included in each period, the hours included in each period, and whether weekdays, weekends, and holidays are included in each period. An example is given below, followed by further comments. This example defines the following:

$$
\begin{gathered}
\text { Peak period: Weekdays } 8 \text { AM }-10 \text { PM, all months } \\
\text { offpeak periods: Weekdays } 10 \text { PM }-8 \text { AM, weekends and } \\
\text { holidays all day, all months. }
\end{gathered}
$$

Main Branchpoint

\$?:V:L:C:D:O:I:E:R:

Section \# to change: 5

"C" indicates the desire to change a section from the main branchpoint in PMAIN: "5" indicates that section 5, the period definition section, is to be changed.

\section{Period Definition \\ \# Periods: 2}

Periods are blocks of time such as peak, offpeak, and shoulder. These periods are utility-defined. "2" above indicates that two utility periods are being used.

Title for Period \# 1: PEAK

Title for Period \# 2: OFFPEAK

Thus period $\# 1$ corresponds to the utility peak period and is labelled accordingly, and period 非 is the offpeak period.- "Peak" and "offpeak" are merely user labels, and have no effect on the running of the program.

\section{More Entires?}

$(\mathrm{N}, \mathrm{Y}): \mathrm{Y}$

The "more entries?" prompt will be made after each block of time has been defined. This prompt should be answered "Y" until all periods have been 
defined, and then answered "N" to terminate the period definition section.

\section{Period \# : 1}

This prompts the user to indicate which period the following data pertain to. Here, the data are for period 1.

\section{First Month: 1}

Last Month: 12

The second number must be greater than or equal to the first. Month numbers must be in the range 1-12, corresponding to January-December.

Error Message:

If entries are not sequential or outside the bounds of 1 through 12 the following error message appears:

*Month Read Help*
You must enter two months between 1 and 12 , with the
second later in the year than the first, would you like
to end "E," change the month definition "C," or read this
period from the start (not the whole section, just the
period you 're doing "R"?

\section{$\gg E: C: R:$}

The user can respond according to necessary changes. If the user has experienced no difficulty, the program continues.

All months between the two numbers are included; that is the months fall in a contiguous block. Here, period 1 includes at least part of every month in the year. If period 1 were on $1 y$ Jañuary-Apr1l dnd 3tulember-December, then there would have to be two definitions for period 1 made, one with months 1-4 and one with months 9-12.

This brings up an important point: several definitions may be (and often are) made for the same period. All definitions made for a period are included. Entries for period definitions must contain only one contiguous block of time (e.g., May-September, 9 AM - 2 PM), but many periods, especially those that run across midnight or New Year's Day, consist of two or more contiguous blocks (e.g., sept. - April, 11 PM - 7 AM would be four blocks: Sept. - Dec., II PM - 12 PM; Sept. - Dec., 12 PM - 7 AM; Jan. April, 11 PM - 12 PM; Jan. - April, 12 PM - 7 AM). Therefore, several passes through the "more entries?" loop should be made when needed, one for each contiguous block. Since all dates/times between months/hours specified are included, care must be taken to include only those dates/ times falling in the period being specified.

$$
\begin{array}{lr}
\text { First Hour: } & 9 \\
\hline \text { Last Hour: } & 22
\end{array}
$$

All hours between the two numbers are included. Hours must fall in the range 1-24, corresponding to $1 \mathrm{AN}$ to $12 \mathrm{P} \%$. The second number must not be 
less than the first.

Error Message:

If sequence or range of entries is incorrect, the following error message is provided:

*Hour Read Help*
You must enter two hours between 1 and 24 , with the second
later in the day than the first, would you like to end "E,"
change the hour definition "C," or redo this period from the
start (not the whole section, just the period you re doing
"R"?

$\gg \mathrm{PE:C:R:}$

The user can respond accordingly to necessary changes.

The hour number refers to the hour period ending at the time specified: hence "1" means 12 PM - 1 AM, and "13" means 12 noon to 1 PM. Otherwise, hours are very much like months, in that they must be defined in contiguous blocks and several definitions should be made if the period does not cover contiguous times.

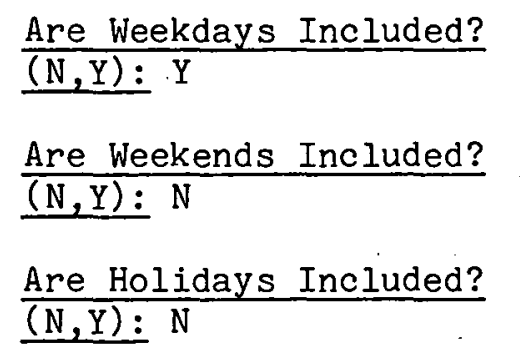

Part of the utility period definition is whether the period includes weekdays, weekends, and holidays. Holidays are as specified in input section 1 (See beginning Section 3.4.2.4).

An important point here is that different period definitions for the same period should not overlap. Thus, if a period is weekdays $1-5$ and weekends 1-24, the definition for hours $1-5$ should say "N" for weekends included, even though the period does include weekends. This is because the second period definition will say hours 1-24, "Y" for weekends included, which covers all hours of all weekends. The first definition is needed only for weekday times. This can perhaps best be seen by visualizing the two contiguous blocks that make up this period. If both blocks include weekends, weekend hours 1-5 are defined twice. It is important that the user check to make certain that all times and dates are defined once--and only once.

We have now completed the definition of period 1, the peak period. This was a simple definition, consisting as it did of only one block. Now we define period 2, offpeak, which consists of three blocks: weekdays 1 AM - 8 AM, weekdays 11 PM - 12 PM, and weekends and holidays all day. 
More Entries?

$(\mathrm{N}, \mathrm{Y}): \mathrm{Y}$

Period 非 2

First Month: 1

Last Month: 12

First Hour: 1

Last Hour: 8

Are Weekdays Included?

$(\mathrm{N}, \mathrm{Y}): \mathrm{Y}$

Are Weekends Included?

$(\mathrm{N}, \mathrm{Y}): \mathrm{N}$

Are Holidays Included?

$(\mathrm{N}, \mathrm{Y}): \mathrm{N}$

This sequence includes hours 1-8, weekdays, for all months of the year in. period 2. The first of the three blocks of period 2 has been defined.

More Entries?

$(\mathrm{N}, \mathrm{Y}): \mathrm{Y}$

Period \#: 2

First Month: 1

Last Month: 12

First Hour: 23

Last Hour: 24

Are Weekdays Included?

$(\mathrm{N}, \mathrm{Y}): \mathrm{Y}$

Are Weekends Included?

$(\mathrm{N}, \mathrm{Y}): \mathrm{N}$

Are Holidays Included?

$(\mathrm{N}, \mathrm{Y}): \mathrm{N}$

This sequence includes hours 23-24, weekdays, for all months of the year in period 2. The second of the three blocks of period 2 has been defined.

More Entries?

$(\mathrm{N}, \mathrm{Y}): \mathrm{Y}$ 
Period \#: 2

First Month: 1

Last Month: 12

First Hour: 1

Last Hour: 24

Are Weekdays Included?

$(\mathrm{N}, \mathrm{Y}): \mathrm{N}$

Are Weekends Included?

$(\mathrm{N}, \mathrm{Y}): \mathrm{Y}$

Are Holidays Included?

$(\mathrm{N}, \mathrm{Y}): \mathrm{Y}$

This sequence includes all weekend and holiday times in period 2 . Period 2 has now been defined as weekdays 1-8 and 23-24 all year, and weekends and holidays all day, for all months of the year:

Periods 1 and 2 have now been defined to include all times of the year, and include them only once. The period definition section is now complete.

\section{More Entries?}

$(\mathrm{N}, \mathrm{Y}): \mathrm{N}$

No more entries are to be made, and "N" returns the user to the main branchpoint (section 3.4.2).

Main Branchpoint

\$?:V:L:C:D:O:I:E:R:

Note that incremental alterations to the definitions cannot be made: that is to say that the previous definitions are erased when changes are made, so an entire set of definitions must be made every time the period definitions are changed. Also, since all definitions are remembered, do not attempt to correct an incorrect definition by reentering it without returning to the main branchpoint and starting over, as this will result in doubly-defined times.

\subsubsection{Default}

"D" (cr) sets the default input values for the performance analysis. They can be viewed by selecting $\mathrm{L}$ (ist) or or $\mathrm{C}$ (hange) (cr). When the user enters "D," they are returned to the PMAIN Branchpoint, Section 3.4.2. 


\section{4 .2 .6 Output}

This option is relevant for those users who have changed a default file and wish to save it for future use.

"0" (cr) returns the prompt with:

Enter information on output file Disk of data file A/B):

The disk for which this file is designated should be entered, either "A" or "B" (cr).

\section{Enter header line:}

The following questions appear at the terminal:

Filename ( 11 chars, no period: blank to escape):

The user should enter a filename of eleven characters, with no periods. If the user does not want to save an input, (cr) is entered and the user is. returned to the PMAIN Branchpoint.

3.4.2.7 Input

"I" ( $\mathrm{cr}$ ), allows the user to input a file created in 3.4.2.6. The prompt returns:

Enter information on input file Disk of data file (A/B):

The proper disk letter should be entered, either "A" or "B" (cr).

Filename ( 11 chars, no period: blank to escape):

An eleven letter file name with no period should be entered $(\mathrm{cr})$. In the event the user does not wish to execute the input command (cr) should be entered, returning the user to the PMAIN Branchpoint.

3.4 .2 .8 End

The selection of "E" ( $\mathrm{cr}$ ) causes the PMAIN program to be terminated without performing a new performance analysis or getting more raw data.

The prompt returns:

\section{Performance analysis section aborted \\ Stop}

3.4 .2 .9 Run

In order to execute the performance analysis, "R" ( $c r$ ) is to be entered.

If an error occurs, then a statement appears. It indicates the probable cause of the error. 
Running.... appears if there are no errors

Aggregate hours/month raw data input completed End performance data section

If no printout was requested in the print option (section 4 of 3.4 .2 .3 ), the following appears:

End performance analysis section. Printout is in file "PERFANAL.PRN" Stop

If a terminal printout was specified the output will be in this form (see Section 3.4.3):

3.4 .3 Output

The following page shows a sample output from the PMAIN program. 


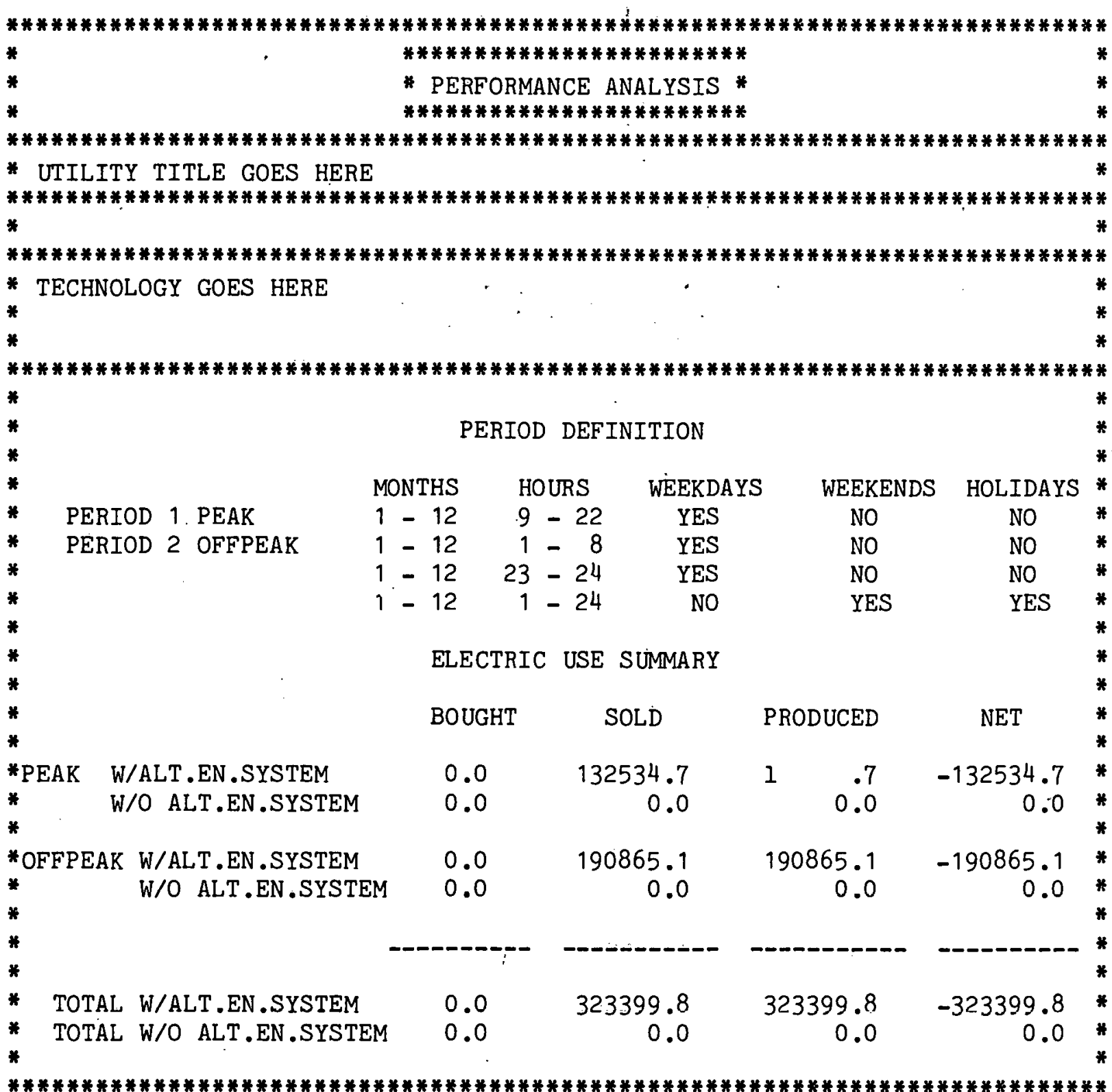

\section{PRINTOUT IS IN FILE "B:PERFANAL.PRN"***}

END PERFORMANCE ANALYSIS SECTION

Note: W/O ALT.EN.SYSTEM refers to electric requirements of firm without installation of $Q F$. If no user's load is entered then zero's will appear in all column's and the net W/ALT.EN.SYSTEM will be negative reflecting incremental production. 


\title{
3.5 AVOIDC: AVOIDED COST CALCULATION
}

\subsubsection{Introduction}

This is the final main program of the SERICPAC Methodology. The output of this program is an avoided cost $(\$ / \mathrm{kWh})$. It represents the marginal cost of electricity which the utility would have had to incur had a $Q F$ not contributed to the grid. The QF's contribution, in SERICPAC, has been adjusted for seasonal, daily and hourly (when applicable) variations in production, availability, and the QF's power demand (net power vs. simultaneous buy/sell). The avoided cost calculated in this section includes these factors.

\subsubsection{Requirements}

To initiate execution of this section the user should have:

* Marginal cost data from SERICOST (or equivalent) per utility time period according to identical time period definitions

* Performance analysis completed. File available in PERFTOTS.DAT.

\section{5 .3 Operation}

To begin execution type AVOIDC (cr) prompt returns:

\author{
*Avoided cost section* \\ Enter marginal cost data per kilowatt-hour for \\ each period \\ Marginal cost, period ( $\$ / \mathrm{kWh})$ :
}

Period indicates the first period specified in the PMAIN. The user should enter the appropriate value calculated in SERICOST. Because the units are $\$ / \mathrm{kWh}$, a decimal point is required ( $\mathrm{cr}$ ).

The previous message returns for as many time periods specified in PMAIN (Performance Analysis) input section 5.

For each period the proper marginal cost is entered with a decimal point. Then the user enters (cr).

When marginal costs for all periods have been entered, the prompt returns.

Do you want calculations based on gross. production? ("No" means not sellbaok will be used)

$(\mathrm{N}, \mathrm{Y}):$

"N" (cr) - The QF's power demand (load) will be subtracted from the total power production to determine net sellback.

"Y" (cr) - Gross power production will be included in avoided cost calculations. This calculation assumes simultaneous purchase and sale. See section 3.3 .3 for further clarification. 


\section{5 .4 Output}

The output from AVOIDC will be in the following form:

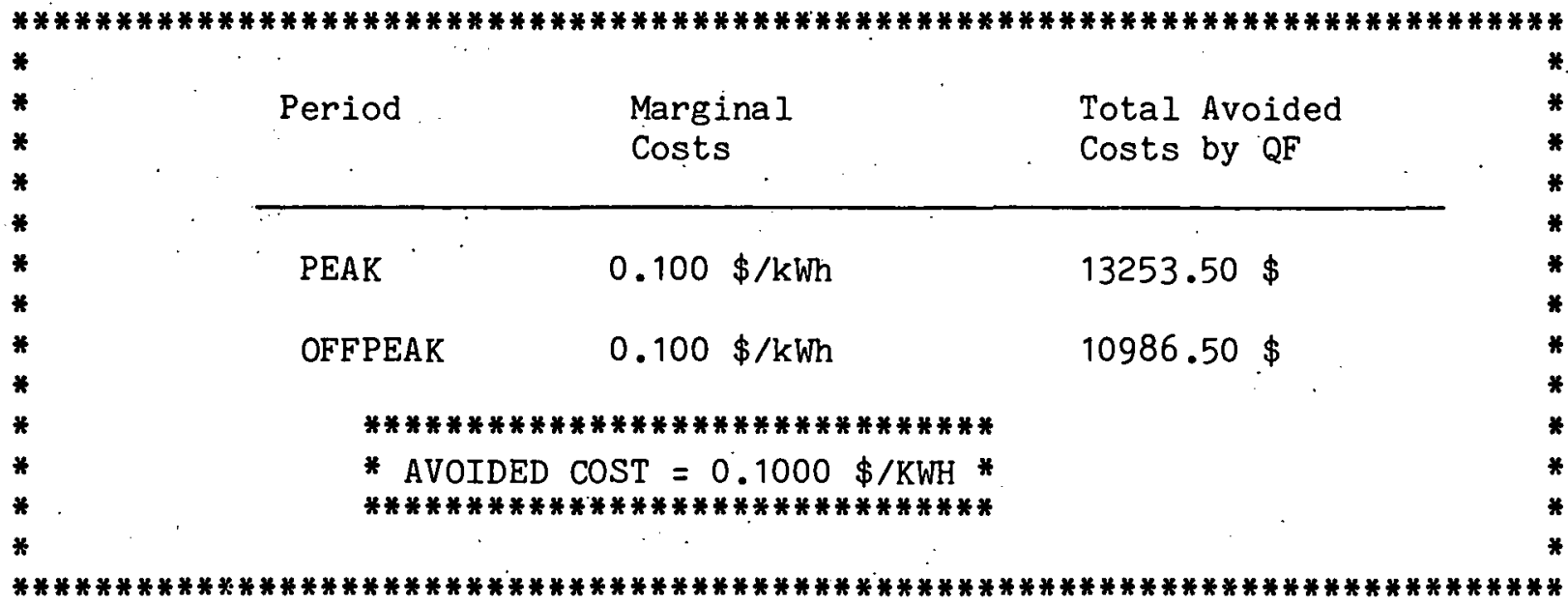

The prompt returns:

Do you wish this output to file as well? $(\mathrm{N}, \mathrm{Y}):$

"N" (cr) - user is returned to the operating system, not any Branchpoint "Y" (cr) - prompt* returns

\section{Nutput. in file "AVOIDC, PRN,"}

\section{Stop}

User is returned to the operating system, not any Branchpoint. 
SECTION 4.0

BIBLIOGRAPHY

Angrist, S. W. Direct Energy Conversion Third Edition. Boston, MA: Allyn and Bacon. Incorporated, 1976.

Ashare, E., Buivivd, M. G., \& Wilson, E. H. Feasibility Study for Anaerobic Digestion of Agricultural Crop Residues. Final Report. Subcontract No. XR-9-8157-1. Solar Energy Research Institute. Cambridge, MA: Dynatech R/D Company, 1979.

Ashare, E., \& Wilson, E. H. Analysis of Digester Design Concepts Engineerino. Report. Contract EY-76-C-02-2991.000, U. S. DOE. Cambridge, MA: Dynatech R/D Company, 1979.

Arthur, D. Little, Inc. Distributed Energy Systems: A Review of Related Technologies. Contract No. EX-76-C-01-3871, U. S. DOE. Cambridge, MA, 1979 .

Berlin, E., Cicchetti, C. J., \& Gillen, W. J. Perspective on Power. Cambridge, MA: Ballinger, 1974.

Bright, R., \& Davitian, H. A Method for Computing Marginal Costs Associated with On-Site Energy Technologies. National Center for Analysis of Energy Systems, Department of Energy and Environment, Brookhaven National Laboratory. BNL 51264. August 1980.

Bright, R. et al. The Avoided Costs Associated with Cogeneration: A Case Study of Con Ed. Department of Energy and Environment. Brookhaven National Laboratory. BNL 51269. August 1980.

Brown, J. W. et al. Biological Conversion of Organic Refuse to Methane. Prepared for ERDA Contract EY-76-5-01-2917. NTIS C00-2917-3V-1. November 1976.

Cicchetti, C., Gillen, W., \& Smolensky, P. The Marginal Cost and Pricing of Electricity: An Applied Approach. National Technical Information Service, PB 225967 , for NSF/RA - 760183, 1976. (Also published by Cambridge, MA: Ballinger Books in 1977.)

Commonwealth of Massachusetts. Cogeneration: Its Benefits to New "England. Final Report to the Governor's Commission on Cogeneration, October 1978 .

Environmental Comment. Cogeneration. U. S. Department of Energy. October 1979, pp. 9-14.

Flaim, T., Considine, T., Witholder, R., \& Edesses, M. Economic Assessment of Intermittent, Grid Connected Solar Electric Technologies: A Review of Methods. SE'RI/I'R-353-474. Draft Report. Golden, Co. Solar Energy Research Institute, 1979. 
Federal Energy Regulatory Commission. Rule Makings on Cogeneration and Small Power Production. Docket No. RM 79-54 order 69, and Docket No. RM $79-54$ order 70,1980 .

Fegan, G. R., \& Percival, D. C. Integration of Intermittent Sources in Baleriaux-Booth Production Costs Models. SERI/TP-35-375. Golden, CO: Solar Enero" Research Institute (SERI), 1979.

Feldman, S. L., \& Wirtshafter, R. M On the Economics of Solar Energy: The Public Utility Interface. Lexington, MA: D. C. Heath and Company, 1980.

Feldman, S. L., Wirtshafter, R. M, Abrash, M., Anderson, B., Sullivan, P., \& Kohler, J. The Impact of Federal Tax Policy and Electro Utility Rate Schedules Upon the Solar Building/Electric Utility Interface. Contract EG-77-G-01-4029, U. S. DOE. Worcester, MA: Clark University, 1979.

Jones, J., \& Radding, S. B. (Editors). Solid Wastes and Residues: Conversion by Advanced Thermal Processes. A Symposium/Sponsored by the Division of Environmental Chemistry at the 175 th Meeting of the American Chemical Society, Anaheim, CA, March 13-17, 1978. Washington, D. C.: American Chemical Society.

Kahn, A. E. The Economics of Regulation Principles and Institution. Vol. 1: Economic Principles; Vol. 2: Institutional Issues. New York: Wiley, 1970 .

Kispert, R. G., Sadek, S. E., Anderson, L. C., \& Wise, D. L. Fuel Gas Production from Solid Waste. Final Report. NSF/RANN/SE/C- $\overline{827-P R / 74} / 5$. Cambridge, MA: Dynatech R/D Company, 1975.

Laitos, J., \& Feverstein, R. Regulated Utilities and Solar Energy: A Legal-Economic Analysis of the Major Issues Affecting the Solar Commercial Effort. Contract No. EG77-C-01-4942, U. S. DOE. Golden, CO: Solar Energy Research Institute (SERI), 1979.

Limaye, D. R., Isser, S., Hinkle, B., \& Friedman, N. R. Introduction to Cogeneration Case Studies. EM-1531, Project 1276-1. Palo Alto, California: EPRI, 1980.

Lovins, A. The Energy Controversy. San Francisco: Friends of the Earth, 1979 .

Morgan, M., \& Talukdar, S. Electric. Power Load Management: Some Technical Economic, Regulatory and Social Issues. Proceedings of the IEEE, Vol. 67 , No. 2 .

National Academy of Sciences. Methane Generation from Human, Animal, and Agricultural Wastes. Washington, D. C., 1977 . 
NOAA. SOLMET User Manual. Asheville, N. C.: National Oceanic and Atmospheric Administration (NOAA), 1978.

Park, G. et al. Planning Manual for Utility Application of WECS. Contract No. EG-77-S-0Z-4450. East Lansing, MI: Michigan State University, Division of Engineering Research, 1979.

Percival, D., \& Harper, J. Electric Utility Value Delimination for Wind Energy, Vol. I: A Methodology. Vol. II: A User's Guide. SERI/TR732604. Golden, CO: Solar Energy Research Institute, February 1981 .

Quindry, G. E. et al. Biological Conversion of Organic Refuse to Methane. Distributed by NTIS C00/2917-3 (vol. 2), 1976.

Scaramelli, A. B. Resource Recovery Research Development and Demonstration Plan. Contract No. AC01-78CS20178, U. S. DOE. Bedford, MA: Mitre Corporation, 1979.

Schwab, C. Energy from Vegetation: Legal Issues in Biomass Energy Conversion, Solar Law Reporter, Vol. 1, No. 4. Golden, CO: Solar Energy Research Institute (SERI), 1980.

Solar Energy Research Institute (SERI). Vol. I: Synopsis and Executive Summary, July 1979; Vol. II: Principles of Gasification, July 1979; Vol. III: Current Technology and Research, April 1980. A Survey of Biomass Gasification. Contract No. EG-77-C-01-4042, U. S. DOE. Golden, CO: SERI.

United States Army Corp of Engineers, New England Division. Hydroelectric Potential at Existing Dams New England Region. Methodology and User Guide, Vol. I, 1979 .

United States Congress. Legislative History PL 95-617, Title II, 1978. United States Congress. Public Law 95-617, November 9, 1978. 92 Stat 3134.

Williams, R. H. Industrial Cogeneration. Annual Review of Energy 1978 , 3:313-56. Palo Alto: Annual Reviews, Inc., 1978. 
THIS PAGE

\section{WAS INTENTIONALLY \\ LEFT BLANK}




\section{APPENDIX A: NOTES ON DISK FILE ACCESS}

SERICPAC was developed on a Vector Graphics VIP (VG-VIP), a 56k RAM microcomputer built around a $\mathrm{Z} 80$ processor. Disk storage is on $2300 \mathrm{k}$ floppy disk drives (designated "A" and "B" drives); therefore, the file OPEN routine in a FORTRAN program must specifiy which disk drive the file is on. On most machines supporting FORTRAN, the user has access to only one disk drive, and this specification is not made. As SERICPAC is currently constructed, FOPEN asks for the disk drive the file is on. On most machines, this question should be removed. The format of the VG-VIP FORTRAN OPEN routine is called by:

CALL OPEN (LUN, filename, drive)

where:

$$
\begin{aligned}
& \text { LUN - logical unit \#, either an integer variable or } \\
& \text { an integer constant } \\
& \text { filename - 11-character ASC11 literal constant or array } \\
& \text { variable, with no period and all } 11 \text { characters } \\
& \text { specified. The CP/M equivalent filename is } \\
& \text { filename. ext, such as TEST0001.DAT, which would } \\
& \text { be specified in CALL OPEN as 'TESTO001DAT'. } \\
& \text { drive - } 0 \text { - currently selected drive is used } \\
& 1 \text { - Drive A is used } \\
& 2 \text { - Drive B is used }
\end{aligned}
$$

The drive specifier should be removed on most machines. Filename format will likely be different. Also, there are frequently other parameters in the statement which vary from machine to machine. Those should be added on an installation-dependent basis.

There are several FORTRAN statements which perform disk-related operations which may be machine-specific. These include: ENDFILE (which closes a file), CALL OPEN, and random-access READ and WRITE statements. These are marked so that they might easily be found: They are immediately preceded by the line:

C (FILEMARK). Any filenames in write formats are also marked in this way.

For use on a different computer, it may be necessary (depending on system conventions) to replace ENDFILE with CLOSE or CALL CLOSE, CALL OPEN with OPEN (and almost certainly with different arguments), and to change filenames to match the system conventions.

Random access on the VG-VIP is done as follows: READ (LUN, FORMAT 非, REC=n) varlist, where $\mathrm{n}$ is the record to be read. Records are always 128 bytes long, automatically blank-filled if needed. Different systems have a variety of ways to point to the record and the different record lengths. There is no associated variable that is automatically incremented on the VG-VIP. 
FOPEN is the subroutine in which user-specified files are always opened. Thus changing this routine to match the system should accomplish much of the necessary alteration. CALL FOPEN is always preceded by C (FILEMARK). Program-specified file opens are done with CALL OPEN and are scattered through SERICPAC, but are primarily concentrated in the main programs (SIMUL, DANDL, PMAIN, AVOIDC). Each routine is marked at the top as to whether it has file-access statements:

$$
\begin{aligned}
& C \text { (NO FILEACCESS) and } \\
& \text { C (FILEACCESS) }
\end{aligned}
$$

are fairly self-explanatory.

\section{C (FILEACCESS)}

indicates the presence of one of the following:

ENDFILE, CALL OPEN, random-access, filename, or CALL FOPEN.

Some computers (IBM computers, for example) specify file management prior to execution of the program rather than under program control. In this case the OPENs and CLOSEs would have to be replaced with operating system specifications. Such changes would have to be made by someone with a thorough knowledge of both the operating system and FORTRAN; there is no easy prescription for this conversion.

A variable format is an I/O format specifier which may be changed under program control, so as to vary as the user desires. This might be used to input data that may be in any of a number of forms. SERICPAC uses variable formats. All variable formats are preceded by the line:

\section{C (VARIABLE FORMAT)}

Usually this line also contains a functional description of how the variable format is used.

Variable formats are stored in arrays, with successive array locations containing successive characters in the format. SERICPAC for the VG-VIP uses INTEGER* 2 arrays. This means that each array location contains 2 characters. A CDC machine stores 6 characters in each integer array location. This should not cause difficulties if the extra spaces are blank-filled; since no literal strings are used in variable formats, blanks should be ignored.

Note that VG-VIP FORTRAN defaults for variable types are LOGICAL*1, INTEGER*2, AND REAL*4. These are used in SERICPAC. Machines using INTEGER*4 or larger integers, or REAL*8 or larger reals, should also run SERICPAC with no difficulty.

Note that NTR and NTW are the terminal real and write LUN's, respectively. On the VG-VIP they are both 1. These are set in the BLOCKDATAs (SBLOCK, DBLOCK, PBLOCK, and ABLOCK). 
APPENDIX B: SOURCE CODE SERICPAC

ij

$\therefore \quad .1$ 


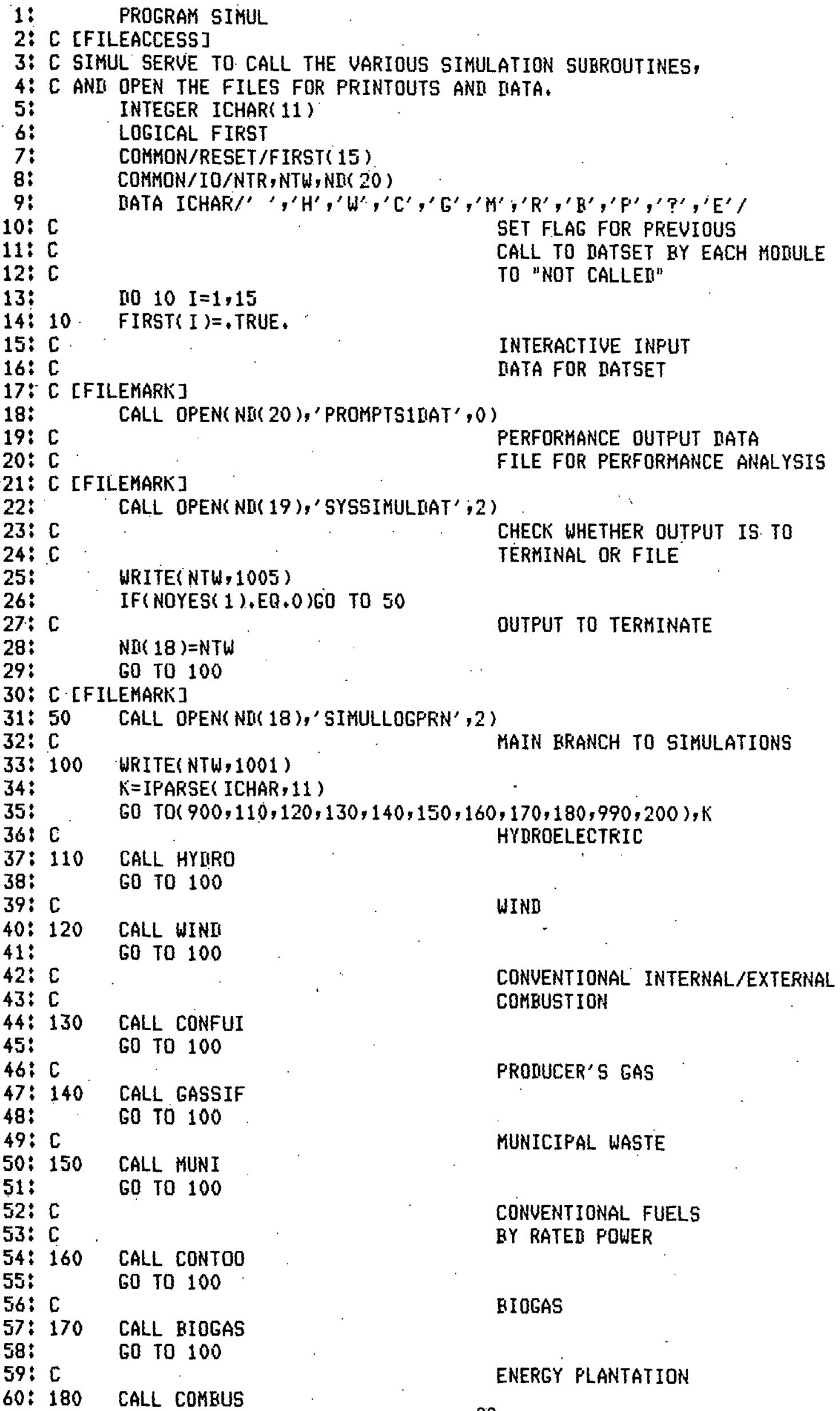


$62: C$ 60 TO 100

$63 \div 200$

$64: C$

$65:$

$66:$

$67: \mathrm{C}$

68: C

69:900

WRITE(NTW, 1003)

END

$70:$

$71: \mathrm{C}$

$72: 990$

IF(NII 18),NE. NTH) WRITE(NTH, 1006)

STOP

$73:$

74: 1001

WRITE(NTW, 1004)

GO TO 100

$75: 1002$

WRITE(NTW, 1002)

NOTIFY. IF PRINTOUT IH FILE

Not

NO RECOGNIZAFLE CHARACTER PRINTEI

SO NOTIFY HELP AVAILAELE

GO TO 100

FORMATS'OSIMULATION TO EXECUTE-')

$76:$

$77:$

$78:$

$79:$

80 :

81:

82:

$83:$

84:

85:

86:

$87:$

$88:$

$89:$

90 :

91:

$92:$

93:

94:

95:

76:

97: 1003

$98: 1004$

99: 1005

FORMATS'OTHIS IS THE SIMULATION SECTION-',

" ENERGY SYSTEHS MAY RE HOIELEI BY THE APFROPRIATE HORULE.'

* 'availlaelle morilles and commanis include:'/

* $5 X$,'H(YIIRO) -HYDROFOWER SIMULATIOH.' 1

* $5 X$, W(INII) -WINI FRODUCTION SIHULATION."

* $5 X, ' G(A S I F Y)$-PROIUUCERS GAS SIMULATION.'

* 5X,' ( (ONUEN) -LEVEL PERFORMANCE, FOR EXAMFLE FOR EITHER' $/$

* 16X,'DIRECT COMEUSTION OR IHTERNAL COHBUSTION, EASEI ON' 1

* 16X, 'FUEL RATE anII HEAT CONTENT.'I

* 5X, RiATEIi) -LEVEL FERFORHANCE FOR ANY'/

* 16\%, 'COHSTART OUTPUT FROCESS, EASEII ON RATEII LEVEL. $\prime$

* 16X.'THIS IS A USEFUL TOOL FOR AHALYSIS OF A TECHNOLOGY',

* $16 \%$ 'WITH A CONSTANT RATEI OUTPUT. $\%$

\$ $5 X^{\prime}$ 'B( IOGAS) -GIOGAS SIYULATION.'

* $5 X$, M(UNI) MUNICIFAL WASTE SIMULATION.'

* 5X.P(LAHTAT)-ENERGY PLANTATION SIMULATION.',

* $5 X, '$ E(NIT). TERYINATE SIMULATION SECTION.'

* /5X,'*NOTE* THAT THERE IS AH INTERACTIUE INPUT TO EACH'/

* 12X,'SECTION, WITH IIEFAULT VALUES ANII PROMFTING.'

* $12 \times$, 'IT IS THEREFORE NOT NECESSARY TO KNOW ALL UARIAELES'/

* 12X, OR TO HEMORIZE THEIR ORDER.' $/ 1$

$100:$

$101:$ [ [FILEHATKK]

102: 1006 FORMAT(" PRINTOUT IS IN FILE "SIMULLOG.PRN")

103: ENI 


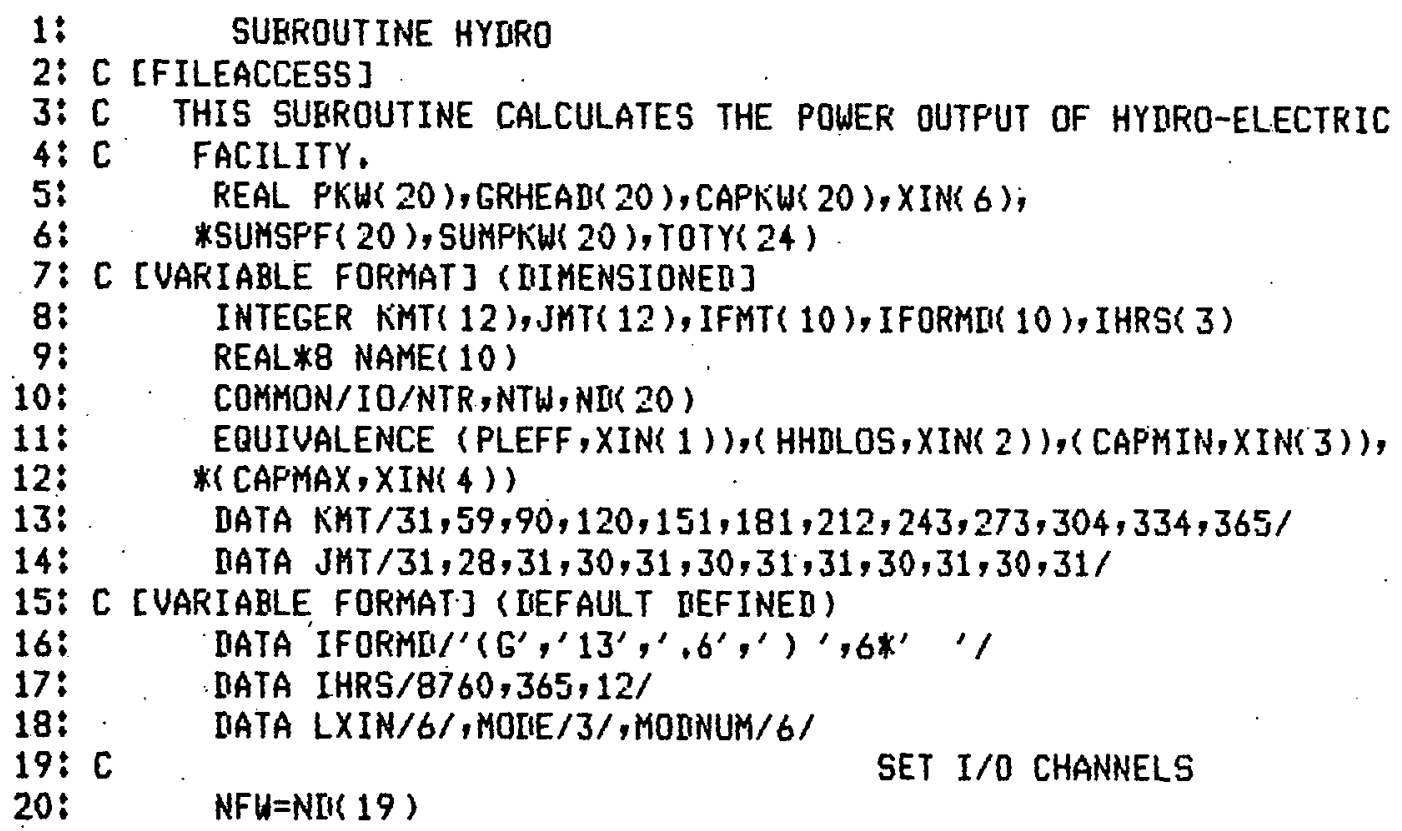

218

$21:$

$23:$

$2.4:$

25:

26:

27:

28:

29: C

$30:$

$31:$

32: 5

33:

34:

$35: 10$

36:

$37:$

38: 20

$N F R=N M(7)$

$N U=N I M(18)$

C

CALL IIATSET ( MODNUH, XIN, IRET)

GET RUN. PARAMETEFS

IF ( IRET . EQ . O )RETURN

URITE( NFW, 1002 )MONE, MONNUM

NSITE $=X I N(5)$

$I V A L=X I N(6)$

[IO $5 I=1,10$

[VARIAGLE FORMAT]

IFHT( I ) $=$ IFORMIU I )

TOTTL $=0.0$

110 $10 \quad I=1,24$

$10 \operatorname{TOTY}(I)=0.0$

II0 $20 \quad I=1,20$

SUMSPF $(I)=0,0$

20 SUMFKKW(I $)=0.0$

SUMCFS $=0.0$

40: $C$

41: $\mathrm{C}$

$42:$

43:

WRITE (NTW, 1001)

GET INPUT IIATA CHANINEL SET

INITIALIZE THE VARIAELES

C [FILEMARK] [VARIABLE FORMAT] (PASSEII FARAMETER)

CALL FOPEN NFR, IFHT, $-1,1$, IRET 2,0 , CNUHYII, AUIHYII)

45: IF(IRET2, EQ.O IRETURN

$46: C$

47: $\mathrm{C}$

48:

49: $\mathrm{C}$

$50:$

$51:$

52:

$53:$

$54: \mathrm{C}$

55: 50

C [FILEMARK]

IF ( IVAL , GT , 0, ANI, IVAL, LT , 4 )GO TO 50

CHECK HODE OF IIATA-HOURLY, IIAILY, OR HONTHLY

C

WRITE(NTU,1014)

INUALIII DATA SELECTION *

ENDF ILE NFR

RETURN

$56:$

$57:$

$58:$

59:

$60:$

IHIS=IHRS ( IVAL )

RMH $=I M M$

DO $80 \mathrm{I}=1$, NSITE

WRITE(NTU.1010)

REAII NTR, 1007 INAME( I)

WRITE(NTW, 1008)

SET COUNTER VALUES FOR THE INO LOOPS 


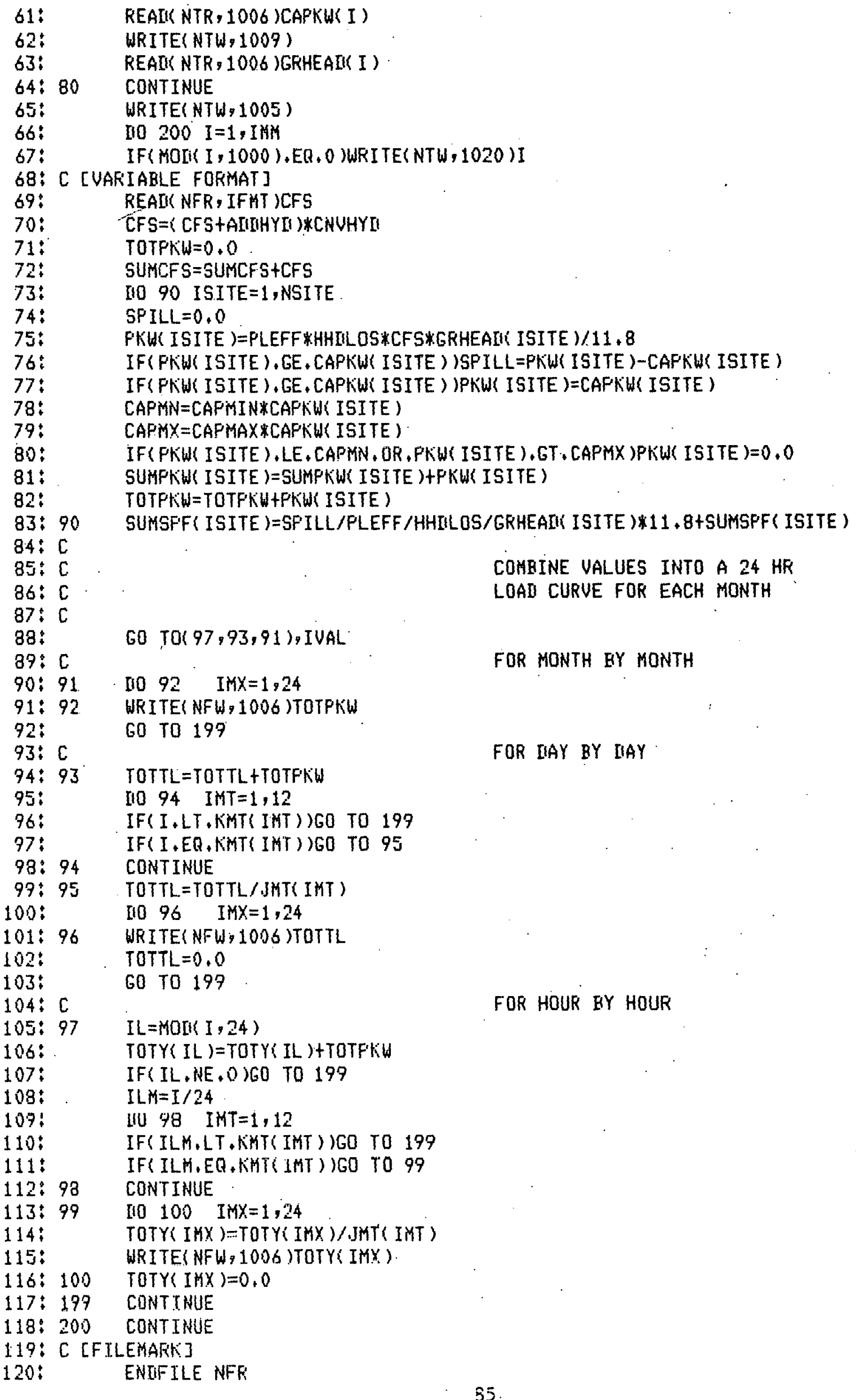


121: C

$122:$

123: C

124: C

125:

126:

$127:$

128:

129: C

130: C

131:

132:

133:

$134: 211$

135:

136:

137: C

138: 1001

139: 1002

$140: 1005$

141: 1006

142: 1007

143: 1008

144: 1009

145: 1010

146: 1011

147: 1012

148: 1013

149: 1014

150 :

151:

152: 1015

153: 1016

$154: 1019$

$155:$

$156:$

157:

1.58:

159: 1020

160:
SURCFS = SUMCF S/RMH

CALCULATE AVE STREAH FLOW

OUTPUT RESULTS

INITIALIZE FRINTOUT ROUTINE

CALL GENOUT(1,XIN,LXIN, NH, MODNUM )

URITE (NG, 1015)

CALL GENOUT 2 , XIN,LXIN, NU, MOINUM)

WRITE(NU, 1016 )SUHCFS

I0 $211 I=1$, NSITE

CALCULATE \& PRINT PLANT FACTOR, SPILLAGE FACTOR, TOTAL KWH

AUPLF $=$ SUMFKWU I )/CAPKWW( I / /RMM 100.0

SUMSFF (I ) $=$ SUKSPF ( I )/SUMCFS $* 100,0 /$ RKM

WRITE( NH, 1019 ) NAME( I ), AUPLF, SUMSPF ( I), SUAPNWW( I )

CALL GENOUT ( 3 ,XIN,LXIN, NW, MOINUUM)

RETURN

FORMAT(' OENTER RATA ON HYDRO IATA FILE( CU FT/SEC )-')

FORMAT (2I3)

FORMATY'ORUNNING, ..')

FORMAT (2G13.6)

FORMAT(AG)

FORHAT(' PLANT CAPACITY(KW): ',

FORMAT(' GROSS HEAII FT.): ')

FORMATS" NAME OF SITE:')

FORHAT!' IS THE GAUGING DATA ENTEKED ON AN HOUR EY HOUR ISASIS?')

FORMAT, IS THE GAUGING DATA ENTERED ON A IAY BY IIAY HASIS?')

FORMAT(' IS THE GAUGING DATA ENTEREN ON A MONTH EY MONTH BASIS?')

FORHATY'OTHIS PROGRAM HAS NO PROUISION FOR CENTURY BY CENTURY',

*'DATA.' $\%$ WE ARE RETURNING YOU TO THE HAIN FROGRAY--CLEAN UF',

*'YOUR ACT.')

FORMAT' * OUTFUT FROH HYIRO SIMULATION', 40X;'*')

FORMAT!'* * AVERAGE STREAH FLOH $=\left(, 613,6,22 x^{\prime}{ }^{\prime} *\right.$ *')

FORMAT!'* *',58X,'* *'।

* * STTE: ', AB, $43 X, X^{\prime} *$ *'j

*'* * PLANT FACTOR $=\prime, 613,6,26 x, ' *$ *'

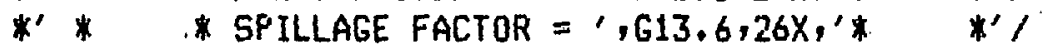

*'* * TOTAL KUH',7X,'=',613,6,26X,'* *')

FORMATI' HOUR:', I5)

END 


\section{1: SURROUTINE WINI}

2: C [FILEACCESS]

3: C UINI FOWER PROGRAM FOR UECTOR GRAFHICS.

4: C AGGREGATE MONTHLY HOUR MEAN \& STANDARII IEUIATION OF WINI

5: C ARE INPUTS; ALSO MEAN MONTHLY AIR TEMPERATURE,

6: $C$

7: C MONTH - MONTH OF YEAR

8: C I TIO LOOP VAR

9: C XIN -ARRAY USEII TO PASS INFO BACK FROH IATSET

10: C STEP -TIME IN HOURS GETWEEN WINI MATA POINTS (ISTEP IS INTEGER FORH)

11: C IHOUR -HOUR OF IIAY

12: $\mathrm{C}$ J -INIEX FOR VELOCITY INTERUAL OPERATEII OH

13: C IUCO -CUTOUT VELOCITYT1, HIGHEST INTERUAL WANTEII IN ARRAYS

14: C IRET -ERROR RETURN FROM SUEROUTINES

15: C NTF -TEFININAL REAII

16: C NTW -TERMINAL URITE \$

17: C NI -ARRAY W/IIISK CHANNEL $\$ S$

18: C NFI -WINI IIATA REAII

19: C NF2 TEMPERATURE IIATA REAII *

20: C NW -PRINTOUT WRITE —

21: C NFW -IIATA OUTFUT $\#$

22: C MOUE - MOIIE OF OUTFUT BATA

23: C IFMT -VARIAGILE FORMAT USEII TO REAII WINII IATA

24: C IFMT2 -VARIAELE FORMAT USEII TO READ TEMP IATA

25: C IFORMII-IEFAULT FORMAT FOR IFMT, IFMT2

26: C LXIN - F FARAMS INPUT IN IIATSET

27: C WFLAG -TRUE IF HOUR EY HOUR UINII IATTA, FALSE IF MEAN \& SII HOUR/MONTH

28: C WKO WEIEULL F'ARAM " $K$ " AT ANEMOM HEIGHT

29: C UK -WEIFULL PARAH " $K$ " ALIUSTEI TO HUB HEIGHT

30: C WCO WEIFULL F'ARAH "C" AT ANEMOM HEIGHT

31: C UC WEIEULL FARAM "C" AIUJ TO HUB HEIGHT

32: C CFAUG - AUG CAF FACTOF FOF YEAR

33: C PAVG -AUERAGE FOWER FROL1/HOUR FOR THE YEAR

34: C DAIRO -IIENSITY OF AIRIKG/M3)

35: C DAIR - MEAN MONTHLY AIR IIENSITY FOR THIS SITE

36: C PYEAR - TOTAL FOUER FROII/YEAR

37: C MOINUM-WINI MOIULE INIIEX AMONG SIMULATIONS

38: ( NUMUAR - OF PARAA TO VARY IF ANY)

39: C IUFLG -1 IF ANOTHER. F'ARH VALUE TO IO WHEN VARYING

40: $C$ H1 -ELEVATION OF CENTEF OF WINIMMILL AHOVE SEA LEVEL

41: C HEIGHT-HEIGHT OF CFNTER OF WINIMILL

42: C AXIS -O:HORIZ AXIS, 1:VERT AXIS

43: C HGHT -IF VERT AXIS, HEIGHT OF HEC

44: C HCLR -CLEARATSCE BETHEEN FIOTOR \& GROURI

45: C ELEV -ELEVATION ABOVE SEA LEVEL

46: C AIIITMP-AIIII TO INPUT TEMP TO CONUERT TO IEG FAR IF MECESSARY

47: C CNUTHP-PULT BY (INPUT TEHF +AIIITHF) TO CONV TO IIEG FAR IF NUEC

48: C HO -HEIGHT OF ANEMON AROUE GFOUAII

49: C TEMF -MEAN MONTHLY TEMP

50: C PHON -TOTAL FOHER FROIUCEIV/MONTH

51: C RPIIIX -0:CONSTANT RPM, 1:VARIAELE RPH

52: C DIAM -IIAMETER OF ROTOR

53: C CSAREA-CFOSSECTIOHAL AREA SUBTENIEU EY ROTOR

54: C APMON - AUG POWER/HR FOR THE HONTH

55: C PTOII -AUG POWEK FOR GIUEN TIME OF IAY

56: C PUEL -POWER AT A GIVEN UELOCITI

57: C VAVG -AUERAGE VELOCITY IN AH IRTERUAL

58: C UR -LOWEST VELO WHERE RATEI FOHER IS PROUUCEM( RATEII VELOCITY)

59: C CFR -POWER COEFFICIENT AT RATEII VELO

60: C UCO -CUTOUT UFLO 


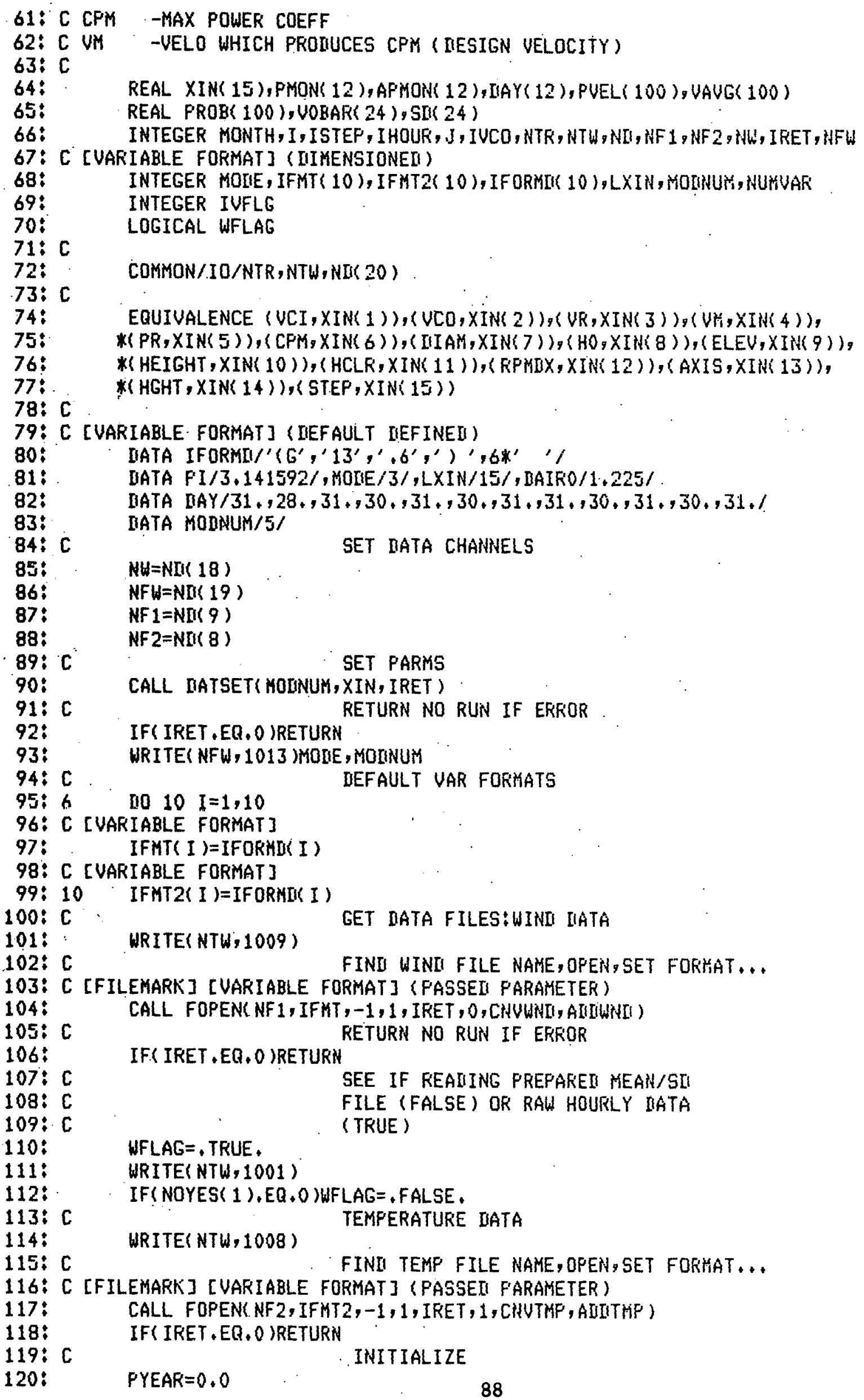




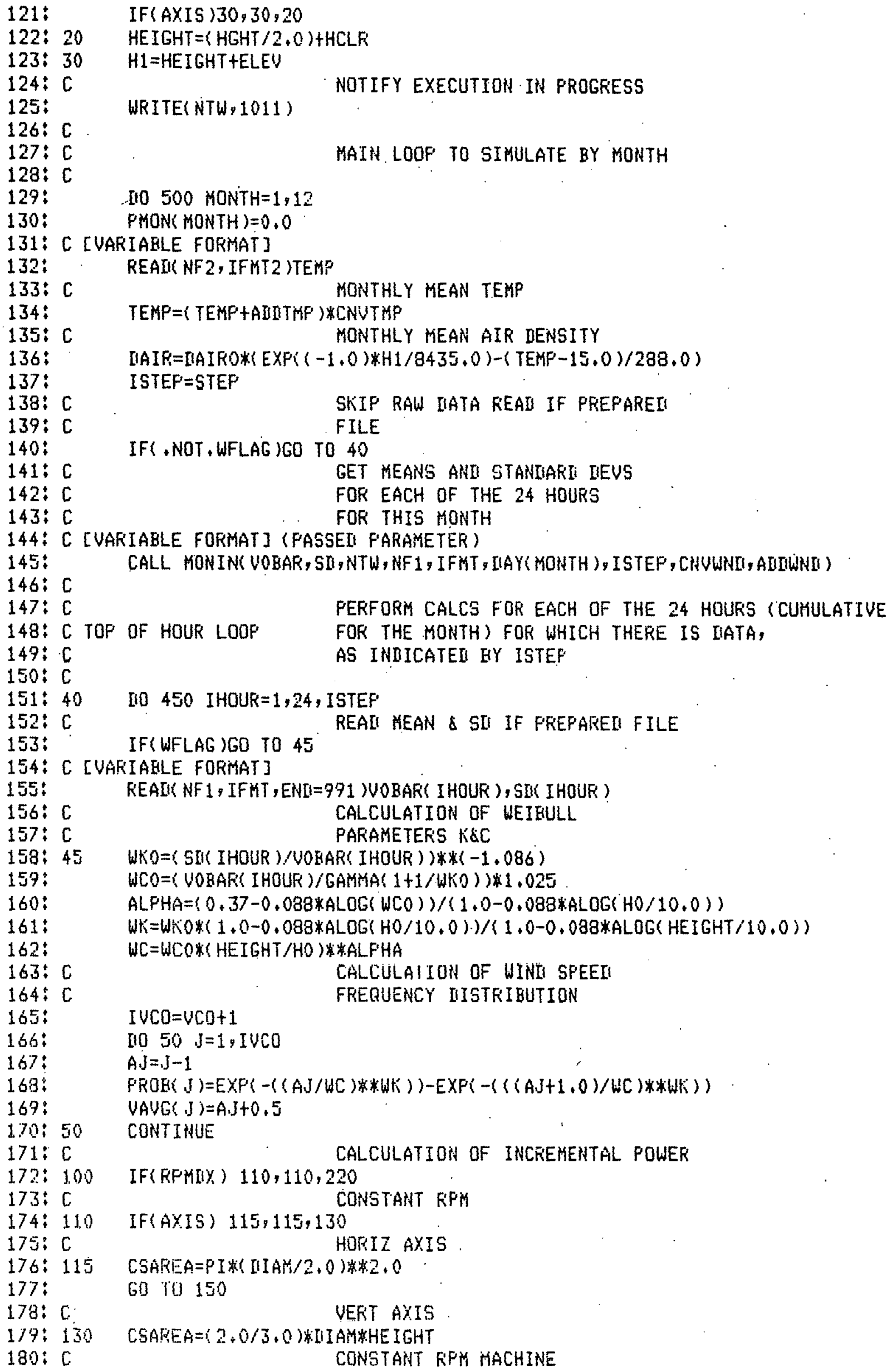




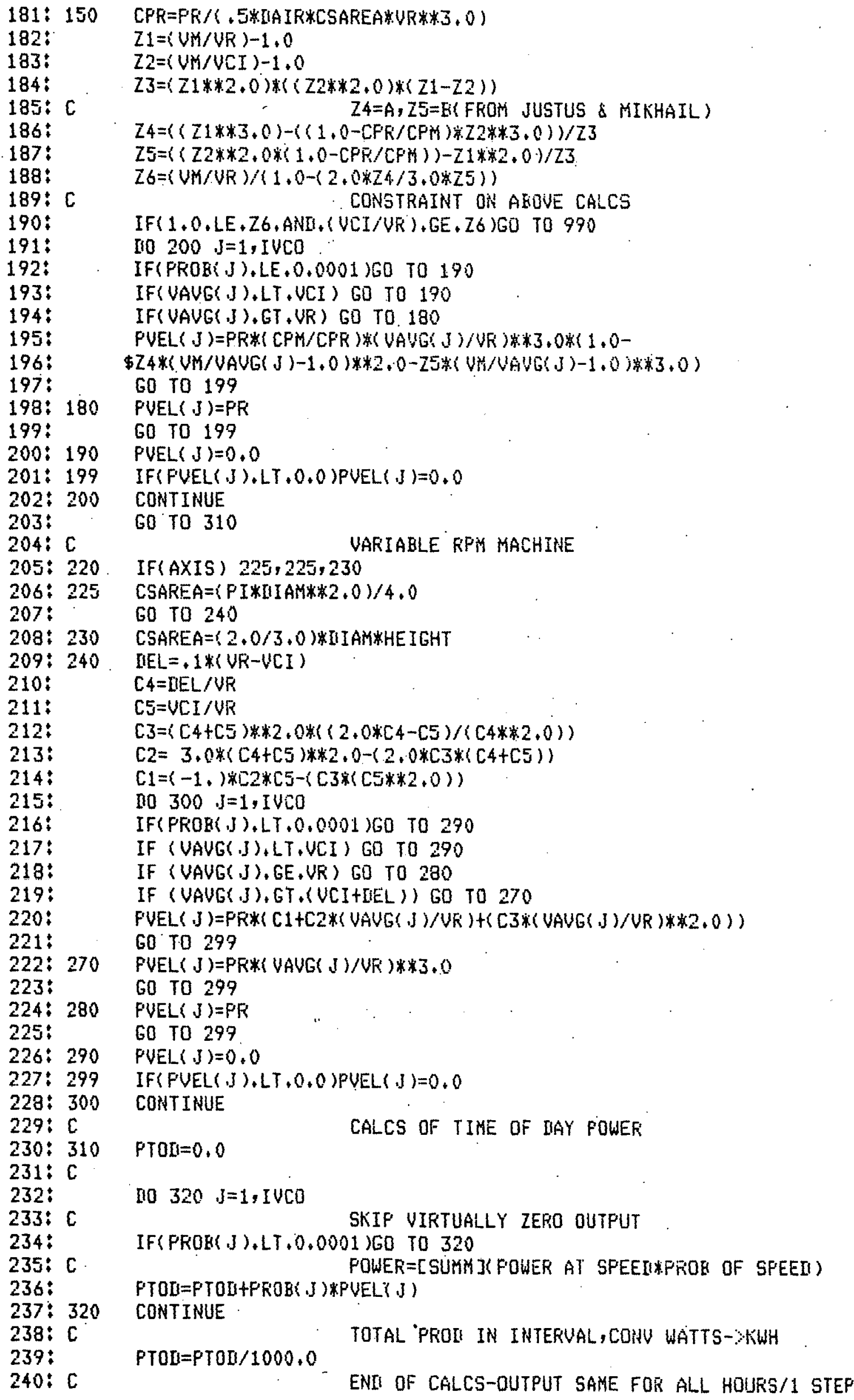




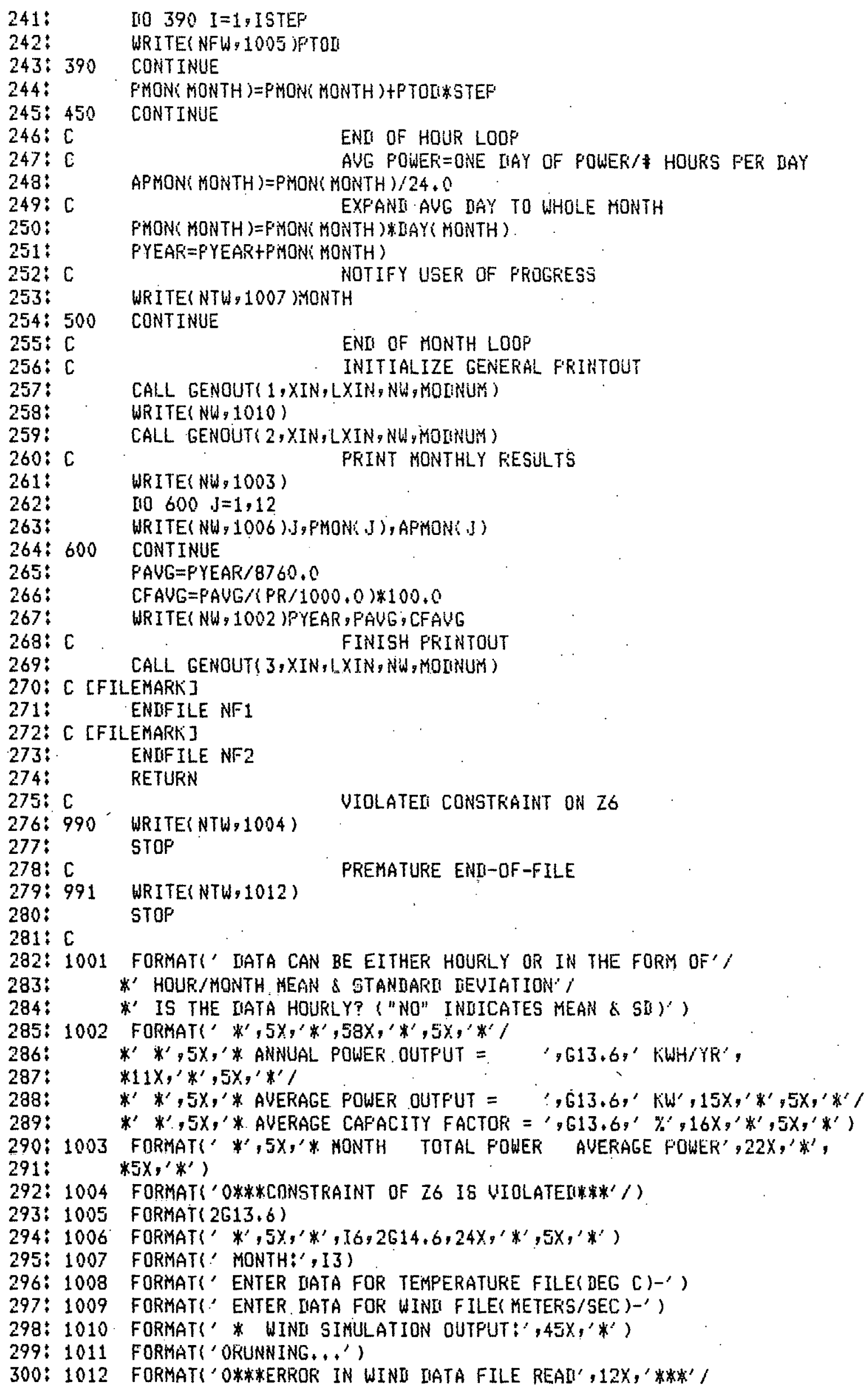


301: *' ***FROBAELE CAUSE: INSUFFICIENT IATA POINTS***')

302: 1013 FORMAT(213)

303:

ENI 
1: SUBROUTINE MONIN VOBAR, SI, NTU, NFR, IFMT, IAYMO, ISTEP, CNULND, AIIUWN )

2: C [NO FILEACCESS]

3: C [VARIAELE FORMAT] (PASSEI PARAMETER)

4: C MONIN INPUTS A MONTH OF HOURLY WINI IIATA AND TURNS IT INTO MEANS

5: C ANI STANIIARI IEUIATIONS FOR EACH OF THE 24 HOURS TO FEEII TO

6: C THE WINI SIMULATION.

7: C [VARIABLE FORMAT] (IIIHENSIONEII)

8: INTEGER HOUR, DAYIN,NFR, ISTEF, I, IFMT( 10$)$, NTW

9: REAL UTOT( 24 ), USRRT 24 ), VOBAR( 24 ), SD( 24 ), DAYMO, CNUWNA, AIIIUND, VELOC

$10: C$

$11: C$

12 :

$13:$

14: 10

$15: \mathrm{C}$

$16:$

$17 !$

18: $\mathrm{C}$

$19 \div \mathrm{C}$

$20:$

21: C

22: C

23: C. [UARIAELE FORMAT]

IIO 10 HOUR $=1,24$, ISTEF

INITIALIZE ARRAYS

UTOT ( HOUR ) $=0.0$

10 USQRT ( HOUR ) $=0.0$

$I=n A Y M O$

II0 40 IIAYIN=1, I

IIO 20 HOUR $=1,24$, ISTEP

LOOP THROUGH DAYS

LOOP THROUGH HOURS AT INTERVAL

SPECIFIED

GET UINI DATA ANI CONVERT TO

METERS/SECONI

REAII NFR, IFMT, ENII=999 ) UELOC

VELOC $=$ ( VELOC +AIIIWND ) *CNUWNI

25:

26: C

$27:$

28:

$29: 20$

UTOT( HOUR ) $=$ UTOT( HOUR ) +UELOC

AIID TO SUM \& SUM OF SQUARES

$30: 40$

31: C

32: $\mathrm{C}$

$33:$

$34:$

$35 t$

$36:$

$37:$

38: 50

$39:$

40: $\mathrm{C}$

41: 999

$42:$

43: $\mathrm{l}$

44: 1001 FORMATI'O***EEROR IN WINI IIATA FILE REAI', 12X,'***';

45: * ***FRORAELE CAUSE: INSUFFICIENT IIATA POINTS***')

46: END

CALCULATE MEAN ANI STANIIARD

IIEVIATION FOR EACH HOUR VELOCITY

IIO 50 HOUR $=1,24$, ISTEF

VOEAR( HOUR $)=$ (UTOT( HOUR ) /DAYMO)

SII (HOUR ) $=($ ( ( USRRT ( HOUR )-IIAYMO*VOFAR( HOUR )**2)/

$\$(I A Y M O-1.0)) * * 0.5) * 0.447$

VOFAR ( HOUR ) $=$ VOBAR( HOUR $) * 0.447$

CONTINUE

RETURN

WRITE(NTH;1001)

STOF

PREMATURE ENII-OF-FILE FOUNR 


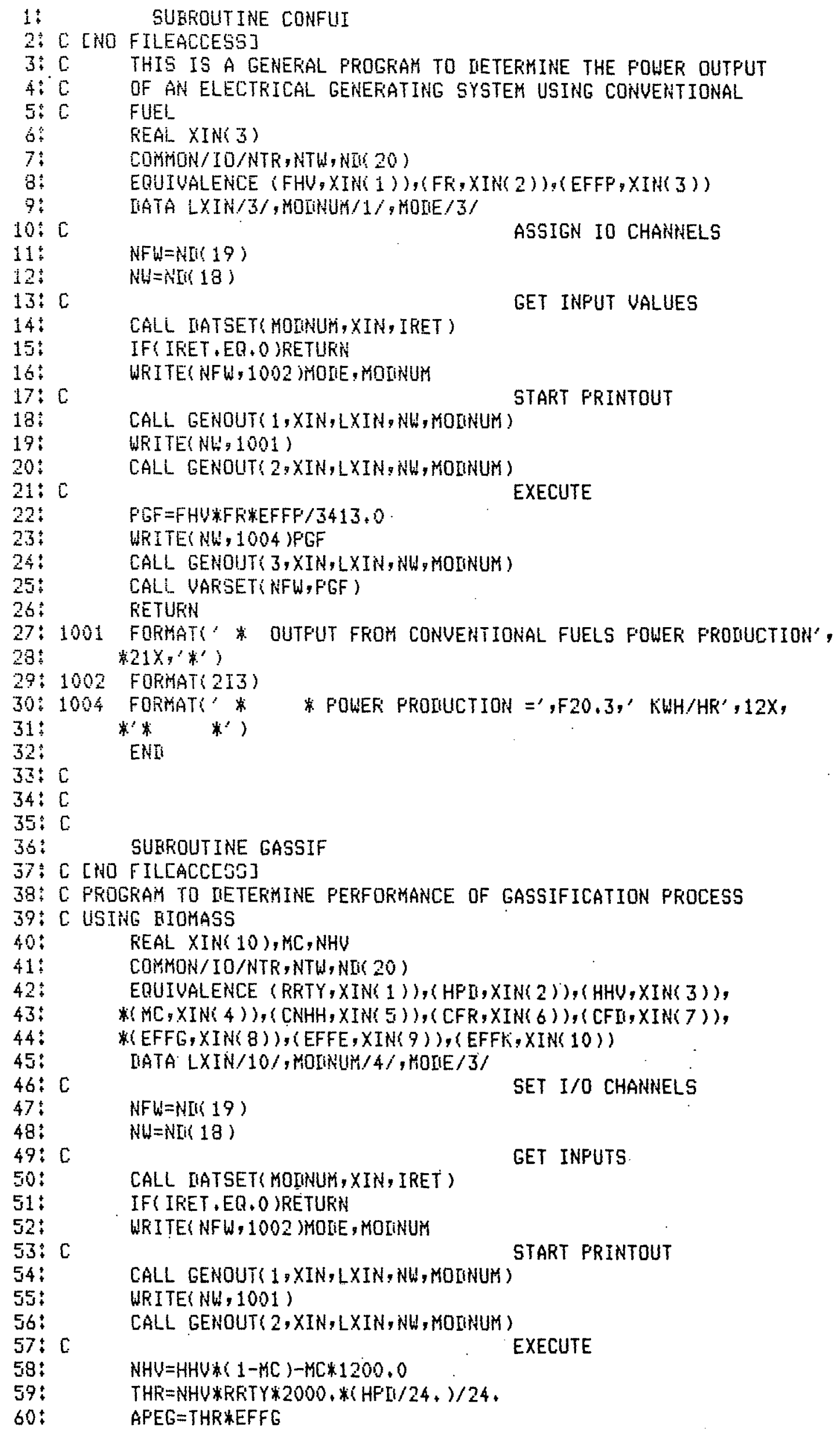

SET I/O CHAHHELS

$A F W=N[(19)$

$N(W=N I i(19)$

CALL IIATSET( MOINNUA, XIN, IRET)

GET INPUTS

IF ( IRET , EQ . O)RETURI

WRI TE ( NFW, 1002 )HOIE, HOTINUH

CALL GENOUT( 1 , XIN, LXIN, NH, MOLINUH)

START PRINTOUT

URITE(NH, 1001)

CALL GEHOUT 2 , XIN,LXIN, NH, HOINUH )

NHU $=H H U$ A $(1-H C)-M C * 1200.0$

EXECUTE

THR=NHUWRFTY $\$ 2000, *(H F[1 / 24) /$,24 。

AFEG $=$ THR $* E F F G$ 


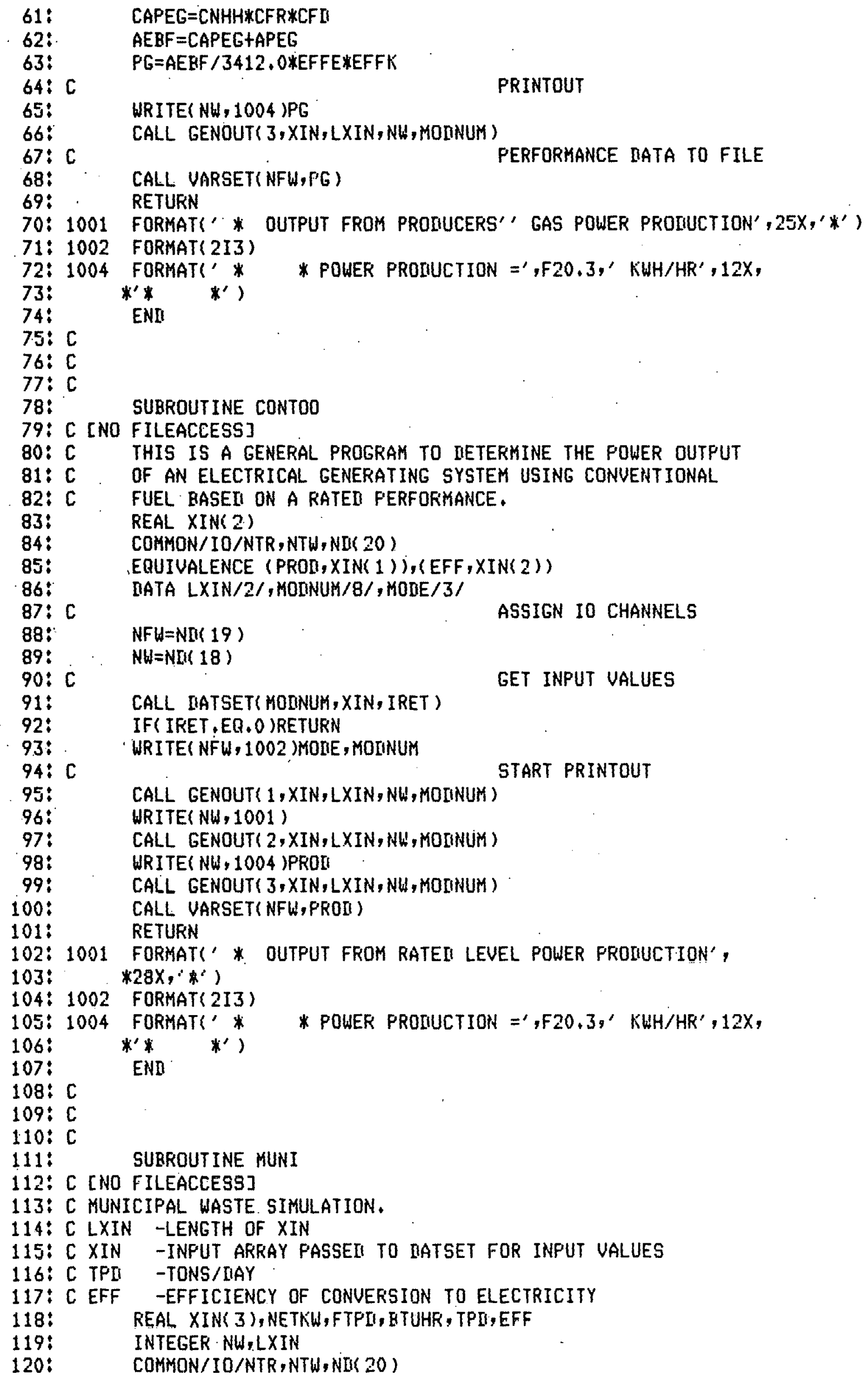




\section{4: 1004 FORMAT( 213)}

$145:$

146:

147: $\mathrm{C}$

148: C

149: C

$150:$

151: C [NO FILEACCESS]

152: C PROGRAM IIOES IIRECT COMEUSTION OF BIOMASS, FIVE OPTIONS AVAILABLE

153: C OPTION 1: CONSTANT FUEL SOURCE

154: C OPTION 2: ENERGY PLANTATION PELLETIZED

$155: C$

156: $\mathrm{C}$

157: C

158: $C$

$159:$

$160:$

161:

$162:$

163:

$164:$

$165:$

$166:$

$167: C$

$168:$

169:

$170: C$

171:

$172:$

173:

$174: C$ OPTION 3: ENERGY PLANTANTION NON-PELLETIZED

OPTION 4: WOOD RESIDUES PELLETIZEII

OPTION 5: WOOD RESI DUES NON-PELLETIZED

175:

$176:$

$177:$

178:

$179:$ 180 :

REAL TAH( 5 ), XIN( 22), J( 5 )

COMMON/IO/NTR,NTW, NO( 20$)$

EQUIVALENCE $(J(1), X I N(1)),(F Y H, X I N(6)),($ HEC, XIN( 7$)),($ HHUP, XIN 8 )), (X) PPF, XIN( 9)),(CIP,XIN 10$)),(C 2 P, X I N(11)),($ AUPP, XIN 12$))$, *( URP, XIN( 13)),(HHUR, XIN( 14)),(PPR, XIN 15)),(CIR,XIN(16)), *(C2R,XIN( 17)),(AUPR,XIN(18)),(HR,XIN(19)),(TON, XIN( 20$))$, *(CP,XIN(21)),( HHUC, XIN( 22)) IIATA LXIN/22/,HOINUM/2/,MOIE/3/

$N F(U=N(19)$

$N(U=N I M 18)$

CALL IIATSET ( MODNUH, XIN, IRET)

IF ( IRET , EQ . 0)RETURN

WRITE( NFW, 1002 ) MODE, MOLINUM

IF (PPP , GT, 1.0$) P P P=P P P / 100.0$

CONUERT \% TO FRAC IF NEEIIED

IF $(C P, G T, 1.0) C P=C P / 100,0$

IF $(C 1 P, G T, 1.0) C 1 P=C 1 P / 100,0$

IF $(C 2 P, G T, 1.0) C 2 P=C 2 P / 100.0$

IF $(A W P P, G T, 1,0) A W P P=A W P P / 100,0$

IF (PPR. GT . 1.0)PFR=PFR $/ 100.0$ 
IF $(J(1), N E+1,0) 60$ TO 5

\author{
CONSTANT INFUT
}

189: C

$190 \div 5$

191:

$192:$

193:

$194:$

195:

$196:$

197:

198:

$199:$

200: C

$201 \div 10$

202:

$203:$

204:

205:

206: C

207:15

$208:$

209:

210 :

211:

212:

213:

214:

215:

216:

217: C

218:20

219:

220:

221:

2221

223: C

224: 25

225:

226:

TAH( 1$)=($ HHUC*(1-CF)-CF*1200, )*TON $2000, * 8760$.

$\operatorname{IF}(3(2), N E+1,0) G 0$ TO 10

ENERGY PLANTATION: PELLETIZEI

THFF $=$ FYH*HEC*PFF

$T P F=$ TWFP

WEPF $=$ CIFTTWPP

WAPF $=(C 2 P *(1.0-C 1 P) * T W P P) /(1.0-C 2 P)$

TWEF $=$ WEPF-WAPF

BTUUF $=$ TWEF $* 2000.0 * 1700.0$

WHP $=$ TPP 150.0

HUPF $=$ HHUF $*(1,0-C 2 P)-C 2 P * 1200.0$

TAH 2 2) $=$ TPF $* 2000.0 * H U F P-B T U U P-W H F$

EMERGY PLANTATION : NON-PELLETIZEN

IF( J 3), NE. 1.0)GOTO 15

$I F(J(2)+E Q+1.0) F F F=0.0$

TWNF = FYHWHE( $(1,0-P F F)$

HUNP $=$ HHUP $*(1.0-C 1 P)-.C 1 P * 1200.0$

TAH( 3) $=$ TWNP 22000.0 KHUNP

IF(J (4).NE.1.0)GO TO 20

WOOD RESINUES: PELLETIZEI

TWPR $=$ WRP $* P P R$

TPR $=$ TWPR HALPR

WEPR $=$ CIRKTWFR

WAPR $=(C 2 R *(1.0-C 1 R) * T$ TWR $) /(1.0-C 2 R)$

TWER = WHFF- WAPF

BTUUR $=$ TWER $* 2000.0 * 1700.0$

WHR $=T P R * 150.0$

HUPR $=$ HHUR $(1,0-C 2 R)-C 2 R * 1200.0$

TAH 4 ) = TPF*2000. O*HUFR-HTUUR-WHF

IF $J(5)$.NE.1.0)GOTO 25

$I F(J(4), E Q+1.0) F F R=0.0$

TWZNF $=$ UFF $*(1,0-F P R)$

HUZNF $=$ HHUR $*(1.0-C 1 R)-C 1 R$ 薄1200.0

TAH $(5)=$ TWZNKRHUZNR 2000.0

TAII $=0.0$

HOOD RESIIUES : NON-PELLETIZEI

IiO $30 \quad I=1,5$

TAI = TAII+TAH(I)

CONTINUE

PROII $=$ TALI/HR/8760.0

CALL GENOUT ( 1 , XIN, LXIN, HW, MOINUM)

WRITE( NW, 1001)

CALL GENOUT ( 2 , XIF, LXIN, INU, MUIXIUH)

WRITE( NH, 1004$)$ PROI

CALL GENOUT ( 3 , XIN, LXIN, RWL, HOUNUUY)

CALL VARSET(NFW,FROI)

RETURN

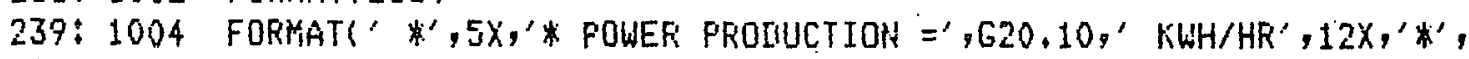

240:

FORMATS * OUTPUT FROH HIOHASS COHEUSTIOH' FOUER FROLUCTIOH', *22 $\left.\left.2 x^{\prime} \prime^{\prime}\right)^{\prime}\right)$

AGGREGATE OUTPUT

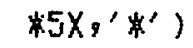


2: C [NO FILEACCESS]

3: C THIS PROGRAM IS A SIHULATIOH OF ANAEFOHIC IIGESTIOH OUTFUT

4: C THE OUTPUT OF THIS SIMULATIOH IS MHETU-- COTVERTEI TO KHH.

5: C GENERATOR EFFICIENCY IS ASSUAEI TO FE $30 \%$

6: $\mathrm{C}$

$7: \mathrm{C}$

8: C

9: $\mathrm{C}$

10: $C$

$11: \mathrm{C}$

$12: C$

$13: C$

14: $\mathrm{C}$

15: $\mathrm{C}$

16: $\mathrm{C}$

17: $\mathrm{C}$

THIS MOIIEL WAS AIOPTEII FROH RESEARCH FERFORUEE FOR SERT, BY IIYNATECH R/D COMFANY IN 1979.

KK IS THE $\$$ OF PIECES OF EQUTFHEMT

$K$ IS THE NUMEER TIMES THE FROGFAY HILL HE RUP:

THE FIRST STEF IS TO IIMENSION THE AFEATS AIIT ASSIGH VALUES

THE VARIAELE FSS IS ASSUHEII TO EE 30\%,

ACCORIIING TO EII ASHARE OF MYNATECH.

\author{
INTEGER FUF (36) \\ REAL XINI 55 ) \\ IIIMENSION THAERT 10), WK (10), ACP(10) \\ COHMON/KWFROE/ELANET \\ COMMON/IO/NTR, NTH, NOC 2O)
}

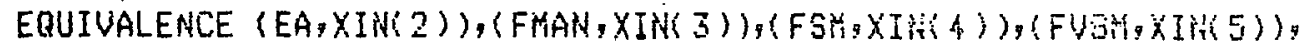

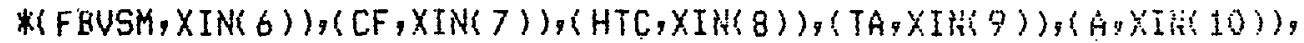

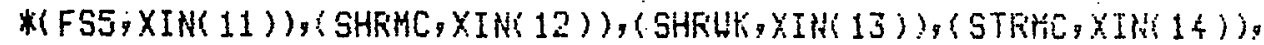

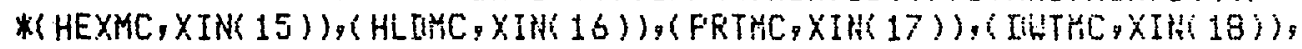

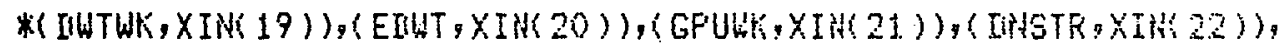

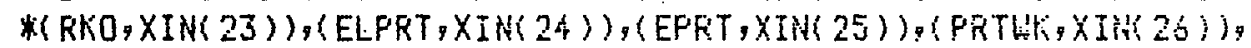

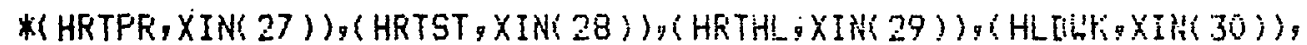
*(INSHL, XIN( 31$)),($ IIUSPR, XIH 32 ))

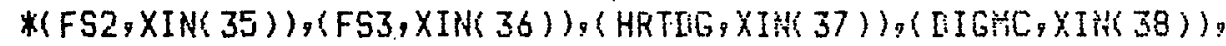

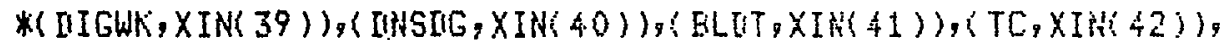

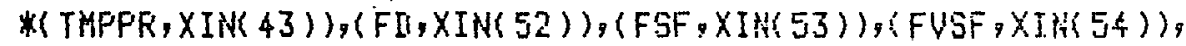
* FEUSF, XIN( 55$)$ )

IIATA MOINUUM/3/,LXIH/55/, HOIE /3/

41:

$42:$

$43: C$

$N W=N(K 18)$

\title{
CALL IIATSET( MOLINUA, XIN, IRET) \\ IF( IRET,EQ, O)RETURA \\ URITE(NFW, 1004 ) HONE, MOIHUH
}

$K K=X I N(1)+.01$

INSHR $=X I N(44)+$ SIGH $, 01, \times(N(44))$

INTIALIZE RUHHY VARTIAELES FOR SYSTEP CORFIGURATIO?

INHLI $=X I N(45)+$ SIGN $.01, X I M(45))$

INPRT $=X I N(46)+$ SIGN $, 01, X$ XN (46))

INSTR $=X I N(47)+S I G N(.01, X I N(47))$

INHEX $=X I N(48)+$ SIGN, $01 ; X I N(48))$

INDIG $=X I N(49)+$ SIGN $.01, X I N(49))$

INIWT $=X I N(50)+5 I G N .01, X I N(50))$

INGFU $=X I N(51)+$ SIGH, $01, X(M) 51)$ )

$S T F=1.0$

RFAIK NTR, 4002 )EUF 


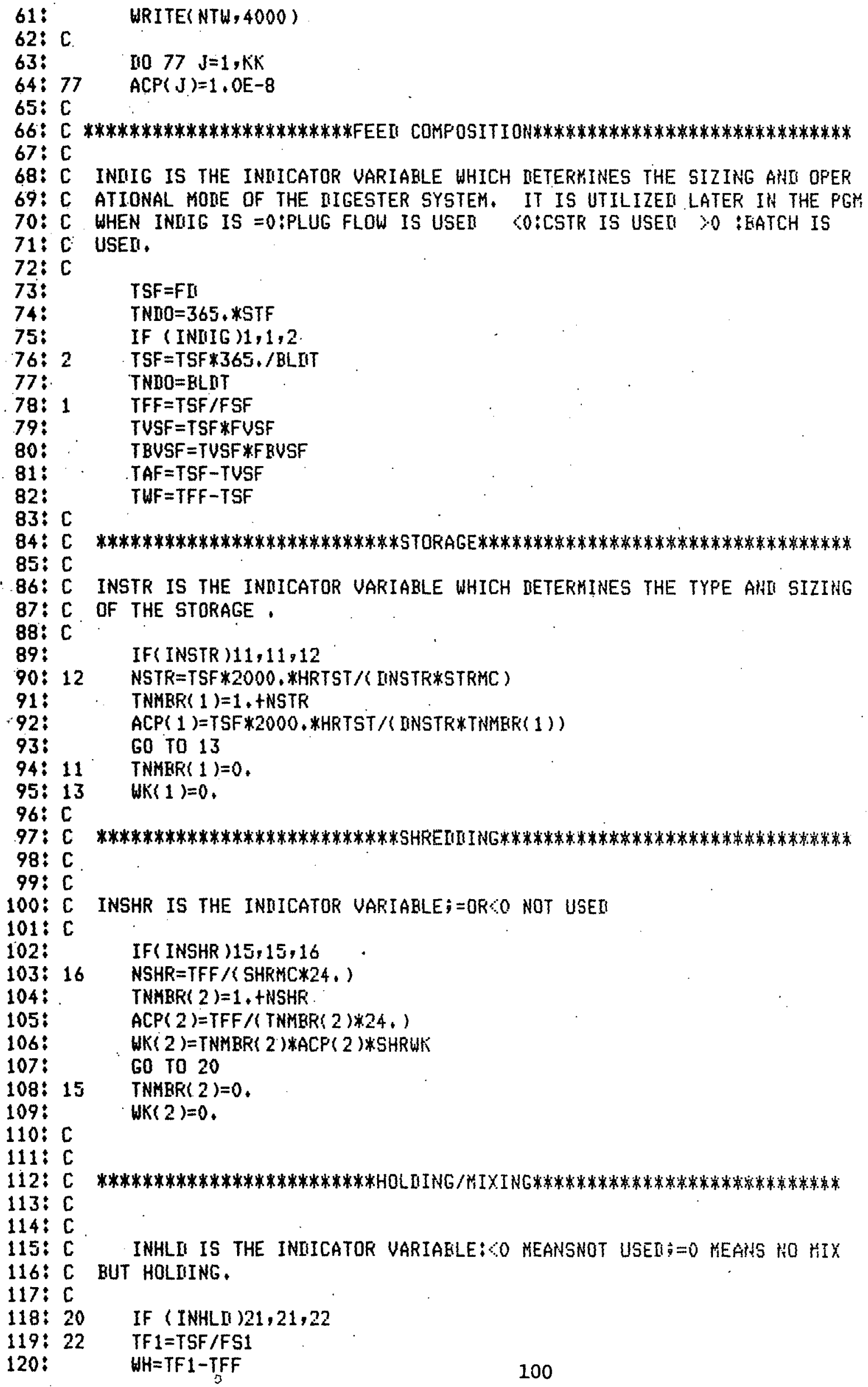




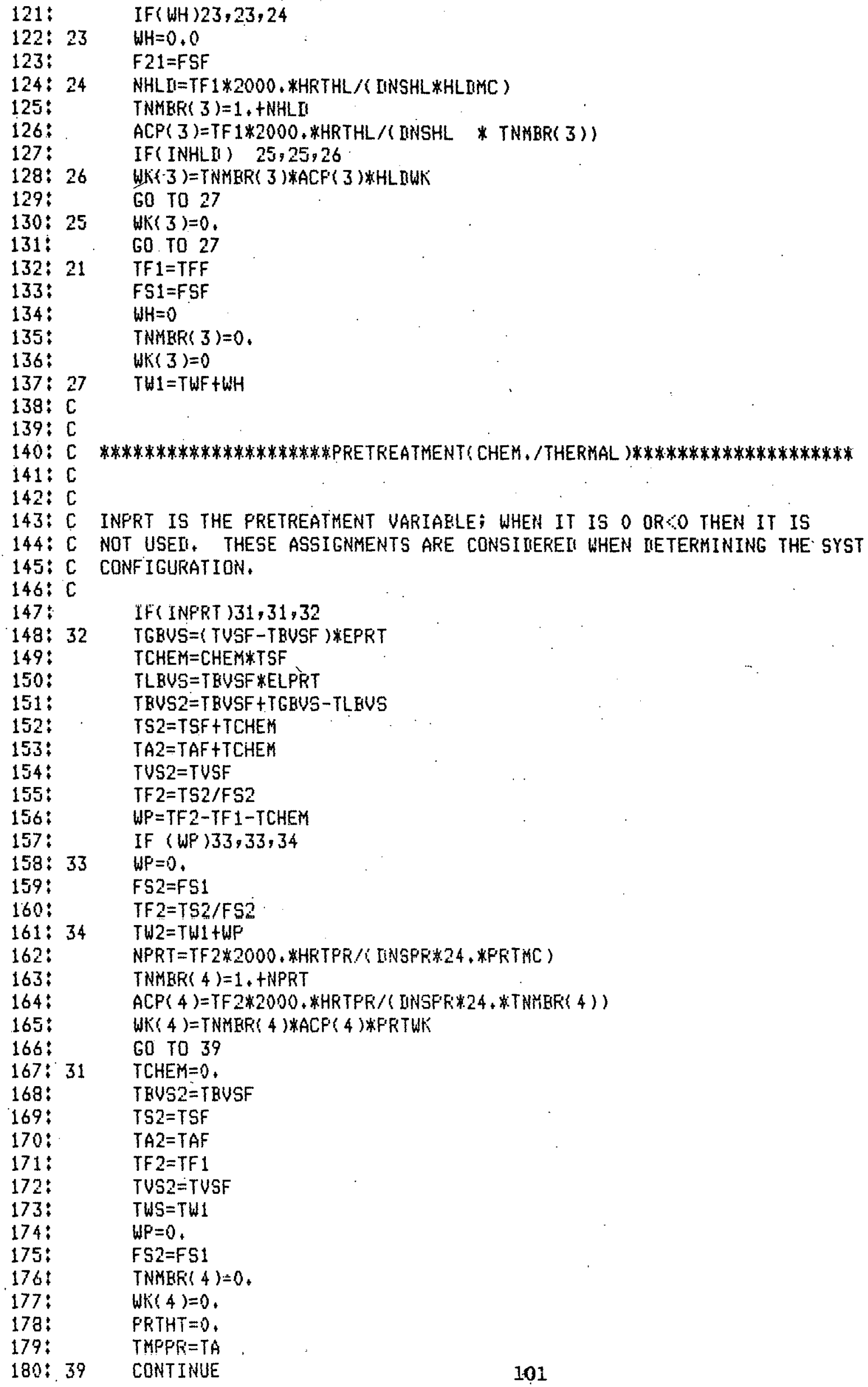

IF( INFRT $31,31,32$

TGBUS $=$ ( TUSF-TBUSF $)$ *EPRT

TCHEM =CHEM $*$ TSF

TLEUS = TEUSF $*$ ELPKT T

TEVS2 $=$ TRUSF + TGEUS - TLEUS

TS2 $=$ TSF + TCHEM

TA2 $=$ TAF+TCHEM

TUS2 $=$ TUSF

TF2 $=$ TS2/FS2

$W P=T F 2-T F 1-T C H E M$

IF (WF) $33,33,34$

$$
W P=0 \text {. }
$$

$F S 2=F S 1$

TF2 $=$ TS2/FS2

$T W 2=T H 1+W P$

NPRT $=$ TF2 2*2000, *HFTPR/I INGPRT24, *FRTMC)

TNMER( 4 ) $=1$ + THPRT

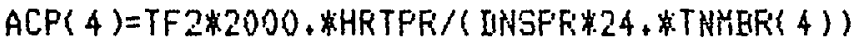

WK( 4$)=$ TNHER( 4$)$ WACF( 4$)$ WFRTWK

60 TO 39

TCHEK $=0$.

TEUS2=TEUSF

$T S 2=T S F$

$T A 2=T A F$

TF $2=T F 1$

TVS2 $=$ TUSF

TUS = TW1

$W P=0$,

$F S 2=F S 1$

TNMER $(4)=0$.

WK $(4)=0$.

FRTHT $=0$,

THPFE $=T A$

CONTIRUE 
181: C

$182: \mathrm{C}$

$183: \mathrm{C}$

$184: \mathrm{C}$

$185: C$

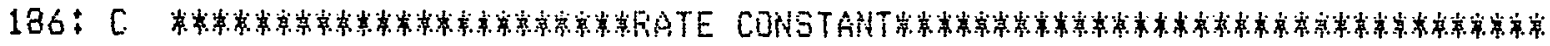

$187: \mathrm{C}$

$189:$

$189:$

$190:$

$191: 9742$

$192: 9943$

IFIRKO+LE.0)SO TO 9942

$F K=F K O A E X(-E A /(1.787+(T C+273+16)))$

GO TO 9943

THS=TS2\%FHAN

193: TS3=THS+TS2

194: TUS3:TUS2+THSSFEVSH

195: TEVS3=TEUS2TTHGFUSH

196: TA3=TA2+THSA 1 - FVSH)

197: TF3=TS3/FS3

199: THU=TMSN(1.-FSM $/ F G H$

$197 \%$

200 :

$201 \div 44$

202 ;

$203:$

$204: 45$

$205:$

206:

$207: \mathrm{C}$

$208 \div \mathrm{C}$

$207 \div \quad \mathrm{C}$

$210: C$

211: $\mathrm{C}$

212:51.

213:

214:52

215:55

216:

217:

218: C

$219: \mathrm{C}$

$220 \div \mathrm{C}$

221: C

$222 ; 59$

223:

$224: 58$

225:

226:

227 :

228 :

229: C

$230: C$

231: C

$232: \mathrm{C}$

233: C

234:

235: 53

236:

237:

238:54

237 :

240 :

WIIIG $=$ TF 3-TF2-THS/FSM

IF (WIII ) $44,44,45$

WIIG $=0$,

TF3 $=$ TF $2+$ TMS $/ F S^{-1}$

FS3 $T$ TS3/TF3

$T W 3=T H 2+H I I G+T H W$

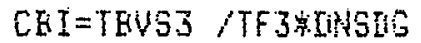

IF (INIIS ) S1,5i,59

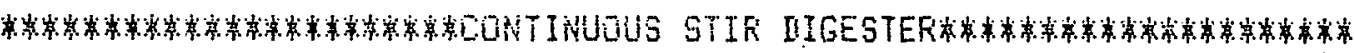

CFE $=$ CEI $/(1+$ +RKHHFTIO $)$

60 TO 55

CEE $=$ CEI $*$ EXF( - RKNHRTIS)

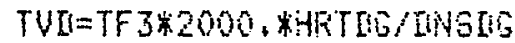

EO TO 58

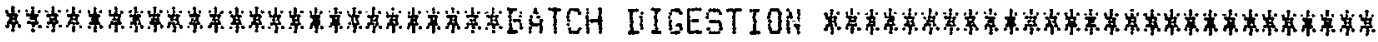

CEE =CEI

TUII $=$ TF $3 * 2000, *$ HIIIT/DISSIS

RIIIG $=$ TUI $/$ IIIGKC

TNMER( 5$)=1+$ +NIIS

ACF $(5)=$ TUD $/$ TAMER ( 5$)$

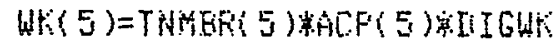

FCONY $=($ CBI - CES $) / C E I$

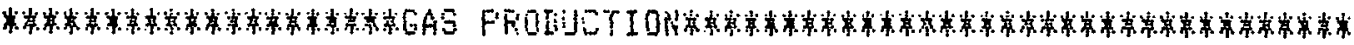

IF (INIIE) $53,53,54$

GFIVA A

IIGF $=$ GF'INT TUI

GO TO 40

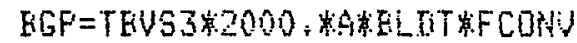

IGP = EGF / HRTIS

GF II $=[\mathrm{IGF} / \mathrm{TUI}$ 
IF( INHEX) $41,41,42$

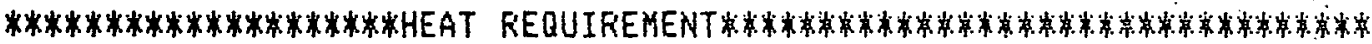

$X X=1.2756$ *EXP $(-5220 . /(T C+233.16))$

$H 20 E V=I G P * X X /(1,-X X) * 0.0474$

TF $4=T F 3-($ H2OEV $/ 2000+$ + ( CEI - CHE $) /$ INYSIG $*$ TF 3$)$

TPF $=T F 4 *(T C-T P E X) / T F 2+T A$

TAHEX $=$ TF 4*2000, $* C F *(T C-T P E X) /($ (TFEX-TA $)$ *HTC 24,$)$

NHEX $=$ TAHEX/HEXMC

TNMER ( 6) $=1$, +NHEX

$A C P(6)=$ TAHEX/ TNMER( 6 )

GO TO 43

TNMBR $(6)=0$.

TPEX $=T C$

$T P F=T A$

$\| K(6)=0$.

IF (INPRT, EQ.1)FRTHT =TF2*3600, *CF

HGAS=IIGP $*(T C-T A) * 0.0723$

HEVAF $=H 20 E U *(1025,+0.805 *(T C-T A))$

HEFF $=$ TF 4*CF $*($ TPEX-TA $) * 3600$.

$H R X N=I I G P * 61.6$

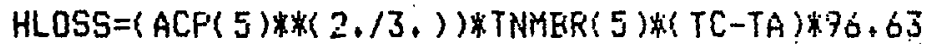

- HREQ $=H G A S+H E V A P+H E F F+H L O S S-H R X N$

IF (INIII , LE, O) HREQ =HGAS +HEVAP +HLOSS-HRXXH

IF ( HREQ,LE, O) HREQ $=0$

TRUS4 $=$ TBUS3 $*(1,-F$ CONV $)$

TUS4 $=$ TUS3-( TBUS3 -TVBS4)

$T W 4=T W 3-H 2 O E V / 2000$.

TS4 $=$ TF $4-T W 4$

TA4 $=$ TS $4-$ TUS 4

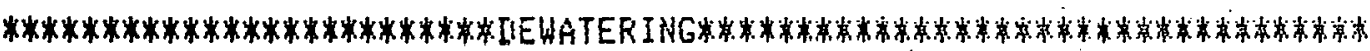

IF( INDWT ) 71,71,72

NIWT $=$ TF $4 /($ IUTMC $* 24$,

$A C P(7)=\operatorname{TF} 4 /(24$, *TNMBR( 7$))$

WK( 7$)=$ TNMER( 7 ) *IWTTHK

TWS $=$ TS4 $* E$ [IWT

$T H S=T S 5 / F S 5 *(1,-F S 5)$

$T F 5=T 55+T W E$

60 T0 73

TNMER 7 )=0. WK( 7$)=0$. $T S 5=0$. TWS $=0$, $T F 5=0$,

$T S 6=T S 4-T S 6$

TF $6=$ TF $4-T^{-T S}$

$T W 6=T W 4-T W 5$ 
301: C

302:

303: 82

304:

305:

306:

307: 81

308:

309: 88

310:

311 :

312:

313:

314:

315: 701

316:

317: 702

318: 803

319: 800

320:

321: 801

322: 805

323: 820

324:

325: 821

326:

327: 822

328: 825

329: 829

330: 810

331:

332: 811

333: 815

$334:$

335: 831

336:

$337: 833$

338:

339: 838

$340: 835$

341:

342: 842

343: 841

344:

$345: 850$

346:

347: 851

348: 852

349: 860

350:

IF( INGPU) $81,81,82$

$A C P(8)=[I G F / 0.6$

TNHER $(8)=1$.

UK $(8)=A C P(8) *$ GPUWK $/ 1$.EG

60 TO 88

TNMER( 8$)=0$,

$H K(8)=0$.

CONTINUE

IIGPM $=[1 G P / 1000$.

HREQM $=H R E Q / 1, E 6$

HRITE( NH, 4003 )BUF

WRITE( NW, 1001 )FII,FSF, FUSF, FEUSF

IF (INSTR ) 701,701,702

WRI TE( NW, 1501),

60 TO 803

WRITE(NW, 1502 )TNMERR 1), ACP(1)

IF (INSHR ) 800,800,801

URITE( NW, 1002)

60 TO 805

HRITE(NH, 1003 )TNMER( 2$), A C P(2)$, WK( 2)

IF ( INHL II )820,821,822

WRITE (NW,1008)

GO. TO 829

HRITE(NH, 1009)

60 TO 825

HRITE(NH, 1010)

WRITE(NW, 1011)THAER( 3), ACP( 3), WK( 3)

IF( INPRT $) 810,810,811$.

HRITE( NH, 1006)

GO TO 815

URI IE( NW, 1007 )CHEM, EPRT, TNMER ( 4), ACP( 4), TCHEM, UK? 4)

URITE(NH, 1012)

IF ( INIIG ) $831,833,838$

WRITE(NH, 1013)

60 TO 835

URITE(NW, 1014)

GO TO 835

HRITE(NH, 1015)

URITE( NW, 1016 )TNMER( 5 ), ACP( 5 ), TC, HRTAG, FCONU, WK( 5 ), GPI, IIGPH

IF( INHEX) $841,341,842$

HRITE( NH, 1017 ) TNMER ( 6), ACP (6)

HRITE( NU, 1018 ) HREQM

IF( INIIHT )850,850,851

HRITE(NH, 1019)

GO TO 852

HRITE(NW, 1020)THMER( 7), ACP(7), WK(7)

IF( INGPU ) $860,860,861$

WRITE( NW, 1021)

GO TO 862

351: 861 HRITE(NW,1022)ACP( 8)

352: 862

353: C

354: C

355: C

356: C

357: C

358:

359:

CONTINUE

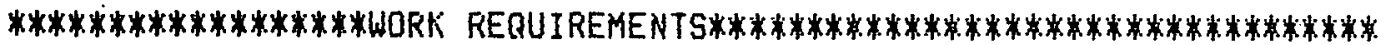

$T H K=0$

IF (INIIG LLT.1)GO TO 130

WK( 8$)=U K(8)$ *HRTIG/TNIIO 
365: C ********aLL SUBROUTINE to CALCULATE NET ELECTRICAL OUTPUT*************

$366:$

$367:$

$368:$

$369:$

370 :

$371: \mathrm{C}$

$372 \div \mathrm{C}$

373: C

374: 100

$375:$

$376:$

$377:$

378: 1002 EFFGEN $=+2$

CALL KUOUTS IIGPM, TUK, EFFGEN, ELPROI, ELUK)

WRITE (NW, 3000 IELFROD, ELUK', ELNET

CALL VARSET (NFW,ELNET)

RETURTI

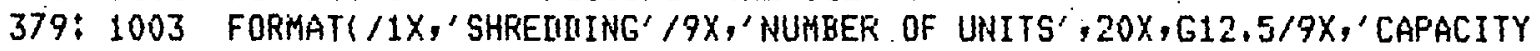

380 :

$381:$

382: 1004

383: 100

384: 1007

385:

386:

$387:$

$388:$

389: 1008

$390: 1009$

391: 1010

392: 1011

393:

394: 1012

395: 1013

396: 1014

397: 1015

398: 1016

399 :

400 :

$401:$

402:

403

$404:$

405: 1018

$406: 1019$

$407 \div 1020$

408 :

409 :

410: 1021

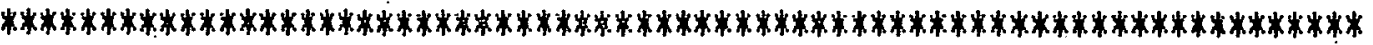

FORMATI 1HI///24X','SYSTEM PERFORMANCE'//1X,'FEEI COMFOSITION'//9X, *'TOTAL SOLIUI', $24 X, 613.6^{\prime}$ TONS/ 'D' /9X,'SOLIUS FRACTION',

*'IN FEEn', 14X,613.6/9X,' VOLATILE SOLIIIS FRACTION IN SOLINS', 3X,613.

*.6/9X,'HIOLEGR, VOL, SOL. FRACT. IN SOL. ',G13.6///)

FORMAT / $1 X$,'SHREIMING-NONE USEI')

*PER UNIT', $13 X, E 10,4$, 'TONS/HR' $/ 9 X$, 'POUER RERUIREMENT'

$\left.*, 20 X, E 11.4,{ }^{\prime} H P^{\prime}\right)$

FORMAT (2I3)

FORMAT( / $X$, , 'PRETREATMENT-NONE USEN')

FORMATY /1X,'PRETREATMENT' $19 X, '$ RATIO OF CHEMICAL TO FEEI' $13 X$

*,612.5/9X,'CONUERSION EFFICIENCY', $16 X, 613.6 / 9 X, '$ NUMEER OF UNITS',

*20X,G12,5/9X,'CAFACITY PER UNIT',13X,E10.4,'CU.FT,',/9X,

*'CHEMICAL REQUIREMENT', 10X,E10,4,'TONS/HR' /9X,'POWER',

*'REQUIREMENT', 20X, E11,4,' HF')

FORMAT( $/ 1 X$, 'HOLIIING-NONE USEI')

FORMAT( / $1 X$, 'HOLDING-NO MIXING')

FORMATI / IX,'HOLIING-MIXING')

FORMATY /9X,'NUMEER OF UNITS', 20X,612.5/9X, CAPACITY PER UHIT',13X,

*E10.4;'CU.FT.'/9X,'POWER REQUIREMENT', 20X,E11.4,' HF')

FORMAT( $/ 1 X^{\prime}$, 'DIGESTION')

FORMAT( $/ 5 X$, 'CSTR' $^{\prime}$

FORMAT / $5 X$, , PLUG FLOW')

FORMAT ( $/ 5 X,{ }^{\prime}$ BATCH')

FORMATY $9 X$, 'NUMEEF OF UNITS', 20X,G12.5/9X,'CAFACITY PER UNIT',13X,

* E10.4,'CU.FT. ' $/ 9 \mathrm{X}$, 'IIIGESTER TEMFERATURE', $16 \mathrm{X}, \mathrm{G} 11.4{ }^{\prime} \mathrm{C}^{\prime} \mathrm{C}^{\prime} / 9 \mathrm{X}$,'

*'RETENTION TIME', $21 X, 613.6$, 'IIAYS' $19 X X^{\prime}$ 'CONUERSION EFFICIENCY', $16 X$,

*613.6/9X,'POWER REQUTREMENT', 20X, E11.4,' HF'/

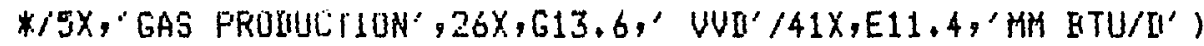

411: 1022 FORMATI1X,'GAS FURIFICATION'//9X,' CAPACITY FER UNIT', 13X,E10.4;

412: * (U.FT, / (I') $^{\prime}$ )

113: 1501 FORMAT(/1X,'STORAGE-NONE USEI')

414: 1502 FORTATL/1X,'STORAGE'/9X,'NUMEER OF UNITS',20X,612.5/9X,'CAPACITY'

415: *,'PER UNIT',14X,G13.6,' CU.FT.')

416: 2000 FORMAT( $/ 1 \%$,'TOTAL WORK REQUIKEMENTS ', G13.6,' HP')

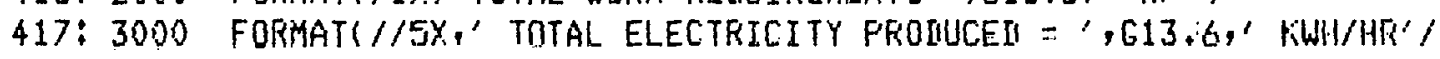

418: * 5X,' TOTAL ENERGY USEO = ",613.6,' KWH/HR''

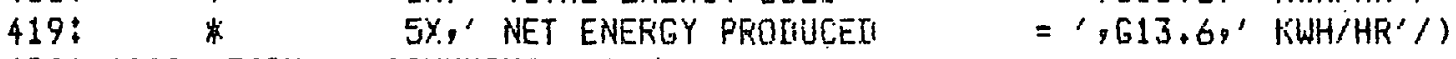

420:4000 FORMAT('ORUNRING...') 
421: 4001 FORMAT' ENTEF SYSTEM HEAIIEF-ONE LIHE-'/)

$422: 4002$ FORMAT (3SA2)

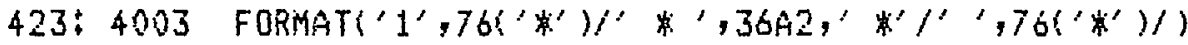

424: ENII

425: SUROUTINE KWOUT( IIGPM Y TWK, EFFGEN, ELPFOI, EL WK )

426: [ [NO FILEACCESS]

427: COMMON/KUFROU/ELNET

428: BTUZAY =ISPTH 1000000.0

429: AKUHFII=BTUIIAY $/ 3412$, OWEFFGEN

430: ELPFOR =AKWHE $[1 / 24.0$

431: $\quad$ ELWK $=$ TUK +746

$432: \quad$ ELNET $=$ ELFROLI-ELWL

433: RETUFN

434: ENE 
2: C [FILEACCESS]

3: C DATSET DEFAULTS VALUÉS FROM DISK FOR THE SELECTEU OPTION, THEN ALLOUS

4: C INSFECTION OR CHANGE OF THOSE VARIABLES. OTHER VARIAELE LISTS MAY BE

5: C DEFAULTEI FROM A IISTK FILE \& SUCH A FILE MAY BE URITTEN FOR THE

6: C. CURRENT LIST.

7: C IOPT 0 THEN PRINTS LIST TO CHANNEL \& SPEC IN IRET

8: C IRET IS 1 FOR NORMAL COMFLETION, O FOR ABORTEI RUN.

9: C IOPT) 100 THEN GETS FOR MOLULE (IOPT-100) DECSRIPTOR \& (IRET)

10: C IRET NOT SET IN THIS OPT

11:

$12:$

13:

14:

$15:$

16:

$17:$

18: C

19: C

$20: C$

21:

22:

23:

24:

25:

26: C

27: 5

28:

29:

$30:$ C

$31:$

32:

33: C

$34:$

35: C

36:

37:

38: C

39: C

40:C

41: C

42: C

43: C

44: C

45: C

46: C

47: C [RANION ACCESS]

IOPT=IOPT1

REAL XIN (1)

INTEGER IOPT, INDEX(15), ICHAR( 9 ), $\operatorname{BUF}(20)$

LOGICAL FIRST, IREUF

CORTON/IO/NTR, NTU, NMU 2O)

COMMON/RESET/FIRST(15)

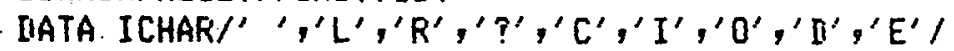

DATA NINDEX/11/

IRBUF $=$, FALSE,

IF( IAES( IOPT),LE. 100$) 60$ TO 5

IRBUF $=$. TRUE,

IOPT $=$ IOP T -100

IOUT $=$ IOPT

IOPT = IAES $($ IOPT ).

ICHAN = IRET

IOFFST $=$ IRET

I TEMP $=N T W$

IF( IOPT,LT, I, OR, IOPT, GT . NINIEX )GO TO 990

O100 THEN RETURN SPEC IIESCRIPTOR

THIS OPT NEEIS REC IH IRET,

XIN AT LEAST 10 LONG (IIESC HERE)

$N F=N I(20)$

NF ILE $=N M(10)$

IOFFST FOR \& FEC IN FILE IIESIREII IF IOPT 100

-1 THEN PRINT TO FILE SFEC IN IRET

48:

49: $C$

$50:$

$51:$

$52:$

$53:$

$54:$

$55:$

$56:$

$57: 10$

REAIN NF, 1020, REC=1)( INIEX ( I ), I=1, NINDEX)

58: 20

IF $1=0$

IRET $=1$

IPOPT $=1$

IF( IOPT.EQ.1)60 TO 20

IOPTT $=$ IOPT -1

II0 $10 \mathrm{I}=1$, IOPTT

IPOPT $=I P O P T+I N D E X(I)$

CONTINUE

INI INIEX (IOPT)

$59:$

$60: \mathrm{C}$

GET LENGTHS

THE FIRST RECORI OF THE IEFAULTS

FILE HAS THE LENGTH OF EACH

MODULES INFORKATION IN TERMS

OF RECORDS OF IIATA (EG. IF

XIN IS FIVE ELEMENTS LONG FOR

THE MOIUULE CALLING WITH IOPT $=2$,

THEN THE SECONI ELEHENT OH' THE

FIRST LINE HILL GE FIUE

IF . NOT , IREUF IGO TO 25

GET IEEFAULTS

GET RUF DESIREI ANI RETURN 


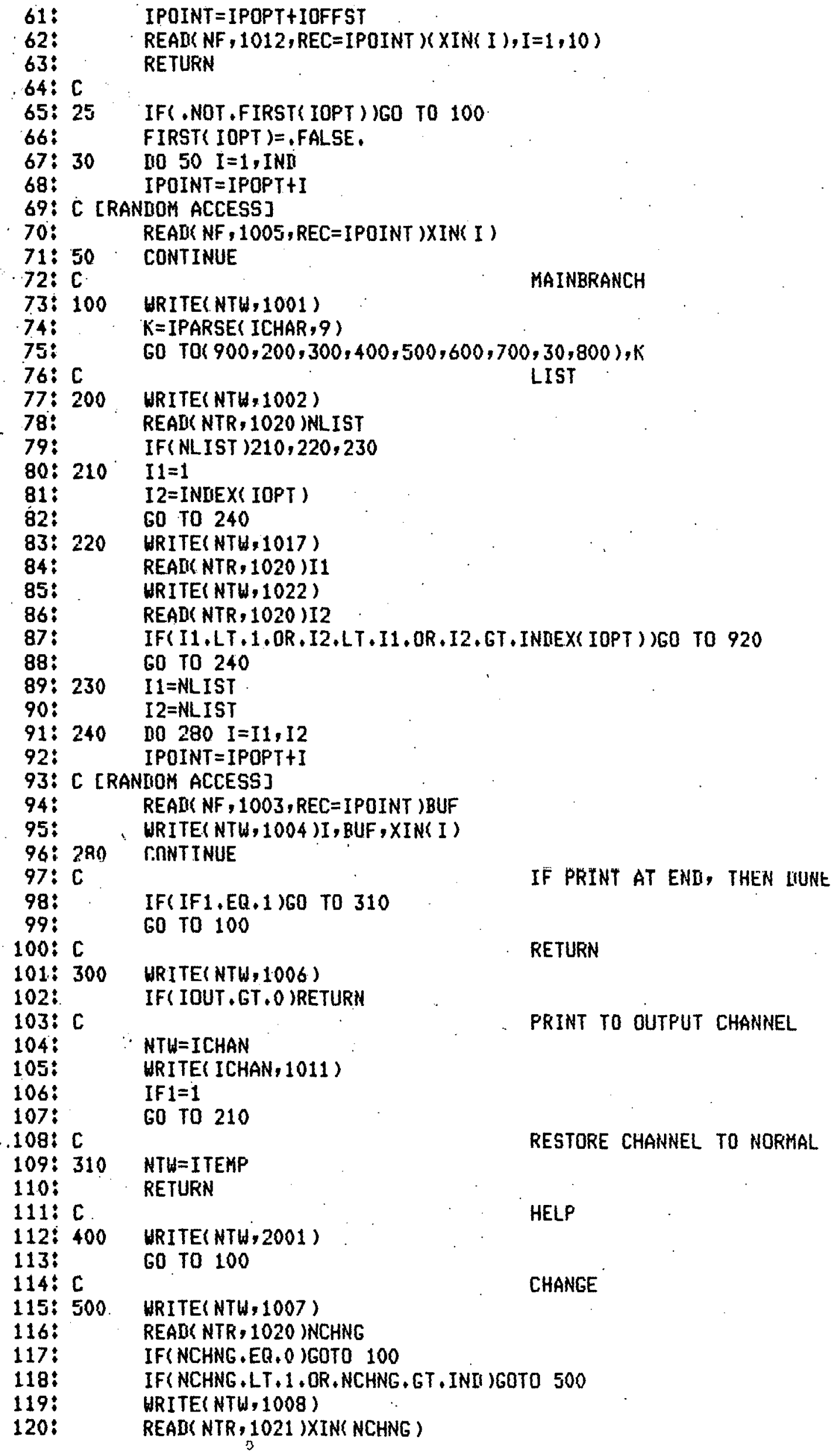

URITE(NTH,2001) 
123: 600 URITE(NTW,1025)

FILE INPUT.

12.4: C [FILEMARK]

125: CALL FOPEN NFILE, BUF, 1,0 , IRET $2,-1$, IUM1, IUM2 )

126:

127:

C [FILEMARK]

128: REAM NFILE, 1020, END $=930$ WOPT

129: IF( IOPT.NE.NOPT)GO TO 910

130: IND= INIIEX( IOPT )

131: $110650 \mathrm{I}=1$, IND

$132:$ [ [FILEMARK]

133: REAIY NFILE, 1026, ENI =930) XIN( I)

134: 650 CONTINUE

135: C [FILEMARK]

136: ENIFILE NFILE

137: GO TO 100

138: C

139: 700 WRITE(NTW,1009)

FILE OUTPUT.

140: C [FILEMARK]

$141:$

$142:$

143: C

$144:$

$145:$

$146:$

$147:$

$148:$

149:

$150:$

$151 \div 750$

CALL FOPEN NF ILE, BUF, 0,0, IRET $2,-1$, IUM1, IUU 2)

IF( IRET2, EQ.0)GO TO 100

152: C [FILEMARK ]

153:

$154:$

$155: C$

$156: 800$

$157:$

$158: C$

$159: 900$

$160:$

161: 910

162:

163: 920

$164:$

$165: 930$

166:

$167: \mathrm{C}$

168: 990

169:

WRITE(NTU,1010)

GET HEAIIER

REAIK NTR, 1003 IBUF

URITE( NF ILE, 1003) BUF

WR ITE (NF ILE, 1020) IOPT

INI = INUEX( IOPT )

I10 $750 \mathrm{I}=1$, IHI

URITE( NF ILE, 1026) XIN( I)

CONTINUE

\section{ENIFILE NFILE}

GO TO 100

170: $\mathrm{C}$

171: 1001

172: 1002

$173: 1003$

174: 1004

175: 1005

176: 1006

177: 1007

178: 1008

179: 1009

$180: 1010$

IRET $=0$

AEORT - RUN

RETURN

WRITE(NTW, 1015)

GO TO 100

WRITE(NTW,1016)

GO TO 100

URITE (NTW, 1018)

GO TO 100

URITE(NTW, 1019)

GO TO 100

URITE(NTW,1027)

INUALIII IOPT

STOP

FORMATI' INTERACTIUE INPUT OPTION: ')

FORMATl' TO LIST (O FOR RANGE, SO FOR ALL):')

FORMAT( 2OA2)

FORMAT!' ', I2,', ',20A2, 1X,G13,6)

FORMAT ( 40X,630.23)

FORMAT!' *ENI IIATA SET SECTION*'/)

FORMAT!" \# TO CHANGE (O TO ESCAPE): ')

FORMAT!' NEG VALUE:')

FORMATI 'OENTER INFORMATION ON OUTPUT FILE-',

FORMAT!' FILE HEAIER:', 
$131: 1011$

$182: 1012$

$133 \div 1015$

184: 1016

$185 \div 1017$

186: 1018

$187: 1019$

$138: 1020$

$189: 1021$

$190 \div 1022$

$191: 1024$

$172 \div 1025$

$173 ; 1026$

$174: 1027$

$175:$

$196:$

197:2001

19a:

197:

200:

201:

202:

$203:$

204:

205:

$206:$

$207:$

$208:$

$207:$

$210:$

211:

212:

213:

$214:$

215:

FORMAT( $/ / 1$ ', 12X, 'ASSUMPTIONS FOR THE ANALYYSIS'/13X,28('-'))

FORHAT (10A4)

FORTAT" WTYPE? FOR HELP*')

FORMATI' WFILE FOR WRONG SYSTEM TYPE*')

FORMATI' FIRST LINE \#:')

FORMAT' ' WNUALII UALUES FOR LIST RANGE"')

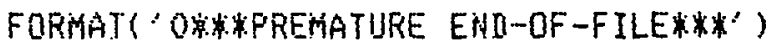

FORHAT (15T3)

FOENAT $(630.23)$

FOEMATI" LAST LINE \#:')

FORIVAT (IIAA)

FOFHAT! 'OENTER INFORTATION ON INFUT FILE-')

FORMAT $(G 13+6)$

FORTAT' OWW*ERROR IN IOPT CALL TO IIATSET',19X,'***',

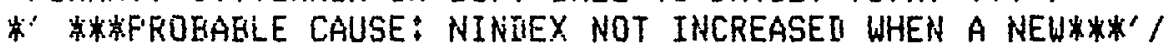

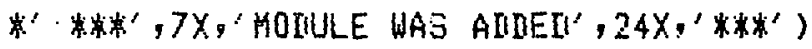

2001 FORMAT' OTHIS IS THE INTERACTIVE INPUT SECTION.'

" AVAILAELE COMMANIS TNCLUIE:"

\$SX,'L(IST) -LISTS VAFIAELES, IF YOU RESPONI TO THE'/

\$10X,'FOLLOWING FROHPT UITH A POSITIVE \#, THAT LINE WILL HE'

*10X, LISTEI. IF THE NUMHER IS LESS THAN ZERO, ALL LIHES WILL'/

* 10X: "EE LISTEN. ENTRY OF A ZEFO CAUSES YOU TO HE PROMPTED'

*10X, FOR A RANGE TO LIST.',

$* 5 X$, C(HANGE) -CHANGES VARIAELES, YOU WILL BE PROMPTEI FOR'

"10X.'THE \# OF THE VAKIABLE TO CHANGE ANII THE NEW VALUE.'/

WEY'RIUA) -RETURNS TO SIMULATION MOIULE TO EXECUTE WITH'I

W $10 X^{\prime}$ : VARTAEIES AS SPECIFIEI IN THIS SECTION.' 1

W5X."IINFUT) -SETS IATA FFOH A PREVIOUSLY "OUTPUT" FILE'

\$5X, OIUTFUT) -SAUES CURRENT IIATA TO FILE, SUITABLE FOR',

W" LATER "INFUT"."

W.5X' 'IV EFAULT )-RESETS TO DEFAULTS. THIS IS IONE'/

WOX, AUTOHATICALLY ON THE FIRST RUN FOR EACH SIMULATION' WLX: HOIULE."

WSX,'E(NII) -AEORTS THIS SECTION WITHOUT PROCEEIING WITH RUN'/) ENO 





1: INTEGER FUNCTION IPARSE( IRAY, LEN)

2: C [NO FILEACCESS]

3: C IPARSE DETERHINES WHICH OF A PASSEI ARRAY OF CHARACTERS IS ENTEREI

4: C AS A RESPONSE. IF CORRECT ENTRY FAILS TUICE, A SFECIAL COIE OF 1

5: C (NUMERIC ONE) IS RETURNEI; ELSE THE POSITIOH OF THE ENTEREI CHARACTER

6: C IS RETURNEI. THUS THE FIRST CHARACTER OF THE PASSEII ARRAY SHOULII BE

7: C BLANK, AS IT IS A IUMMYY. IF LEN IS NEGATIUE, NO FROMPT IS HADE, \&

B: C NO SECONI INPUT IS ALLOWEN.

9: $\mathrm{C}$

10: C ILEN -ABSOLUTE VALUE OF LEN

11: C IFLAG-MARKS FOR SECONI FAILURE

12: C IRAY -PASSEI CHARACTER ARRAY

13: C LEN - OF CHARACTERS TO HE SEARCHEI IN AFFAY

14: C IN -USER RESPONSE

15: C

$16:$

$17:$

18:

19: $\mathrm{C}$

$20:$

21:

22:

23: $\mathrm{C}$

$24: 100$

25:

26: 150

27: C

28:

29:

$30: 200$

31: $\mathrm{C}$

32: $\mathrm{C}$

$33:$

$34:$

$35:$

$36:$

$37:$

38: 1001

39: 1002

40: 1003

41:

$42: C$

43: $C$

44: $\mathrm{C}$

45:

46:

C [NO FILEACCESS]

INTEGER LEN, IRAY (LEN), IN, J, ILEN

LOGICAL IFLAG

COMMON/ IO/NTR, NTW, NIU 20)

IFLAG $=$, FALSE,

IF $(L E N, L T, 0)$ IFLAG $=$, TRUE,

ILEN=IABS ( LEN )

IF(LEN.LT. O)GO TO 150

PROMPT

WRITE( NTH, 1001) (IRAY 3$), \mathrm{J}=2$, ILEN)

REAU (NTR, 1002)IN

DO 200 IPARSE $=2$, ILEN

LOOP TO SEARCH FOR IHPUT CHAR

IF( IRAY IPARSE),EQ. IN )RETURN

CONTINUE

IPARSE $=1$

NO MATCH AT ALL

CHECK FOR SECONI FAILURE

IF ( IFLAG )RETURN

IFLAC $=$. TRIIF.

WRITE(NTW, 1003) (IRAY ( J), J=2, ILEN)

GO TO 100

FORHATY' Y',10(A1,':'))

FORHAT(A1)

FORKAT!' ENTER ONE OF THE FOLLOUING: ', $10{ }^{\prime \prime \prime \prime, ~ A 1, ' ", ') ~}$

END

47:

48:

$49:$

$50:$

$51:$

$52:$

$53:$

$54:$

$55:$

C STATISTICAL FUNCTION FOR WIND SIMULATION

REAL G(101),KO,F, AHUL, FP

INTEGER I

IATA G $/ 1,0, .9943, .9888, .9936, .9784, .9735,, 9687, .9642,+9597, .9555$,

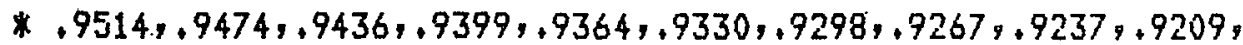

*.9182,.9156,.9131,.9108,.9085,+9064,.9044,.9025,+9007,.8990,

*.8976,.8960,.8946,.8934,+8922,.8912,.8902,.8893;,8885\%,8879,

*.8873,.8868, .8864,.8860,.8858,.8857,.8856,.8856, .8858, .8860,

* .8862, .8866,.8870,.8876, ,8882,.8887,.8896,.8905, .8914, +8924,

*.8935,.8947,.8959,.8972,.8986,.9001,.9012,.9033,+9050,+9088,

*.9084,.9106,.9126,.9147,.9168,.9191,.9214,.9238,+9262,+9288,

*.9314,.9341,.9369,.9397,.9426,.9456,.9487,.9518,.9551,.9534,

$*+9618, .9652, .9688, .9724, .9761, .9799, .9838,+9876,+9917, .9958$,

* 1.01 


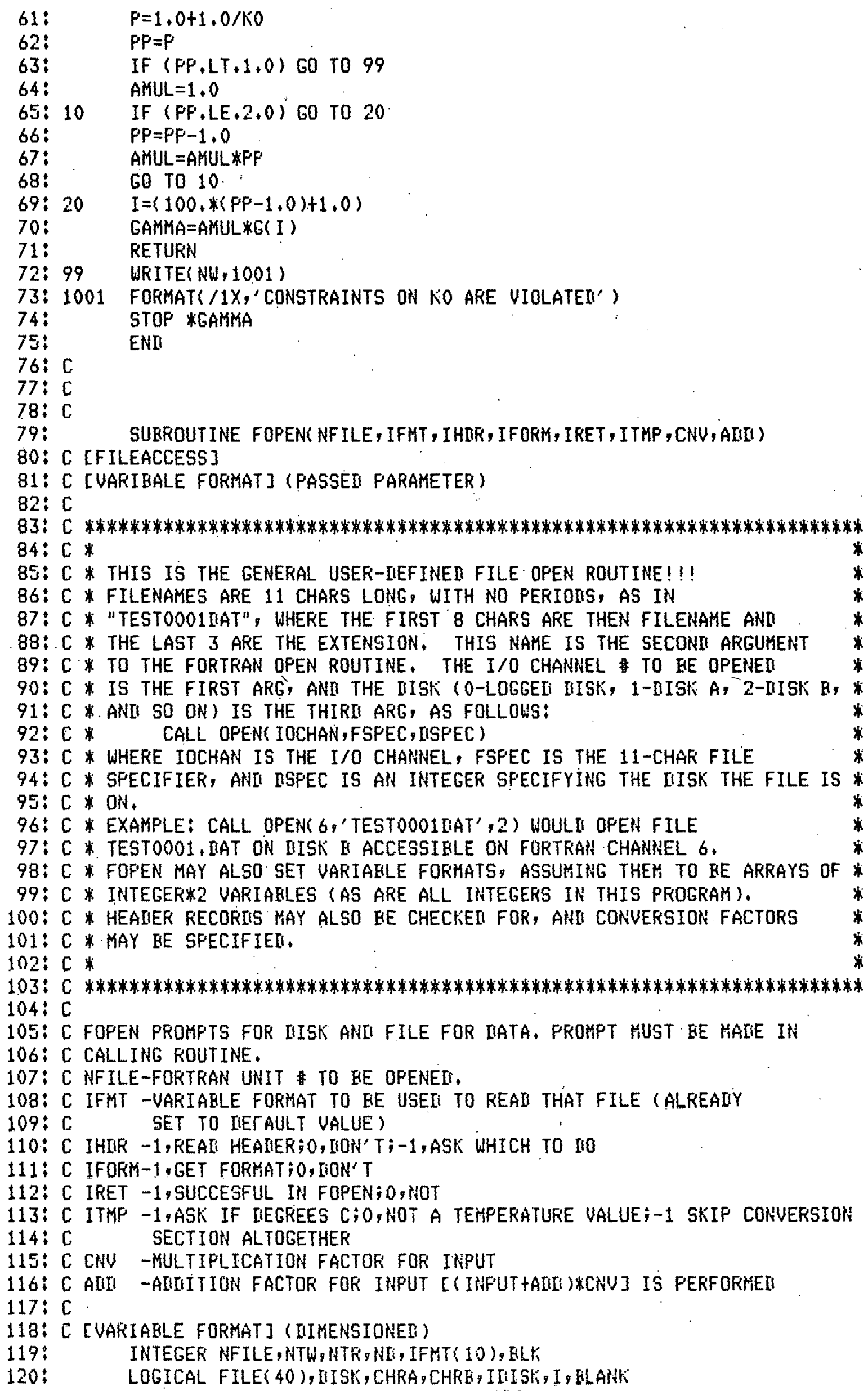


121: COMMON/IO/NTR, NTW, NM 20)

123: C

$124:$

$125:$

$126: C$

127: 1

$128:$

$129:$

$130:$

131:

132:

$133: 10$

134:

135: C

$136: C$

$137:$

138:

139: 15

$140: C$

$141: \cdot \mathrm{C}$

142:

$143:$

$144:$ C [FILEMARK]

145: 17 CALL OFEN( NFILE, FILE, IIISK)

$146: C$

$147: C$

148:

$149: C$

$150 \div 18$

151 :

$152: 19$

153:

$154: C$

155: 20 (F(IFORH ) $40,40,25$

$156: C$

157: C [VARIAELE FORMAT] (WRITTENS OUT)

158:25 HRITE(NTW.1006)IFHT

159: IF(NOYES(1).EQ.1)GO TO 40

160: WRITE(NTW91009)

161: C [UARIAELE FORMAT] (REAI IM)

162: REAIM NTR, 1007)IFHT

16.3: IIO $30 \quad I=1,10$

$164:$ C [VARIAELE FORYAT] (COHFAREII)

165: IF(IFMT(I), HE, ELLK) 60 TO 40

166: 30 CONTINUE

$167: C$

168:

169:

$170: C$

171: 40

172:

173:

$174: C$

$175: 45$

IRET $=0$

RETURiN

$176:$

$177: \mathrm{C}$

178:

AIII $=0.0$

CNU $=1.0$

IF ( ITHF ) $900,60,45$

IF BLAIKK FILEHAHE SPECIFIEN, RETUR:!

FLATH FILETIATEE, SO ETIII

HITH U:TSUCCESSFUL CONE

SKIP IF HEAIER NOT SPECIFIEII,

OR REAII, OR ASK LHHAT TO IO

ASK IF REAII HEAIIEK

ASK FORHAT ORLY IF SPECIFIEI

GET IATA FORHAT

ELATK FORKAT-EHT UHSUCCESSFUL

CORVERSIOHS

IIO TEMFERATURE CORUERGIOT:

URITE( NTW:1010)

IF(NOYES( 1 ). EQ.1)GO TO 50

AIIi $=(-32.0)$

III FAREIHEIT 
$C N V=.555555$ 
181:C

$182: 50$

183: C

184: 60

$185:$

$\because 186:$

$187:$

$188:$

189:

$190: 900$

191: C

192: 990 URITE(NTW,1005)

193: C [FILEMARK]

194:

195:

196:

$197:$

$198:$

199: C

$200: 1001$

$201 \div 1002$

202: 1003

203: 1004

$204: 1005$

205: 1006

206:

$207: 1007$

208: 1008

209:

210: 1009

211: 1010

212: 1011

213:

214:

215: 1012

216: 1013

217: 1014

218:

219: C

220: C

221: C

222:

223:

[NO FILEACCESS

224: C VARSET ALLOWS A DIURNAL OR MONTHLY VARIATION IN PRODUCTIOH:

225: C LEVEL OF AN OTHERUISE CONSTANT PROCESS.

226: C IT OUTPUTS THE FACTOR BY HOUR

227: C AND/OR HONTH AS NEENEI.

228:

229:

230: C

231:

232:

$233:$

234: 600

235:

236: 1009

237:

238: C

239: C

$240: C$
IN CENTIGRAIIE

GENERAL CONUERSION

ERROR MSG
ENDF ILE, NFILE

$K=K+1$

IF $(K, E R .1) G 0$ TO 1

IRET $=0$

FORKATI! OIISK OF IIATA FILE(A/B):')

FORMAT( 40A1)

FORHAT!' FILENAME( 11 CHARS, NO PERIOD: ELANK TO ESCAPE):')

FORHATI' HEAIER: ', 40A1/)

FORKAT('O***FILE NOT FOUND***'/)

FORMATI" DO YOU WISH USE THE DEFAULT DATA FORMAT?',

(1X,10A2)

FORMAT (10A2)

*' ("YES" SHOULII BE THE IIEFAULT CONIIITION)')

FORHAT(' ENTER NEH FORKAT (INCLUIING PARENS: HLAHK TO ESCAPE):'/)

FORHAT(' IS THE IATA IN CENTIGRAIIE? ("NO" FOR FARENHEIT)')

FORMATI" DATA MAY BE ADJUSTEII BY THE FORMULA:'/

*' FINALDATA=( RAULATATAIIIFACTOR )*HUL TFACTOR' /

*'Oenter factor to and to raw inata:')

FORMAT $(613,6)$

FORMAT!' ENTER FACTOR TO MULTIPLY IIATA GY AFTER AIIUITION:')

FORMAT!' IS THE DATA IN THE PROPER UNITS? (AS SFECIFIEI AEIOUE)')

END

REAL HFAC( 24 ), MFAC( 12 )

COHMON/IO/NTR, NTW, NIY 2O)

10. $600 \mathrm{I}=1,12$

no $600 \mathrm{~J}=1,24$

HRITES NFH, 1009 JPROI

CONTINUE

RETURN

FORMAT $(613.6)$

END 
241: SUBROUTINE GENOUT( IOPT, XIN, NUN, NW, HODNUM)

242: C GENOUT IDES GENERALIZEI OUTPUT FOR SIMULATION MOIELS:

243: C IOPT -SPECIFIES OPTION FOR PRINT:

$244: C$.

245: C

246: C

247: C

1) PRINT TOP LINES UP. TO HEAIER(HEAIIER PRINTEI IN CALLING ROUTINE)

2) PRINT INPUTS ANI RIGHT UP TO OUTPUT(ALSO IN CALLING ROUTINE)

248: C XIN -INPUTS ARRAY USED TO CALL IATSET IN CALLING ROUTINE

249: C MOLHUM-MOIULLE \#

250: C NUM - ELEMENTS IN XIN

$251: C$

252 :

253: C

REAL XIN(1), EUF( 10)

254: C

255:

$256: \mathrm{C}$

$257: 100$

258:

$259:$

260 :

261: C

$262: 200$

263:

$264: \mathrm{C}$

265:

266 :

$267:$

$268:$

$269: 250$

270 :

$271:$

272:

273: C

$274: 300$

$275:$

$276:$

$277:$

$60 \mathrm{TO}(100,200,300)$, IOPT

BRANCH TO EXECUTE OFTION

WRITE(NW, 1006)

WRITE( NH, 1001)

WRITE(NW, 1002)

RETURN

WRITE( NW, 1002)

PRINT INPUTS

WRITE(NH, 1003)

TOP OF PRINTOUT

IIO $250 \quad I=1$, NUH

LOOP THROUGH INPUTS

MTEMP $=$ MOLINUH +100

ITEMP $=$ I

CALL IIATSET( MTEMF, RUF, ITEMP)

WRITE $(N H, 1004) I,(\operatorname{BUF}(J), J=1,10)$, XINU I )

WRITE $(N L, 1002)$

WRITE $(N H, 1005)$

RETURN

WRITE(NH, 1005)

WRITE (NH, 1002)

WRITE $(N H ; 1001)$

$278: \mathrm{C}$

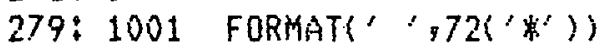

280: 1002 FORHAT', $\left.{ }^{\prime}, 70 x_{9}^{\prime} *^{\prime}\right)$

281: 1003 FORMATS * INPUTS:',61X,'*')

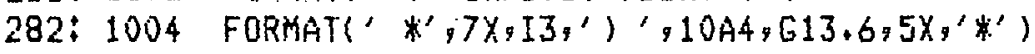

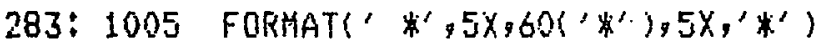

284: 1006 FORHAT' '1')

285: EसD

$286: C$

287: C

$288: C$

$289:$

INTEGER FUACTION HOYES( J)

290: C. [NO FILEACCESS]

291: C NOYES RETUR'NS O IF THE AHSWER IS HO, 1 IF IT IS YES.

292: C THERE IS NO FFOUISIOH FOR OTHER FESFOHSES.

293: C IF I IS NEGATIVE, HO FROMPT IS MAIIE.

$294: \mathrm{C}$

$295:$

IHTEGER IC( 2$)$, IN, I, J

296:

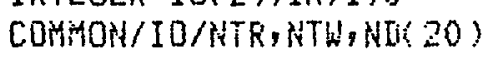

297 :

$298: C$

299: $\mathrm{C}$

IIATA ILI'N', 'Y'I

FOTTOH OF PRINTOUT

$300: 50$

PROHFT

IF (J,GE,O)WRITE(NTH,1001) 
301: REAIINTF, 1002)II

$302 \div C$

$303:$

$30.4:$

$305:$

$305 \div 100$

$307: \mathrm{C}$

$308:$

$309: \mathrm{C}$

310 :

$311:$

$312 \div 1001$

$313 \div 1002$

$314 \div 1003$

315:

Iii) $100 \cdot I=1,2$

NOYES $=I-1$

COHTIUUE

WRITE(NTW.1003)

IFU.LT. OSGTOF

60 TO 50

FORHAT(AI)

EVII
LOOF TO IBEHTF IFFUT CHAR

IFI ICI I . EQ, IH RETURH

FORYAT:' (HQY):')

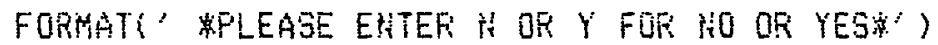

HO HATCH HT ALL

IF HO PROHFT; TERHIHATE(FILE REAI EFRON) 
1: FROGRAM IAANIL

2: C [FILEACCESS]

3: C DAANIL IIERATES PERFORMANCE ON A LEVEL, HOUFLY, ANI MONTHLY EASIS, IT.

4: C THEN INTEGRATES A SPECIFIEII LOAII UITH THE FERFORIMANCE TO IIETERMINE

S: C NET ELECTRICITY BOUGHT, SOLII ANI PROIUCEII.

6: C. [VARIABLE FORIAAT] (IIIMENSTONED)

7: INTEGER IFORM (T 10), IFMT(10), IFMT2(10)

8: REAL HOURF( 24 ), HOUFL ( 24 ), IHOURP( 24), DIIAILY( 24 ), IIMONTH( 12 ), *IIAYS: 12 ), ILLEVEL LOGICAL FLAGHK 2), FLAGI( 2 ),FLAGDK, FLAGUII

COMHUN/IO/NTR, NTW, RIV 20 )

COMMUN/UAT/MINMOI, MAXMOI

IIAIA IIAYSS $\$ 31.0,28,0,31.0,30.0,31.0,30.0,31.0,31.0$,

$\$ 30,0,31.0 \times 30,0,31.01$

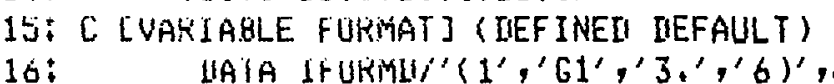

$16:$

17: $\mathrm{C}$

18:

19:

$20 \%$

i1:

223

$23:$

24 i

$25:$

$26:$

21:

$28:$

$27:$

$N P R=N I(1)$

NLR $=N$ NII 2 )

NF $U=N I(3)$

$N$ Ni $=N I(4)$

$k=1$

CAUPER $=1.0$

AUIUPER $=0.0$

CNVLOA $=1.0$

AIIILOA $=0.0$

III) $98 I=1,20$.

SET FORHAT TO DEFAULT FORMAT

[ [VARIABLE FORMAT]

IFMT2(I) =IFORHIC I )

31: [C [VARIABLE FORHAT]

32: 98 IFMT( I ) =IFORMI( I)

33: WRITE(NTW,1001)

$34 \div \mathrm{C}$

35: 99 WRITE(NTW,1034)

36: IF(NUYEST 1 ), EQ.1)60 TO 2

37: C

38: $\quad$ PLALGK $=$,FALSE,

39: MUUEL $=1$

40: $1101 \mathrm{I}=1,24$

$41: 1 \cdot \operatorname{HOURL}(I)=0.0$

42: . 60104

$43: \mathrm{C}$

$44: 2$

$45:$

$46 \div c$

$47:$

$48: 3$

49:

$50 \div \mathrm{C}$

$51:$

$52:$

$33:$

$54 i$

WRIIE(NTW, 1035)

SEE IF ENTERED FKOH TERHINAL

IF(NOYES( 1$), E(S .0) 60$ TO 21

SEE IF DESIRED TO ENTER LOAI

IIEFAULT LOAII TO ZERO

FLAGLIK $=$, FALSE,

YES, ENTER FROM TERMINAL

WRITE(NTW, 1036)

REALI NIU, 1013 MOIEL

IF MULLEL +LT, 1, OR, HOUEL, GT , 2)GO TO 3

ONLY MODES $1 \& 2$

$L=$ MUUIEL -1$)$ ) $23+1$

IiU $19 I=1, L$

WKITE(NTW, 1037)I

55: REALINTR, 1021 HOURL(I)

$56: 14$ CONTINUE

$5 \%: \quad 60104$

58: 6

$54 \div 21$

60 :

FLAGIIK= . TRUE .

GET FRON FILE

WRTTF( NTW+1002) 
$65: \quad$ DO $1=1,24$

66: 5 CONTINUE

67: $006 I=1,12$

68: DNONTH( I ) $=1.0$

69: 6 CONTINUE

70: ILEUEL $=1.0$

71: URITE(NTH;1004)

72: IF(NOYES( 1),EQ.0)GOTO 10

73: WRITE(NTW,1005)

74: REAIN NTR, 1021 IILEVEL

75: 10 URITE(NTW,1007)

76: IF(NOYES( 1$), E Q .0)$ GOTO 20

77: WRITE(NTW,1008)

78: $1015 \mathrm{I}=1,24$

79: URITE(NTW,1009)I

80: : REAII NTR, 1021 JIIAILY(I)

81: 15 CONTINUE

82: 20 HRITE(NTW,1010)

83: IF (NOYES (1),EQ.0) GOTO 28

84: WRITE(NTW,1011)

85: $\quad$ I0 $25 \mathrm{I}=1,12$

86:

87:

$88: 25$

89: C

90: 28 FLAGSH $=$, TRUE,

91: URITE(NTW,1029)

92: IF(NOYES( 1),EQ,1)GO TO 35

93: 29 WRITE(NTW,1038)

94: C [FILEMARK] [VARIABLE FOKMAT] (PASSEI FARAMETER)

95: CALL FOPEN NPR, IFHT, $-1,1$, IRET 2, 0, CNUPER, ADIIFER)

96: IF(IRET2,EQ.0)GO TO 28

97:. HRITE(NTW,1039)

98: FLAGSH =,FALSE,

99: IF(NOYES 1 1),EQ.1)GO TO 40

100:31 URITE(NTW,1042)

101: REAUCNTR, 1013 MOIEP

102: FLAGSH $=$, TRUE.

103: C

$104:$

105: C

106: $\mathrm{C}$

107:

108: C [UARIABLE FORMAT] (FASSED PARAMETER)

109: 32 (ALL MODE10 (NFR, IFHT)

110 :

111:

$112:$

113: C

$114: 33$

$115:$

CALL OPENY NPR,'SYSSIMULIIAT', 2)

REAIK NPR, 1013 , ENII $=991$ ) MODEP

60 TO 41

CHECK TO SEE IF USER-IEFINEU FILE

MOLNUK $=0$

MARK AS USER-DEFINED FILE

IF MOIIE 10, AGGREGATE INTO MOUE 3

IN DEFAULT FILE AND PROCESS NOMALLY

$116: C$ CFILE)

117: 35 CALL OPEN NFR,'SYSSIMULDAT', 2 )

118: 40 REAIK NPR, 1020, ENII=991) MODEP, MODNUM
$119: 41$. IF(FLAGSH) 60 TO 42

119: 41 . IF(FLAGSM) 60 TO 42

120 : MOLNUM $=0$

IF ILLEGAL MODE, ASK AGAIN IF ( HOIEF , LT , HINYON, OR, MODEF, GT . MAXMOD )GO TO 31 60 TO 45

EHARK ] 
121: C

122: 42

123: $\mathrm{C}$

124:

125:

$126:$

127 :

128:

127: 4

130: C

131: C [FILEMARK]

$132:$

133: C

134:

135:

136: C

137:

138 :

139:

140 :

141: C

142:

143: C

144: C

$145: C$

146: C

147 :

148:

149:

$150:$

151:

152 :

$153:$

$154:$

$155:$

$156 \div 50$

157: 100

158:

159: C

$160 \div 200$

161:

$162 \%$

163 :

164 :

$165:$

$166:$

$167 \div 220$

168:

169:250

170:300

$171:$

172: C

173: 400

$174:$

1754

176:

$177^{\circ}$

178:

$179:$

$180: 410$

GO TO 41

MOSE $=3$

CONTINUE
IF (MOIEF, NE, 10$) 60$ TO 45

CHECK TO SEE IF HOUR EY HOUK

YES, SO AGGREGATE INTO IIEFAULT FILE

\section{[UARIABLE FORMAT] (FASSEU PARAMETER)}

CALL HODE 10 (NPR, IFMT)

CALL OPEN(NFR,'SYSSIMULIIAT',2)

REALI NPR, 1013 , ENII=991) MODEF

45 IF (FLAGUK IREAUU NLR , 1013, ENII=992 MONEL

OPEN IIATA OUT FILE

CALL OPEN NFW,'LOAIOUTIDAT',2)

WRITES NFW, 1020 MOIE, MOIINUM

FLAGM( 1 ) = .TRUE .

OUTPUT IS ALHAYS HODE 3

FLAGM 2 ) = ,TRUE.

FLAGL( 1 )= .TRUE.

FLAGI $(2)=$. TRUE.

WRITE $(N T W, 1045)$

LOOP. TO HANULE MULTIPLE RUNS

NOTIFY THAT EXECUTION IS PROCEEUING

INTEGFATE LOAD \& PERFORMANCE, ONE AGGREGATE

MONTH AT A TIHE; IIERATE LOAII FIRST

L10 600 MONTH $=1,12$

GET PERFORMANCE

IF( . NOT . FLAGKI 1) )60T0 200

II0 $100 \quad I=1,24$

IF( . NOT . FLAGD (1))GOTO 50

[UARIABLE FORMATT]

REAIR NFR, IFMT, ENI $=993$ )HOURP( I)

HOURP (I )= (HOURF( I ) +AIIIPER ) KCNUPER

IF (MOUEP + LE + I)FLAGM 1$)=$, FALSE.

GOTO 100

HOURP $(I)=$ HOURP $(1)$

IF ( MOUEF, LE, 2 IFLAGM 1) = FALSE,

IF( . NOT. FLAGM 2 ) )GOTO 400

II0 $300 \quad I=1,24$

IF( . NOT . FLAGII 2) )GOTO 250

C. [UARI ABLE FORMAT]

IF . NOT. FLAGIK IGO TO 220

REAIU NLR, IFMT2, ENII $=994$ ) HOURL(I)

HOURL (I ) $=$ ( HOURL ( I ) +AIIILOA ) *CNULOA

IF ( MOIEL . LE, I )FLAGII 2 ) = ,FALSE 。

GOTO 300

HOURL (I )=HOURL(1)

CONTINUE

IF ( MOIIEL, LE, 2 IFLAGH( 2 ) =,FALSE,

INTEGFATE

Ii] $500 I=1,24$

IHOURF (I )=HOURP( I ) *ILEVEL *IIIAILY( I ) WIMONTH( HONTH)

BOUGHT $=0.0$

SOLII $=0.0$

ANET = (HOURL(I)-IHOURP( I ) *IIAYS! HONTH)

IHOURP (I) =IHOURP( I ) WIAYS S MONTH)

IF( ANET $) 410,430,420$.

SOLII $=(-1.0)$ WAHET 


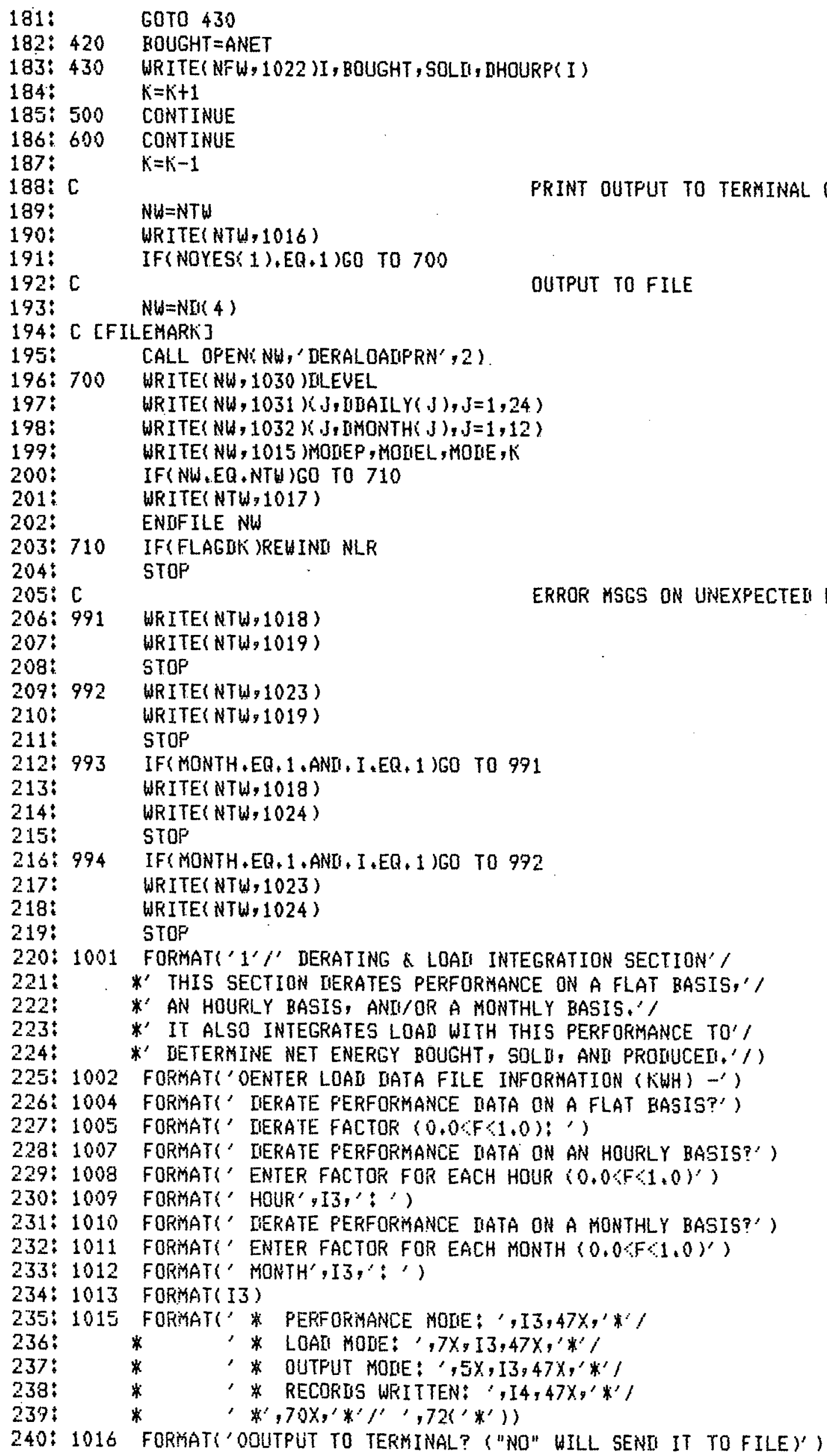


241: C [FHLEMARK] (FILENAME)

242: 1017 FORMATI'OFRINTOUT IN FILE "IIERALOAU,PFN"'/)

243: 1018 FORKAT( 'OW

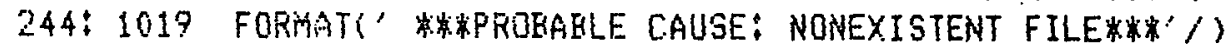

245: 1020 FOFMAT(213)

246: 1021 FORMAT $(613.6)$

$247: 1022$ FORMAT $(12,3613,6)$

243: 1023 FORMAT'OOWWERFOF IN LOAU FILE REAU

$249: 1024$

$250:$ \$

$251: 1025$

FORMATS ON"WERROR IN LOAII FILE REAII

FOFHAT!" WFROBABLE CAUSE: INSUFFICIENT

事事)

" FORMAT(AD)

IIATA POINTS IN FILE

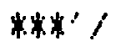

FORMAT(A1)

252: 1026 FORMAT'OWWLARNING: EXCESS IIATA FOIHTS AT

253: * ENI OF PERFORMANCE IIATA FILE.

25 q: $^{2}$

$255 \div 1027$

* * RUNS CONCLUDEI NORMALLY

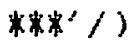

256

$257:$

$259: 1028$

FORMATI'OWWHARNING: EXCESS IIATA FOINTS AT

w W WNI OF LOAII IIATA FILE.

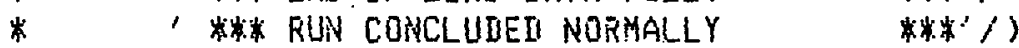

$250^{\circ} 1029$ FORMAT ODERATING AN. LOAI INTEGRATION SECTION CDNCLUIECI

$260:$ 'WHE SIMULATION SECTION?')

26l: 1030 FORMAT('1'/' ',72!'*')/' *', 70X,'*';

262: * IIERATING ANI LOAII INTEGRATION SECTION, $31 \times, * 1$

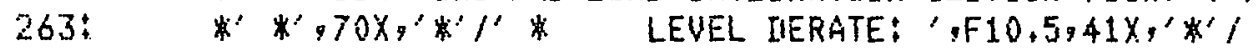

264: W' $970 x^{\prime},^{\prime} w^{\prime}$ )

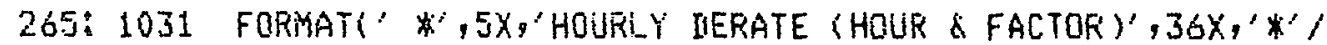

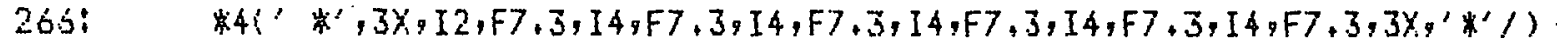

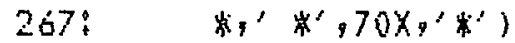

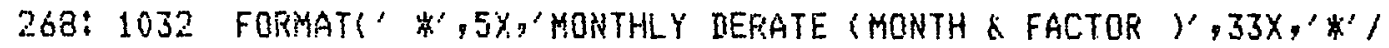

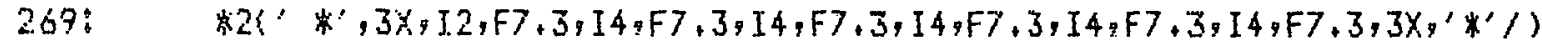

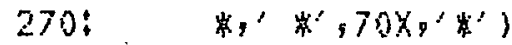

271: 1034 FORMATS' ID YOU UISH TO HAVE A USER LOAI INTEGRATEI?';

272: W' "YES" SHOULI GE USEI FOR NET SELLEACK IETERMINATIONY')

273: 1035 FORMAT?' 'IO YOU UISA TO ENTER THE LOAI FROM THE TERHINAL?',

274: " ("NO" WILL RESULT IN IISK REAII PROMFTS)')

$275: 1035$ FOFTAT: 'MUIE FOR LOAUI IATA ( 1 OR 2 ONLY)?')

276: 1037 FORMATS" ENTER USER LQAAII FOR HOUR', 13,'(KUH):')

277: 1038 FORMAT: ENTER PERFORMANCE IIATA FILE INFORMATION (KUH/HOUR) -')

278: 1039 FORTAMT( IOOES THE FILE HAUE A HOLE A'S ITS FIRST RECORLI?')

279: 1042 FORMAT!' ENTER MOIE THE IIATA FILE IS IN $(1-3$ OR 10):')

280: 1045 FORMAT' OFUNHING..'')

$281:$

ENIO 


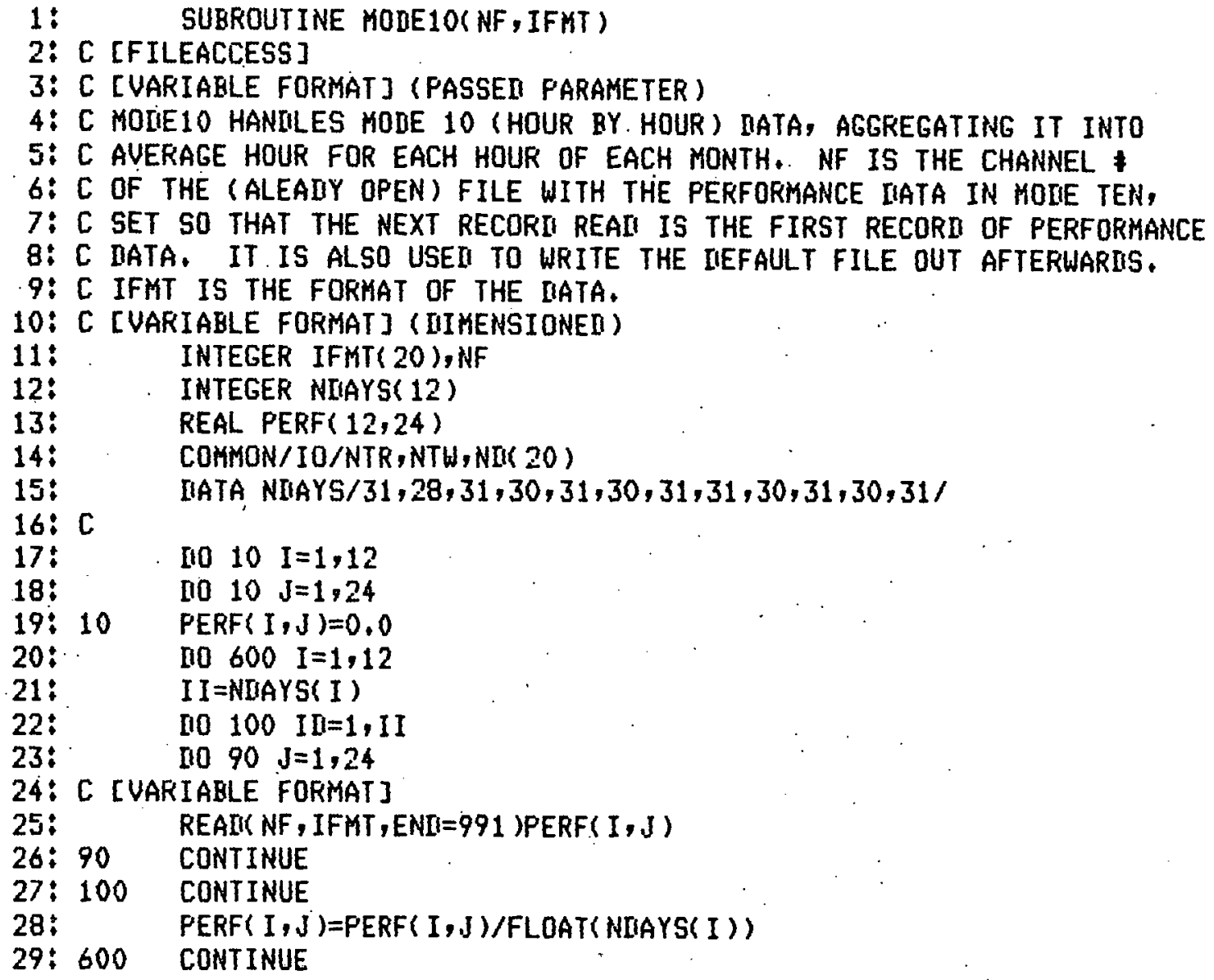

4: C MOTIE10 HANILES HODE 10 (HOUR BY. HOUR) MATA, AGGREGATING IT INTO

5: C AUERAGE HOUR FOR EACH HOUR OF EACH MONTH. NF IS THE CHANNEL \&

6: C OF THE (ALEAIY OPEN) FILE WITH THE PERFORMANCE IIATA IN HOIE TEN,

7: C SET SO THAT THE NEXT RECORII REAII IS THE FIRST RECORI OF PERFORMANCE

8: C BATA. IT IS ALSO USEI TO WRITE THE IIEFAULT FILE OUT AFTERWARIS.

9: C IFMT IS THE FORMAT OF THE IIATA.

10: C [VARIAELE FORMAT] (IIIMENSIONED)

11: INTEGER IFMT( 20), NF

12: INTEGER NIIAYS( 12)

13: REAL PERF $(12,24)$

14: COMMON/IO/NTR,NTH,NM(20)

15: IIATA NIIAYS $/ 31,28,31,30,31,30,31,31,30,31,30,31 /$

16: C $11010 \quad I=1,12$

$18: \quad$ II0 $10 \mathrm{~J}=1,24$

19: $10 \quad \operatorname{PERF}(I, J)=0,0$

$20: \quad 110600 \quad I=1,12$

21: II NIIAYS( I)

22: I10 $100 \quad I I I=1, I I$

23: $\quad$ I0 $90 \mathrm{~J}=1,24$

24: [ [UARIABLE FORMAT]

25: REAIN NF, IFMT, ENII=991)PERF $(I, J)$

26:90 CONTINUE

27: 100 CONTINUE

28: PERF $(I, J)=$ PERF $(I, J) / F L O A T(N I I A Y S(I))$

29: 600 CONTINUE

30: $\quad$ REAIM NF, 1001 , ENII $=700$ )I

31: C

32: WRITE(NTW, 1002)

33: C [FILEMARK ]

34: 700 ENDFILE NF

35: C [FILEMARK]

36: CALL OPEN(NF,'SYSSIMULIIAT',2)

37: $M O D E=3$

38: WRITES NF, 1004 MONE

39: IIO $800 \quad I=1,12$

40: $\quad 110800 \mathrm{~J}=1,24$

41: 800 . HRITE(NF, 1003$) \operatorname{PERF}(I, J)$

42: C [FILEMARK]

43: ENIFILE NF

44: RETURN.

45: $\mathrm{C}$

46:991 HRITE(NTH,1005)

NOTIFY EXCESS DATA POINTS

47:

48:

49:

50: 992 WRITE(NTH,1007)

$51:$

52: 1001

$53: 1002$

$54:$

$55:$

$56: 1003$

57: 1004

58: 1005

IF(I,EQ, 1, AND, III,EQ, 1, AND, J,EQ, I)GO TO 992

WRITE(NTH, 1006)

STOP

59: 1006

STOP

F.ORMAT( A1)

FORMATI'OW* * WARNING: THERE ARE EXCESS IIATA FOINTS IN THE*W*'/

*' *** PERFORHANICE BATA FILE. EXECUTION', 10X,'***'

*' *** PROCEEIING NORMALLY,',23X,'***')

60 :

FORHAT( G13,6)

FORMAT( I3)

FORMAT' 'O***ERROR IN PERFORMANCE IIATA FILE', 14X,'***')

FORMAT!' ***PROEABLE CAUSE: INSUFFICIENT DATA POINTS, ***'; *'***

(8760 REQUIRED $\left.)^{\prime}, 20 X,^{\prime} * * *^{\prime}\right)$ 
61: 1007 FORHATI" ***PROBABLE CAUSE: NON-EXISTENT DATA FILE $\left.* * *^{\prime}\right)$

$62:$

$63:$

END 


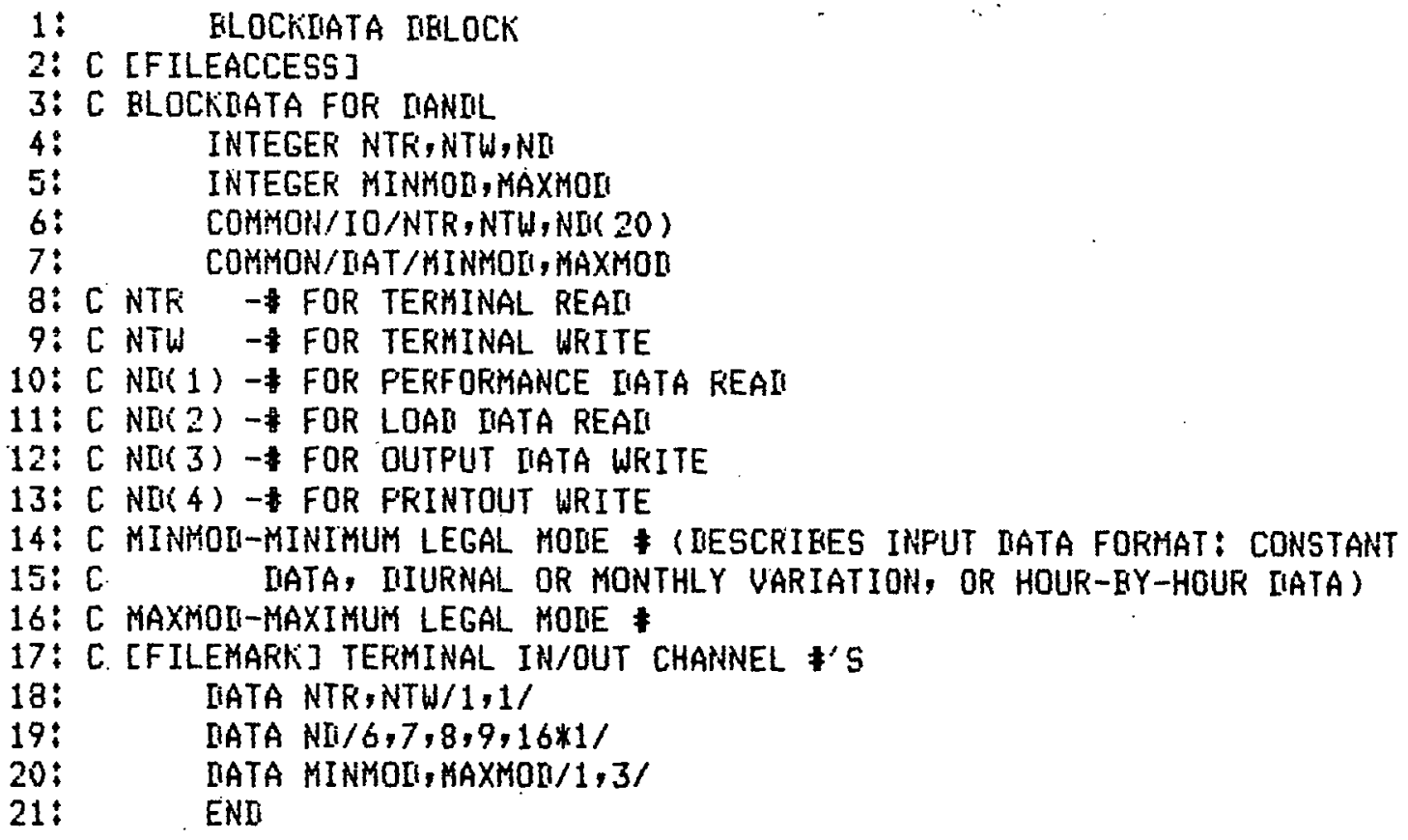




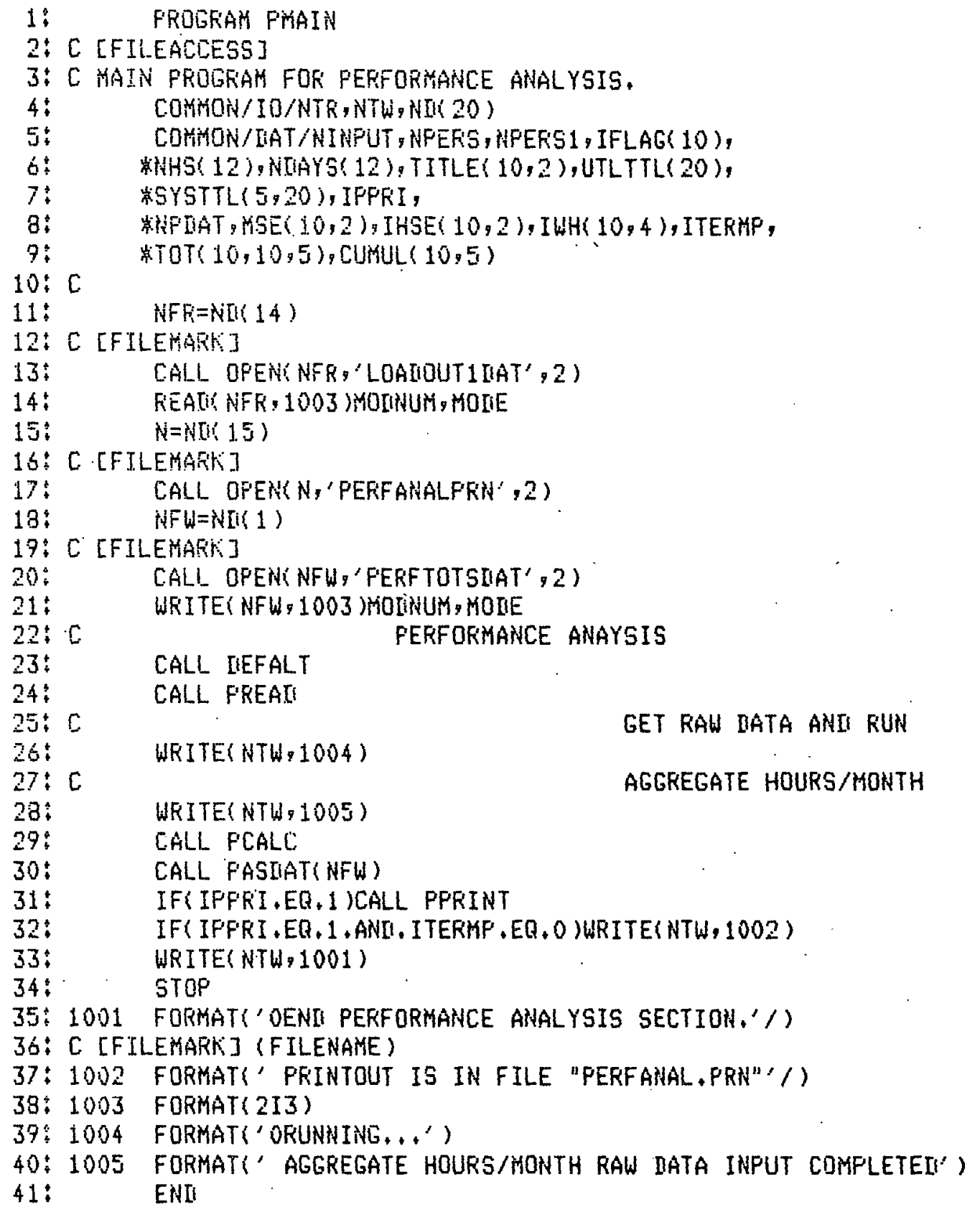


1: SUBROUTINE GOGET

2: C [NO FILEACCESS]

3: C GOGET TRANSFORMS RAU SIMULATION IIATA, REAII FROH FILE, INTO TIME-OF-

4: C USE AGGREGATEI IIATA, FOR ALL MONTHS, HOURS, AND INPUTS.

5: C FINISHEI IATA IS IN TOT.

6: C

7: C TEMF - MONTHLY TOTAL VALUES FOR INPUT FOR HOUR

8: C HOLI -TEMP STORAGE FOR RECORI FROM FILE; IF THO ELEMENTS, THE

9: $\mathrm{C}$

10: $C$

$11:$

$12:$

13:

14: C

15:

$16:$

REAL HOLIK 3), TEMP1( 24), TEMP2( 24), TEMP3( 24)

REAL SHOLII 24)

INTEGER MONTH, INPUT, I,J

COMMON/IO/NTR, NTW, NU( 20$)$

CONMON/DAT/NINPUT, NPERS, NPERS1, IFLAG 10),

*NHS( 12 ), NIIAYS 12 ), TITLE $(10,2)$,UTLTTL 20$)$,

*SYSTTL $(5,20)$, IPPRI,

*NPIAT, HSE $(10,2)$, IHSE $(10,2)$, IHH 10,4$)$, ITERMP,

*TOT $(10,10,5)$, CUMUL $(10,5)$

NDR=NM(14)

no $50 \mathrm{I}=1,10$

ZERO ARRAY

I10 $49 \mathrm{~J}=1,10$

$1048 K=1,5$

$\operatorname{TOT}(I, J, K)=0.0$

CONTINUE

CONTINUE

CONTINUE

IIO 400 MONTH $=1,12$

LOOP THROUGH EACH MONTH \& INPUT

$110200 \quad I=1,24$

GET CUMULATEI HOURLY TOTALS FOR EACH HOUR OF THE MONTH

GET DHE FILC RECORD

REAIK NIIR, 1001 , ENII $=991$ ) ( HOLII $\mathrm{J}$ ), J=1, NINFUT), SHOLIK I)

TEMP 1 $(I)=H O L B(1)$

SAUE (ASSUMEI IN KUH FROM IIANIL.)

TEMP2 $(I)=H O L D(2)$

TEMPZ I I $)=H O L D(3)$

CONTINUE

CALL SPLITS( MONTH, 1, TEMP 1, SHOLII)

CALL SPLITSI HONTH, 2, TEMP2, SHOLII)

CALL SPLITS( MONTH, 3, TEKP3, SHOLII)

CONTINUE

RETURN

WRITE(NTW, 1002)

ERROR IN FILE REAII

IF(MONTH.EQ, 1,ANI, I EQ , I)GO TO 992

URITE(NTW, 1006)

STOP

URITE $(N T W, 1003)$

STOP

FORMAT $(2 X, 6613,6)$

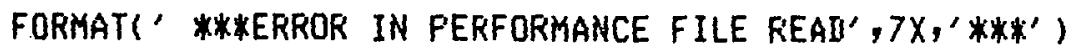

FORMAT!' ***PROBARLE CAUSE: NON-EXISTENT FILE ***',

*'***',9X,'FROM IIANIL', 18X,'***')

FORMATI A 1 ) 
$64 \div C$

$65: C$

66: $C$

67:

ENI

68: [ [NO FILEACCESS]

69: [ SPLITS AGGREGATES AN. INPUT BY PERIOU EG, PEAK, SHOULIIER, . . .).

70: C INPUT MUST HE MONTHLY TOTALS FOR EACH OF 24 HOURS,

71: C. IN ARRAY TEMP.

72: $\mathrm{C}$

73: C MONTH -MONTH IIATA IS FOR (1-12)

74: C INPUT - OF INFUT BEING AGGREGATED

75: C TEMF -MONTHLY TOTAL VALUES FOR INPUT FOR HOUR

$76: \mathrm{C}$

$77:$

$78:$

79: $\mathrm{C}$

80:

$81:$

82:

83:

84:

85:

86: $\mathrm{C}$

$87 \div C$

88:

$89: \mathrm{C}$

$90:$

91:

$92: C$

93:

REAL TEMP( 24),FTEMP, SHOLM(24)

INTEGER MONTH, INFUT, HOUR, PER

C

CONMON/IO/NTR, NTH, NIM 2O)

COMMON/RAT/NINFUT, NPEFS, NFERS1, IFLAG (10),

*NHS( 12 ), NIIAYS( 12$)$, TITLE $(10,2)$, UTLTTL(20),

*SYSTTL $(5,20)$, IPPKI,

*NPIIAT, HSE $(10,2), \operatorname{IHSE}(10,2), \operatorname{IHH}(10,4)$, ITERHP,

*TOT $(10,10,5)$, CUMUL $(10,5)$

II0 200 HOUR $=1,24$

LOOP ACCUMULATES HOUR-EY-HOUR

IIO 100 PEF $=1$, NPERS

LOOP ACCUMULATES EY PERTOI

FTEMP = FACTOR ( MONTH , HOUR , PER )

TTEMP $=$ TEMP ( HOUR $)$ *FTEMF

TOT ( INFUT, F'ER, 1 ) =TOT ( INFUT, PER, 1) + TTEMP

$94:$

95: C

$96:$

97: 100

ACCUNULATE TOTAL FOR INPUT

98: 200

99:

100:

ACCUMULATE EY PERIOD FOR INPUT

TOT( INPUT, NFERS1, 1 )=TOT( INFUT, NPERS 1,1 ) +TTEMP

CONTINUE

CONT INUE

RETURN

ENI 


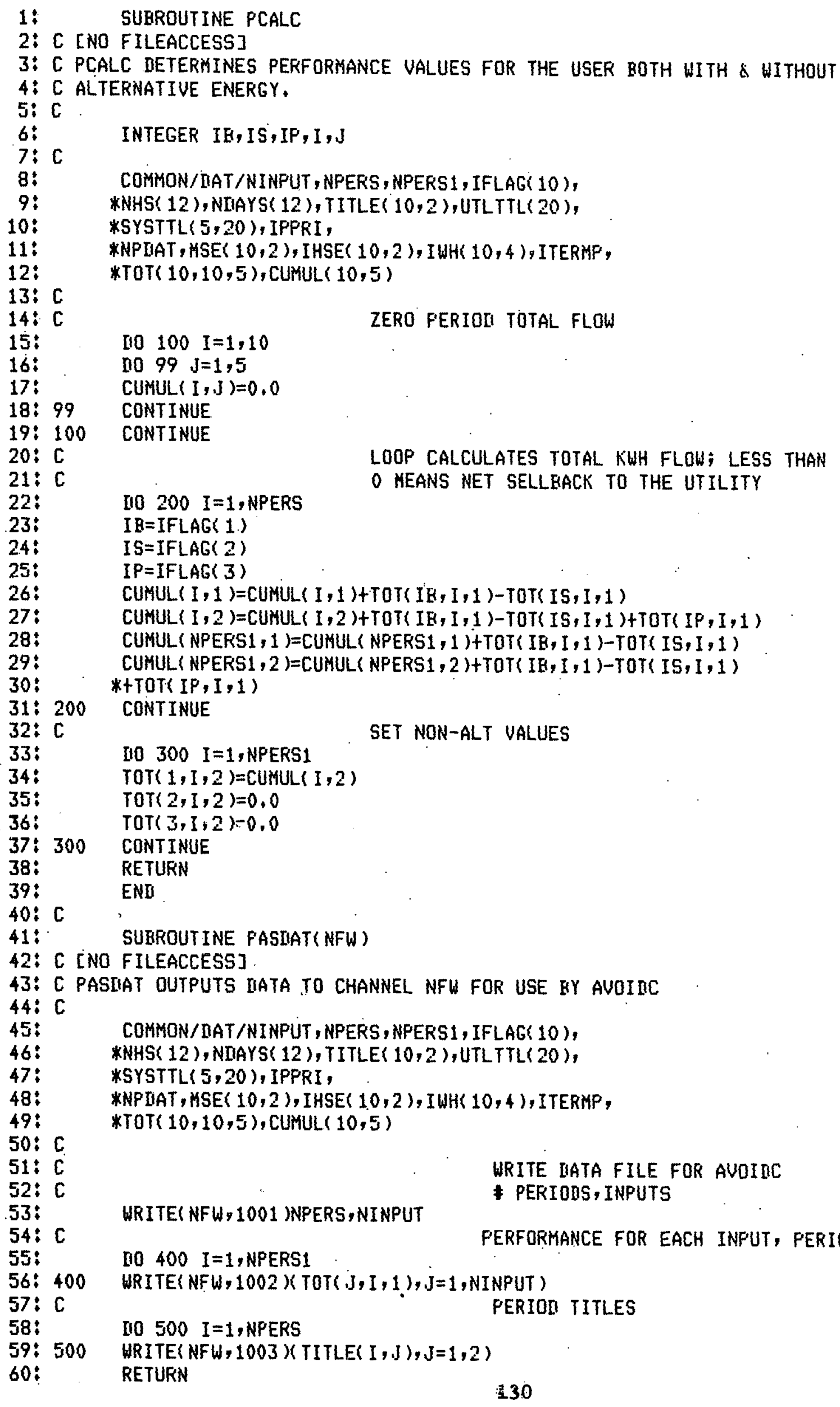




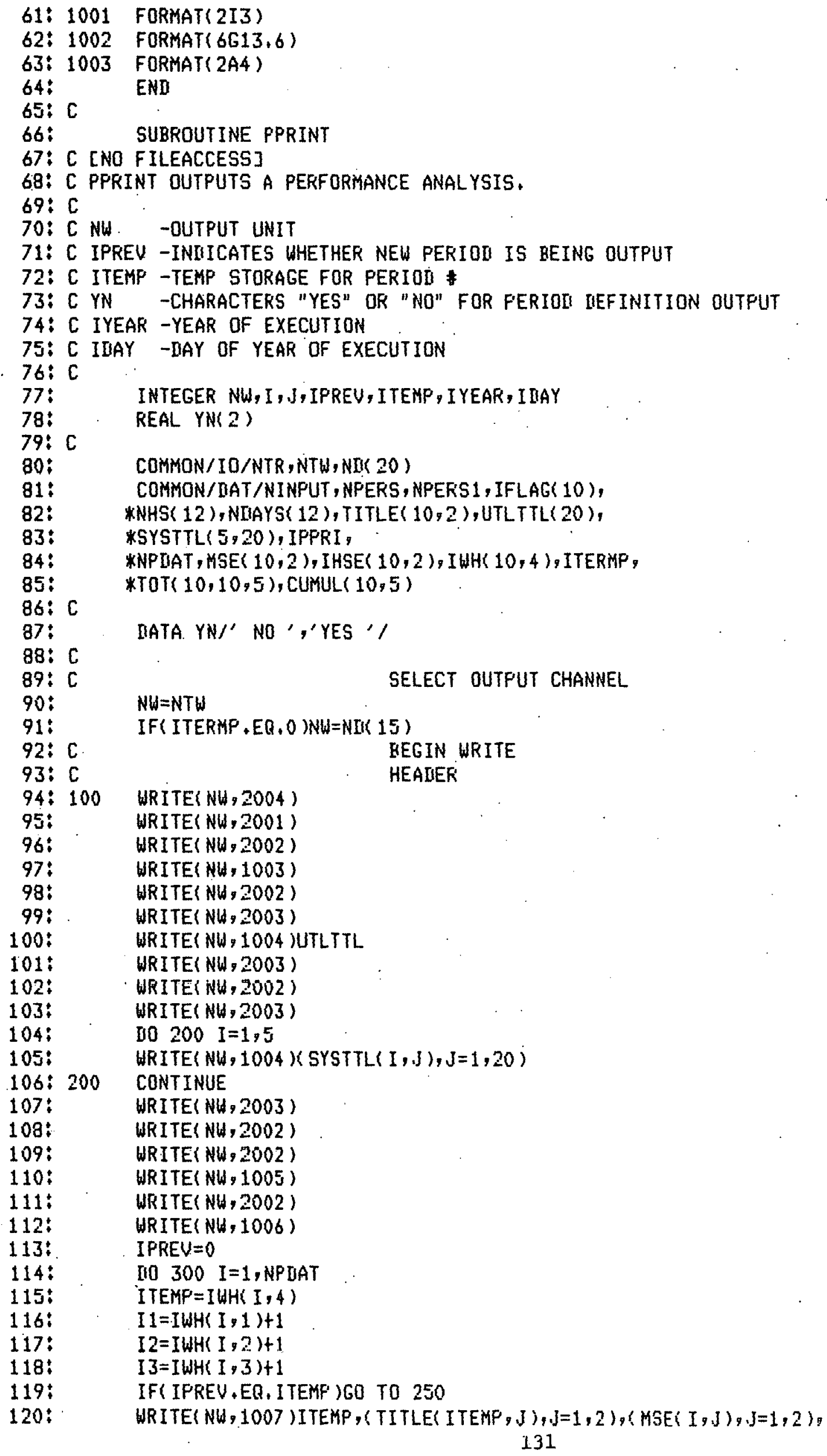


121:

122:

123: 250

124:

125: 290

126: 300

127:

128:

129:

130:

$131:$

132:

133:

134:

$135:$

136:

137:

138: 400

139:

140:

141:

142:

143:

144:

145:

146: 1003

147:

148:

149: 1004

150: 1005

151: 1006

152:

153: 1007

154:

155: 1008

\section{5 b:}

157: 1009

158: 1010

159:

160: 101

161:

162: 1012

163: 1013

164:

165: 1014

166:

167: 1015

168:

169: 2001

170:2002

171: 2003

172: 2004

173:

* (IHSE (I,J),J=1,2), YN(I1),YN(I2),YN( I3)

GO TO 290

URITE(NH, 1008$)(\operatorname{MSE}(I, J), J=1,2),(\operatorname{IHSE}(I, J), J=1,2), Y N(I 1), Y N(I 2)$,

*YN(I3)

IPREV $=$ ITEMF

CONTINUE

URITE(NH, 2002)

HRITE $(N H, 2002)$

HRITE(NU, 1009)

URITE $(N H=2002)$

HRITE (NU, 1010)

URITE(NH, 2002)

DO $400 \mathrm{I}=1$, NPERS

URITE (NU, 1011)(TITLE(I, J), J=1,2),(TOT $, \mathrm{J}, 1,1), \mathrm{J}=1$, NINPUT $)$,

*CUMUL $(I, 1)$

HRITE(NH,1012) TOT $(J, I, 2), J=1$, NINPUT $),$ CUMUL $(I, 2)$

URITE(NU, 2002')

CONTINUE

HRITE $(N H, 1013)$

HRITE(NW, 1014)(TOT( 3, NPERS1, 1$), \mathrm{J}=1$, NINPUT), CUMUL (NPERS1, 1 )

UR ITE (NU, 1015) (TOT, , NPERS1, 2),,$=1$, NINPUT ), CUMUL (NPERS1, 2)

URITE(NH, 2002)

URITE(NH, 2002)

WRITE(NH, 2001)

RETURN

FORMATI $\left.1 X,{ }^{\prime} *^{\prime}, 31 X, 241^{\prime} *^{\prime}\right), 15 x, 16 x, x^{\prime} \prime$

$* 1 X, *^{\prime}, 31 X, ' *$ PERFORMANCE ANALYSIS *',31X,'*',

$* 1 X,{ }^{\prime} *^{\prime}, 31 X, 24$ ( $\left.^{\prime} *^{\prime}\right), 31 X, *^{\prime}$ )

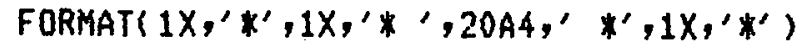

FORMAT( $1 X,{ }^{\prime} *$, $34 X,{ }^{\prime}$ PERIOD IEFINITION',35X,' $\left.*^{\prime}\right)$

FORMAT $1 X,{ }^{\prime} *$ ',26X,'MONTHS ' HOURS ',

*' HEEkIIAYS nEEKENIIS HOLIDAYS ',09X,'*')

FORMAT( $1 X,{ }^{\prime} X^{\prime}, 06 X,{ }^{\prime}$ PERIOD', I2,1X,2A4,1X,

$\left.* 2\left(13,,^{\prime}-', I 3,1 X\right), 3(3 X, A 4,3 X), 12 X, *^{\prime}\right)$

FORHAT( $1 X,{ }^{\prime}, 24 X$,

(2) (I3, - $\left., I 3,1 X), 3(3 X, A 4,3 X), 12 X, *^{\prime}\right)$

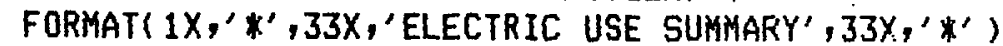

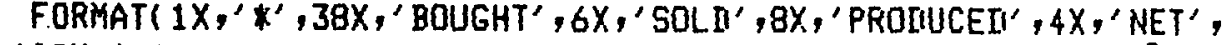
*09X,' *')

FORMATI $1 X,{ }^{\prime} *^{\prime}, 2 X, 2 A 4,1 X, ' W /$ ALT, EN, SYSTEM',2X,

*4F12,1,06X,'*')

FORHAT $1 X, X^{\prime}, 11 X, ' W / 0$ ALT. EN, SYSTEM',2X,4F12,1,06X,'*')

FORMAT $\left.\left(1 X,{ }^{\prime} *^{\prime}, 32 X,{ }^{\prime}, 111^{\prime}\right)^{\prime}\right)$,

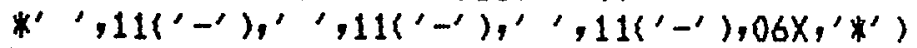

FORMATI 1X,'*',05X,'TOTAL',1X,'U/ ALT. EN, SYSTEM',2X,

*4F12,1,06X,'*')

FORKATY 1X,' *',05X,'TOTAL',1X,'W/O ALT, EN, SYSTEM',2X,

*4F12, 1,06 $\left.x^{\prime} *^{\prime}\right)$

FORMAT $\left(X, 88\left({ }^{\prime} *^{\prime}\right)\right)$

FORMAT( $\left.1 X,{ }^{\prime} *^{\prime}, 86 x,{ }^{\prime} *^{\prime}\right)$

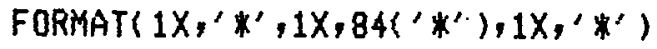

FORMAT(' 1 ')

ENII 
3: C PREAII REAIIS THE CONTROL IATA FOR INFUTTING PERFORMANCE IIATA.

$4: \mathrm{C}$

5: C ICHAR2-CHARACTER ARRAY FOR BRANCHPOINT DIALOGUE

6: C NFF - F FOR FILE REAII

7: C NFW. - \$ FOR FILE WRITE

8: C YN -ARKAY FOR"NO" ANI "YES" IN WRITES

9: C

COMMON/IO/NTR, NTW, NII 2O)

COMMON/DAT/NINFUT, NFERS, HPERS1, IFLAG 10),

$16:$

17:

$18:$

$19:$

$20: C$

$21:$

22:

23: $\mathrm{C}$

$24: C$

$25: 5$

26:

27:

$28: C$

$29 \div$ C

30: $\mathrm{C}$

$31 \div 100$ WNHS( 12 ), NIIAYS $(12)$, TITLE (10,2), UTLTTL (20), *SYSTTL(5, 20), IFFRI, *NPIIAT, MSE $(10,2)$, IHSE $(10,2)$, IHH( 10, 4 ), ITERHP, WTOT $(10,10,5)$, CUMUL $(10,5)$

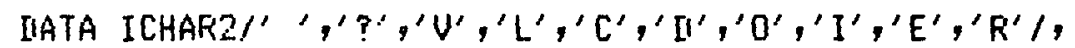
WYNI' NO ', 'YES ' $/$.

WRITE $N T W, 1011)$

MAIN GRANCHFOINT

$K=$ IPARSE (ICHAR2,10)

GO TO( $950,950,700,200,400,100,850,800,999,600), K$

$32:$

$33: \mathrm{C}$

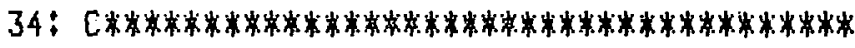

35: C

$35: C$

$37 \div 200$

$39:$

$39:$

40 :

$41:$

42:

43:

44: $\mathrm{C}$

$45: 220$

46:

$47:$

43:

$47 \div 225$

$50:$

$51:$

$52: C$

$53: 240$

$54:$

$55:$

$55:$

$57: C$

CALL IIEFALT

SET IIEFAULTS

GO TO 5

LIST SECTION

WRITE(NTW, 1013)

REAIK NTR, 1058 K1

IF KKI, LT. O. OR, K1, GT.5)GO TO 5

$k K 1=1$

IF $\{K 1, E Q .0) 60$ TO 220

$K K 1=K 1$

$60 \mathrm{TO} 220,240,250,280,290), K 1$

WRITE (NTW, 1014 KKI

* HOLIIIAYS/MONTH

WRITE(NTH, 1019)

IIO $225 \mathrm{I}=1,12$

WRITE (NTU, 1020)I, NHS( I)

CONTINUE

IF $(K 1, N E, 0) 60$ TO 5

$K K 1=K K 1+1$

WRITES NTW, 1014 HKKI

UTILITY TITLE

WRITE( NTW, 1022 UTLTTL

IF $\{K 1$. NE, O)60 TO 5

$k k 1=k K 1+1$

WRITE(NTW, 1014 KKI

WRITE $(N T W, 1023)($ SYSTTL $(I, J), J=1,20), I=1,5)$

IF KK1. NE. O )6O TO 5 


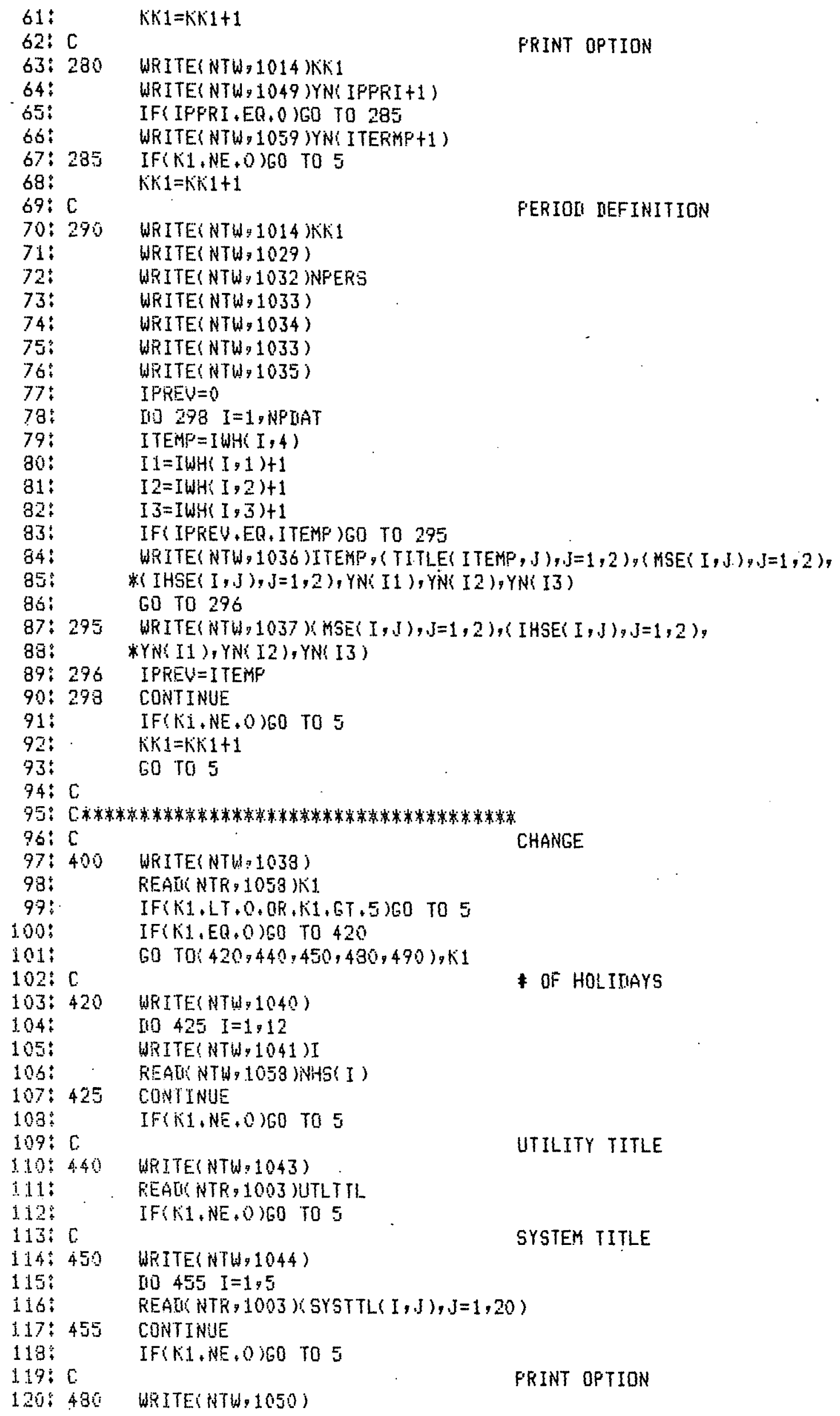




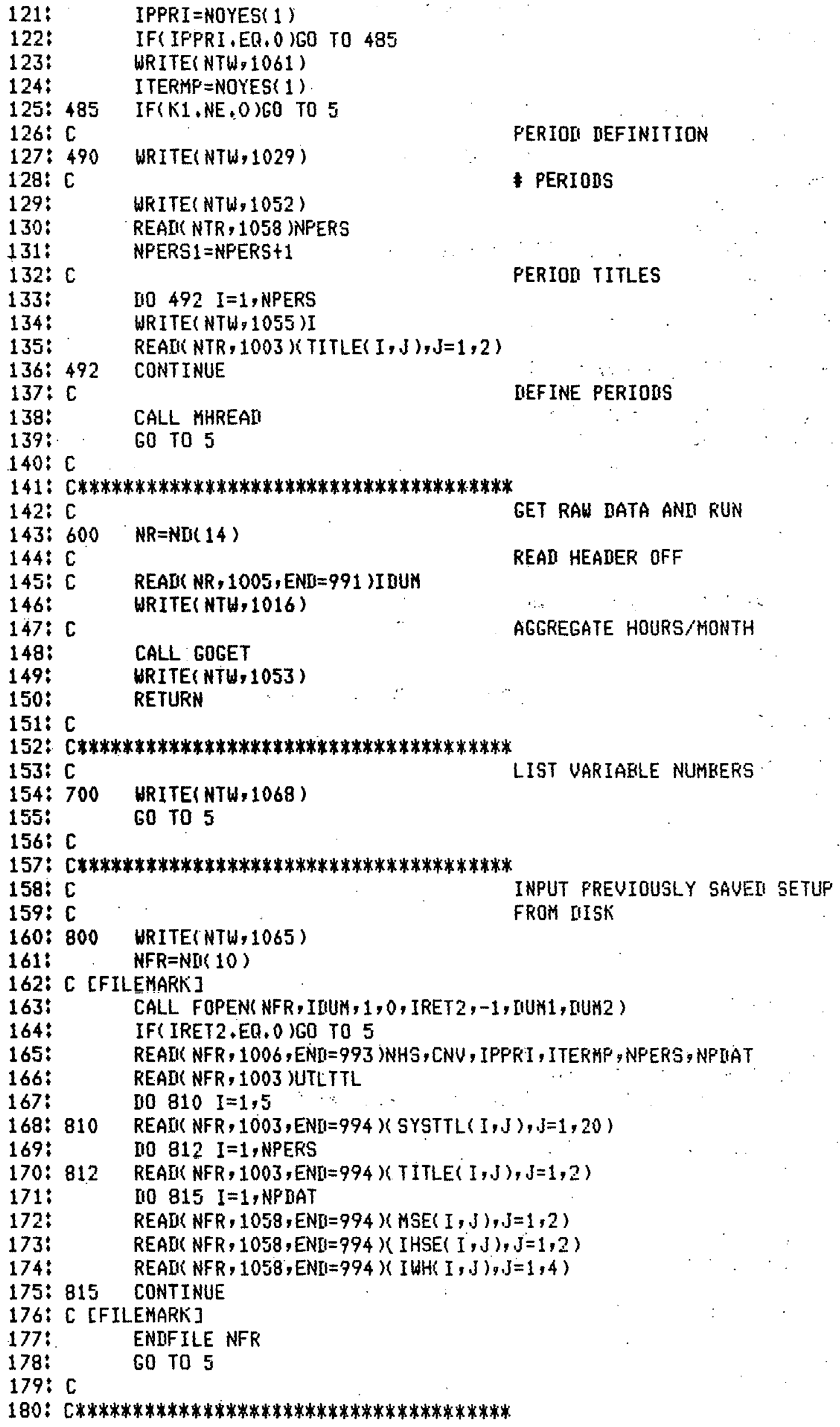




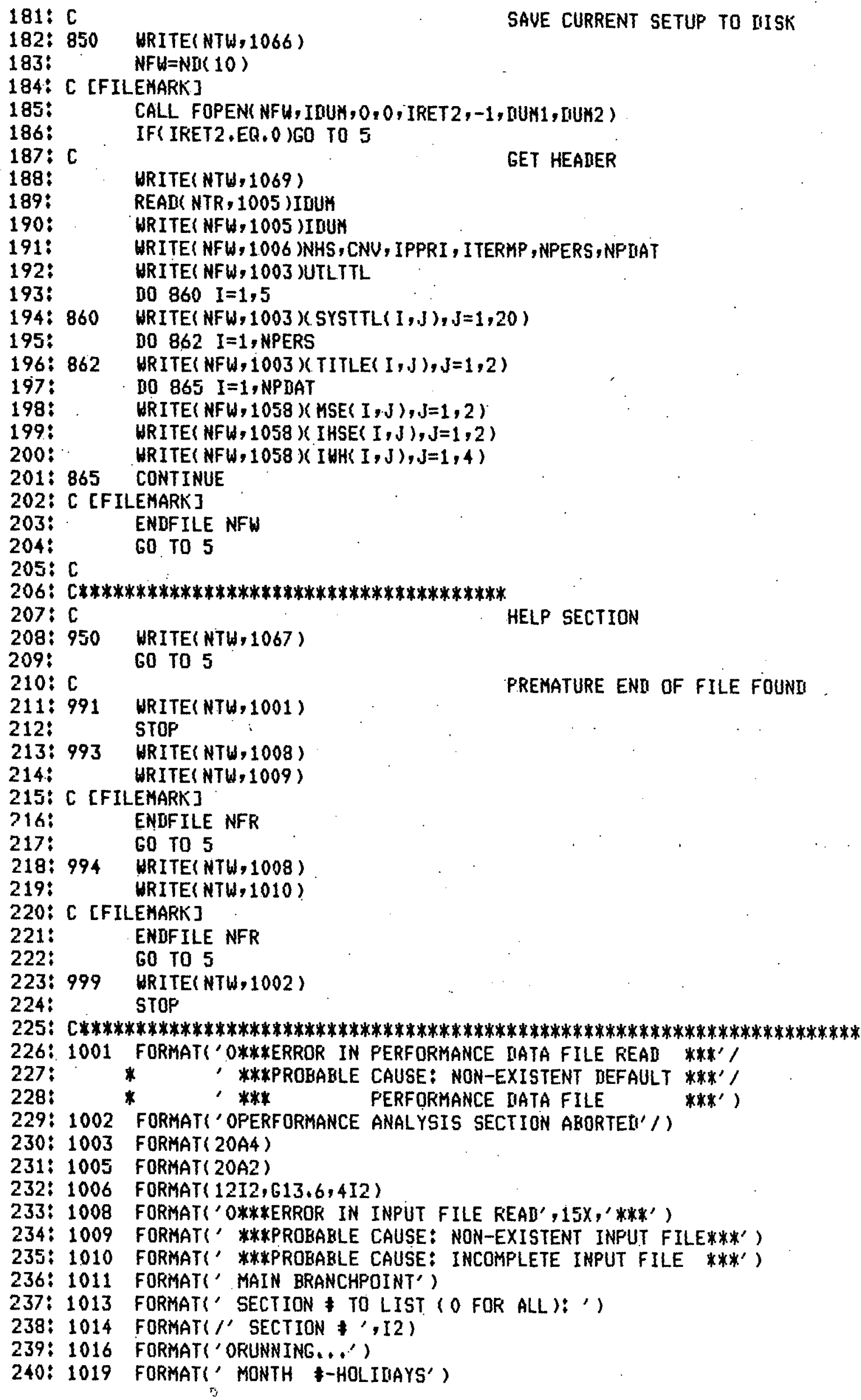


241: 1020

242: 1022

$243: 1023$

244: 1024

245: 1029

246: 1032

$247: 1033$

248: 1034

249: 1035

250:

251: 1036

252:

253: 1037

254: 1038

255: 1040

256: 1041

257: 1043

258: 1044

259: 1045

260: 1049

261: 1050

262:

263: 1052

264: 1053

265: 1054

266:

$267: 1055$

268: 1058

269: 1059

$270: 1060$

271: 1061

272 :

273: 1065

274: 1066

275: 1067

276:

277:

27a:

279:

280 :

281:

282:

233:

$284:$

285 :

286:

$287:$

289: 1068

297:

290 \%

291 ;

272 :

293:

274: 1059

295:
FORMAT $2 X, 12,7 X, 12)$

FORMAT(' UTILITY IIESCRIPTION:' $/$ ',20A4)

FORWAT(' SYSTEM IIESCRIPTION:'/5(/' ',20A4)

FORMATI' OF UARIABLES/RECORD $=', 11$ )

FORMATI' PERIOII IIEFINITION SECTION')

FORMATI' \# OF PERIOUS =',I2)

FORMAT( $1 X)$

FORMAT ( $31 X$.'PERION DEFIHITION')

FORMAT( $23 X$, , MONTHS HOURS ',

*' WEEKIIAYS WEEKENIIS HOLIIIAYS')

FORMAT( $3 X,{ }^{\prime}$ PERIOD', $12,1 X, 2 A 4,1 X, 2\left(13,0^{\prime}-', I 3,1 X\right)$,

*3( $3 X, A 4,3 X))$

FORHAT $(21 X, 2(13, \prime-(, 13,1 X), 3(3 X, A 4,3 X))$

FORMAT(' SECTION \& TO CHANGE: ')

FORMAT' FOR HONTH \$, ENTER — OF HOLIIIAYS')

FORMAT(' MONTH',I2,':')

FORMATY" UTILITY TITLE (80 CHARS MAX): '/)

FORMAT(" SYSTEM TITLE (80 CHARS MAX, 5 LINES REQUIRED): '/)

FORMAT(' \&ARIABLES/RECORTI:')

FORMAT(' PERFORTANCE ANALYSIS PRINT - ',A4)

FORMATI' WOULI YOU LIKE THE PERFORMANCE ANALYSIS PRINTEII'

*' TO EITHER THE TERMINAL OR FILE?')

FORMATS!' F FERIOIS:')

FORMAT!' AGGREGATE HOURS/NONTH RAW DATA INPUT COMPLETED')

FORMAT!' ALTERNATE SERUENTIAL HOURS/YEAR RAW DATA INPUT',

*' COMPLETEU').

FORMATl' TITLE FOR PERIOD * ',I2,' :')

FORHAT ( 4 I5)

FORMAT(' PRINTOUT TO TERMINAL (IF NO THEN TO FILE)- ',A4)

FORMAT!' PRINTOUT CHANNEL $¥ ', I 3)$

FORMAT!' PRINT OUTPUT TO TERMINAL?',

*' (ANSHER NO FOR PRINT TO FILE): ',

FORMAT(' ENTER INPUT FILE INFORMATION-')

FORMAT!' ENTER OUTPUT FILE IINFORMATION-',

FORMATY'OTHIS IS THE FERFORMANCE ANALYSIS SECTION-',

\$5X,' IIATA MAY BE IIEFAULTED, READ FROH FILE, OR SPECIFIEI BY THE ',

*'USER.' $/ / 5 X$,'AUAILABLE COMMANIS ARE:'/

*10X,'IIEFAULT )-SET IIATA TO IIEFAULT VALUES,$\prime$

\$ $10 X, ' L(I S T)$-LIST EXISTING VALUE OR VALUES.'

* $10 X$, 'C(HANGE) -CHANGE EXISTING VALUE OR VALUES.'

*10X,'R(UN) -GET RAW IIATA \& EXECUTE F'ERFORMANCE ANALYSIS."

*10X.'E(ND) -TERHINATE THIS SECTION WITHUUT PERFORMING A NEW'/

*21X,'PERFORMANCE ANALYSIS OR GETTING MORE RAU DATA.',

* $10 X, ' U(A R S)$-LIST *'S OF VARIAELES FOR LIST OR CHANGE',

*1X,'PURFOSES.'/

*10X, 'I(NPUT) -REAI A PREUIOUSLY WRITTEN DATA SETUP FROH FILE'

*10X,'O(UTFUT) -WRITE THE CURRENT IIATA SETUP TO.FILE'/)

FORMATI' VARIAELES:',

*5X,'1-\$ HOLIIAYS/RONTH',

*5X,'2-UTILITY TITLE'/

\$5Y,'3-SYGTEM TITLE'

*5X,'4-PRINT PARAMETERS' 1

*5X,'5-PERIOII IIEFINITION')

FORMATI' ENTER HEAIER LINE:')

ENI 
3: C FACTOR RETURNS THE FRACTION OF THE (MONTH,HOUR) THAT FALLS IN PER.

4: $\mathrm{C}$

5: C RATHOL-RATIO OF HOLIIIAYS/TOTAL IAYYS FER MONTH

6: C TEMP -TEMPORARY STORAGE FOR OUERALL FERIOI FACTOR

7: C PERKUL-PULTIPLIER TOACCOUNT FOR WEEKENIS \& WEEKIIAYS

8: C HOLMUL-ZULLTIPLIER TO ACCOUNT FOF HOLIIIAY INCLUSION

9: $\mathrm{C}$

10:

11:

12: [

13 :

14:

15:

16:

REAL FERMUL, HOLMUL, RATHOL, TEMP

COMMON/IAT/NINPUT, NPERS, NPERS1, IFLAG (10), *HHS( 12$)$, NIIAYS(12), TITLE $(10,2)$, UTLTTL( 20$)$, *SYSTTL (5.20), IPPEI, *\#PIIAT, HSE $(10,2), \operatorname{IHSE}(10,2)$, IUH 10,4$),$ ITERHF, *TOT $(10,10,5)$, CUMUL $(10.5)$

$$
\text { FACTOR }=0.0
$$$$
\text { IIO } 500 \quad k=1, \text { NPDAT }
$$

ZERO VALUE

\section{IIO FOR ALL FERIOU IEFINITIONS}

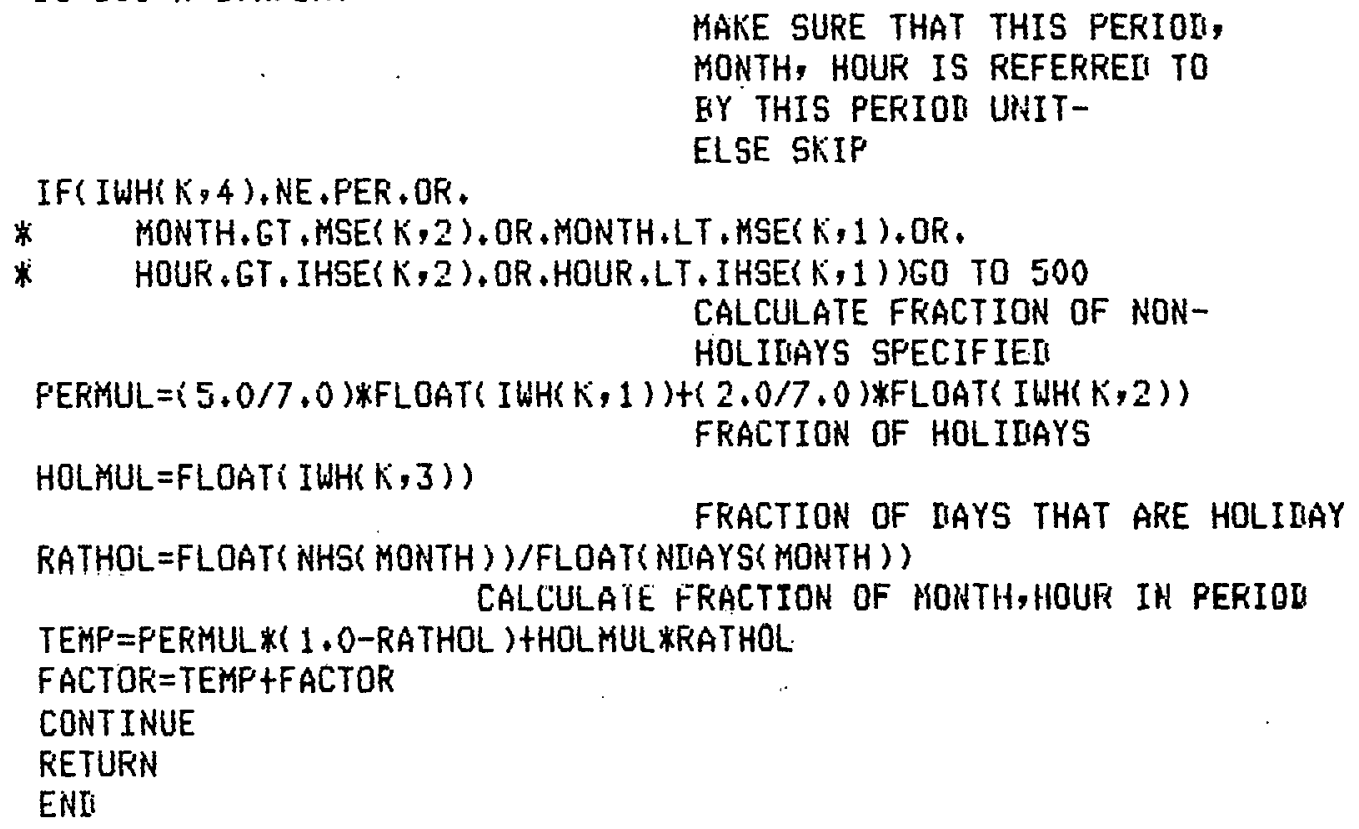




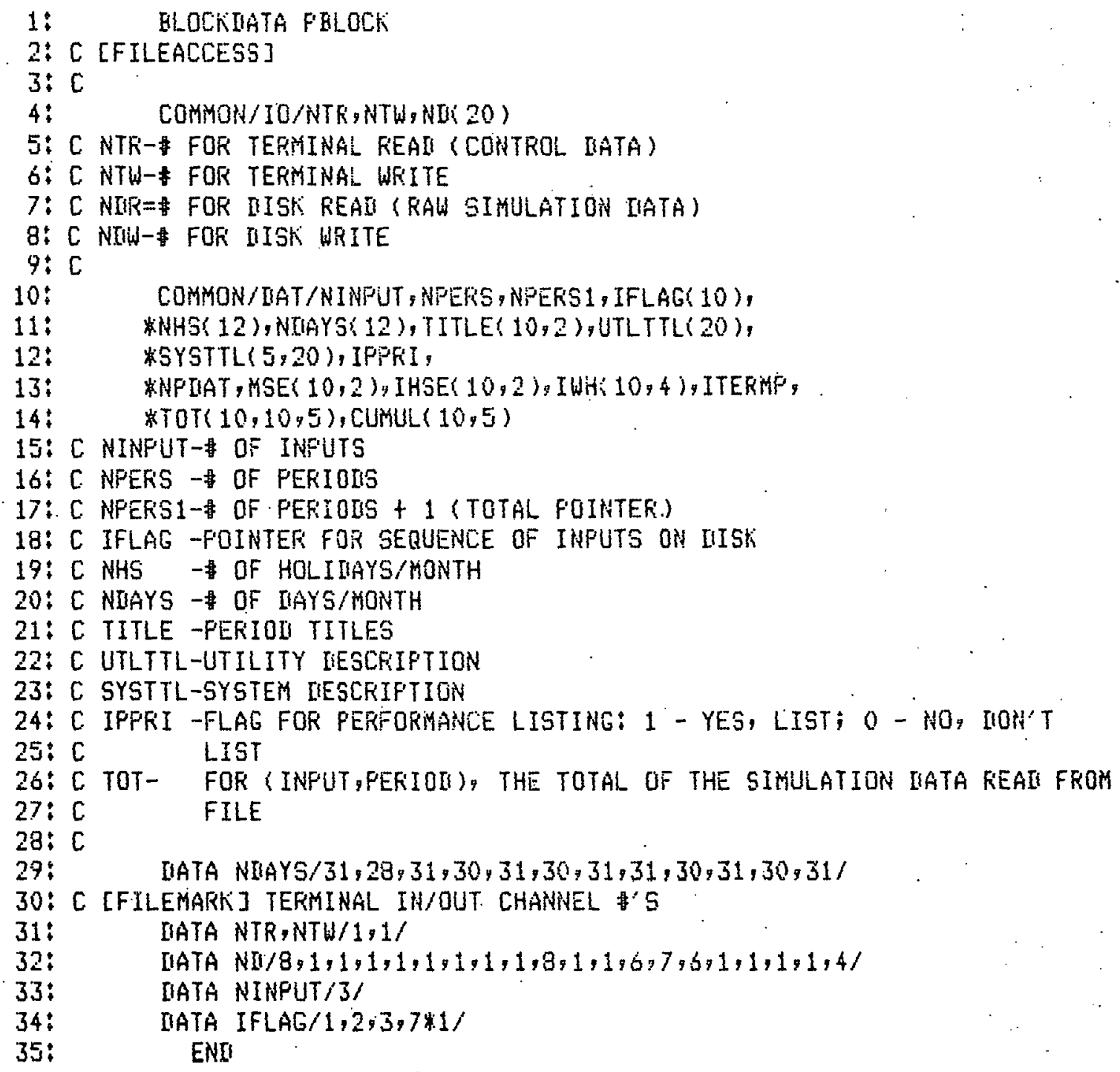


3: C DEFALT SETS IEFAULT VALUES FOR PMAIN. THESE ARE THE VALUES SET

4: C AT THE BEGINNING OF EACH RUN.

5: C

8: $\mathrm{C}$

\section{COMMON/IO/NTR, NTW, NIU 2O)}

COMMON/DAT/NINPUT, NPERS, NPERS1, IFLAG(10), *NHS( 12 ), NIIAYS ( 12 ), TITLE (10,2), UTLTTL( 20), *SYSTTL 5,20$)$, IPFRI, *NPIIAT, MSE $(10,2)$, IHSE $(10,2)$, IWH 10,4$),$ ITERHF, *TOT $(10,10,5)$, CUMUL $(10,5)$

IIATA IHTEMP $/ 1,0,0,0,1,0,1,0,1,0,1,1 /$,

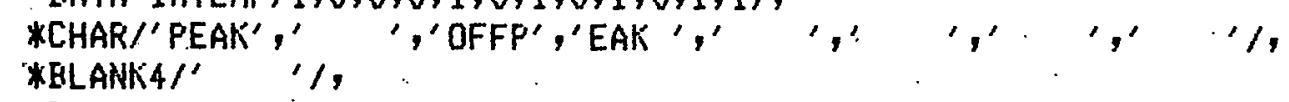
*EUF1/'UTIL','ITY ','TITL','E GO','ES H','ERE ', 14*' '/, *BUF2/'TECH', 'NOLO' ,'GY G','OES ','HERE', 15*' ' ' $/$, *LMSE $/ 1,1,1,1,0,0,0,3 * 0,12,12,12,12,0,0,00,3 * 0 /$, *LIHSE $/ 9,1,23,1,0,0,0,3 * 0,22,8,24,24,0,0,0,3 * 0 /$, *LIWH $/ 3 * 1,7 * 0,3 * 0,1 * 1,6 * 0,3 * 0,1 * 1,6 * 0,1,2,2,2,0,0,0,3 * 0 /$

$$
\text { NINPUT }=3
$$

NFERS $=2$

NFERS $1=N P E R S+1$

IFLAG $(1)=1$

IFLAG $(2)=2$

IFLAG 3 ) $=3$

I10 $100 \quad I=1,12$

NHS( I )=IHTEKP(I)

CONTINUE

IIO $200 \quad I=1$, NPERS

$I X=(I-1) \times 2+1$

$I Y=I * 2$

$\operatorname{TITLE}(I, 1)=$ CHAR $(I X)$

TITLE $(I, 2)=$ CHAR( IY )

$60: 650$

CONTINUE:

$$
10300 \quad I=1,20
$$

UTLTTL (I )=EUF 1 ( I )

CONTINUE

I10 $400 \quad I=1,20$

SYSTTL $(1, I)=E U F 2(I)$

CONTINUE

I10 $500 \quad I=2,5$

no $450 \mathrm{~J}=1,20$

SYSTTL $(I, J)=$ FLANK 4

CONTINUE

CONTINUE

NPIIAT $=4$

I10 $650 \mathrm{I}=1,10$

IIO $640 \mathrm{~J}=1,2$

$\operatorname{MSE}(I, J)=\operatorname{LKSE}(I, J)$

IHSE $(I, J)=L I H S E(I, J)$

CONTI INUE

I10 $645 \mathrm{~J}=1,4$

$I H H(I, J)=L I H H(I, J)$

CONTINUE

CONT INUE 


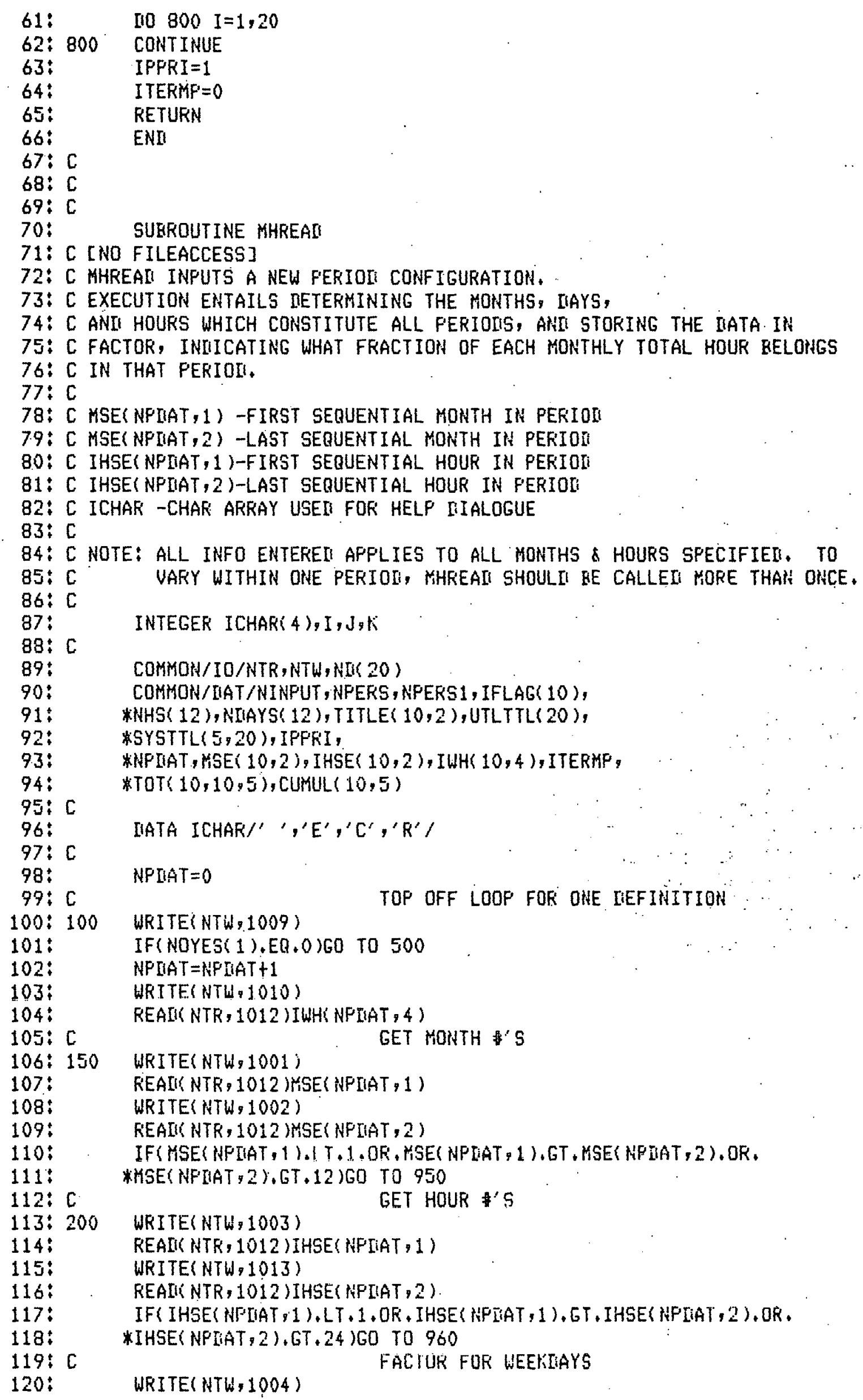




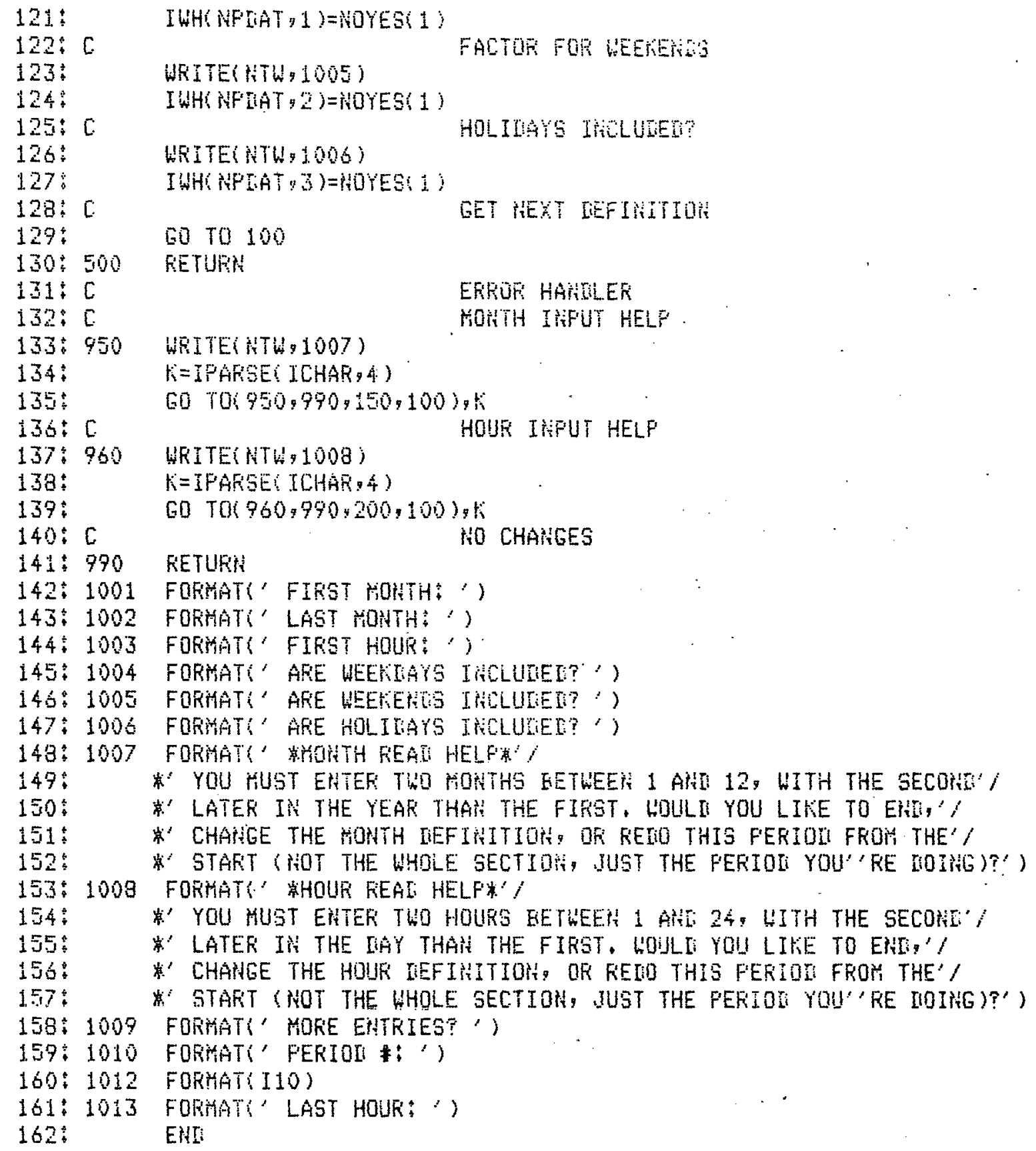


1: RLOCKIATA ABLOCK

2: C [FILEACCESS]

3: C THIS IS THE ELOCKIATA FOR AVOIIC

4: COMMON/IO/NTR,NTW,NM 20)

5: C NTR- \#FOR TERMINAL REAI

6: C NTW- F FOR TERHINAL HRITE

7: ( NII 1)-\$ FOR FILE REAII

8: ( $\mathrm{NI}(2)-\$$ FOR FILE WRITE

9: C [FILEMARK] TERHINAL IN/OUT CHANNEL \#'S

$10:$

$11:$

IIATA NTR, HTW/1,1/

$12:$

IIATA NII/6,7,18*1/

END 


\section{1: : PROGRAM AVOIIIC}

2: C [FILEACCESS]

3: C AVOIDC IIETERMINES AVOIDEI COSTS, BASEII ON KWH PROIUCTION FIGURES

4: C BY PERION SUPPLIEN FROM THE PERFORMANCE ANALYSIS SECTION UIA

5: C THE FILE 'PERFTOTS. MAT', OUTPUT IS TO TERMINAL ANI MAY BE TO

6: C FILE AS WELL (USER'S CHOICE).

7: C

8: C INPUT -THE $\$$ OF THE PRONUCTION VALUE USEI ( $2=50 L 11,3=$ FROIUCEII)

9: $C$ NPERS - OF PERIONS TO BE PASSEII FROM PHAIN

10: C NPERS1- $\neq$ OF PERIONS FLUS 1

11: C NINPUT- $\$$ OF INPUTS TO BE PASSEII FROM FHAIN

12: C TOT: -FOR EACH INPUT, TOTAL PERFORMANCE EY PERIOI (INFUT,PERION)

13: C COSTS - MARGINAL COSTS BY PERIOII

14: C CPKWH -COST. PER KILOWATT-HOUR

15: C TCOST -TOTAL COST BY PERIOI

$16: \mathrm{C}$ TITLE -8 CHARACTER PERION TITLES

17.: C I,J,K -DO LOOP INDICES

18: C NTR - $\$$ FOR TERMINAL REAIS

19: C NTH - FOR TERMINAL URITES

20: C NFR - FOR FILE REAIS (IIATA FKOH PMAIN IN "PERFTOTS, IIAT")

21: C NFW -CHANNEL - FOR FILE WRITES (IF OUTPUT IIESIREI, IN "AVOIIIEIC, PRIH"

22: C ND -DUMMY ARRAY TO FILL COMMON REQUIREI EY SUBROUTINE HOYES

23: $\mathrm{C}$

REAL COSTS( 10$),$ CPKWH,TCOST $(10), T O T(5,10), \operatorname{TITLE}(10,2)$

26: : COMHON/IO/NTR,NTH,NI 20)

27: $\quad$ NFR=NI( 1)

28: $\quad$ NFH=NII 2)

29: C

$30: \mathrm{C}$

31: C

32: C [FILEMARK]

33: CALL OFEN(NFR,'PERFTOTSIIAT', 2)

34: . REAM NFR, 1009 , ENI =997) MONE, MOINUM

35: READ NFR , 1009 , END $=997$ ) NPERS, NINPUT

36: NPERS1=NPERS 1

$37: \mathrm{C}$

45: $\mathrm{C}$

46: $\mathrm{C}$

IIO $10 \mathrm{~J}=1$, NPERS 1

GET PERFORHANCE ANII PERION IIATA

PASSEI FROM F'HAII!

$56: C$

$57: \mathrm{C}$

REAII NFR , 1008, ENI $=998)($ TOT $(I, J), I=1, N I N F U T)$

CONTINUE

DO $20 \quad I=1$, NPERS

GET PERION TITLES

READ( NFR , 1010, END $=999)(\operatorname{TITLE}(I, J), J=1,2)$

CONTINUE

WRITE $(1,1001)$

INPUT COSTS/KHH/FERIOI

II0 $100 \mathrm{I}=1$, NPERS

WRITE(NTW, 1002$)(\operatorname{TITLE}(I, 3), J=1,2)$

REAII (NTR, 1003 )COSTS (I)

CONTINUE

I10 $200 I=1$, NPERS 1

CALCULATE TOTAL COSTS

$T \operatorname{COST}(\mathrm{I})=0.0$

CONTINUE 
I10 $300 \quad I=1$, NPERS

AND OVERALL

$63:$

$64:$

65: 300

$66: C$

$67 \div \mathrm{C}$

$68: C$

$69:$

$70: C$

$71 \div \mathrm{C}$

$72:$

TCOST $(I)=$ TOT ( INFUT, I $*$ COSTS $I$ )

TCOST ( NPERS1) =TCOST NFERSI + TCOST(I)

CONTINUE

CPKHH $=$ TCOST ( NPERS 1$) /$ TOT ( INPUT, NPERS1 $)$

CALCULATE AUERAGE AVOIUEI COST

FOR ALL PERIONS (SINGLE AVOIDEI

COST $\$)$

$73:$

$74:$

$75 \div 400$

$76:$

$77 \div \mathrm{C}$

$78:$

$79:$

$80:$

\section{(1)}

81:

$82 \div \mathrm{C}$

83!

$84:$

85:

$86 \div 500$

$87:$

$88 \div$

$39 \div 990$

$90 \div \mathrm{C}$

91:997

WRITE(NTW, 1005)

START OUTPUTTING RESULTS

I0 $400 \mathrm{I}=1$, NPERS

WRITE(NTH, 1006)(TITLE $(I, J), J=1,2), \operatorname{COSTS(I),TCOST(I)~}$

CONTINUE

- URITE( NTH, 1007 )CFKWH

WRITE(NTW, 1015)

CHECK IF OUTPUT TO FILE IESIREI

IF (HOYES( 1 ), NE , 1$) 60$ TO 990

$92:$

$93:$

$94: 998$

95:

$96:$

$97 \div 999$

$98:$

$99:$

$100 \div C$

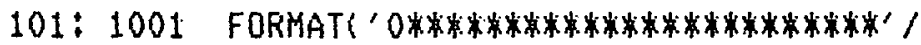

102: * A * AVIIIEII COST SECTION *'/

103: $\quad$ * '

104: * ENTER MARGIRAL COST IIATA F'ER KILOWATT-HOUR',

105: * ' FOR EACH PERTOI:'/)

106: 1002 FORMATS' MAKGIHAL COST, PERIOI ', 2A4,' (\$/KWH):')

107: 1003 FORHAT (G15.8)

108: 1004 FORHATY' IO YOU WANT CALCULATIOHS BASEI ON GROSS PROIUCTIOH?',

$109 \vdots$

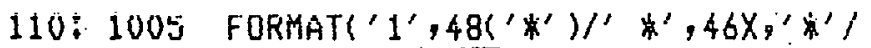

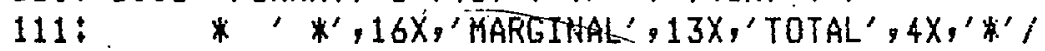

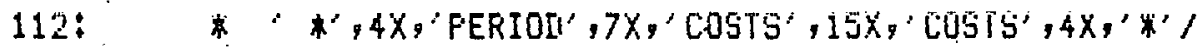

113: * * *', $\left.*^{\prime}, 38\left({ }^{\prime}-^{\prime}\right), 4 X X^{\prime} *^{\prime}\right)$

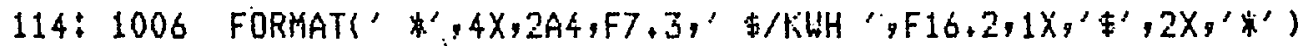

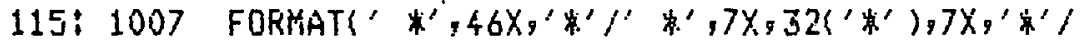

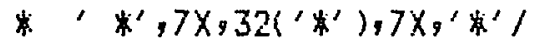

* $\left.\left.\left.2 r^{\prime} *^{\prime}, 46 x, *^{\prime} /\right) r^{\prime}, 484^{\prime} *^{\prime}\right) /\right)$

120: 1009 FORMAT(2I3) 
121: 1010 FORHAT(2A4)

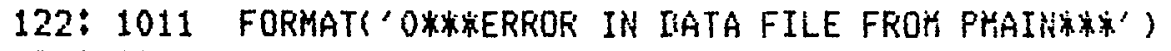

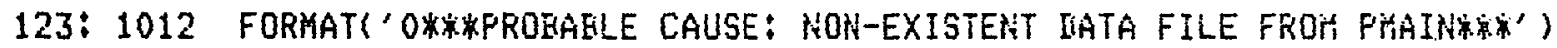

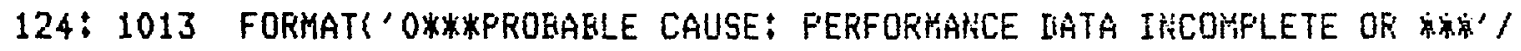

125: * ' ***',9X,'INCOHSISTENT UITH \$PERIOIS/IYFUTS IATA

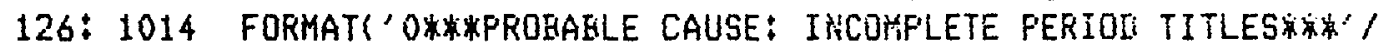

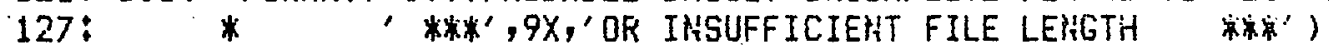

128: 1015 FORHAT' OIO YOU WISH THIS OUTPUT TO FILE AS WELL?')

129: [ [FILEKARK]

130: 1016 FORMATI OOUTPUT IN FILE "AVOI IEEIC, FRis"//)

131:

ENI 


\begin{tabular}{|c|c|}
\hline \begin{tabular}{|c|c|c|}
$\begin{array}{c}\text { Document Control } \\
\text { Page }\end{array}$ & $\begin{array}{l}\text { 1. SERI Report No. } \\
\text { SERI/TR-09275-1 }\end{array}$ & 2. NTIS Accession No. \\
\end{tabular} & 3. Recipient's Accession No. \\
\hline \multirow{2}{*}{$\begin{array}{l}\text { 4. Title and Subtitle } \\
\text { A User's Guide to Sericpac: A computer Program for } \\
\text { Calculating Electric Utility Avoided Cost Rates }\end{array}$} & $\begin{array}{l}\text { 5. Publication Date } \\
\text { May } 1982\end{array}$ \\
\hline & 6. \\
\hline $\begin{array}{l}\text { 7. Author(s) Robert Wirtshafter, Michael Abrash, Michael Koved, } \\
\text { Stephen Feldman }\end{array}$ & 8. Performing Organization Rept. No. \\
\hline \multirow{2}{*}{$\begin{array}{l}\text { 9. Performing Organization Name and Address } \\
\text { University of Pennsylvania } \\
\text { Energy Center } \\
\text { Philadelphia, PA } 19104\end{array}$} & 10. Project/Task/Work Unit No. \\
\hline & $\begin{array}{l}\text { 11. Contract (C) or Grant (G) No. } \\
\text { (C) } \times S-0-9275-1 \\
\text { (G) }\end{array}$ \\
\hline \multirow{2}{*}{$\begin{array}{l}\text { 12. Sponsoring Organization Name and Address } \\
\text { Solar Energy Research Institute } \\
1617 \text { Cole Boulevard } \\
\text { Golden, Colorado } 80401\end{array}$} & $\begin{array}{l}\text { 13. Type of Report \& Period Covered } \\
\text { Technical Report }\end{array}$ \\
\hline & 14. \\
\hline
\end{tabular}

15. Supplementary Notes

16. Abstract (Limit: 200 words) SERICPAC is a computer program developed to calculate average avoided cost rates for decentralized power producers and cogenerators that sell electricity to electric utilities. SERICPAC works in tandem with SERICOST, a program to calculate avoided costs, and determines the appropriate rates for buying and selling of electricity from electric utilities to qualifying facilities (QF) as stipulated under Section 210 of PURPA. SERICPAC contains simulation models for eiaht technologies including wind, hydro, biogas, and cogeneration. The simulations are converted in a diversified utility production which can be either gross production or net production, which accounts for an internal electricity usage by the QF. The program allows for adjustments to the production to be made for scheduled and forced outages. The program takes the production and divides it into cost periods defined in SERICOST. The final output of the model is a technology-specific average annual rate. The report contains a description of: the technologies and the simulations as well as a complete user's guide to SERICPAC.

17. Document Analysis

a. Descriptors S Codes ; Manuals ; Electric power ; Electric utilities ; Sellback ; Public Utilities Regulatory Policies Act

b. Identifiers/Open-Ended Terms Avoided capacity costs

c. UC Categories

18. Availability Statement

National Technical Information Service

U.S. Department of Commerce

5285 Port Royal Road

Springfield, Virginlid 22161 